\title{
Anja Pülsch
}

\section{Emigration \\ als literarisches Verfahren bei Zinovij Zinik}

Verlag Otto Sagner München · Berlin · Washington D.C.

Digitalisiert im Rahmen der Kooperation mit dem DFG-Projekt „Digi20“

der Bayerischen Staatsbibliothek, München. OCR-Bearbeitung und Erstellung des eBooks durch den Verlag Otto Sagner:

http://verlag.kubon-sagner.de

( $)$ bei Verlag Otto Sagner. Eine Verwertung oder Weitergabe der Texte und Abbildungen, insbesondere durch Vervielfältigung, ist ohne vorherige schriftliche Genehmigung des Verlages unzulässig. 


\title{
SLAVISTISCHE BEITRÄGE
}

\author{
Begründet von \\ Alois Schmaus
}

Herausgegeben von

Peter Rehder

\author{
Beiral: \\ Tilman Berger - Walter Breu - Johanna Renate Döring-Smimov \\ Wilfried Fiedler - Walter Koschmal - Miloß Sedmidubský · Klaus Steinke
}

BAND 329

\section{Verlag OtTo SAgner MÜNCHEN 1995}




\author{
Anja Pülsch
}

Emigration als literarisches Verfahren bei Zinovij Zinik

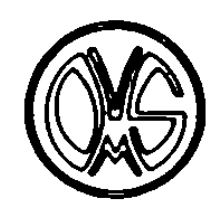

\title{
VERLAG OTTO SAGNER MÜNCHEN 1995
}




\section{Bayerische Staatsbibliothek München}

ISBN 3-87690-612-1

(C) Verlag Oto Sagner, München 1995 Abreilung der Firma Kubon \& Sagner D-80328 München 


\section{VORBEMERKUNG}

Der vorliegende Text entstand als Magisterarbeit an der Fakultát für sprach- und Literaturwissenschaft II der Ludwig-Maximilians-Universität München und wurde im oktober 1994 beendet und eingereicht. Ich habe damit mein studium der Komparatistik am Institut für Allgemeine und Vergleichende Literaturwissenschaft abgeschlossen. Mein Magistervater war Prof. Dr. Aage Hansen-Löve vom Institut für Slavische Philologie, dem ich für die Betreuung danken möchte.

Die Anregung $2 u$ dem Thema erhielt ich von Prof. Dr. Renate Döring-Smirnov. Mein besonderer Dank gilt zinovij zinik für das Interview und die Hilfe bei der Quellensuche. Darüber hinaus bin ich Igor' Pomerancev, Aleksandr Pjatigorskij, Vladimir Bukovskij, Irina Ratusinskaja, Viktor Suvorov, Aleksandr Donde und Leonid Finkelstein für die informativen Gespräche verbunden. Professor Arnold McMillin von der Londoner "School of Slavonic and East European Studies" hat mich ebenfalls bei der Recherche unterstützt. Anna Mielert und Birqit Markhof qinqen mir bei der überarbeitung des Textes zur Hand. Schlieblich möchte ich Prof. Dr. Dieter Lamping als zweitem Prüfer Dank aussprechen.

In der Regel ist allen russischen zitaten meine eigene übersetzung beigefügt. Bei der Analyse der primärliteratur beziehen sich die seitenzahlen in klammern jeweils auf die Ausqabe oder Veröffentlichung, die beim ersten Verweis auf das betreffende Werk genannt wird.

Ich danke Prof. Dr. Peter Rehder für die Aufnahme des Textes in die Reihe "slavistische Beitráqe" und dem Institut für slavische Philologie der LMU München für den DruckkostenzuschuB. 
Einleitung $\ldots \ldots \ldots \ldots \ldots \ldots \ldots \ldots \ldots \ldots \ldots$

I. TEIL:

\section{Exil und En igrantenliteratur als porschungsgegenstand}

1. Probleme und Defizite

1.1. Die Beqriffe "Exil" und "Emigration" ...... 13

1.2. Das Phänomen und seine Erfassung ........ 15

1.3. Zur Dritten Welle ................... 19

2. Theoretische überlegungen zu einer Literatur des Zwischenraums

2.1. Zwischen der eigenen und der fremden Kultur 24

2.2. Die Sprachproblematik ............... 27

2.3. Selbstbestimmung in der Narration ....... 32

II. TEIL:

Die russische Literatur in der Bnigration

1. Grundzüge der russischen Emigration seit 1917

1.1. Historischer AbriB ................. 39

1.2. Politisierung .................... 41

1.3. Konservative und retrospektive Tendenzen ... 44

2. Die Frage der Spaltung der russischen Literatur ... 48

3. Die Dritte Enigrationswelle

3.1. Exilierung der Dissidenten ........... 53

3.2. Konsequenzen der jüngsten Entwicklung .... 56

3.3. Die Opposition von Kontinent und sintaksis 59

3.4. Die AuBenseiter .....................63

3.5. Beispiele für die Umsetzung der Emigration 67

4. Russische Autoren in England

4.1. Großbritannien als Aufnahmeland ........ 73

4.2. Die Verarbeitung der Emigration ......... 80 
III. TEIL:

\section{Das Verk yon Zinovij Zinik}

1. Literarische Entfaltung in der Emigration

1.1. Biographie .................... 85

1.2. Die Poetik von Zinovij Zinik .......... 90

1.3. Die Darstellung der englischen Kultur ..... 97

2. Russkaja sluzba

2.1. Als Sowjetbürger in England ......... 102

2.2. Die Metaphorik .................. 106

2.3. Rußland-Mythen und Heldenrollen ........ 110

2.4. Funktionen der Fremdsprachigkeit ....... 115

3. The Mushroom-Picker

3.1. Handlung, Rezeption und Verfilmung ...... 120

3.2. Eine Engländerin in Moskau .......... 125

3.3. Kostyas kulinarisches Weltbild ......... 129

3.4. Psychodrama und Politfarce ........... 132

3.5. Der Autor und sein Held ............ 136

4. The Lord and the Ganekeeper

4.1. Aufbau und Handlung ............... 139

4.2. Demaskierung im Irrenhaus ........... 143

4.3. Der Dissident und der falsche Lord ...... 146

4.4. Der übersetzer, das Plagiat und die

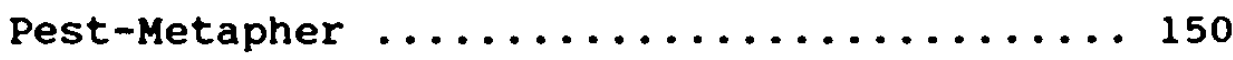

5. Die Erzāhlungen

5.1. Vorbemerkung ...................... 154

5.2. Besuch aus der Verganqenheit .......... 154

5.3. Konfrontation mit seinesgleichen ....... 158

5.4. Fremdsein in London und in Moskau ....... 161

5.5. Der neue Roman ................. 166

6. Pazit ............................. 172

ANHANG: Gesprăch nit Zinovij Zinik ........... 179

BIBLIOGRAPHIE ......................... 189 


\section{EINLEITUNG}

Zinovij zinik emigrierte in den 70er Jahren aus der Sowjetunion uber Israel nach GroBbritannien, wo er sich in London niederlieb. Er gehört damit $2 u$ den russischen Künstlern, die mit der sogenannten Dritten Auswanderungswelle unter dem Regime von Leonid Breżnev ihr Land verlieBen, begann aber erst im Ausland seine schriftstellerische Laufbahn. Die Emigration ermöglichte nicht nur seine kreative Entfaltung, sondern wurde zum stimulierenden und prägenden Faktor seines literarischen Schaffens. Denn in seiner Prosa gestaltet zinik direkt oder indirekt seine eigenen Erfahrungen in der Fremde nach der totalen und endgültigen Trennung von der Heimat.

Das Thema der vorliegenden Arbeit bezieht sich in seiner Formulierung auf einen Essay von zinik mit dem Titel "Émigracija kak literaturnyj priëm" ("Emigration als literarisches Verfahren"), in dem er die Bedeutung des freiwilligen Exils für sein werk selbst reflektiert. Der Begriff "Verfahren" bezeichnet bei inm im weitesten sinn den schöpferischen Akt als solchen und bezieht sich nicht nur auf die stilistische Ebene. Vielmehr liefert die Emigration dem Autor in erster Linie den Stof $f$ für seine Narration, was er in dem genannten und anderen Essays theoretisch ausführt sowie in seinen Romanen und Erzählungen praktisch umsetzt. Bei der Textanalyse für diese Arbeit zeigte sich, daB sein Interesse vorrangig psychologischen Aspekten und der Frage der selbstbestimmung gilt, also weniger der Funktion der Emigration als rein technischem "Verfahren", wie es das Motto seiner Poetik zunächst vermuten läßt. Die Emigration schlägt sich bei zinik vor allem deutlich thematisch-inhaltlich nieder, während die stilmittel dazu dienen, diese Thematik zu transportieren. Diese These soll anhand seiner Werke eingehend belegt werden. 
In übereinstimmung mit ziniks Poetik gehen die theoretischen Überlegungen im ersten Teil der Hausarbeit hauptsächlich von dem psychischen zustand aus, den das Exil verursacht und bedingt. Um die Verarbeitung der westlichen bzw. englischen Kultur im Kontrast zur sowjetischen bzw. russischen $z u$ erfassen, werden außerdem kultursemiotische Kategorien herangezogen. Insgesamt wird festgelegt, welches Verständnis von Emigrantenliteratur der Arbeit zugrunde liegt. Zuvor skizziert ein Abschnitt den Forschungsstand im Bereich der Exil- und Emigrantenliteratur allgemein sowie der Dritten Welle im besonderen.

Im zweiten Teil informiert ein historischer AbriB zunächst über die Emigration von Schriftstellern aus der sowjetunion in diesem Jahrhundert sowie die wesentlichen Merkmale, Zentren und Persönlichkeiten der Dritten Welle. Großbritannien lag stets am Rand der russischen Diaspora, so daß diese studie auch dazu dient, einmal einen Blick über den Kanal $2 u$ werfen. Das Anliegen besteht jedoch primär darin, zur Diskussion über die Charakteristika von Emigrantenliteratur beizutragen. Der noch relativ unbekannte Zinovij Zinik ist für die komparatistische Exilforschung besonders deshalb interessant, weil er umfassend die spezifische situation des Emigranten zwischen zwei Kulturen, seine Suche nach einer neuen Identität und sein Fremdsein in England verarbeitet hat. Die Kontinuität dieser Thematik und der interkulturellen Momente durch sein gesamtes Werk ist in der Literatur der Dritten Welle einzigartig, obgleich durchaus Parallelen $z u$ anderen Prosaikern der jüngeren Generation existieren.

Der dritte Teil stellt das Werk von Zinovij Zinik vor. Eine Betrachtung seiner Essays gibt Aufschluß über seine Poetik und sein Selbstverständnis als Autor der Emigration. Die anschließende Analyse untersucht die Umsetzung in den einzelnen Romanen und Erzählungen, wobei sie lediglich die frühen Romane ausschließt, die auf ziniks Aufenthalt in Israel basieren. Ansonsten wird versucht, sein Schaffen erstmals in seiner Gesamtheit $z u$ erschlieBen, da es bislang nur sporadisch in der wissenschaftli- 
chen Auseinandersetzung mit der Dritten Welle berücksichtigt wurde und sich die sekundärliteratur weitgehend auf Rezensionen beschränkt. Ergänzend finden sich im Anhang ein persönliches Gespräch mit dem Autor sowie ein vollständiges und aktuelles Verzeichnis seiner literarischen Veröffentlichungen mit allen Quellenangaben. Die Werke sind fast ausschlieblich in russischer sprache, aber mehrheitlich ins Englische und andere sprachen ubersetzt worden und teilweise zuerst in der Fremdsprache erschienen, so daB in der Analyse auch mit den übersetzungen gearbeitet wird. 
Anja Pülsch - 9783954790913

Downloaded from PubFactory at 01/10/2019 03:06:54AM

via free access

$0005192 C$ 
Exil- una Emigrantenliteratux als Forschungsgegenstand

\section{PROBLEME UND DEFIZITE}

\subsection{Die Begriffe "Exil" und "Bnigration"}

Als Exil- und Emigrantenliteratur wird in der Regel die Literatur bezeichnet, die in der realen situation des Exils und der Emigration in der Muttersprache des jeweiligen Verfassers entstanden ist. Das bedeutet, der Autor muBte sein Heimatland aus politischen, religiösen, ethnischen oder wirtschaftlichen Gründen auf Dauer verlassen. In den Sonderfällen des "inneren Exils" und der "inneren Emigration" erfolgt die Isolation innerhalb der Landesgrenzen. Der Zwang kann direkt sein, nämlich in Form einer strafe oder einer akuten Verfolgungsgefahr; es kann sich aber auch um eine Lossagung aus freiem willen handeln, wobei dieser EntschluB freilich durch die Umstände indirekt ebenfalls erzwungen ist. ${ }^{l}$ Die Ursachen und die Situation des Exils und der Emigration stimmen im wesentlichen überein. Paul Tabori hat die Semantik des "Exil"-Begriffs eingehend untersucht und erklärt:

"(1) An exile is a person who is compelled to leave his homeland - though the forces that send him on his way may be political, economic, or purely psychological. It does not make an essential difference whether he is expelled by physical force or whether he makes the decision to leave without such an immediate pressure. (2) The status of exile, both materially and psychologically, is a dynamic one - it changes from exile to emigrant or emigrant to exile. These changes can be the results both of circumstances altering in his homeland and of the assimilation in his new country. An essential element in this process is the attitude of the exile to the circumstances

1 Der Begriff umfaBt seit der Antike beide Aspekte, wie ein Blick in die Geschichte, insbesondere die Rechtsgeschichte zeigt; s. dazu Robert Edwards, "Exile, Self, and Society", Exile in Literature, hg. Maria-Inés Lagos-Pope, Lewisburg, London u. Toronto, 1988, S. 17-18. 
prevailing in his homeland which are bound to influence him psychologically."2

Tabori unterstreicht, wie wichtig das Selbstverständnis der Betroffenen und ihre sicht der eigenen Lage bei der Definition von Exil ist. ${ }^{3}$ Damit hängt auch der Unterschied zwischen Exulant und Emigrant zusammen: Der eine hofft - freilich mit den Jahren immer weniger und oft vergeblich - auf eine radikale Veränderung der Verhältnisse in der Heimat, die inm eine Rückkehr ermöglichen würde; für den anderen ist die Trennung von vornherein endgülig." GemäB der wortbedeutung des lateinischen exilium drückt "Exil" vornehmlich den Zustand der Verbannung aus und wird stärker als "Emigration" mit Schmerz, Heimweh, Leid, Verstoßen- und Ausgestoßensein sowie Einsamkeit assoziiert.5 In diesem sinn scheint der "Exil"-Begriff bezüglich der Schriftsteller, die in den vergangenen Jahrzehnten aus der Sowjetunion in den Westen kamen, nicht ganz adäquat. Denn sie gelangten aus einem totalitären staat in eine pluralistische, wirtschaftlich starke Demokratie, so daß den Verlusterfahrungen der Gewinn der Freiheit und des Wohlstands gegenübersteht. Abgesehen davon ist es üblich, bei der russischen Literatur des 20. Jahrhunderts im Ausland eher von Emigranten- als von Exilliteratur $z u$ sprechen, weil sie im Rahmen des historischen Phänomens der drei Auswanderungswellen aus der sowjetunion gesehen wird. ${ }^{6}$ Andererseits setzt der "Exil"-Begriff den Akzent traditionell auf die politische Motivierung. Er impliziert also stärker als "Emigration" die Nötigung durch das kommunistische Re-

2 P. Tabori, The Anatomy of Exile: A Semantic and Historical study, London, 1972, S. 37. Das Buch erläutert die Geschichte des Exils von der vorchristlichen zeit bis in die Gegenwart und bietet einen umfassenden überblick uber die Verbannung von Andersdenkenden, Vertreibung von Minderheiten sowie Massenflucht- und Migrationsbewegungen.

Vgl. Tabori, a.a.0., S. 31-37.

Vgl. Tabori, a.a.0., s. 27.

5 vgl. Edwards, S. 15. Bezeichnend sind auch Buchtitel wie The Bitter Air of Exile (hg. Simon Karlinsky u. Alfred Appel jr., Berkeley u.a.., 1977).

Für die von den deutschen Nationalsozialisten vertriebenen Autoren ist hingegen der Begriff "Exilliteratur" gebräuchlicher, weil das phänomen nicht in einen entsprechenden demographischen zusammenhang gestelit wird und temporär war. 
gime, das die betreffenden Autoren außer Landes trieb, so daB er zu ihrer Binordnung ebenfalls verwendet wird.

In der vorliegenden Arbeit treten beide Termini weitgehend synonym auf. Eine deutliche Trennung ist schon aus den angeführten Gründen kaum möglich und auch nicht notwendig. Denn im Vordergrund steht die Frage, wie sich die spezifische situation des exilierten oder emigrierten Autors - und diese Unterscheidung ist, wie gesagt, meist nicht eindeutig - auf die Literatur auswirkt, wobei die Konfrontation mit der fremden Kultur von zentraler Bedeutung ist.

\subsection{Das Phänomen und seine Brfassung}

Die literaturwissenschaftliche Auseinandersetzung mit Exil- und Emigrantenliteratur findet in erster Linie innerhalb der einzelnen Philologien statt. Phänomene wie die Literatur der russischen Emigration im 20. Jahrhundert, die deutsche Exilliteratur der Jahre 1933 bis 1945 oder die zeitgenössischen Exilautoren aus lateinamerikanischen Diktaturen werden weitgehend unabhängig voneinander betrachtet. Doch bereits bei solchen zeitlichen und nationalen Beschränkungen besteht das literaturwissenschaftliche Problem darin, daß die Autoren vor allem durch ihre Situation verbunden sind, während ihre Werke stilistisch und thematisch sehr heterogen sein können. Dies ist insbesondere auch bei den aus RuBland emigrierten Autoren der Gegenwart der Fall.?

7 Josephine Woll z.B. beginnt ihren Aufsatz "Guests from the Future" mit der Feststellung: "Any attempt to survey recent Russian émigré prose is an exercise in frustration. There is too much of it, by too many authors, in too many different genres." Russian Review, Nr. 43, 1984, S. 377. Vgl. Arnold McMillin: "My own bibliography of third-wave prose writers contains more than two hundred names, and their works extend over a wide variety of themes, genres and style [...]." In: "The Effect of Exile on Modern Russian Writers: A Survey", Renaissance and Modern Studies, Nr. 34, 1991, S. 20. 
Gerade bei politischen Gründen für das Exil schieben sich biographische, historische und ideologische Aspekte in den Vordergrund. Exemplarisch ist die Rezeption der "Dritten Welle": Schon allein der Begriff stellt keine literarische Klassifikation dar, sondern eine demographische Bezeichnung für die Auswanderung aus der Sowjetunion in den 70er Jahren, die aber zugleich die damals in den westen gekommenen Autoren zusammenfaBt. Da viele von ihnen als Dissidenten bekannt wurden, ist der Behelfsbegriff "Dritte Welle" von vornherein politisch konnotiert.

Ein Vergleich bietet sich an mit der deutschen Exilliteratur, deren vertreter sich ebenfalls dem zugriff eines totalitären Regimes entzogen hatten und in der germanistischen Exilforschung lange vorrangig in ihrer Rolle als geistige opposition gesehen wurden. Erst Anfang der 80er Jahre bemängelten unter anderen John Spalek, Joseph strelka und Guy stern nachdrücklich die starke Vernachlässigung der rein literaturwissenschaftlichen Analyse und arbeiteten erstmals typische Gattungen, Themen, Metaphern und Symbole heraus.8 Ähnliche Gliederungen finden sich auch in den historischen Darstellungen der russischen Literatur in Westeuropa in den 20er und 30er Jahren. Bezüglich der Dritten Welle kann man in dieser Hinsicht eine vielzahl einzelner Beobachtungen feststellen.

Für die Komparatistik schließt sich die Frage an, wie weit solche Ergebnisse übertragbar sind, das heiBt, ob es eine Typologie der Exilliteratur an sich gibt. Lassen sich synchron und diachron Konstanten in der literarischen Verarbeitung der Exilsituation und -erfahrung nachweisen, und zwar in Inhalt und Form? Zeichnet sich Exilliteratur durch bestimmte Ausdrucksweisen und Verfahren aus, so daB man schlieblich eine Poetik des Exils entwerfen könnte? Und andererseits: wie lassen sich die Unterschiede festma-

8 John M. Spalek U. R. F. Bell (Hg.), Exile: The Writer's Experience, Chapel Hill, 1982; Joseph Strelka, Exilliteratur: Grundprobleme der Theorie, Aspekte der Geschichte und Kritik, Bern u.a., 1983, S. 11-86; Guy Stern, "Prolegomena zu einer Typologie der Exilliteratur", Schreiben im Exil: Zur Asthetik der deutschen Exilliteratur 1933-1945, ha. A. Stephan U. H. Wagner, Bonn, 1985, S. 1-17. 
chen, und durch welche Faktoren sind sie bedingt? Eine Untersuchung dieser Fragen kann nur die Komparatistik umfassend leisten und würde unmittelbar auch die Abgrenzung von Exilliteratur erleichtern. ${ }^{9}$

Bislang liegen freilich nur wenige komparatistische Publikationen vor, die in dieser Hinsicht AufschluB geben, indem sie Werke und Autoren aus verschiedenen Kulturen (mit schwerpunkt auf der Gegenwartsliteratur) in einen Zusammenhang bringen. ${ }^{10}$ AuBerdem gibt es vereinzelt Initiativen, exilierten und emigrierten Schriftstellern selbst auf einer internationalen plattform das wort $2 u$ geben. Dieses Material kann zumindest dazu beitragen, das Verständnis für spezifische probleme $z u$ vertiefen und den Blick für kulturelle Unterschiede $z u$ schärfen. ${ }^{11}$ Die wechselseitigen Einflüsse zwischen exilierten Autoren und der Literatur des Aufnahmelandes bilden ein weiteres kompara-

9 In der Germanistik z.B. ist die zeitliche Eingrenzung auf die Jahre 1933 bis 1945 ublich, aber nicht unumstritten, da sie Kontinuitäten ignoriert, "als ob das Kriegsende diese Literatur einfach abgeschafft und erledigt hätte", wie etwa Michael Hamburger kritisiert ("Einige Bemerkungen zur Kategorie Exil-Literatur", Literatur und Kritik, Nr. 128, 1978, S. 481). Bezüglich der russischen Literatur offenbaren sich die Definitionsprobleme in der Streitfrage, ob sie sich im 20. Jahrhundert gespalten hat oder nicht (s. II.2.).

10 James whitlark und Wendell Aycock $2 . B$. vereinen in The Literature of Emigration and Exile (Lubbock, Texas, 1992) Aufsätze über Literatur aus der ganzen Welt. Literature and Exile von David Bevan (Amsterdam u.a., 1990) stellt ebenfalis Autoren mit vollkommen unterschiedlichem kulturellen und sozialen Hintergrund vor, allerdings auf der Basis einer auf soziale Randgruppen ausgeweiteten Definition von "Exil".

II Literature in Exile (hg. John Glad, Durham u. London, 1990) ist die Dokumentation einer entsprechenden Konferenz in Wien. Ota Filip und Egon Larsen (Die zerbrochene Feder, Stuttgart, 1984) forderten Autoren aus über 20 Ländern Europas, Asiens, Afrikas und Amerikas auf, sich zu ihrem Exil bzw. ihrer Emigration zu äuBern. Das Buch zeigt unter anderem, daß die Osteuropäer überwiegend direkt ihre persönlichen Erfahrungen mitteilen, während die Lateinamerikaner eher in der Fiktion erzählen. Die Herausgeber sehen einen möglichen Grund für die unterschiedliche Distanz zu den eigenen Erlebnissen darin, daB die Exulanten aus Lateinamerika oft in Nachbarländern oder spanien zuflucht fanden, so daB der Kulturwechsel weniger gravierend war als für die osteuropäischen Autoren im Westen. 
tistisches Untersuchungsfeld, das erst in einigen Bereichen bearbeitet ist. 12

Das Interesse an einer Poetik des Exils verlangt jedoch letztlich eine systematische und theoretische Erfassung des Phänomens Exilliteratur. In dieser Hinsicht offenbart sich ein Defizit in der vorhandenen Literatur zum Thema. Am fruchtbarsten erschienen mir der kultursemiotische Ansatz, den Bol'dt, Segal und Flejšman in einem Aufsatz zur russischen Emigrationskultur in den 20er und 30er Jahren entwickeln, und das psychoanalytische Modell von Elisabeth Bronfen, die von der psychischen und existentiellen Erfahrung des Exils ausgeht. ${ }^{13}$

Die vorliegende studie behandelt einen einzelnen Autor und verengt somit den Blick, statt inn $z$ weiten, wie oben gefordert. Die angesprochenen Definitionsprobleme bestimmen jedoch die zentralen Aspekte der Analyse und sollen in diesem Einzelfall konkretisiert werden. Denn im wesentlichen geht es um die Frage, wie zinovij zinik die Emigration literarisch verarbeitet hat und was sein werk

12 Einen Vorstoß in dieser Richtung machte ein internationales Symposium, das in dem Band Kulturelle Wechselbeziehungen im Exil/Exile across Cultures dokumentiert ist (hg. Helmut F. Pfanner, Bonn, 1986). In der Germanistik machte $2 . B$. Guy Stern 1980 auf den Mangel einer komparatistischen Wirkungsgeschichte in der Exilforschung aufmerksam ("Komparatistik und Exilforschung", Literatur im Exil: Gesammelte Aufsatze 1959-1989, München, 1989, S. $53-55)$.

13 F. Bol'dt, D. Segal u. L. Flejšman, "Problemy izučnija literatury russkoj emigracii pervoj treti $X X$ veka", Slavica Hierosolymitana (Jerusalem), Bd. III, 1978, S. 7588: E. Bronfen, "Exil in der Literatur: Zwischen Metapher und Realität", Arcadia, Bd. 28, H. 2, 1993, S. 167-183. Auf die Psychoanalyse stützt sich z.B. ebenfalls Bettina L. Knapp in Exile and the writer: Exoteric and Esoteric Experiences: A Jungian Approach (Univ. Park, Pennsylvania, 1991), versteht dabei jedoch "Exil" auch als Metapher für die Urbedingung des menschlichen Daseins und stellt ein anthropologisches Interesse in den Mittelpunkt. - Versuche einer Theoretisierung finden sich darüber hinaus bei Michael Seidel, dessen Studie Exile and the Narrative Imagination (New Haven u.a., 1986) poststrukturalistisch ausgerichtet ist, und bei Terry Eagleton, der seine Untersuchung Exiles and Emigres: Studies in Modern Literature (London; 1970) mit einer Analyse der englischen Kultur verbindet. Beide beschränken sich allerdings auf die angloamerikanische Literatur. 
als Prosa der Emigration kennzeichnet. Dabei stehen interkulturelle Momente im Vordergrund, etwa das in der literarischen wiedergabe ausgedrückte Verhältnis zum Gastland und zur Fremdsprache sowie Ziniks Rezeption in England.

\subsection{Zur Dritten Welle}

Die seit 1917 emigrierten Intellektuellen und Künstler waren in der Sowjetunion bis zur politischen wende in der zweiten Hälfte der 80er Jahre offiziell verdammt und verschwiegen. Nur während der "Tauwetter"-Periode Mitte der 50er Jahre bis 1964 wurde auch dieses Tabu etwas gelockert. Danach setzte sich die in dieser phase begonnene Rezeption der Literatur der 20er und 30er Jahre im Untergrund fort. Die wissenschaftliche Auseinandersetzung mit der russischen Emigrantenliteratur fand folglich jahrzehntelang ausschlieblich im Westen statt. Eine umfangreiche Bibliographie der Histoire de la littérature russe belegt, daß entsprechende Publikationen mit Beginn der 50er Jahre vorrangig in Frankreich, Deutschland und den USA erschienen; erst 1988 setzte eine Flut von Veröffentlichungen in der sowjetunion selbst ein.14

Die Literatur der sogenannten Ersten Welle, das heiBt, der russischen Emigranten in Westeuropa in den 20er und 30er Jahren ist literaturhistorisch verhältnismäBig gut aufgearbeitet. Meistens umfaBt die Betrachtung auch die weniger bedeutsame Zweite Welle, die auf die Kriegsjahre datiert wird. 15 während die Erste Welle im Rückblick

11 Etkind, E., G. Nivat, I. Serman U. V. Strada (Hg.), Histoire de la litterature russe (Le XXe siécle), Bd. 3: Gels et Dégels, Paris, 1990, S. 1000-1020.

15 stellvertretend hier zwei der wichtigsten Publikationen: das standardwerk von Gleb Struve Russkaja literatura $v$ izgnanii, 2. u. erw. Aufl., Paris, 1984 (1956); und die Aufsatzsammlung von Nikolaj Poltorackij Russkaja literatura $v$ emigracii: Sbornik statej, Pittsburgh, 1972. Beide Bände stelien jeweils ausführlich die einzelnen Autoren, Zeitschriften und Tendenzen der Literaturkritik vor. Darüber hinaus gibt es eine Reihe von Darstellungen des Kulturlebens in der Diaspora, darunter Michèle Beyssac, La vie culturelle de l'emigration russe en France: Chronique (1920-1930), Paris, 1971; Robert Johnston, New Mecca, New 
erschlossen wurde, ist der literarischen Produktion der Dritten Welle, die in den 70er und Anfang der 80er Jahre in den Westen kam, von Beginn an Aufmerksamkeit zuteil geworden. Dabei wurde sie nicht immer von der sowjetliteratur abgegrenzt und als eigenständiges Phänomen gesehen. Petr Vajl' und Aleksandr Genis beispielsweise stellen die emigrierten Autoren in Sovremennaja russkaja proza (Ann Arbor, 1982) in eine Reihe mit den offiziellen und nichtoffiziellen Autoren in der Sowjetunion, ebenso Geoffrey Hosking in einem Beitrag $2 u$ The Cambridge History of Russian Literature über die russische Literatur zwischen 1953 und 1980.16

Die Beschäftigung mit der Dritten Welle beschränkt sich zum großen Teil auf Fachzeitschriften. Eine grundlegende Bestandsaufnahme wie bei der Ersten welle gibt es zu diesem zeitpunkt nicht und kann es möglicherweise auch (noch) nicht geben.17 Als eine der ergiebigsten Quellen erweist sich das Material diverser Konferenzen. Hervorzuheben ist das Treffen von westlichen Experten und russischen Autoren in Los Angeles im Mai 1981, bei dem spezifische Probleme, Merkmale und Tendenzen erörtert wurden. Olga Matich hat die Vorträge und Diskussionen gemeinsam mit Michael Heim in Tret'ja volna/The Third Wave: Russian Literature in Emigration (Ann Arbor, 1984) dokumentiert. Bei der Konferenz 1978 in Genf $2 u$ der Frage Une ou deux litte-

Babylon: Paris and the Russian Exiles, 1920-1945, Montreal, Kingston, 1988; Marc Raeff, Russia Abroad: A Cultural History of the Russian Emigration, 1919-1939, New York, oxford, 1990. S. zur Illustration auch Michael Glenny $u$. Norman Stone, The other Russia: The Experience of Exile (New York, 1991) mit den persönlichen Lebensgeschichten von vertretern aller drei Emigrationswellen auf der Grundlage von authentischem Material wie Interviews und Manuskripten.

16 G. Hosking, "The Twentieth Century: In Search of New ways, 1953-1980", The Cambridge History of Russian Literature, hg. Charles A. Moser, Cambridge, 1989, S. 520-594.

17 Titel wie A History of Post-War Soviet writing von Grigori Svirski (Ann Arbor, 1981) und Jurij Mal'cevs Freie russische Literatur 1955-1980 (Frankfurt, 1981) beschränken sich auf die inoffizielle Literatur in der Sowjetunion, sind aber insofern auch zur Dritten welle aufschluBreich, als beide Phänomene eng zusammenhängen und die Autoren teilweise identisch sind. 
ratures russes?/Odna ili dve russkich literatury? (hg. Georges Nivat, Lausanne, 1981) stand zwar überwiegend die Erste Welle zur Debatte, zum Teil wurde aber auch die Dritte Emigration berücksichtigt.

DaB die Konferenzergebnisse die Grundlage für weitergehende Untersuchungen bilden können, zeigt Kathryn Henrys Dissertation Between Cultures: Third-Wave Russian Fiction in Russian and English (Stanford, 1990), die sich wesentlich auf den Band von Matich und Heim stützt, um ein Porträt der Dritten Welle zu entwerfen und deren Meinungsspektrum wiederzugeben. Die Arbeit ist besonders dadurch interessant, daß sie systematisch Kritiken in den amerikanischen Medien auswertet und somit Erkenntnisse über die Rezeption im Westen liefert.

Die Beziehungen zwischen den Emigranten und ihren Aufnahmeländern, also interkulturelle Aspekte sind bislang wesentlich weniger thematisiert und behandelt worden als das Verhältnis der Dritten welle zur sowjetunion und der sowjetischen Literatur. Die Aufsatzsammlung Under Eastern Eyes: The west as Reflected in Recent Russian Emigré writing (hg. Arnold McMillin, New York, 1992) trägt ebenso wie Henrys Studie dazu bei, solche Lücken zu füllen: sie zeigt, welche Haltung verschiedene schriftsteller zum Westen einnehmen und wie sich ihre Ansichten und Erfahrungen in ihrem Werk niedergeschlagen haben. Andere Aspekte, die ebenfalls lange eher zweitrangig waren, wurden 1986 von der Zeitschrift Slavic and East European Journal in dem "Forum: The Third Wave" in den Mittelpunkt gestellt: die betreffenden Aufsätze erörtern nämlich sprachliche Innovationen in der russischen Gegenwartsliteratur außerhalb der Sowjetunion. 18 Jüngere Sammelveröffentlichungen nach thematischen oder stilistischen Kriterien wie die genannten Beispiele schließen auch schriftsteller ein, die insbesondere in den 70er Jahren im Schatten der bereits etablierten Autoren standen. Edward J. Brown spricht in sei-

18 Slavic and East European Journal (SEES), Bd. 30, H. 3, Herbst 1986, S. 380-419; H. 4, Winter 1986, S. 509-552. 
ner Einleitung zum "Forum" des SEEJ von einem groBen Nachholbedarf in dieser Beziehung:

"Some of these writers are accorded honor and obeisances in the critical and quasi-critical literature, but, with some well-known exceptions, they have not been subjected to sophisticated critical analysis, and, one might venture to say, are not yet part of Russian literary culture already enshrined in the Academy, a body of writing which does include such eminent and acknowledged figures as Nabokov and Solzenicyn."19

Gerade innerhalb der Emigrantenzirkel selbst waren einzelne Personen wie Aleksander Solženicyn beherrschend, und politische MaBstäbe standen über literarischen, was sich in der Emigrationspresse widerspiegelt. Dessen ungeachtet erfülte sie freilich eine zentrale Funktion für die Literatur der Dritten Welle. Die betreffenden zeitschriften sind daher für jede wissenschaftliche Untersuchung auf diesem Gebiet unentbehrliche Quellen.20

Mit der jüngsten politischen und gesellschaftlichen Entwicklung in RuBland haben die Intellektuellen im Ausland inre Funktion als geistige opposition verloren, was den Blick auf die Literatur freigemacht hat. Je mehr die historischen Faktoren in den Hintergrund rücken, desto starker werden die schriftsteller an ihren literarischen Leistungen (statt an ihren Aussagen und Taten) gemessen. Die Frage, wie ihre Werke im Kontext der russischen Gegenwartsliteratur insgesamt einzuordnen sind, stellt sich inzwischen unter neuen Vorzeichen. Es hängt jedoch von den Maßstäben $a b$, ob bereits vom Ende der Emigrantenliteratur

19 E. J. Brown, "Russian Literature beyond the Pale", SEES, Bd. 30, H. 3, Herbst 1986, S. 388. - Pionierarbeit leistet hier wolfgang Kasack; davon zeugen die aktualisierten Ausgaben seiner übersicht über die russische Literatur nach 1945, in die er einige relativ unbekannte Autoren (inkl. Zinovij zinik) aufgenommen hat. (Die russische Literatur 1945-1982, wesentl. erw. Neuaufi. d. Darst. Die russische Literatur 1945-1976, München, 1983; Russian Literature 1945-1988, München, 1989).

20 Die von Leonid Knotin herausgegebene Bibliographie Abstracts of Soviet and East European Emigre Periodical Literature (ab 1991 Zarubeznaja periodičeskaja pećat' na russkom jazyke) geben eine wertvolle orientierungshilfe. S. auch die Bibliographie von T. L. Gladkova, L'emigration russe: Revues et recueils, 1920-1980, Paris, 1988. 
gesprochen werden kann. Neben der verstärkten Aufarbeitung der Dritten Welle nach Kriterien der künstlerischen Qualität besteht deshalb eine wichtige Aufgabe der Literaturwissenschaft darin $z u$ verfolgen, wie weit sich die Literatur außerhalb RuBlands eigenständig weiterentwickelt. 


\section{THEORETISCHE ÜBERLEGUNGEN}

\section{ZU EINER LITERATUR DES ZWISCHENRAUMS}

\subsection{Zwischen der eigenen und der freeden Kultur}

\section{Die theoretische Erfassung von Exil und Emigration} als Grenzüberschreitung von einer Kultur in die andere setzt eine bestimmte Definition von Kultur voraus. Die Kultursemiotik geht hierbei von der menschlichen Kultur als "Gesamtheit von zeichenhaften Phänomenen" aus.21 Jede Kultur bildet aus verschiedenen zeichensystemen, die funktional korreliert sind, ein Gesamtsystem. ${ }^{22}$ Nach außen definiert es sich in Abgrenzung zur Nicht-Kultur bzw. zum Fremden, das folglich eine konstitutive Funktion innehat und zum Eigenen in Opposition steht.

Veränderungen der Zeichensysteme resultieren aus einer dialektischen Wechselbeziehung zwischen immanenter Entwicklung und interkulturellen Kontakten, wobei jeweils das Fremde gewissermaßen verinnerlicht oder importiert wird. ${ }^{23}$ Das Fremde (čużoe) ist im sinn einer Alterität zu verstehen, das heißt, es stellt die eigene Identität in Frage. 24 In einem dynamischen Prozeß der Auseinandersetzung mit dieser Alternative und der anderen Identitat wird das

21 Ivan Bystrína, "Die Kultur und ihre Codes", Zeichen und Realitat, hg. Klaus Oehler, Bd. III, Tübingen, 1984, S. 22023 .

die Zeichensysteme bestehen aus zeichentypen und Regeln, Kultursemiotik werden in diesem Bereich maßgeblichen Tartuer Schule erläutert (hier die Quellenangaben der deutschen übersetzungen): Ju. M. Lotman, B. A. Uspenskij, V. V. Ivanov, V. N. Toporov $u$. A. M. Pjatigorskij, "Thesen zur semiotischen Erforschung der Kultur (in Anwendung auf slawische Texte)", Semiotica Sovietica, Bd. 1, Aachen, 1986, S. 85-118; Ju. M. Lotman u. B. A. Uspenskij, "Zum semiotischen Mechanismus der Kultur", Semiotica Sovietica, Bd. 2, Aachen, 1986, S. 853880.

S. u.a. Jurij Lotman, "K postroeniju teorii vzaimodestvija kul'tur (semiotičeskij aspekt)", Izbrannye stat' $v$ trech tomach, Bd. 1, Tallinn, 1992, S. 117 ff.: Lotman, "Der Einfluß im kulturellen Feld", wiener slawistischer Almanach, Nr. 12, 1983, S. 5-19.

21 Der Begriff strannost" ("Fremaheit") kennzeichnet demgegenüber das Neuartige, überraschende, enthält also eine ästhetische Komponente. 
Eigene fortlaufend bestätigt oder erneuert: Die eigenen Koordinaten werden mehr oder weniger stark auf das Fremdphänomen projiziert, aber auch rückwirkend modifiziert. Im Extremfall können die eigenen Traditionen fundamental transformiert oder umgekehrt das Fremde vollkommen vereinnahmt werden. Literatur fungiert als Medium für diese vorgänge. ${ }^{25}$ Bei der Darstellung der anderen Kultur formuliert, reflektiert und korrigiert sie die stereotypen, die in der eigenen Kultur bezüglich dieser anderen vorherrschen.

Im Fall des Exils und der Emigration unterliegt die Kontrastierung des Eigenen mit dem Fremden den besonderen Bedingungen der Isolationssituation. Die Konfrontation mit dem Fremden findet ausschlieblich innerhalb einer fremden Kultur statt und reduziert sich auf das Individuum oder das Kollektiv, das aus der eigenen kultur in das andere System versetzt wurde. ${ }^{26}$ Die ständige Beeinflussung durch die umgebende Kultur geht einher mit der Bewahrung der eigenen Wahrnehmungsmuster und Werte sowie der Pflege der eigenen Traditionen im Kollektiv. Die Distanz zu den Einheimischen verringert sich zwar schrittweise, doch bleibt der Exulant oder Emigrant bis zu einem gewissen Grad immer der Fremde, das heiBt, derjenige, der nicht dazugehört,27 was sich seit Entstehung der Nationalstaaten vornehmlich an der Nation festmacht. Insofern markiert das Exil einen Raum zwischen den (nationalen) Kulturen, die Peripherie sowohl der eigenen als auch der fremden kultur und somit den Schnittbereich verschiedener semiotischer Felder. (Die zeitgenössischen russischen Autoren in Großbritannien be-

25 Dieser ProzeB läBt sich v.a. an Reiseliteratur nachvollziehen. Daniela Magill analysiert $2 . B$. in Literarische Reisen in die exotische Fremde: Topoi der Darstellung von Eigen- und Fremdkultur (Frankfurt/M., Bern, New York, Paris, 1989) entsprechende Textbeispiele auf der Grundlage des kultursemiotischen Modells.

$26 \mathrm{Vgl}$. mit dem ethymologischen Ursprung des wortes "Exil" im lateinischen exsalire für "herausspringen", von dem sich exilium ("Verbannung") ableitet. - Emigranten stellen einen besonderen Typ kultureller Minderheiten dar. Eine Abgrenzung ihrer Literatur $\mathrm{zu}$ der anderer Minderheiten findet sich in Bol'dt, Segal und Flejśman, "Problemy izučenija ..." a.a.O.. S. $76 \mathrm{ff}$.

27 Vgl. Julía Kristeva, Fremde sind wir uns selbst, Frankfurt/M., 1990, S. 104-105. 
finden sich überdies auch an der Peripherie der Emigrantengemeinschaft.)

Genauer betrachtet handelt es sich nicht um einen $\mathrm{Zu-}$ stand, sondern einen übergang: Durch die unüberwindliche räumliche und zunehmende zeitliche Distanz zur eigenen Kultur wird die persönliche zugehörigkeit zu dieser immer mehr in Frage stellt (Entfremdung), während sich die Einflüsse des Fremden zunehmend auswirken und $2 u$ seiner allmählichen Aneignung führen können (Assimilierung). Die Literatur des Exils und der Emigration entsteht im spannungsfeld dieser Prozesse, so daß sich die Kategorien des Eigenen und des Fremden darin entsprechend verändern und überlagern können.

Die Literatur, die ein Kollektiv emigrierter Kulturträger produziert, kann im kultursemiotischen sinn als system gelten, das zum einen mit der Literatur in der Heimat und zum anderen mit der des Aufnahmelandes bzw. seiner Kultur in einer Wechselbeziehung steht. Dieser Ansatz liegt der systematischen Untersuchung von Bol'dt, Segal und Flejśman zur Literatur der russischen Emigration im ersten Drittel des 20. Jahrhunderts zugrunde. ${ }^{28}$ Bei der Dritten welle ergibt sich eine kompliziertere Konstellation dadurch, daß sich die Literatur in der Sowjetunion in einen offiziellen und einen inoffiziellen Zweig aufspaltet, $z u$ denen die Literatur im Westen als drittes subsystem in Relation gesetzt werden muß.

28 Die Literatur, die im Ausland entstand, und die Literatur, die sich zur gleichen zeit in der sowjetunion entwickelte, fassen die Autoren als zwei subsysteme (oder "literarische Reihen") des systems "russische Literatur" auf und bestimmen mittels dichotomischer parameter deren Verhältnis. Darüber hinaus ordnen sie die russische Emigrantenkultur in den Kontext der westeuropäischen Avantgarde-strömungen ein ("Problemy izučenija ...", a.a.o.). S. auch Lazar Flejšmans Aufsatz "Neskol'ko zamečanij k probleme literatury russkoj emigracii" in odna ili dve .... (hg. Nivat, a.a.0., S. 63-76), in dem er die synchronen und diachronen Wechselbeziehungen zwischen den genannten Subsystemen in den Blickpunkt rückt. - Der Ansatz läßt sich auf ähnliche Phänomene wie z.B. die polnische Kultur im Londoner Exil nach dem Zweiten Weltkrieg übertragen. 
Ein wichtiges Moment für komparatistische Fragestellungen ist die doppelte vermittlungsfunktion von Exilliteratur. ${ }^{29}$ Einerseits exportiert sie die eigene kultur. Im 20. Jahrhundert betrachteten die Emigranten aus RuBland es sogar stets als Mission, im Ausland die russischen Werte und Traditionen $z u$ repräsentieren. AuBerdem gewährten sie dem Westen Einblick in verschiedene Bereiche des sowjetischen Lebens. Umgekehrt sind Exilautoren prädestiniert, dem Leser in der Heimat die Fremde näherzubringen (freilich unter der Voraussetzung, daB ihre werke ubberhaupt $z u$ inm gelangen, was bei den sowjetischen Schriftstellern nur sehr begrenzt gegeben war). Die Literatur kann so den interkulturellen Austausch fördern. Da zinovij zinik in seiner prosa zugleich ein Bild der Sowjetunion und Englands entwirft, wobei er nationale stereotypen aufgreift und zum Teil hinterfragt, ist sein werk ein anschauliches Beispiel für den standpunkt des emigrierten Autors zwischen den Kulturen.

\subsection{Die Sprachproblenatik}

Kulturen verfügen uber unterschiedliche Kodes (Regelsysteme) für die Regelung von Informationsprozessen; im engeren Sinn wird unter Kode die Sprache (1angue) verstanden. ${ }^{30}$ Mit dem Exil und der Emigration erfolgt nicht unbedingt, aber oft auch das Eindringen in einen anderen Sprachraum, was für den Autor existentielle Bedeutung hat, weil die Muttersprache das Medium seiner Kunst ist. Er gerät in eine sprachliche Isolation, die Joseph Brodsky wie folgt umschreibt:

29 Literatur dient allgemein dazu, kulturelle Fremaheit abzubauen und die Sensibilität für kulturelle Differenzen zu stärken, wie Norbert Mecklenburg darlegt ("Über kulturelle und poetische Alterität: Kultur- und literaturtheoretische Grundprobleme einer interkulturellen Germanistik", Hermeneutik der Fremde, hg. Dietrich Krusche u. Alois wierlacher, München, 1990, S. 96).

30 Zum Begriff s. z.B. Ivan Bystrina, "Die Kultur ...", a.a.o.. S. 1023-1039; ders.. "Kodes und Kodewandel", Zeitschrift fur Semiotik, Nr. 5, 1983, S. 1-22. 
"[...] to be an exiled writer is like being a dog or a man hurtled into outer space in a capsule [...]. And your capsule is your language. [...] For one in our profession, the condition we call exile is, first of all, a linguistic event: an exiled writer is thrust, or retreats, into his mother tongue. From being his, so to speak, sword, it turns into his shield, into his capsule." 31

Wenn der Autor, wie das Bild suggeriert, auf seine sprache angewiesen, aber von ihrer alltäglichen Realisierung sowie ihrer Entwicklung innerhalb der eigenen Kultur abgeschnitten ist, besteht die Gefahr, daB sein stil an Lebendigkeit, Sicherheit und Ausdrucksstärke verliert oder auch maniriert wird.32 Für einige Angehörige der Dritten Welle stellte sich in diesem zusammenhang das spezifische Problem, daß die anspielungs- und nuancenreiche äsopische sprache, die sie unter der zensur entwickelt hatten, im Westen überflüssig wurde und der adäquate Adressat plötzlich fehlte. ${ }^{33}$ AuBerdem gab es Verständnisschwierigkeiten und Differenzen in stilfragen mit den vertretern der vorhergehenden Emigrationswellen, die - abgekapselt von der kulturellen Entwicklung in der Sowjetunion - eine klassische sprache konserviert hatten. 34

Ein Aspekt, den Brodskys Metapher vernachlässigt, ist die permanente Konfrontation mit der Fremasprache. ${ }^{35}$ sie

31 Joseph Brodsky, "The Condition we Call Exile", Renaissance and Modern Studies, Bd. 34, 1991, S. 7 .

S. dazu u.a. Manfred Durzak, "Laokoons Söhne: Zur Sprachproblematik im Exil", Akzente, Bd. 21, H. 1, 1974, S. 53-63; Wulf Köpke, "Die Wirkung des Exils auf Sprache und Stil: Ein Vorschlag zur Forschung", Exilforschung, Bd. 3, 1985, S. 225-237. - Zur Veranschaulichung $s$. auch die diesbezüglichen Aussagen von Autoren der Dritten Welle selbst in "Emigré Experience of the West as Related to Soviet Journals" von Julian Graffy, Under Eastern Eyes, hg. McMillin, a.a.0., S. 135-140.

33 Zum phänomen an sich s. z.B. Wolfgang Kasack, "Formy inoskazanija $v$ sovremennoj russkoj literature", Odna $i l i$ dve .... hg. Nivat, a.a.O.. S. 123-135.

34 Marija Rozanova schildert in dieser Hinsicht ihre Beobachtungen in "Na raznych jazykach", Odna ili dve .... hg $_{35}$ Nivat, a.a.O., S. 202-216.

35 Natal'ja Gorbanevskaja stellt die These auf, daB dieser Faktor für einen Lyriker (wie Brodsky) weniger relevant ist, weil er seinen sprachstil eher unabhängig von der unmittelbaren umgebung entwickelt als ein Prosaiker ("Jazykovye problemy poeta $v$ izgnanii", Tret'ja volna: Almanach literatury i iskusstva (Paris $u$. New York), Bd. 15, 1983 , S. 35-38). 
kann sich positiv und negativ auf den sprachstil auswirken, und zwar umso mehr, wenn sie zur Alltagssprache wird. Manfred Durzak spricht von der Möglichkeit einer "überfremdung der Muttersprache von der Adoptiv-Sprache" im Rahmen der allmählichen kulturellen Assimilierung. ${ }^{36}$ Sie kann in letzter Konsequenz zum sprachwechsel führen, also zu einer gänzlichen Ubernahme des fremden Kodes. In der Einleitung $z u$ dem Band von John spalek und Robert Bell wird dieser Schritt als endgulltige Ablösung von der eigenen Kultur gesehen:

"[...] the writer in exile is most often regarded as the exile per se. The quality that gives him this representative status is the tool of his trade: his native language, which he cannot abandon without simultaneously surrendering his identity with the culture he represents." 37

Bei dem zitat läßt sich einwenden, daB die von der eigenen Kultur geprägten Wahrnehmungs- und Denkmuster bis zu einem gewissen Grad erhalten bleiben und die Integration in die andere kultur nie absolut sein kann. Bei einem Sprachwechsel hat der Autor das Weltbild der eigenen Kultur aber zumindest weitgehend abgelegt. In der Regel wendet er sich gleichzeitig thematisch der anderen Kultur zu und benennt die Fremdphänomene mithin direkt, statt sie in den eigenen Kode $z u$ übertragen und auf diese Weise in das eigene Koordinatensystem einzuordnen. ${ }^{38}$ Die Überwindung der sprachlichen Isolation belegt die fortgeschrittene vertrautheit mit der anderen Kultur. Das folgende zitat des tschechischen Schriftstellers Jan Novak konkretisiert diesen Sachverhalt:

"When you change languages, you change your perception of the world. My last book, which was written in English, draws on my experiences in the working world of corporate America. [...] The book could not have been written in Czech, because the czech language does not have the words that this computer world uses." 39

36 Durzak, a.a.0., s. 60 .

37 Spalek u. Beli, a.a.o., s. xii.

38 S. zu diesem Mechanismus Lotman, "K postroeniju ...". a.a.o. S. 118 .

39 Glad, Literature in Exile, a.a.0., S. 68. - Novak hat Glads biographischen Angaben zufolge seine persönlichen Arbeitserfahrungen in einer Firma für Fernmeldetechnik literarisch verwertet. 
Das überspringen der sprachbarriere bietet mithin prinzipiell die Chance, "sich eine neue Geisteswelt und neue Ausdrucksmöglichkeiten $2 u$ erobern", wie es die Schriftstellerin Hilde Spiel, die in den 30 er Jahren nach England ging, formuliert hat. ${ }^{10}$

Autoren, die im Exil die Fremdsprache auch als künstlerisches Medium wählen und sogar Teil der anderen Nationalliteratur werden, sind freilich die Ausnahme."1 Häufiger hinterläßt die Zweitsprache stilistische spuren, indem es zu syntaktischen verzerrungen kommt und Ausdrücke wörtlich übersetzt oder direkt übernommen werden, wenn die eigene Sprache - wie in Novaks Beispiel - keine Äquivalente enthält. Im Russischen erweitert die Notwendigkeit der Transkribierung die optionen zusätzlich. Die Durchdringung eines literarischen Textes von Elementen des fremden Kodes (code-switching) verursacht Interferenzen auf verschiedenen Ebenen und erschwert die Dechiffrierung. Ein solcher Text ist nicht nur mit dem eigenen, sondern bis $z u$ einem gewissen Grad auch mit dem fremden Kultursystem korreliert. Als stilintention macht das codeswitching so kulturelle Differenzen semantisch wirksam. 12

10 H. Spiel, "Das Haus der Sprache", Die zerbrochene Feder, hg. Filip u. Larsen, a.a.o., S. 14 .

11 Unter den emigrierten Russen dieses Jahrhunderts sind Vladimir Nabokov und Joseph Brodsky die herausragenden Beispiele. Elizabeth Klosty Beaujour berücksichtigt in inrer Abhandlung Alien Tongues: Bilingual Russian writers of the "First" Emigration (Ithaca u. London, 1989) noch weitere Namen. - Über das Exil hinaus gibt es natürlich viele andere situationen, in denen ein Dichter oder Schriftsteller sich veranlaßt sehen kann, in seiner zweitsprache zu schreiben. Leonard Forster untersucht in the Poet's Tongues: Multilingualism in Literature (London, 1970) bei ganz unterschiedlichen Autoren und Strömungen von der Literatur des Mittelalters bis zum Dadaismus und Surrealismus, wie der sprachwechsel jeweils motiviert und im kulturellen Kontext $z u$ verstehen ist.

${ }^{2}$ Boris A. Uspenskij erläutert den Zusammenhang mit dem Problem des standpunkts im literarischen Text, indem er die Verwendung des Französischen in Tolstojs Vojna i mir zur Redecharakteristik und Kennzeichnung kultureller Unterschiede untersucht (Poetik der Komposition: struktur des kunstlerischen Textes und Typologie der Kompositionsform, Frankfurt/M., 1975, S. 56-61). - Antonina Filonov Gove analysiert das verfahren beispielhaft in "Multilingualism and Ranges of Tone in Nabokov's 'Bend Sinister"", Slavic Review, Nr. 32, 1973, S. 79-90. 
Il'ja Levin sieht darin ebenfalls ein typisches Verfahren der Literatur von Emigranten zur Kennzeichnung des Fremden und des Fremdseins, betont aber mit dem Begriff "Kollision der Sprachen" stärker die resultierende spannung von semantischen Feldern als deren überlagerung:

"Особенности стилистики варваризмов и иноязычия в эмигрантской литературе связаны со специфическими условиями развития литературного процесса в чужеродной языковой и культурной среде, на фоне взаимостолкновения языков в эмигрантском речевом обиходе. [...] Чужое слово принадлежит чужому миру и выражает одновременно враждебность этого мира рассказчику и неприятие рассказчиком этого мира."

("Die Besonderheiten der stilistik der Barbarismen und Fremdsprachlichkeit in der Emigrantenliteratur sind verbunden mit den spezifischen Bedingungen, unter denen sich der literarische Proze $B$ in einer fremden sprachlichen und kulturellen Umgebung und aufgrund der wechselseitigen Kollisionen der Sprachen in der Sprachwelt des Emigranten entwickelt. [...] Das fremde Wort gehört zu einer fremden Welt und drückt deren Feindseligkeit gegenüber dęm Erzähler ebenso aus wie seine Ablehnung dieser Welt." 13

Im letzten Satz beschreibt Levin im Grunde nur eine bestimmte Funktion des code-switching, das umgekehrt auch die zunehmende zugehörigkeit zur anderen welt signalisieren kann. Bei einigen Autoren der Dritten Welle, die hauptsächlich der jüngeren Generation angehören, treten fremdsprachliche Einflüsse in ganz verschiedenen Varianten auf (s. II.3.5.). Zinovij Zinik gehört ebenfalls zu dieser Gruppe. Sein Verhältnis zur englischen sprache und das code-switching in seinem werk sind besondere Gesichtspunkte der späteren Analyse.

13 I. Levin in "Ob èvolucii literaturnogo jazyka v emigracii", The Third Wave, hg. Matich u. Heim, a.a.o., S. 265 u. 267. 


\subsection{Selbstbestimung in der Narration}

Die kultursemiotischen Kategorien bieten sich vor allem an, um eine bestimmte Exilliteratur im ganzen als system $z u$ erfassen. Wenn der Gegenstand der Betrachtung aber, wie in dieser Fallstudie, die literarische Verarbeitung der Grenzüberschreitung im Werk eines einzelnen Autors ist, müssen die psychologischen Aspekte des "Versetztseins" miteinbezogen werden. Mit der Trennung von Heimat und Vergangenheit, Familie und Freunden haben die früheren Identifikationsmomente keine Geltung mehr, weil sie an die gesellschaftlichen Normen und Institutionen der eigenen Kultur gebunden sind. Die Psychoanalytiker Leon und Rebeca Grinberg haben die psychische verarbeitung dieses verlustes erforscht und bewiesen, daB er das Identitätsgefühl nachhaltig erschüttert. 14

In Konfrontation mit der fremden Umgebung und Kultur ist das selbst gezwungen, sich neu $z$ u bestimmen. Exulanten aus totalitären staaten, wie im Fall der Dritten Welle, müssen dabei zunächst lernen, sich in einer pluralistischen Gesellschaft zurechtzufinden. Dieser Kulturschock kann die Identitätskrise verschärfen. ${ }^{15}$ Grundsätzlich bewegt sich die Neuorientierung zwischen drei Polen: der Identifikation mit dem status des Exilierten, der Integration in die andere Gesellschaft und der Nostalgie. Exilliteratur muB im Kontext dieser Standortsuche gesehen werden, wie unter anderen Joseph Strelka betont:

"Das Nichtgelingen totaler Assimilation oder aber Isolation und die daraus resultierende spannung zwischen Erinnerung an eine Heimat, die es in der erinnerten Form nicht mehr gibt, und das Fußfassen in einem Gastland, das

14 L. U. R. Grinberg, Psychoanalyse der Migration und des Exils, München u. Wien, 1990, S. 147-154.

45 In den Autoreninterviews, die J. Graffy untersucht hat, wird die erste zeit im westen fast ausschlieblich negativ geschildert. Dabei fallen folgende Ausdrücke: von Null anfangen, ein Niemand sein, Schockerlebnis, innere Isolation, Kampf um wirkliche Freineit, langer LernprozeB, aus der Bahn geworfen, no-future-Gefühl, innere Krise. Unterschiedlich wird hingegen von den Schriftstellern die Frage beantwortet, wie weit sie sich inzwischen assimiliert haben (Under Eastern Eyes, hq. McMillin, a.a.o., s. 118-128). 
erst innerlich erarbeitet werden muB, ist eines der wenigen wesenheitsbestimmenden Merkmale der Exilsituation, wie sie auch ihren Niederschlag in der Exildichtung findet. "16

Der Mangel einer festen Position im sozialen Gefüge, der in diesem zitat formuliert wird, wirft das Individuum auf sich selbst zurück. Strelkas These ist auf die deutsche Exilliteratur ausgerichtet. $\mathrm{zu}$ einer ähnlichen Aussage gelangt aber auch Robert Edwards, der von der Literatur der Antike und des Mittelalters ausgeht. ${ }^{17} \mathrm{Nach}$ dem damaligen Verständnis des Verhältnisses von Individuum und Gesellschaft habe der Bruch mit kulturellen und sozialen Traditionen zur Selbstentfremdung, unter Umständen aber auch zur selbstfindung geführt, erklärt Edwards. Darauf bezogen abstrahiert er das Exilerlebnis - ähnlich der kultursemiotischen Differenzierung von Kultur versus NichtKultur - als Schwellenerfahrung zwischen ordnung und Einöde ("threshold between organized space and the wasteland outside") ${ }^{48}$ mit der Möglichkeit, einen eigenen weg $z u$ finden und eine neue persönlichkeit zu bilden.

Emigrantenliteratur steht im Zeichen des Übergangs vom alten zum neuen Ich, von der vergangenheit zur Gegenwart sowie vom Eigenen zum Fremden. Sie trägt diese Gegensätze in sich und macht sie fruchtbar. Nach den Worten von Elisabeth Bronfen ist die Exilsituation "nicht nur der Inhalt" des literarischen Exiltextes, "sondern auch sein konstitutiver Moment". 19 wie Edwards stellt Bronfen ebenfalls das selbst in den Mittelpunkt ihres Modelis, wählt aber einen psychoanalytischen Ansatz. Sie kommt zu dem Ergebnis, das die Narration des Exils durch die Gestaltung der dargestellten Bewußtseinslage eine identitäts- und sinnstiftende Funktion erhält:

"Für die aus der Erfahrung des Exils entstehende Literatur ergibt sich demnach folgendes Muster: Aus der Realität des Verlustes soll eine neue Identität gewonnen werden, und zwar mit Hilfe eines narrativen Selbstentwurfes." 50

16 strelka, a.a.0., s. 22 .

17 Edwards, a.a.0., s. 15-31.

48 Edwards, a.a.0., s. 21.

19 Bronfen, a.a.o., s. 168.

50 Bronfen, a.a.o., s. 172 . 
Während Edwards auf die Dichotomie von ordnung und Chaos zurückgreift, überträgt Bronfen das Freudsche Konzept des "Unheimlichen", um den "Zwischenraum", in dem sich Exilliteratur entfaltet, begrifflich zu machen. Demnach handelt es sich um einen psychischen zustand zwischen dem "verlorenen Heimlichen und einer kulturellen wiederverortung". Literarisch äuBere sich die Schizophrenie in der Produktion "textueller Doppelgänger" sowie einer Verdoppelung der zeit und des ortes. Allgemein läBt sich der Faktor Exil und Emigration laut Bronfen biographisch-referentiell, thematisch-inhaltlich und auch textasthetischstrukturell nachweisen.51 Edward J. Brown wertet hier die Verfremdung als natürliches Verfahren des Exilautors, in dessen BewuBtsein Bilder der Erinnerung und der aktuellen Realität sich überlagerten. Die Doppelperspektive ermögliche die Wahrnehmung sowohl der zurückgelassenen vertrauten als auch der gegenwärtigen neuen welt aus der Distanz eines Fremden und gebe auf diese Weise kreative Impulse.52 In der Verfremdung werden demnach zugleich Fremderfahrung und selbstentfremdung ausgedrückt und überwunden.

Insqesamt sieht Bronfen (in Anknüpfung an Freuds Erkenntnisse über die Beziehung des Traums zum Trieb) im literarischen Text eine "Repräsentanz" der Exilerfahrung, das heiBt, deren Fixierung als Realität durch die Artikulation über eine Vermittlungsinstanz mit der Konsequenz:

51 Bronfen, a.a.0., S. 171. - Edwards findet in der Literatur der Antike und des Mittelalters über die thematische Ebene hinaus "modes of literary transformation", die sich durch das Exil erklären und in musterhaften Gestaltungen fiktiver welten äuBern $(\mathrm{a} . \mathrm{a} .0 . \mathrm{S} .23 \mathrm{ff.})$. Strelka erkennt in der deutschen Exilliteratur typische Ausdrucksformen für das Grunderlebnis der "gesteigerten Unsicherheit" im Exil, etwa die Bevorzugung traditioneller, geschlossener Formen (a.a.0.. S. 67-86). Allgemein kritisiert er, daB die germanistische Exilforschung "über einzelne Ansätze zur Bewältigung dieses Grundproblems nicht hinausgelangt ist" (S. 68).

52 E. J. Brown, "The Exile Experience", The Third Wave, hg. Matich u. Heim, a.a.0., S. 53-61. 
"Die Repräsentanz steht ein für den Exilierten, vertritt inn explizit als einen, der durch den verlust von Heimat verdrängt wird aus dem gesellschaftlichen system." 5$\}^{\prime}$

Ein anschauliches Beispiel für diese Stellvertreterfunktion ist das werk des römischen Dichters ovid, dessen Bücher nach seiner Verbannung ans Schwarze Meer in Rom weiter verbreitet werden durften, so dab sie inn dort quasi verkörperten. 54 Bezüglich der Dritten Welle läBt sich sagen, daB die Publikationsmöglichkeiten im Ausland aus dem inneren Exil in der Sowjetunion heraus eine "Emigration von Texten" auslösten, die in gewissem MaB der tatsächlichen Emigration vorausging. 55

Das literarische Werk des Exils und der Emigration fült mithin eine Leerstelle, ein Vakuum. Das Verlorene oder der Mangel werden durch dessen Ausdruck ersetzt, oder anders formuliert: Die situation bringt unmittelbar den Text hervor. ${ }^{56}$ Michael seidel versteht sie sogar metaphorisch als Grundbedingung für die Genese von Narration überhaupt, weil sie die schöpferische Phantasie veranlaBt, fremde welten in der Fiktion $2 u$ schaffen. ${ }^{57}$ seidels Ansatz zeigt, wie stark der Begriff "Exil" ausgeweitet werden kann. Bronfen erläutert hierzu, daB die literarische $\mathrm{Ka}-$ tegorie "Exil" in kritischen Diskursen und literarischen Texten nicht nur auf die reale Exilerfahrung bezogen, sondern gleichzeitig auch als Metapher universell und ab-

53 Bronfen, a.a.o., S. 169.

54 S. Edwards, a.a.o., S. 21-22; Seidel, a.a.0., s. 9-10.

55 Bol'dt, Ségal und Fiejšman beobachten eine ähnliche Verselbständigung und Verdinglichung von Texten der russischen Literatur in den 20 er und 30 er Jahren und verwenden in diesem zusammenhang ausdrücklich die Bezeichnung teksty-emigranty ("Problemy izucenija...", a.a.0., s. 86 $\left.\mathrm{ff}_{(56}\right)$.

$56 \mathrm{Vgl}$. David M. Bethea, "Emigration and Heritage", Sla$v i c$ and East European Journal, Nr. 31, 1987, S. 156-157: "To cite the example of Nabokov, the émigré who at some point ceases to be a displaced person and becomes a genuine artist in exile is the one whose rodina is metaphysical (Ultima Thule) and temporal (childhood) rather than physical and actual [...] This rodina is the absence that all men feel, but the exiled artist fills with the presence of words." Zuvor spricht Bethea in diesem sinn von "self-definition through language". $1-16$. 
strahierend gebraucht werde, also als sinnbild für zeitlose existentielle Erfahrungen, insbesondere für das Dichter- und Künstlertum. 58

In seinem Essay "Emigracija kak literaturnyj priëm" ("Emigration als literarisches Verfahren") gebraucht Zinovij zinik den Begriff des Emigranten einleitend ebenfalls metaphorisch, indem er diesen zum "Helden unserer Zeit" erklärt. ${ }^{59}$ Sein Dasein sei gekennzeichnet durch einen fortwährenden spannungszustand, "a constant urge to become part of something, belong to something, and at the same time the inner knowledge of your own uniqueness and separateness" - so ein zitat aus dem im Anhang dokumentierten Gespräch mit dem Autor.60 Insbesondere der freiwillige Exulant ist ein Einzelgänger, da er alle Bindungen aufgegeben hat, aber von seiner kulturellen prägung daran gehindert wird, eine neue Identität anzunehmen. Er bleibt am Rand des anderen Kulturraumes, ein Fremder, nachdem er sich aus dem eigenen für immer "ausgesperrt" hat, um eine Metapher von zinik aufzugreifen. Er erklärt nämlich mit ihrer Hilfe, daB jede Abbildung aus dieser Perspektive des AuBenseiters letztlich in eine selbstkarikatur umschlägt:

"When you look from the outside into a house, you have to press your face against the window, so your face becomes distorted. So as a result you always get a caricature." - "But of yourself?" - "Of course of myself. The moment I start writing, it is already a part of me, but a
caricatured part of me." $6 !$

Ziniks Prosa zeugt von dem fortlaufenden versuch einer selbstbestimmung im kulturellen und psychischen $\mathrm{zwi-}$ schenraum des freiwilligen Exils. Sie ist zugleich dessen Produkt, zumal der Autor erst nach der Auswanderung Schriftsteller geworden ist, so daß sie die Textgenese im

58 Bronfen, a.a.o., s. 172 ff. - Der Aufsatz bringt Beispiele für die "Vérschränkung dieser beiden diskursiven Umgangsweisen mit dem Exil" (S. 173) und für die Verwendung des Exils als Metapher in der Mythopoetik (S. 174 $\left.\mathrm{ff}_{59}\right)$ "Émigracija kak literaturnyj priëm", sintaksis, Nr. 1160 1983. S. 168 .

in London: s. Anhang, S. 181 .

61 Persönliches Gespräch mit Zinik, Anhang, s. 179-180. 
wörtlichen sinn bedingt hat. Sein werk soll hier weitgehend vor dem Hintergrund von ziniks realen Erfahrungen gelesen werden, die darin eingegangen sind und thematisiert werden. 
$\Rightarrow \mathrm{s}$,

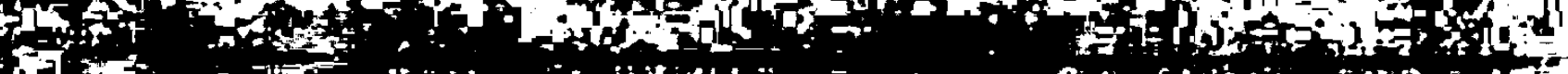

19.20

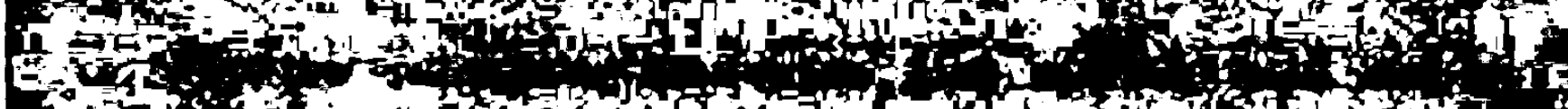

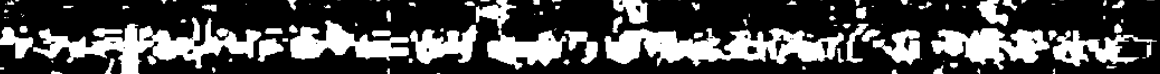
$1 \mathrm{se}$

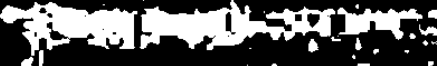

fint 31 to of

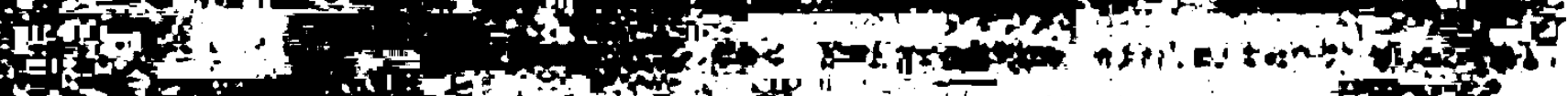

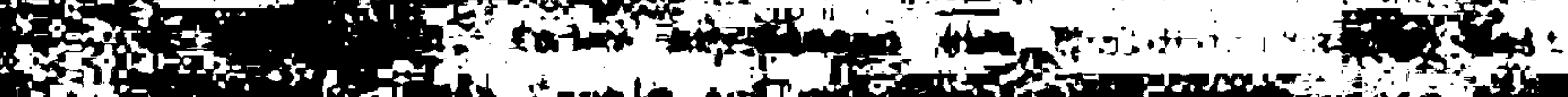

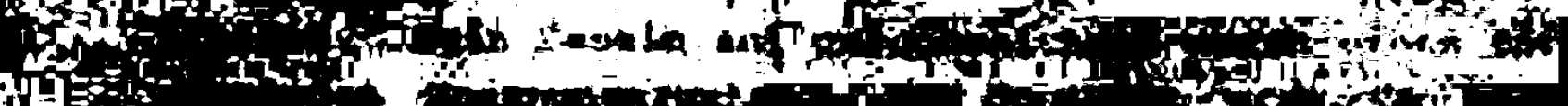
Af

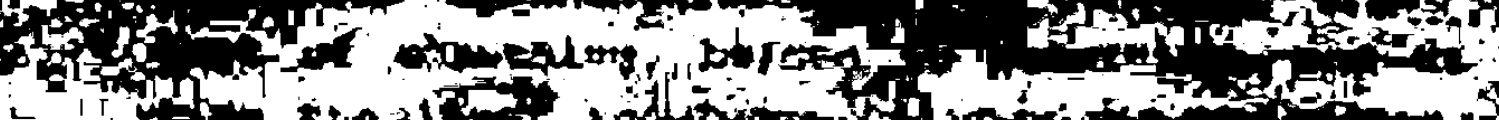
1

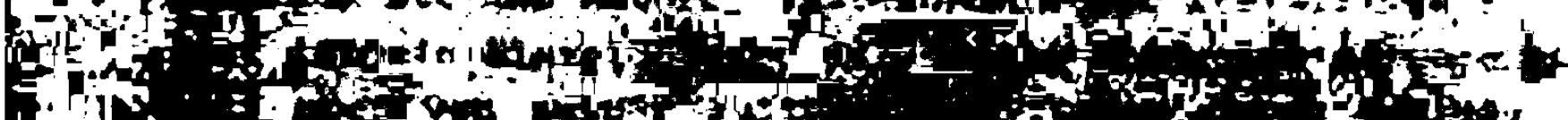
3.

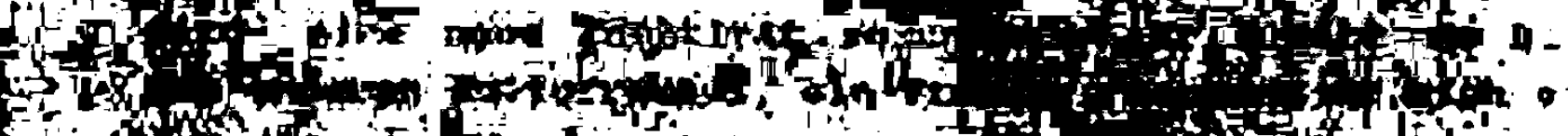
1. for 10 in

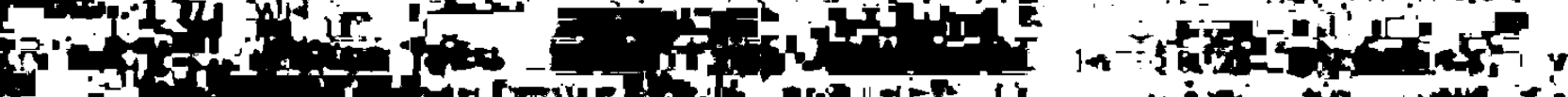

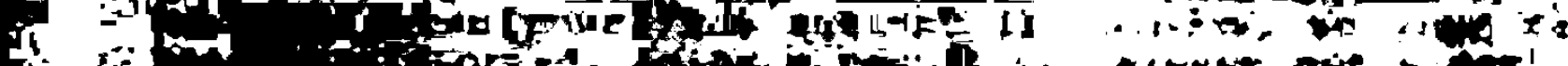
Lit a T.

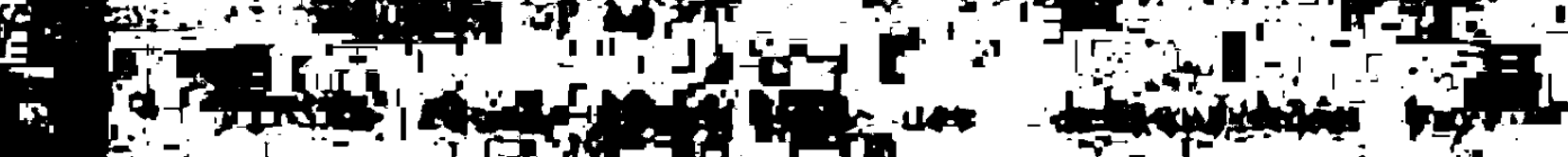

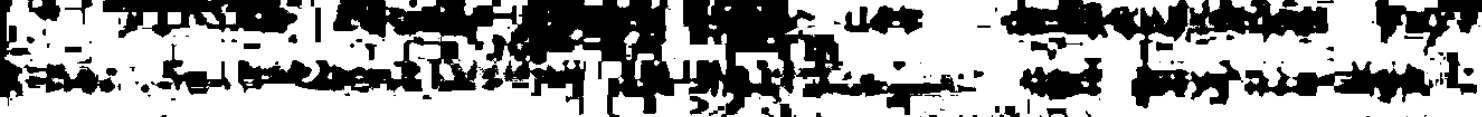

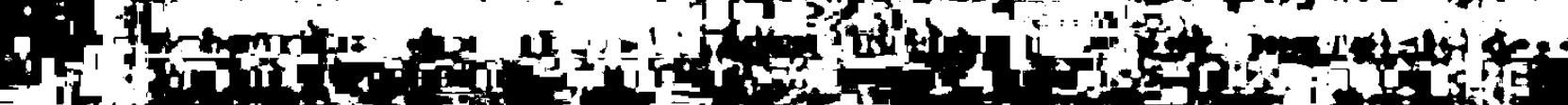

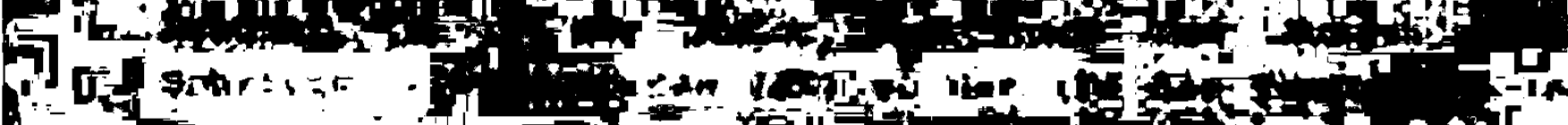

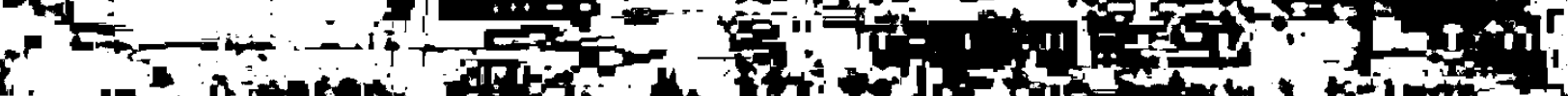

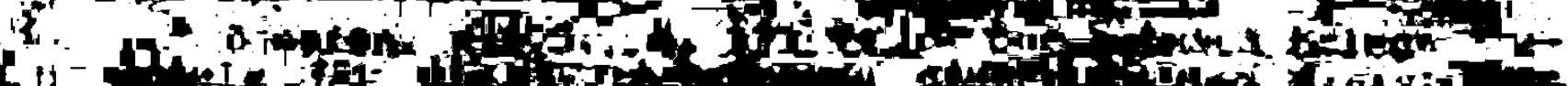

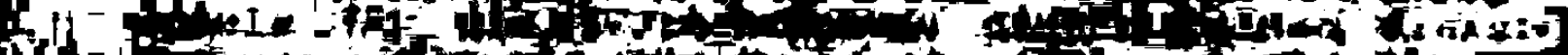

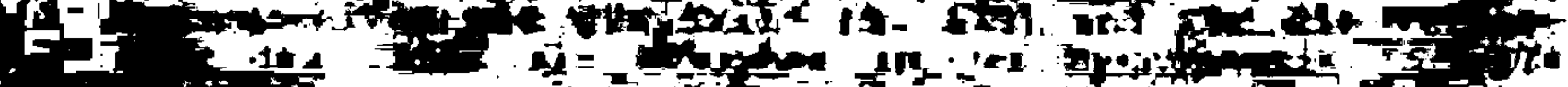

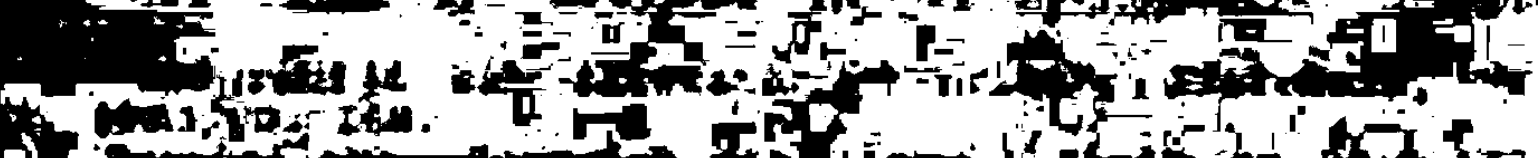
3: d.

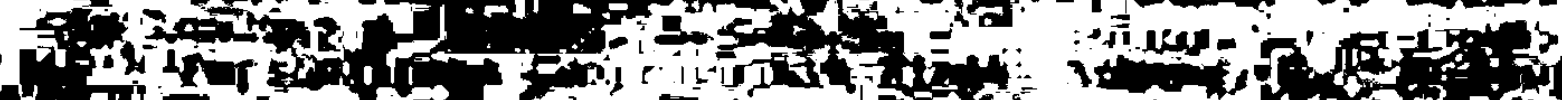
AFiv be :

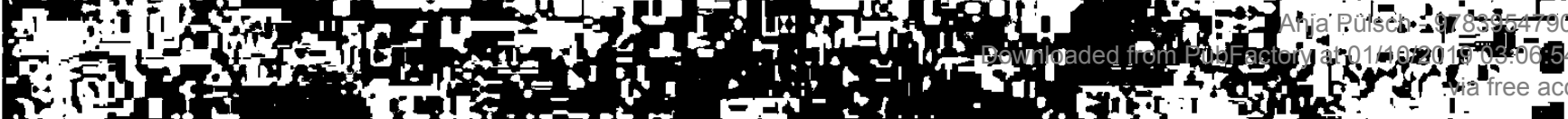


II. Tei $\mathbf{I}=$

Die russische literatur in

aer Emigration

1. GRUNDZŨGE DER RUSSISCHEN EMIGRATION SEIT 1917

\subsection{Historischer AbriB}

Die Literatur der russischen Emigration ist in ihrer Bedeutung quantitativ wie qualitativ begründet. Unter den Millionen, die das kommunistische RuBland im Lauf seiner Geschichte verlieBen, 1 war nämlich ein beträchtlicher Anteil der kulturellen, geistigen und somit auch literarischen Elite des Landes vertreten. Diese Schriftsteller setzten inr Schaffen im Ausland fort, jüngere Generationen entfalteten sich dort zum Teil erst richtig. Durch die politischen Verhältnisse war die Literatur der Exulanten jahrzehntelang von der sowjetischen Kultur abgeschnitten. Angesichts dieser Langfristigkeit ist es angebracht, nach Konstanten $z u$ fragen. Ein kurzer Rückblick soll zeigen, welche Grundzüge die Dritte Emigration mit den früheren gemein hat, auch wenn - wie ebenfalls deutlich wird - der demographische, soziale und kulturelle Hintergrund jeweils unterschiedlich ist. ${ }^{2}$

Die $E$ r $t$ e we 1 l e wird von 1919 bis 1939 angesetzt. Die Revolution und der anschlieBende Bürgerkrieg lösten eine Massenflucht aus, die mit der sozialen und geistigen oberschicht auch viele bedeutende künstlerische Persönlichkeiten der vorrevolutionären zeit nach west-

1 Der Gesamtumfang der Emigration seit 1917 läBt sich nur schätzen. In The other Russia: The Experience of Exile (hg. Glenny u. Stone, London u. Boston, 1990) ist z.B. von mindestens drei Millionen Menschen die Rede (S. XV).

2 Die Verbannung und Auswanderung aus RuBland seit dem 16. Jahrhundert bis 1991 dokumentiert John Glad in einer detaillierten Chronologie in Conversations in Exile: Russian Writers Abroad, Durham u.a., 1993, S. 271-294; in seiner Einleitung faBt er die wichtigsten Daten zur Entwicklung der Literatur im Ausland ab 1917 zusammen (S. 128). 
europa verschlug. Berlin, Paris und Prag fungierten als Zentren der Diaspora, die sich uber die ganze welt verteilte. 3 Unter den Autoren wird zwischen der "älteren" und der "jüngeren" Generation getrennt, und zwar nicht nach dem Altersunterschied. Zur ersteren zählen vielmehr diejenigen, die bereits vor der Auswanderung etabliert waren.' Zugleich kamen in der Emigration junge Talente zum Durchbruch oder zur Reife.5 Insgesamt gelten die 30er Jahre vor allem im Bereich der Lyrik als Blütezeit der russischen Emigrantenliteratur.

Während des Zweiten Weltkriegs nahmen viele Russen die Chance wahr, unter dem Schutz der deutschen Truppen der stalin-Diktatur $z u$ entkommen oder aus Deutschland nicht in die Heimat zurückzukehren. Sie bildeten zusammen die $Z$ w $i$ e $w$ e $l 1$ e von 1939 bis 1945, die deutlich schwächer ausfiel als die vorhergehende und sowohl von der Zahl als auch vom Rang her wesentlich weniger künstlerisches Potential mit sich brachte. Sie sicherte die Fort-

3 Die Auswanderer fanden auBerdem im Baltikum, auf dem Balkan, in China, Australien, Südamerika und den USA Zuflucht. Die Emigration wird insgesamt mit ein bis zwei Millionen veranschlagt (z.B. laut Wolfgang Kasack, Lexikon der russischen Literatur des 20. Jahrhunderts, München, 1992, S. 296). Zur Aufschlüsselung nach Aufnahmeländern $\mathbf{s}$. Glenny u. Stone, a.a.O., S. xvi-xvii; außerdem Marc Raeff, "La culture russe et l'émigration", Histoire de la littérature russe (Le XXe siecle), hg. Efim Etkind u.a., Bd. 2: La Revolution et les annees vingt, Paris, 1988, S. 859860. Der folgende Rückblick stützt sich im wesentlichen auf diese zusammenfassende Darstellung von Raeff (S. 6196) und den entsprechenden Aufsatz von René Guerra, "L'émigration russe des années trente aux annés soixante", Histoire de la litterature russe (Le XXe siecle), hg. Efim Etkind u.a., Bd. 3: Gels et Dégels, Paris, 1990, S. 116-139; darüber hinaus auch auf Nikolaj Andreev," "O nekotorych faktorach razvitija zarubeźnoj vetvi russkoj literatury s 20-go po 40-j god", Odna ili dve russkich literatury?, hg. Georges Nivat, Lausanne, 1981, S. 91-102; Glad, Conversations .... a.a.0., S. 2-11. ( $\mathrm{zu}$ weiteren Literaturangaben s. 1.2. des I. Teils.)

Z.B. Ivan Bunin, Dmitrij Merežkovskij, Aleksej Remizov, vladislav Chodasevic, Konstantin Bal'mont u.v.a.

5 Am berühmtesten von innen wurde vladimir Nabokov (alias Sirin), und der Ruf der Dichterin Marina Cvetaeva gründet besonders auf dem in der Emigration entstandenen Werk. AuBerdem könnnen hier weniger bekannte Namen wie Georgij Ivanov, Nina Berberova und Boris Poplavskij genannt werden. 
dauer des Kulturlebens und der literarischen Produktion im Exil, wobei die Vertreter der Ersten welle weiter dominierten. 6 Neben der Entstehung neuer Nebenzentren in München und Frankfurt kam es $z u$ einer Verschiebung des kulturellen Mittelpunkts von Paris nach New York bzw. in die Vereinigten staaten, wo beide Emigrationswellen zusammenflossen, was sich unter anderem in gemeinsamen Publikationen niedergeschlagen hat.

Entsprechend wurden die USA, insbesondere New York und auch Los Angeles für die Emigranten, die von Anfang der 70er bis Mitte der 80er Jahre aus der Sowjetunion strömten, 7 zum wichtigsten Anlaufpunkt. Hauptsächlich überwanden Juden mit dieser $D r i t$ e $n \quad w l l e$ den Eisernen Vorhang, so daB Israel ebenfalls einen groben Teil aufnahm. AuBerdem kamen zahlreiche Dissidenten infolge von Ausweisung oder freiwilliger Ausreise in den Westen. Wie bei der Ersten Emigration hatten sich etliche der betroffenen schriftsteller bereits vor verlassen des Landes einen Namen gemacht, während andere (so Zinovij zinik) ihre Karriere erst im Ausland begonnen haben. Diesmal waren die Lyriker in der Minderheit.

\subsection{Politisierung}

Die Emigration aus RuBland war bis zur jüngsten "vierten Welle" der Wirtschaftsflüchtlinge, die durch den Zerfall des Ostblocks ausgelöst wurde, stets in erster Linie politisch motiviert. Schon im Zarenreich konnte nonkonformistisches Verhalten ins innere oder Auslandsexil führen. Im 19. Jahrhundert waren viele bekannte Intellektuelle und Revolutionäre davon betroffen, allerdings nur

6 Zur Zweiten Welle s. u.a. Glad, Conversations .... a.a.0., S. 11-21. Ansonsten wird sie in der angegebenen Literatur zur Ersten jeweils mitbehandelt. Aufgrund inrer geringen Bedeutung soll sie auch hier nur am Rand erwähnt weffden.

Für die Dritte Welle gibt $J$. Glad folgende Zahlen an: 15000 in 1971,35000 in 1972,67000 in 1979,22000 in 1981 , unter 8000 in 1982 (Conversations ..., a.a.0., s. 290-292). 
wenige Schriftsteller. ${ }^{8}$ Erst im 20 . Jahrhundert trieben die politischen Ereignisse und das sowjetische Regime auch einen Teil der russischen Literatur auf Dauer außer Landes. Die meisten dieser Schriftsteller verstanden sich als geistige Opposition im Ausland. Aus dieser Rolle erklärt sich, daß sie sich politisch sehr engagierten und $z u$ wortführern der russischen Emigranten machten.

Ihr wichtigstes Medium dafür waren zahlreiche russischsprachige zeitungen und zeitschriften unterschiedlicher Couleur, die dazu dienten, Ansichten auszutauschen, meinungsbildend $z u$ wirken und die geistige Verbindung untereinander sowie mit dem Heimatland $2 u$ erhalten. Besonders die Erste Welle war von einer Blüte der Publizistik in den 20er Jahren gekennzeichnet, wobei sich die Presse und das verlagswesen bis 1924 in Berlin konzentrierten; anschließend avancierte Paris zum kulturellen Zentrum.9 während der Dritten welle kam es abermals zu etlichen Neugründungen von zeitungen und Zeitschriften, die sich $z u$ den etablierten Blättern reinten und im einzelnen später noch vorgestellt werden.

Die organe der russischen Auswanderer spiegeln durchgehend ein breites spektrum an weltanschauungen und Einstellungen wider. Auch wenn die Kontroversen im einzelnen jeweils im historischen Kontext gesehen werden müssen, läBt sich allgemein thematisch und inhaltlich eine gewisse Kontinuität von einer Emigrationswelle zur anderen beobachten. Zur Debatte standen im wesentlichen immer wieder die Vergangenheit, Gegenwart und zukunft Rußlands, insbe-

$8 \mathrm{Zu}$ den russischen Exulanten des 19. Jahrhunderts $\mathbf{s}$. u.a. Paul Tabori, The Anatomy of Exile: A Semantic and Historical Study, London, 1972, S. 123-128. - Der bekannteste und bedeutendste unter innen war der Schriftsteller und Revolutionär Aleksandr Gercen (Herzen), der in der Schweiz, London, Genf und Brüssel lebte. Manche Schriftsteller verbrachten aufgrund inrer an westeuropa orientierten Gesinnung eine zeit inres Lebens auBerhalb RuBlands, 2.B. Nikolaj Gogol' in Rom und Ivan Turgenev in Deutschland und Frankreich, kehrten dann aber wieder in die Heimat zurück.

S. u.a. Raeff, a.a.0., s. 71-74; Guerra, a.a.0., s. 116-125; Gleb Struve, Russkaja literatura v izgnanii', 2 . Aufl., Paris, 1984, S. 49-79. 
sondere die ideale Gesellschaftsform für das russische Volk, wobei der Westen in die kritische Analyse einbezogen wurde. Die Auseinandersetzung war mitunter sehr polemisch und führte wiederholt zur zersplitterung, was mit der ideologischen Motivation der Auswanderung zusammenhängt. Schon unter einzelnen Gruppen der Ersten Welle traten heftige streitereien auf. ${ }^{10}$ Nach dem Zweiten Weltkrieg spaltete die Frage nach der richtigen Haltung gegenüber der Sowjetunion die russischen Emigranten endgültig in verfeindete Fraktionen, wobei die Vertreter der zweiten welle eine radikal antisowjetische position einnahmen.11 In den 70er Jahren formierten sich wiederum zwei politische Lager, worauf das Kapitel zur Dritten welle auch näher eingent.

Die russische Emigration war mithin stets von einer Dominanz der politischen Agitation geprägt, die zum Teil mit einer Politisierung der Literatur einherging. viele sahen in der Literatur vorrangig eine gesellschaftspolitische Funktion, indem sie Werte und Wahrheiten vermittelte, solange in der Sowjetunion keine Meinungsfreiheit herrschte. 12 Die enge Verflechtung von Politik und Literatur manifestierte sich auch darin, daß die zeitschriften, in denen die diversen Gesinnungen propagiert wurden, in der Tradition der tolstye zurnaly zugleich die literarischen Texte der emigrierten Schriftsteller veröffentlichten. Sie spielten damit eine Schlüsselrolle für die Entwicklung der Literatur auBerhalb RuBlands.

In der vorliegenden Arbeit wird deutlich, daß sich zinovij zinik, zusammen mit einigen, vornehmlich jüngeren

10 S. Raeff, a.a.0., S. 84 .

11 Dies bemerkt z.B. Gleb struve in "Russian Writers in Exile: Problems of an Emigré Literature", Comparative Literature, Bd. 2 (Proceedings of the 2 . Congress of the Int. Comparative Literature Ass. at the Univ. of North Carolina), Chapel Hill, 1959, (UNC Studies in Comparative Literature, 24), S. 605. S. auch Guerra, a.a.0., S. 135136.

12 Ähnlich stand auch die deutsche Exilliteratur im Zeichen des Kampfes gegen ein totalitäres Regime. S. 2.B. John M. Spalek u. Robert F. Bell (Hg.), Exile: The Writer's Experience, Chapel Hill, 1982, S. xiii. 
Autoren der Dritten Welle, von der typischen Tendenz zur Propaganda in der russischen Emigration absetzt. Sein Werk repräsentiert eine Emigrantenliteratur, die sich nicht aus einer politischen oppositionshaltung heraus definiert, sondern den Auswanderer als Individuum in den Mittelpunkt stellt.

\subsection{Konservative und retrospektive Tendenzen}

Die Flüchtlinge der 20er Jahre errichteten in den Aufnahmeländern einen russischen Mikrokosmos, ein "MiniRuBland", in dem sich ein reges Kulturleben entfaltete. Im zuge der totalen äußeren Abnabelung von der Heimat durch die politische Entwicklung fühlten sich die Exulanten umso stärker innerlich den für sie wahren nationalen Werten verbunden. Das Bewahren des präsowjetischen kulturellen Erbes wurde zur Mission und zur Quelle für Schaffenskraft und Kreativität. ${ }^{13}$ Im Rahmen der Dritten Welle, die hauptsächlich in den USA die kulturellen Institutionen der früheren Emigranten weiterführten, vertraten Aleksandr Solženicyn und seine Anhänger erneut dieses Selbstverständnis. Insgesamt prägt es die Literatur der russischen Emigration ebenso wie die Neigung der emigrierten schriftsteller, die eigene Rolle und Funktion im Hinblick auf die Sowjetunion und die russischen Traditionen $z u$ thematisieren und $z u$ diskutieren. 14

13 Michael Seidel erkennt darin ein spezifisches Merkmal des politischen Exils: "Especially if exile is the result of contingent political circumstances or self-imposed ideological ones, its victim claims to possess the values of his native place, as it were, in proxy - he is the truer version of the place from which he is barred." (Exile and the Narrative Imagination, New Haven u.a., 1986, S. 9). - Ein weiteres Beispiel für diese Haltung ist die polnische Exulantengemeinschaft in London nach dem zweiten Weltkrieg; $s$. dazu zbigniew $R$. Wilkiewicz, Polnische Exilliteratur 1945-1980: Eine Bestandsaufnahme, Köln, 1991 .

If Bzgl. der Ersten Welle s. Raeff, a.a.O., S. 91-93; Guerra, a.a.0., S. 125-127; N. Andreev, a.a.0., S. 95. Zur Dritten Welle s.u. 
Die Besinnung der Ersten Welle auf das "Silberne Zeitalter" äuBerte sich literarisch vielfach in einer nostalgischen Beschwörung des verlorenen Vaterlandes. 15 AuBerdem war die Revolution ein wichtiges Thema.16 Die Schriftsteller, die durch den Zweiten Weltkrieg in den Westen gekommen waren, verarbeiteten fast ausnahmslos das Trauma des stalinismus in Prosawerken mit autobiographischem und dokumentarischem Charakter.17 Von den Exulanten aus der Brezinev-zeit widmete sich eine Reihe vollkommen der Aufgabe, die jüngste Geschichte inres Landes und die Realität im Sowjetstaat wahrheitsgetreu aufzuzeichnen und kritisch $2 u$ analysieren; dieser Impuls herrscht bei vielen bis heute vor. Eine Sonderstellung nimmt solienicyn ein, der in den USA seinen Romanzyklus Krasnoe koleso fortsetzte, in dem er den Weg RuBlands vom Zarenreich zum Bolschewismus gestaltet. Die Literatur der russischen Emigration im 20. Jahrhundert ist also seit jeher $2 u$ einem großen Teil retrospektiv und artikuliert historische Tatsachen und werthaltungen, die in der Sowjetunion nicht ausgesprochen werden durften. Entsprechend typisch sind Gattungen wie Memoiren, Zeitzeugenberichte und Erinnerungen. 18

Der fixierte Rückblick auf die Heimat resultiert freilich auch aus einer gleichgültigen oder negativen Einstellung gegenüber Kultur und Gesellschaft des Aufnahme-

15 S. Guerra, a.a.0., S. $130 ;$ N. Andreev, a.a.0., S. 98.

16 S. Raeff, a.a.0., S. 90-91.

17 S. u.a. Glad, Conversations.... a.a.o., S. 16-17.

18 Guerra hat eine lange Liste von Titeln aus der ersten Hälfte des Jahrhunderts zusammengestellt (a.a.0., S. 954955). S. dazu u.a. auch die Analyse von V. Piskunov, "Cisty ritm Mnemoziny: o memuarach i memuaristach russkogo zarubez'ja", Literaturnoe obozrenie, H. 10, 1990, S. 2131. - Die Erinnerung spielt für Exilliteratur allgemein eine zentrale Rolle. Die deutsche Emigrantenliteratur wird z.B. von Werner Vordtriede in seinem Aufsatz "Vorläufige Gedanken $2 u$ einer Typologie der Exilliteratur" prinzipiell als "Heimwehdichtung" gesehen (Akzente, Bd. 15, H. 6, 1968, S. $562 \mathrm{ff.)}$. Robert Edwards findet in der mittelalterlichen Literatur Beispiele für den Blick vom AuBenstandpunkt des Exulanten in die Vergangenheit sowie auf die eigene Kultur und Gesellschaft ("Exile, Self, and Society", Exile in Literature, hg. Maria-Inés Lagos-Pope, Lewisburg, London u. Toronto, 1988, S. 24-25). 
landes. In der Literatur der Ersten Welle wird das Exildasein in der Regel als Leiden in der Fremde geschildert. 19 Die meisten Emigranten der 70er und 80er Jahre wiederum waren überwältigt oder enttäuscht von der westlichen Welt, was zusätzlich dazu beitrug, daB sie innerlich in der eigenen blieben und sich thematisch ausschlieblich der Sowjetunion zuwandten. ${ }^{20}$ Diese Haltung ist nicht nur politisch, sondern auch psychologisch als Festhalten am Eigenen und Vertrauten erklärbar. Georges Nivat beispielsweise begründet seine Feststellung, daB die Dritte welle in der Nostalgie verharre, mit orientierungsproblemen und der Angst vor einem Identitäts- und Funktionsverlust.2l Für Joseph Brodsky gibt sich der typische Exilautor der Retrospektive hin, weil er die konfrontation mit der gegenwärtigen Realität scheue und mit seiner freiheit nicht zurechtkomme. 22

Die erläuterten konservativen und retrospektiven Tendenzen bedingen bis $z u$ einem gewissen Grad die Fortsetzung literarischer Traditionen, insbesondere die orientierung am präsowjetischen Realismus, an den die bekanntesten Repräsentanten der Dritten Welle mehrheitlich anknüpfen (s. II.3.). Die Werke der zweiten welle stimmen stilistisch mit dem Sozialistischen Realismus überein, obgleich sie inhaltlich genau die entgegengesetzte Ideologie ausdrücken. 23

19 S. 2.B. Gedichte und prosa aus den frühen 20er Jahren über das Leben in der stadt Berlin, etwa von vladislav Chodasevic, Marina Cvetaeva, Andrej Belyj und Vladimir Nabokov. Zu Paris gibt es u.a. bei Nina Berberova und Aleksej Remizov Werkbeispiele. - Das Leiden war freilich über die seelische Not hinaus auch durch materielle und soziale Schwierigkeiten bedingt.

20 Die Desillusionierung der Emigranten in den USA beschreiben Petr Vajl' und Aleksandr Genis in "Poterjannyj raj. Emigracija: popytka avtoportreta. Fragmenty knigi", Novyj mir, Bd. 68, H. 9, Sept. 1992, S. 135-165.

21 G. Nivat, "Nostalgies russes", Le Magazine litteraire, $\mathrm{Nr}, 221$, Juli-August $1985, \mathrm{~S} .54 \mathrm{ff}$.

22 Brodsky, "The Condition We Call Exile", Renaissance and Modern Studies, Bd. 34, 1991, S. 4 ff. - Die Beobachtung geht of fenbar von den russischen Emigranten aus und kann meiner Ansicht nach nicht unbedingt verallgemeinert werkden.

23 S. u.a. Struve, "Russian writers ...", a.a.0., S. 605. 
Insgesamt ist die russische Emigration im 20. Jahrhundert aber nicht nur ein Hort für Traditionen, sondern auch der Boden für literarische Innovation. In den 30er Jahren war das stilistische spektrum besonders breit gefächert: Auf der einen seite wurden die vorrevolutionären Stilrichtungen wie Realismus, Symbolismus und Akmeismus fortgeführt und weiterentwickelt; auf der anderen seite stehen formelle Experimente und neue Verfahren infolge westeuropäischer Einflüsse, die sich ausgesprochen fruchtbar gerade bei jüngeren Autoren auswirkten. 24 Aber auch innerhalb der Dritten welle gibt es - ebenfalls vorwiegend im Werk der jüngeren Generation - Beispiele für diverse sprach- und stilexperimente.

Zinovij zinik gehört zur jüngeren Generation der Dritten Welle. Er befaßt sich zwar aufgrund seiner Erfahrungen und Erinnerungen ausgiebig mit der sowjetischen Realität und Mentalität. Insofern läBt er sich ohne weiteres innerhalb der Dritten welle einordnen, aber nicht in das Lager der Realisten. Fern von deren Anspruch der Wahrheitsverkündung und Wertevermittlung ist seine prosa ein Versuch, die eigene Vergangenheit und Gegenwart anstelle der kollektiven Vergangenheit des ganzen Volkes zu bewältigen. Außerdem beschränkt sich zinik inhaltlich nicht auf die Heimat, sondern setzt sich ebenso mit der anderen Kultur auseinander, was nur bei wenigen russischen Exilautoren der Fall ist.

$24 \mathrm{Vgl}$. Lazar Flejšman in "Neskol'ko zamečanij...", Odna ili dve .... hg. Nivat, a.a.0., S. 66 (bezüglich der Ersten Welle): "Novoe opisanie émigrantskoj podsistemy, bazirujuśceesja na vyjavlenii specifiðeskich formal'nych charakteristik poètičeskich proizvedenij, vskroet mechaniszm prelomlenija v nej 'tradicij' $i$ 'antitradicij'." ("Eine neuartige [nicht nur an thematische und inhaltliche Kriterien gebundene] Beschreibung des Subsystems der Emigrantenliteratur durch das Herausstellen spezifischer formeller Merkmale der literarischen Werke wird den Mechanismus der immanenten Brechung von 'Traditionen' und 'Antitraditionen' offenbaren.") - $\mathrm{Zu}$ den westeuropäischen Einflüssen s. 2.B. auch Victor Terras, Handbook of Russian Literature, New Haven u. London, 1985, S. 122; zur Bereicherung durch die französische Literatur auch Guerra, a.a.O., s. 128-129. 


\section{DIE FRAGE DER SPALTUNG DER RUSSISCHEN LITERATUR}

Die ideologische Lockerung der Politik unter Lenin von 1921 bis 1926 erlaubte noch Verbindungen der Diaspora zur Heimat auf verschiedenen Ebenen, etwa durch den Import von Büchern und Zeitschriften der Emigranten. Erst nach Stalins Machtantritt wurde die Sowjetunion bis 1931 vollkommen abgeriegelt. ${ }^{25}$ Bol'dt, segal und Flejsman versuchen in ihrem Aufsatz über die Erste Welle, der historischen Entwicklung terminologisch gerecht $2 u$ werden, indem sie zwischen der zarubežnaja literatura ("Literatur im Ausland") bis 1925 und der anschließenden émigrantskaja literatura ("Emigrantenliteratur") unterscheiden. ${ }^{26}$ Der erste Begriff bezeichnet eine geographische verlagerung und ist somit neutraler als der zweite, der sich unmittelbar durch die Emigration definiert und eine eher qualitative Kategorisierung gegenüber der Literatur in der sowjetunion vornimmt. Bei seiner grundlegenden literaturgeschichtlichen Bestandsaufnahme der Ersten und Zweiten welle bevorzugt Gleb Struve wiederum ausschließlich den Ausdruck zarubez'e und nennt sein Buch Russkaja literatura $v$ izgnanii ("Die russische Literatur in der Verbannung"), um $2 u$ betonen, daß auch diese Literatur nach wie vor in Rußland beheimatet war:

"Эта зарубежная русская литература есть временно отведённый в сторону поток общерусской литературы, который - придёт время - вольётся в общее русло этой литературы."

("Diese russische Literatur im Ausland ist ein vorübergehend abseits geführter strom der gesamten russischen Literatur, der - mit der zeit - in das gemeinsame Flubbett dieser Literatur [wieder] einmünden wird.") 27

Diese Prognose hat sich politisch gesehen inzwischen erfüllt, aber erst nach Jahrzehnten. In welcher Beziehung stand die Literatur der Emigration in dieser zeit zur sowjetischen? Die Termini zarubežnaja literatura und èmi-

$25 \mathrm{Vgl}$. Raeff, a.a.0., S. 77-83.

26 Bol'dt, Segal u. Flejśman, "Problemy izučenija literatury russkoj émigracii pervoj treti XX veka", slavica Hierosolymitana (Jerusalem), Bd. III, 1978, , S. 84 .

27 Struve, Russkaja literatura..., a.a.0., s. 7. 
grantskaja literatura machen deutlich, daß es verschiedene Betrachtungsweisen gibt. In der Literaturwissenschaft und -kritik sowie unter den russischen Intellektuellen im Untergrund und in der Diaspora wurde immer wieder heftig debattiert, wie weit sich die russische Literatur im 20 . Jahrhundert gespalten hat. In dieser Grundsatzdiskussion ging es um die Gewichtung der Unterschiede gegenüber den Gemeinsamkeiten zwischen der Literatur im Ausland und der in der Sowjetunion, also primär um das verhältnis beider Zweige zueinander und weniger um den Begriff "Exilliteratur" als solchen. Wăhrend der Dritten Welle gewann diese streitfrage neue Aktualität und Relevanz. Sie ist von entscheidender Bedeutung für das selbstverständnis und die Einordnung der emigrierten schriftsteller innerhalb der russischen Literatur. 28

Die zugespitzte Formulierung "Odna ili dve russkich literatury?", die 1978 das Motto einer Expertenkonferenz in Genf war, 29 bedeutet eine grobe vereinfachung und impliziert provokativ eine Alternative, die es prinzipiell gar nicht gibt. Geht man von der sprache sowie dem kulturellen und nationalen Hintergrund aus, so existiert zweifellos nur eine russische Literatur. ${ }^{30}$ Die Werke, die diesseits und jenseits der Landesgrenzen verfaBt wurden, divergieren jedoch bis $z$ einem gewissen Grad in Inhalt und Form. Das AusmaB dieser Differenzen variiert von Generation $z u$ Generation und von Fall $z u$ Fall, je nachdem, wie verwurzelt

28 Die Autoren der Dritten Welle selbst haben in der Regel stets betont, daB sie sich uneingeschränkt zur russischen Literatur zugehörig fühlten. Dies belegen z.B. die Diskussionen bei der Konferenz in Los Angeles 1981 (The Third Wave: Russian Literature in Emigration, hg. Olga Matich u. Michael Heim, Ann Arbor, 1984, S. 23-50) und die von J. Graffy ausgewerteten Interviews (Under Eastern Eyes: The West as Reflected in Recent Russian Emigre Writing, hg. Arnold McMillin, New York, 1992, S. 135-140). a. a. 0 .

30. Auf der Genfer Konferenz erklärte Efim Etkind entsprechend, daB die Bildung einer eigenständigen Literatur durch Massenemigration die Entstehung einer neuen Nation voraussetze. Die russischen Exulanten hingegen seien stets der Heimat und der eigenen Kultur verbunden gewesen. ("Russkaja poézija XX veka kak edinyj process", Odna ili dve .... hg. Nivat, a.a.0., s.9-11.) 
die emigrierten Autoren geistig in RuBland blieben und wie weit sich ihr Erfahrungshorizont mit dem ihrer dortigen zeitgenossen deckte.

Nach diesen Maßstäben ist die Einheit der russischen Literatur im 20. Jahrhundert am wenigsten bei der jüngeren Generation der Ersten Welle gewahrt. ${ }^{11}$ Ihre Vertreter waren zur Zeit der Revolution im Kindesalter und später vom Aufbau des Sozialismus total abgeschnitten, so daB sie weder die Vergangenheit noch die Gegenwart ihrer Heimat kannten. Ihr Werk ist eher westeuropäisch beeinfluBt und unterscheidet sich wesentlich von der literarischen Produktion der gleichen Generation in der Sowjetunion. Bei der Zweiten Welle hingegen war die Kontinuität wiederhergestellt, weil ihre prosa ein Gegenstück zum Sozialistischen Realismus darstellt, mit dem sie an sich nur in den Aussagen nicht übereinstimmt. Die Auswanderung spielte lediglich insofern eine Rolle, als sie diese ÄuBerung von Systemkritik ermöglichte.

In den Werken der Dritten welle spiegelt sich mehrheitlich ebenfalls wider, daB die Schriftsteller mit der sowjetischen Realität, die sich in ihrer Abwesenheit nur geringfügig veränderte, vertraut und von ihr geprägt waren. Es ist unmöglich, einen schnitt zur Literatur der gleichen periode in der Sowjetunion $\mathrm{zu}$ machen, zumal die Emigration nicht plötzlich, sondern über mehrere Jahre erfolgte, aus der sowjetischen Untergrundkultur hervorging und diese fortsetzte. 32 statt einer spaltung in zwei systeme erkennt man ein zusammenspiel der im Ausland und der inoffiziell in der Sowjetunion entstandenen Literatur mit

31 Die folgenden Erläuterungen beziehen sich u.a. auf $\mathrm{Zi}$ naida Sachovskaja, "Literaturnye pokolenija", Odna ili dve - ij, hg. Nivat, a.a.0., S. 53-62.

' 32 ' Vgl. Geoffrey Hosking: "[...] the word 'émigre' is imprecise, since the concerns of these writers remained Soviet ones, and their links with the homeland were much closer than those of earlier generations of exiles." ("The Twentieth Century: In Search of New Ways, 1953-1980", The Cambridge History of Russian Literature, hg. Charles A. Moser, Cambridge, 1989, S. 538.) 
der von den sowjetischen zensoren anerkannten Literatur, also von insgesamt drei subsystemen. 33

Die Verbindung von äuBerem und innerem Exil konkretisiert sich in einer überschneidung von Tamizdat (aus tamosnij - "dortiger" und izdatel'stvo - "Verlag") und Samizdat (wörtlich "Selbstverlag"): Texte, die für die führenden Kreise in der Sowjetunion aus ideologischen oder ästhetischen Gründen inakzeptabel waren, wurden einerseits durch ausländische Verlage herausgegeben, andererseits im Inland illegal vervielfältigt und verbreitet. 34 Manche Autoren der Dritten Welle erschienen vor und nach der Ausreise hier wie dort; auBerhalb der Sowjetunion gedruckte russische Bücher und zeitschriften gelangten verdeckt ins Land, so daB für die emigrierten schriftsteller weiter eine Brücke zur heimat bestand. ${ }^{35}$ Tamizdat und Samizdat beeinflubten indirekt auch das sowjetische literarische Establishment und zwangen das Regime schon durch ihre Existenz zu Zugeständnissen. So entstand ein komplexes Geflecht literarischer wirkungen bei fließenden Grenzen zwischen den drei subsystemen. ${ }^{36}$

33 Zur Entwicklung in allen drei Bereichen von den 60er bis Anfang der 80er Jahre s. Andrzej Drawicz, "La litterature des années soixante-dix et du début des années quatre-vingt", Histoire de la litterature russe, Bd. 3 , a.a. 34 . S. 680-706.

34 Der Samizdat war das Medium der Dissidentenbewegung, der ein eigener Abschnitt gewidmet ist. Er expandierte zwischen 1965 und 1975 und ging dann zurück durch den Tod, das Verstummen oder eben die Emigration vieler Autoren. Die Exulanten stärkten dafür entsprechend den Tamizdat ab der 70er Jahre in Bedeutung und Umfang (Drawicz, a.a.o., S. 704 ).

35 Diese Funktion erfüllten auch das amerikanische "Radio Liberty" in München, der britische "BBC Russian Service" in London und die "Deutsche Welle" in Köln.

${ }_{36} \mathrm{Zu}$ den Abgrenzungsproblemen $\mathrm{s}$. Carl R. Proffer in "The Remarkable Decade that Destroyed Russian Enigré Literature", The Third wave, hg. Matich u. Heim, a.a.o., s. 81-86. Proffer, der als Autorität unter den Tamizdat-Verlegern galt (Verlag "Ardis", Ann Arbor, Michigan), rechnet darin vor, daB jährlich 20 bis 30 prozent der im Ausland hergesteliten russischen Bücher (bis zu 50000 Exemplare) letztlich die Sowjetunion erreichten (S. 85). - Die Unmöglichkeit einer klaren Trennung zwischen den drei genannten Bereichen betonen im gleichen Band zudem Andrej Sinjavskij ("Dve literatury ili odna", S. 23-24) und Deming Brown ("An Outsider's Perspective on the Third Wave", S. 63-66). 
Rechnet man zur Literatur der Dritten welle alle Autoren, die in den vergangenen zwei Jahrzehnten im Ausland gelebt oder publiziert haben und eine oppositionelle Haltung einnahmen, so bleiben die Umrisse des Phänomens unscharf. Denn diese bio-bibliographischen Aspekte allein bedeuten noch keine spezifische Kennzeichnung gegenüber der sowjetischen Literatur. Eine deutlichere Klassifizierung der Emigrantenliteratur als solche erfordert eine Einschränkung der Begriffsverwendung aufgrund thematischer und stilistischer Merkmale, die durch die äuBere Emigration bedingt sind und bei der in der Heimat verfaBten Literatur nicht auftreten. Aber auch von den im Ausland entstandenen Werken entspricht nur ein Teil, ein bestimmter Typ solchen Maßstäben. ${ }^{37}$

Schriftsteller, die ausschlieblich über die Heimat und im gleichen stil wie vor der Auswanderung geschrieben haben, können in diesem engeren Sinn kaum Autoren der Emigration genannt werden. Vielmehr muB sich das erzwungene oder freiwillige Exil konkret als Faktor im literarischen Text nachweisen lassen. Die vorliegende Arbeit versucht, mittels einer exemplarischen Untersuchung die Kategorie "Emigrantenliteratur" näher $\mathrm{zu}$ bestimmen und dafür Kriterien zu entwickeln.

Vgl. auch D. Brown, "On the Relationship between the Literature of the Third Emigration and Soviet Literature on the Eve of "Glasnost'", Russianness: Studies on a Nation's Identity, hg. Robert L. Belknap, Ann Arbor, 1990, S. 2930 .ำ

37 Im Rahmen der Diskussion um die spaltung der russischen Literatur wurde der Begriff "Emigrantenliteratur" oft als Abwertung abgelehnt, da er die zugehörigkeit zur russischen Literatur in Frage stelle (s. z.B. Proffer, a.a.0., S. 81). Die hier vorgeschlagene Definition aber bezweckt keine Ausgrenzung, sondern eine Abgrenzung. 


\section{DIE DRITTE EMIGRATIONSWELLE}

\subsection{Exilierung der Dissidenten}

Die Dritte Auswanderungswelle war in ihrer kulturellen Identität insgesamt russisch, ethnisch aber eine "jüdische Emigration", da die Grenzen sich vornehmlich für die russischen Juden öffneten. Gleichzeitig vertrieb das kommunistische Regime direkt und indirekt einen groBen Teil der nicht auf der Parteilinie liegenden Intelligenz und Kulturelite, was die Dritte Welle zu einem zeichen für die Unnachgiebigkeit der führenden kreise gegenüber Andersdenkenden machte.

Die Dissidentenbewegung hat inre wurzeln in der "Tauwetter-Periode" unter Generalsekretär Nikita chrušcëv (1953-1964), der insbesondere auch in der Kulturpolitik vom Dogmatismus seines Vorgängers stalin abrückte. Gerade junge Künstler nutzten den gewährten Freiraum, wobei sie von einer woge der Popularität getragen wurden. 38 Das frühzeitige Ende dieser vergleichsweise liberalen phase führte zur Bildung einer geistig-künstlerischen opposition, die gegen die ideologische verschärfung der Politik und für die Einhaltung der Menschenrechte eintrat sowie die wahrheit über das sowjetsystem aufdecken und vermitteln wollte.

Die Nonkonformisten veröffentlichten ihre Texte im Samizdat oder im Ausland und führten zum Teil eine Doppelexistenz. Zur symbolfigur wurde Andrej sinjavskij, der an der Moskauer Universität als Dozent für Literatur lehrte und zugleich unter dem Pseudonym Abram Terc systemkritische prosa im westen drucken lieB, bis man inm 1966 zusammen mit dem Satiriker Julij Daniel' (alias Nikolaj Arzak) den ProzeB machte. Aleksandr Solženicyn stand an der spitze der Dissidentenbewegung, die der staat mit

38 S. 2.B. Ljudmila Alekseeva, The Thaw Generation: Coming of Age in the Post-stalin Era, Boston u.a. 1990. Die Formierung der Dritten Welle aus dieser Generation erläutert Vittorio Strada in "Du "dégel" à la "dissidence": La nouvelle émigration", Histoire de la litterature russe, Bd. 3, a.a.0., S. 741-749. 
Repressionen und harten strafen bekämpfte. Hunderte kamen ins Gefängnis, Arbeitslager oder in psychiatrische Anstalten. 39

Ab Anfang der 70er Jahre erwies sich dann auBerdem die Exilierung durch Ausweisung und die Erteilung von Ausreisegenehmigungen, oft verbunden mit dem Entzug der Staatsbürgerschaft, als wirksames Mittel, den inneren widerstand $2 \mathrm{u}$ schwächen. ${ }^{10} \mathrm{Nicht}$ alle Freidenker und Künstler, die so in den westen gelangten, waren aktive Dissidenten und mit Leib und Leben in Gefahr gewesen. Viele entschlossen sich zur Auswanderung allein deshalb, weil sie die stagnation des systems erkannt hatten und sich damit nicht auf Dauer arrangieren wollten. In jedem Fall war die Emigration kein Schicksalsschlag wie bei der Ersten und zweiten Welle, die unmittelbar durch politische und historische Ereignisse ausgelöst wurden, sondern die letzte Konseguenz einer langjährigen oppositionstätigkeit oder -haltung. Von den beiden vorhergehenden unterschied die Dritte Welle auch, daß die Umstände eine äuBerst geringe Hof fnung auf Rückkehr lieBen.

Auf der anderen Seite des Eisernen Vorhangs erhielten die sowjetischen Dissidenten in den ersten Jahren viel Aufmerksamkeit, was durch den Kalten Krieg bedingt war,

39 Zur geistigen opposition in der sowjetunion und der Literatur des Samizdat s. u.a. Josephine Woll, Soviet Dissident Literature: A Critical Guide, Boston, 1983; Jurij Mal'cev, Freie russische Literatur 1955-1980, Frankfurt, 1981; Grigori Svirski, A History of Post-War Soviet Writing, Ann Arbor, 1981; S. P. de Boer, E. J. Driessen U. H. L. Verhaar, Biographical Dictionary of Dissidents in the Soviet Union, 1956-1975, The Hague u.a., 1982; "Dossier: La littérature et l'exil", Le Magazine litteraire, Nr. 221, Juli/August 1985, S. 14-65; "Writers in Exile: A Conference of Soviet and East European Dissidents", Partisan Review, Bd. 50, H. 3, 1983, S. 327-372.

10 Informationen über die Betroffenen vermitteln die durch bibliographische Angaben ergänzten Kurzbiographien in Free Voices in Russian Literature 1950-80s: A BioBibliographical Guide von Bosiljka Stevanovich u. Wladimir Wertsman, New York, 1987; s. auch Peter Boris, Die sich lossagten: Stichworte $z u$ Leben und werk von 461 Exkommunisten und Dissidenten, Köln, 1983; Martin Tucker (Hg.), Literary Exile in the 20th Century: An Analysis and Biographical Dictionary, New York, 1991. 
aber die Literatur als solche im Prinzip zur Nebensache degradierte und ihre Rezeption mit politischen Vorzeichen versah." Gefragt war die "Lagerliteratur", also dokumentarisch und autobiographisch geprägte, anklagende schilderungen der Menschenrechtsverletzungen in der Sowjetunion. sie hatten unter anderem auch das ziel, die westliche öffentlichkeit über MiBstände zu informieren, und erreichten dabei oft relativ hohe Auflagen. ${ }^{12}$

Abgesehen davon konnten sich die literarischen Werke der Dritten Welle auf dem freien Buchmarkt nur selten durchsetzen.13 Auch aufgrund dieser - oft unerwarteten Akzeptanzprobleme blieben die meisten Autoren sprachlich und thematisch weitgehend auf inre Landsleute ausgerichtet" 14 und auf den Tamizdat sowie die Emigrantenpresse angewiesen. Ihre Rezeption beschränkte sich so hauptsächlich auf die russischen Minderheiten und spezialisten im westen sowie enge Zirkel in der Sowjetunion. Die allgemeine Dominanz der Prosagattungen in der Literatur der Dritten Emigration hängt nicht zuletzt mit der damaligen Nachfrage zusammen: Die Emigrantenzeitschriften bevorzugten Erzählungen und Essays, während die westlichen Verlage am ehesten Romane herausgaben. 15

11 Bezeichnend dafür ist die von der Zeitschrift Partisan Review veranstaltete Konferenz "Writers in Exile" in Boston 1982, die trotz des Titels die Teilnehmer in erster Linie als Dissidenten präsentiert (a.a.0.; s. auch Teil II in Bd. 50, H. 4, 1983, S. 487-525; und Teil III, Bd. 51, H. 12,1984, S. $11-44)$.

Ein typisches Beispiel sind die Titel von vladimir Bukovskij, einer der Autoren in Grobbritannien, die im einzelnen noch vorgestellt werden.

13 Kathryn Henry erläutert in inrer Dissertation Between Cultures: Third-Wave Russian Fiction in Russian and English (Stanford, 1990) die Publikationsbedingungen für die Russen in den USA (S. 76-129). Dabei geht sie auch auf die falschen Erwartungen der Emigranten ein (S. 67-75). S. ferner die entsprechenden Beiträge "Kak izdavat'sja na zapade?" von Sergej Dovlatov und "Book Publishing and the Emigré Writer" von Ashbel Green in The Third wave, hg. Matich u. Heim, a.a.0., S. 235-243 bzw. 244-250.

11 Einige Autoren orientieren sich nach eigenen Angaben bis heute primär am russischen Leser; s. Graffy, Under Eastern Eyes, hg. McMillin, a.a.0., S. 135-140.

${ }_{15}$ S. Henry, a.a.0., S. 127 . 


\subsection{Konsequenzen der jüngsten Entwicklung}

Mit dem ReformprozeB in der Sowjetunion, den Michail Gorbačëv nach seinem Amtsantritt als Generalsekretär 1985 in Gang brachte, hat sich das Gesamtsystem der russischen Gegenwartsliteratur vollkommen gewandelt. Der zusammenbruch der Parteidiktatur machte die Verbannung von Teilen der Literatur in den Untergrund und ins Ausland hinfällig. Perestrojka und glasnost' bereiteten den Boden für eine umfassende Aufarbeitung der russischen Emigration und inrer kulturelien Leistungen. ${ }^{46}$

Die Rückführung der Exilliteratur durch eine Flut von Veröffentlichungen begann etwa 1986 mit der Ersten Welle und erfaBte zwei Jahre später auch die zeitgenössischen Autoren. Der Schwerpunkt lag zunächst auf Kenntnisnahme und Rezeption. Erstmals waren diese werke auch in RuBland allgemein zugänglich und aktuelles Thema der öffentlichen Diskussion sowie der literaturwissenschaftlichen und -kritischen Auseinandersetzung. ${ }^{17}$ Dabei wurde die Frage nach der spaltung der russischen kultur und Literatur neu aufgeworfen bzw. öfentlich nachgeholt. ${ }^{48}$ Die Einrichtung von Sonderrubriken in zeitungen und zeitschriften ${ }^{49}$ oder eigener Abteilungen an den Universitäten manifestierte vorerst eine isolierte Betrachtung der Emigrantenliteratur, also

16 Eine komprimierte Darstellung bietet Karl Schlögel in "Das andere RuBland: Zur Wiederentdeckung der Emigrationsgeschichte in der Sowjetunion", Die Umwertung der sowjetischen Geschichte, hg. Dietrich Geyer, Göttingen, 1991 , S. 238-256.

17 Ein Bsp. ist das Sonderheft "Literatura russkogo zarubez'ja 1918-1940" der Zeitschrift Rossijskij literaturovedkeskij zurnal, Nr. 2, 1993; $\mathrm{s}$. insbesondere auch die Einleitung von E. P. Ćelyśev, "Ob izučenija literatury russkogo zarubež'ja", S. 3-4.

18 Bsp. einer entsprechenden stellungnahme: V. A. Zajcev, "Sovremennaja poèzija russkogo zarubeí'ja", Vestnik Moskovskogo Universiteta, Bd. 9, H. 1, Jan/Feb 1992, S. 3. Zur Debatte um die Neuinterpretation der Emigrationsgeschichte allgemein s. Schlögel, a.a.O., S. 255-256.

19 An der ErschlieBung der Emigrantenliteratur beteiligten sich oktjabr', Novyj mir, Literaturnoe obozrenie, Literaturnaja gazeta, Moskva, slovo, Junost', Znamja, Russkaja literatura, voprosy literatury, u.v.a. 
(noch) nicht im Kontext der russischen Literatur ab 1917 als Gesamtsystem. 50

Ende der 80er Jahre entwickelte sich auch ein lebhaftes Interesse an den einzelnen Personen der Dritten welle. Die ehemaligen Dissidenten wurden $z u$ Interviews und Konferenzen eingeladen. Bis 1990 erhielten alle ihre staatsbürgerschaft zurück.51 Ihre Heimat steht ihnen seither wieder offen, und die meisten haben sie bereits mehrfach besucht und dort publiziert. Bezüglich des literarischen Establishments in RuBland bleiben sie freilich AuBenseiter, auch nachdem die alten strukturen aufgebrochen sind. ${ }^{2}$ Die respektvolle Aufmerksamkeit, die die rehabilitierten Abtrünnigen zunächst genossen, hat seit Anfang der 90er Jahre stark abgenommen. Ihre Meinungen gelten nicht mehr soviel wie anfangs oder stoBen sogar auf unverhohlene $\mathrm{kri-}$ tik. Am DemokratisierungsprozeB waren sie bislang weniger beteiligt als von ihnen allgemein erwartet. AufschluB über die unterschiedliche Wahrnehmung der Rolle, die den Emigranten im aktuellen literarischen und gesellschaftlichen Leben zukommt, gibt eine Diskussion in der Literaturnaja gazeta 1991. Sie wurde von der Literaturkritikerin Alla Latynina ausgelöst, die den Intellektuellen im Ausland vorwarf, zu Unrecht als Sprecher des Volkes und Lehrmei-

50 Wolfgang Kasack beschreibt den allmählichen ProzeB, den er "Auf dem Wege zur Wiederherstellung der Einheit der russischen Literatur" nennt, in Neueste Tendenzen in der Entwicklung der russischen Literatur und Sprache: Probleme in Forschung und Lehre, hg. Erwin Wede, Hamburg, 1992, S. 101-109; s. ebenso Andrzej Drawicz, "La littérature russe à la $f$ in des années quatre-vingt", Histoire de la littérature russe, Bd. 3 , a.a.0., S. 891-906; an dieser stelle sei nochmals auf die umfangreiche Bibliographie im gleichen Band (S. 1000-1020) verwiesen. Wolfgang Kasack wiederum hat alle Autoren und Werke zusammengestellt, die bis zur Gorbačëv-Ära nur im westen erschienen waren ("Zarubežnye publikacii russkoj literatury", Voprosy literatury, Nr. 3, 1989, S. 110-133).

51 Entsprechendes' Präsidentendekret am 15.8 .1990 laut Graffy, Under Eastern Eyes, hg. McMillin, a.a.O., S. 149.

52 Das erste Treffen von Exilautoren mit Vertretern der sowjetischen Literatur 1988 in Dänemark veranschaulichte die kluft zwischen beiden seiten. Zusammenfassungen der Konferenz: "Kollegen von einst", Die Presse, 16./17.4.1988, S. 6: Marija Rozanova, "Perestrojka i perestrelka", Sintaksis, Nr. 21, 1988, S. 3-17. 
ster aufzutreten, da sie von den Umwälzungen nicht betroffen seien. 53

Die früheren Oppositionellen haben nicht nur ihre bisherige politische und gesellschaftliche Funktion verloren, sondern auch den AnschluB an die Entwicklung im Heimatland. Etliche Exilrussen fühlen sich erst jetzt wirklich ausgeschlossen und entfremdet. Zinik beschreibt den Zusammenbruch des Kommunismus wie folgt:

"The people there emigrated to a new country. The old country slipped off from under their feet, and they are now in the new one. And it is as alien to them as it is to me. But they have already emigrated to that country and are going to live there and adapt to the new country, and me not. So it is a parting point, I think." 54

Eine Rückkehr käme einer zweiten Auswanderung gleich, die die meisten scheuen. Bis auf wenige Ausnahmen wie Aleksandr Solzenicyn, der im Herbst 1993 die Heimreise antrat, will daher keiner der Emigranten wieder in RuBland leben, sei es aus wirtschaftlichen, politischen, persönlichen oder anderen Gründen. 55

53 A. Latynina, "Kogda podnjalsja zeleznyj zanaves ...", Literaturnaja gazeta, Nr. 29, 24.7.1991, S. 9 u. 11. Dazu nahmen Stellung: Vladimir Vojnovic, Eduard Limonov, Jurij Miloslavskij, Marija Rozanova (Nr. 33, 21.8.1991, S. 11); Grigorij Pomeranc (Nr. 37, 18.9.1991, S. 11): Vladimir Maksimov (Nr. 41, 16.10.1991, S. 11); Efim Etkind (Nr. 44, 6.21 .1991 , S. 9).

51 Persönliches Gespräch mit zinik; s. Anhang, S. 185.

55 Dies belegt eine entsprechende Umfrage von Wolfgang Kasack ("Heimatlos in der Fremde", Manuskript für die "Deutsche Welle" vom 18.5.1994). In den von Graffy analysierten Interviews erklären manche Befragten ihre Absicht zurückzukehren, führen aber eine Reihe von Bedingungen an; die Mehrheit lehnt den Gedanken von vornherein ab (Under Eastern Eyes, hq. McMillin, a.a.0., S. 140-144). Bemerkenswert ist in diesem Zusammenhang Graffys Beobachtung, daß in vielen Gesprächen über den Begriff rodina ("Heimat") sowie die Verwendung von my und vy ("wir inr") Verwirrung herrscht, was die Unsicherheit über die heutige kulturelle Zugehörigkeit des jeweiligen Autors beweist (S. 117). - Zur Bedeutung einer möglichen oder erfolgten Rückkehr für das Identitätsgefühl von Emigranten s. auch die psychoanalytischen Erläuterungen bei Leon $u$. Rebeca Grinberg, Psychoanalyse der Miqration und des Exils, München u. Wien, 1990, S. $205 \mathrm{ff}$. 
Unter diesen Umständen ist strittig, ob von einem Ende der Emigrantenliteratur gesprochen werden kann. Die russischen Autoren im Ausland befinden sich weiter in einem Grenzbereich, müssen darin aber ihre Position neu bestimmen. Da die einst gegebene, politisch bedingte Basis für einen Konsens fehlt, ist eine verstärkte Fragmentierung $z u$ erwarten. Grundsätzlich ist der Faktor der Emigration mit der Aufhebung des politischen Exils für die literarische produktion der Dritten welle keineswegs bedeutungslos geworden, sondern wirkt sich weiter aus, etwa in der Verarbeitung der Vergangenheit oder der anderen Kultur. Möglicherweise wird sich der thematische Schwerpunkt infolge fortgeschrittener Assimilierung und einer abnehmenden Neigung zur Retrospektive immer mehr auf die hiesige wirklichkeit verschieben. Der Begriff "Emigrantenliteratur" bleibt in jedem Fall auch im aktuellen Kontext der russischen Gegenwartsliteratur als literarische Kategorie angemessen, um jene werke $z u$ erfassen, die außerhalb Rußlands entstehen und spezifische, durch die Emigration geprägte Merkmale aufweisen.

\subsection{Die Opposition von Kontinent und sintaksis}

Die politischen, geistigen und literarischen strömungen innerhalb der Dritten welle fanden ihren Niederschlag in zahlreichen Zeitschriften, die ab Mitte der 70er Jahre in der Emigration entstanden und florierten, bis in der zweiten Hälfte der 80er Jahre infolge der politischen Entwicklung ein allgemeiner Niedergang einsetzte. Die wichtigsten organe waren in Paris ansässig und trugen wesentlich zur Formierung verschiedener Fraktionen bei.56

56 Die folgenden Informationen stammen aus Matich, "Literature and Politics in Emigration", The Third Wave, a.a.0., S. 99-103, und im gleichen Band "Emigrantskaja pressa: gruppovaja diskussija" (S. 158-178); Henry, a.a.0.. S. 86-116; Arnold McMillin, "Exiled Russian Writers of the Third Wave and the Emigré Press", The Modern Language Review, Nr. 84, H. 2, April 1989, S. 406-413; Petr Vajl' u. Aleksandr Genis, Sovremennaja russkaja proza, Ann Arbor, 1982, S. 131-139; C. Regnaut-Labord, "Vers la fin de la troisieme émigration soviétique?", 
Am bekanntesten ist die sozio-politische und literarische Zeitschrift Kontinent, die erstmals 1974 in Paris herauskam, sich am besten etablierte und starken EinfluB ausübte. Durch fremdsprachige Ausgaben und Verbindungen zum Samizdat reichte inr wirkungskreis auch in die westliche öffentlichkeit und den sowjetischen Untergrund hinein. Unter Chefredakteur Vladimir Maksimov vertrat Kontinent einen dogmatischen Anti-Kommunismus, einen russischen Nationalismus und eine extrem kritische Einstellung gegenüber den westlichen Liberalen.

Zu Maksimovs Verbündeten zählten unter anderen die älteren Emigranten. So stellten sich die angesehene zeitschrift Russkaja mysl' und das sprachrohr der russisch-orthodoxen Exilgemeinde Vestnik russkogo christianskogo dviženija, die beide aus der Ersten Welle hervorgeganqen waren, an die seite von Kontinent. Im Vestnik, personell und ideell wiederum mit dem traditionellen Emigrantenverlag YMCA verknüpft, waren regelmäBig Beiträge von Aleksandr Solženicyn zu lesen. Das Idol der Dissidentenbewegung repräsentierte einen ethnisch und religiös begründeten Messianismus und verschrieb sich dem Kampf für sein Volk und die traditionellen werte des vorrevolutionären RuBlands, wobei er trotz seiner absoluten zurückgezogenheit in den USA eine Autorität blieb. Das westliche Demokratiemodell hat er stets abgelehnt.

Maksimov und Solženicyn führten gemeinsam das Establishment der russischen Emigranten an. Ästhetisch erklärten sie und ihre Anhänger die Tradition des Realismus zum obersten stilprinzip und forderten die Einhaltung sprachlicher Normen. Die Literatur sahen die Konservativen

Revue d'etudes comparatives Est-Ouest, Bd. 14, H. 4, 1983, S. 119-124; Françoise de Bonnières, "Russian and East European Emigré Publications in France", Proceedings of the Second International Conference of Slavic Librarians and Information Specialists, hg. Marianna Tax Choldin, New York, 1986, S. 178-192. - Zur Existenzkrise im Zuge der politischen Veränderungen $a b 1986$ s. z.B. Henning Sietz, "Auch 'Kontinent' am Ende?", Neue Zurcher Zeitung, 14.2.1987. Kontinent, das einstige Flaggschiff der Emigrantenpresse, wird mittlerweile in Moskau mit relativ geringen Auflagen herausgegeben. 
in politischer und historischer Verantwortung, also im engeren Sinn als Waffe gegen den Sowjetstaat, indem sie die Wahrheit über das totalitaristische system und seine Geschichte ausspricht und kritik äuBert. Das ziel, die kommunistische Gesellschaft $z u$ entlarven, veranlabte ferner Satiriker wie vladimir Vojnovic und Aleksandr Zinov'ev, nach der Ausreise 1980 bzw. 1977 nach Deutschland in dem für die sowjetliteratur typischen Genre weiterzuarbeiten. Die Kreise um Maksimov und Solženicyn schlossen rigoros alle Autoren aus, die inhaltlich und sprachlich gegen Tabus verstießen.

Um auch ihnen eine Plattform zu geben, gründete Andrej Sinjavskij, der einst mit Maksimov zusammengearbeitet hatte, 1978 ebenfalls in Paris gemeinsam mit Marija Rozanova Sintaksis. Die programmatische Ausrichtung der zeitschrift war in allen Punkten der von Kontinent explizit entgegengesetzt, nämlich liberal, pluralistisch, analytisch und westlich orientiert. 57 Im Bereich der Literatur verurteilte Sinjavskij die Dominanz politischer Kriterien gegenüber ästhetischen ${ }^{58}$ und setzte sich für Innovation ein, zumal sein eigenes werk sich durch phantastische züge und einen eigenwilligen stil auszeichnet. ${ }^{59}$ sintaksis konzentrierte sich allerdings auf die Publizistik, während für literarische Texte ein gleichnamiger Verlag eingerichtet wurde. Im gleichen Jahr wie sintaksis, nämlich 1978, gaben in Paris noch zwei andere zeitschriften ihr Debut: Echo und Kovčeg. Sie hielten sich von der Politik fern und

57 Marija Rozanova erläuterte das Konzept auf der Konferenz in Los Angeles 1981 und hob dabei u.a. hervor, daß sie Konformismus und Tabus prinzipiell ablehne (The Third Waye, hg. Matich u. Heim, a.a.0., S. 167-170).

58 S. 2.B. Sinjavskij, "Dve literatury ili odna", The Third Wave, hg. Matich u. Heim, a.a.O., S. 24-29.

$59 \mathrm{Vgl}$. Edward J. Brown: "For him style is the essence of the matter, and each of his productions involves serious play with the materials of verbal art: memory, images of the real world, fantasies, and the Russian language itself." ("Russian Literature beyond the Pale", Slavic and East European Journal, Bd. 30, H. 3, Fall 1986, S. 384). S. auch Catherine Theimer Nepomnyaschchy, "Sinyavsky/Tertz: The Evolution of the writer in Exile", Soviet and East European Literature in Exile, hg. Olga Matich, Sonderheft der Humanities in Society, Bd. 7, Nr. 3-4, Summer/Fall 1984, S. 123-142. 
widmeten sich ganz der Publikation experimenteller Literatur. Hier fanden vor allem Autoren der jüngeren Generation eine Nische.

Aus den bisherigen Feststellungen ist ersichtlich, daß sich bis Ende der 70er Jahre zwei fundamental verschiedene Denkrichtungen herausbildeten, die sich in der opposition von Kontinent und sintaksis verfestigten. Zwar ist es unangemessen, von einer totalen, gleichmäBigen und statischen Polarisierung der Dritten Welle zu sprechen.60 Doch spielten die Auseinandersetzungen zwischen den entsprechenden Lagern zeitweise eine beherrschende Rolle. Dabei waren die $\mathrm{zwistigkeiten} \mathrm{oft} \mathrm{von} \mathrm{Polemik} \mathrm{und} \mathrm{Anfeindun-}$ gen gekennzeichnet und behinderten die Entwicklung der Literatur. Denn die politischen und persönlichen Kontroversen bestimmten maBgeblich, welche Autoren von welchen zeitschriften veröfentlicht und gefördert wurden.

Zinovij zinik hat die meisten Essays und einige Erzählungen in sintaksis veröffentlicht; im gleichnamigen Verlag erschienen zwei Romane. ${ }^{61}$ An dem Konflikt der Zeitschrift mit Kontinent war er allerdings nicht direkt beteiligt. Seit 1976 ist zinik außerdem mit seiner prosa regelmäßig in Vremja $i$ my vertreten. Diese Monatszeitschrift, der die gleiche Gesinnung wie sintaksis zugrunde liegt, rief Viktor Perel'man 1975 in Tel Aviv ins Leben, später wechselte sie nach New York. In der Tradition der tolstye żurnaly enthalten die Hefte jeweils zur Hälfte Belletristik. Die Auswahl der Beiträge richtete sich von Beginn an nach Perel'mans eigenen Worten ausschlieblich nach der literarischen Qualität. 62

60 Regnaut-Labord vertritt die Ansicht, daß der Eindruck, die Emigranten hätten sich in einen "linken" und einen "rechten" Flügel gespalten, auf westlichen Wahrnehmungsschemata beruhe und die persönliche Feindschaft von Maksimov und Sinjavskij unzulässig verallgemeinere. Stattdessen müsse man bei der Betrachtung der Dritten Welle differenzieren und die allmähliche Entwicklung im Auge behalten $\left(a_{61}\right.$ a.O... s. 123).

61 Russkaja služba (1983), Niša v Panteone (1985).

62 Stellungnahme anläßlich der Konferenz the Third wave (hg. Matich u. Heim, a.a.O., S. 171-174). 


\subsection{Die AuBenseiter}

Viele Autoren der Dritten welle waren bereits vor inrer Emigration mehr oder weniger bekannt und verfolgten die jeweils eingeschlagene künstlerische Richtung danach im wesentlichen weiter. Für andere aber bedeutete die Auswanderung den Anfang ihrer freien Entfaltung und der Ausformung eines individuellen stils.63 sie setzten sich vom Gros der Emigrantenschriftsteller $a b$ und suchten abseits der vorherrschenden Normen ästhetisch eigene Wege. Manche von innen, wie Zinovij zinik, haben überhaupt erst im Ausland mit dem Schreiben begonnen. Diese Einzelgänger sind überwiegend in den 40er Jahren geboren und gehören damit der sogenannten jüngeren Generation an.64

Ihr werk ist für die Frage nach den spezifika der Emigrantenliteratur besonders interessant, weil seine Genese direkt durch die Auswanderung bedingt ist. Die damit verbundenen Erfahrungen und die Begegnung mit der fremden Kultur bilden hier einen inhaltlichen schwerpunkt und gaben den AnstoB für stilistische Innovationen. Beispiele findet man besonders in der Prosa. Die betreffenden Erzählungen und Romane greifen Themen auf, die von den Dissidenten und traditionelien Realisten ausgegrenzt wurden, und verwenden experimentelle, phantastische, parodistische und satirische Verfahren. Bei teilweise groBen Unterschieden haben diese werke gemeinsam, daB sie individualistisch, apolitisch und wider jegliche Tabus sind.

Deshalb hatten es die Autoren zumindest bis Mitte der 80er Jahre schwer, in den Kreisen der russischen Auswanderer und im westlichen Literaturbetrieb Resonanz und Anerkennung $z u$ finden, denn hier setzte die Dissidentenliteratur die Maßstäbe. Igor' Pomerancev (Jahrgang 1948), der bis vor wenigen Jahren in London lebte und mit seinen

63 Entsprechende Entwicklungen zeichneten sich schon am Rand der Samizdat-Literatur ab, verlagerten sich dann aber in die Emigration, die dafür genügend Freiraum schuf. Vgl. Kasack, Russian Literature 1945-1988, München, 1989, S. 96 $\mathbf{f} \mathbf{f}_{\mathbf{6}}$

zur Unterteilung der Dritten welle in drei Generationen s. Regnaut-Labord, a.a.O., S. 120 . 
eigenwilligen, sprachlich anspruchsvollen und avantgardistischen Erzählungen und Gedichten nur kleineren kreisen bekannt ist, verurteilt stellvertretend für viele in einem zynisch-ironischen Essay die einseitig orientierte, westliche Rezeptionshaltung (bei spielerischer vertauschung der geographischen Bestimmungen). Zitat:

"It happens to be the case that the North only accepts those Western (Eastern, Southern) poets who have had their finger nails pulled out at home. The vulnerability of finger nails, or their absence, is - like it or not - somehow connected with poetry. [...] Fate, pain, finger nails, like music, do not need translation. You believe them." 65

In einem Interview gab Pomerancev auBerdem 1986 an, daB bis dahin in der russischen Literatur eine "Diktatur der Wahrheit", wenn auch der "Anti-Regime-Wahrheit" geherrscht habe ("anti-regime truth, which is no better than any other dictatorship"). .66 sie verliere erst jetzt allmählich inre Macht zugunsten der Ästhetik. Den Verlust literarischer kriterien in der russischen Literatur und mangelnde Beachtung apolitischer werke beklagten auch andere jüngere Schriftsteller. Der 1943 geborene Eduard Limonov zum Beispiel, der sich zunächst in New York niederlieB, dort seine ersten prosawerke verfaBte und 1980 nach Paris ging, kommentierte 1987 auf einer internationalen Konferenz:

"Russian literature has, in a sense, been force-fed
with politics. The Russian writer is automatically ex-
pected to be either exclusively Soviet or exclusively dis-
sident." 67

Vor diesem Hintergrund verkörpert Limonov den Rebellen. Mit seinem in jeder Hinsicht blasphemischen Roman ito ja - Édička (1979; engl. It's Me, Eddie!, 1983; dt. Fuck

65 I. Pomerantsev, "Lost in a strange City", The Times Literary Supplement, H. 4395, 26.6.1987, S.695. In dem Essay karikiert Pomerantsev typische Verfahren der Dissidentenlyrik und inren jeweiligen effekt auf die westlichen Leser.

66 Interview mit Sally Laird, "Igor Pomerantsev: Out of Step", Index on Censorship, Bd. 15, H. 3, März 1986, S. 18

67 Limonov, "Thirteen studies on Exile", Literature in Exile, hg. John Glad, Durham u. London, 1990, S. 51. 
off, Amerika, 1982), der im nächsten Abschnitt kurz vorgestellt wird, setzte er das Fanal für einen Bruch mit thematischen und spachlichen Tabus.68 Limonovs propagiertes credo besteht darin, $d a \beta$ er bewuBt nur über und für sich selbst schreibt und dabei gemeinsam mit einigen Gleichgesinnten, unter die er auch zinik reint, eine neue prosa in der russischen Literatur begründet: "My soveršenno novyj fenomen - my russkaja literatura vne politiki." ("Wir sind ein vollkommen neues Phänomen, nämlich eine russische Literatur auBerhalb der Politik.") 69

Olga Matich stellt unter der rhetorischen Frage "Is there a Russian Literature beyond Politics?"70 fest, daB erst die Emigration den jüngeren Autoren der Dritten welle trotz der Akzeptanzprobleme, die Matich ebenfalls berücksichtigt," eine eigenständige Entwicklung erlaubt habe. In der Sowjetunion hingegen hätten die politischen verhältnisse die Schriftsteller jeden Alters stets aneinandergebunden. ${ }^{72}$ sie unterstreicht allerdings, daB die apoliti-

68 Interessant ist in diesem zusammenhang, wie Zinik Limonovs Roman beurteilt. In einer Rezension betont er, es handle sich um einen "Augenzeugenbericht" in bloBer Reaktion auf die angeblich abgelehnten Kategorien der Dritten Welle, also an sich kein fundamental neuartiges Werk. Das heiBt, eine wirkliche Absetzung kann für inn nur durch die rein fiktive Literatur erfolgen, für die er sich auch selbst weitgehend entschieden hat. ("East-side, WestSide", The Times Literary Supplement, H. 4224, 16.5.1984, S. 6967 ).

69 "Limonov o sebe", The Third wave, hg. Matich u. Heim, a.a.0., S. 219. - Innerhalb der Dritten welle stehen sich somit verschiedene Selbstdefinitionen gegenüber. Matich stellt im gleichen Band fest: "Solzhenitsyn and Maximov value primarily the civic and testimonial functions of literature, while Limonov and Bokov, let's say, want to be viewed as literary nonconformists. This is a reflection of what appears to be an urgent need to establish a hierarchy between life and art, social consciousness and individualism." (S. 102). S. dazu insbesondere K. Henry, die die Auffassungen von Solženicyn, Sinjavskij und Limonov über die Rolle des Autors näher erläutert und miteinander vergleicht (a.a.0.. S. 16-56).

70 Matich, "Is there ...", The Third wave, hg. Matich $u$. Hejm, a.a.o., S. 180-187.

" Matich, "Is there...", The Third wave, hg. Matich u. Heim, a.a.o., S. 182 .

12 Matich, "Is there ...", The Third wave, ng. Matich $u$. Heim, a.a.o.. S. 181 . - In' dem Interview in Index on Censorship bestätigt Pomerancev, daß das Regime unter Breżnev 
sche, anti-realistische und experimentelle Prosa, für die Matich die Bezeichnung "neue Prosa" gebraucht, nicht nur eine Domäne der jüngeren Generation sei. ${ }^{73}$

Einer ihrer bekanntesten Vertreter zum Beispiel, Vasilij Aksënov, ist rund zehn Jahre älter, nämlich 1932 geboren. Er machte sich bereits in der Sowjetunion einen $\mathrm{Na}-$ men als Initiator der "jungen Prosa", indem er während der "Tauwetter"-Periode uber die Probleme der sowjetischen Jugend schrieb. Danach geriet Aksënov immer mehr in Schwierigkeiten, so daß er die Auswanderung 1980 in die USA selbst als Befreiung sieht, die seine schöpferische Entwicklung erheblich förderte und ihn zum "Emigrantenautor" machte. 74 In dieser Hinsicht stimmt er mit zinik überein, für den die Emigration die Quelle seiner Inspiration und Kreativität darstellt. ${ }^{75}$

Die erwähnten Autoren repräsentieren Nebenströmungen in der Literatur der Dritten Welle, die zunehmend an Bedeutung gewinnen könnten. Zinik selbst sieht in der stilistischen vielfalt die zukunft der russischen Gegenwartsliteratur. Auf einer Konferenz 1988 in Lissabon kritisierte er, daß die Literatur der Dritten Welle durch Dogmatismus, Moralisierung und Fixierung auf die Sowjetunion erstarrt sei. ${ }^{76}$ Im Rahmen der allgemeinen Aufarbeitung der Emigrantenliteratur sowie einer konseguenten Entpolitisierung und Entideologisierung müsse den Individualisten in der russi-

nicht nur mittels offener Repression, sondern auch indirekt die künstlerische Entfaltung einzelner Schriftsteller beeinträchtigt oder verhindert habe, indem es eine bestimmte "Atmosphäre" geschaffen habe (a.a.0., s. 17).

13 Matich, "Is there ...", The Third Wave, hg. Matich $u$. Heim, a.a.O., S. 184-185.

14 S. V. Aḱsënov, "Lučšee sostajanie literatury - èmigracija" ("Der beste zustand der Literatur ist die Emigration"), Sem' dnej, Nr. 50, 1984, S. 20-24. - Den meisten Erfolg hatte Aksënov mit Ostrov Krym (1981) und Oźog $(1980)$.

vgl. diesbezüglich den genannten Aufsatz von Aksënov (Sjataksis, Nr. Il, 1983, S.167-187).

Z. Zinik, "Silence, Exile \& Glasnost: A Bilingual Minority", The Encounter (London), Bd. 74, H. 5, Juni 1990, S. 70. (Russischer Originaltext: "Dvujazycnoe men'śinstvo", Sintaksis, Nr. 22, 1988, S. 185-198.) 
schen Literatur endlich der rechtmäBige platz eingeräumt werden :

"During this new period, possibly one of the most liberal in Russian letters, we must rehabilitate not only certain specific names, but whole layers of literary and colloquial speech. We must be ready to accept outsiders and outcasts [...]" 77

\subsection{Beispiele für die Unsetzung der Bigration}

Prinzipiell stehen in der "neuen Prosa", die im vorhergehenden Abschnitt angesprochen wurde, die Helden als Individuum mit ihren Gedanken, Gefühlen und Nöten im Mittelpunkt. 78 Die Darstellung wird durch ein psychologisches Interesse motiviert. Insbesondere bei Limonov, Aksënov und $\mathrm{zinik}$ treten die Hauptfiguren auch als russische Emigranten auf, so daß die Autoren jeweils inre eigene Emigration und inre Erfahrungen in westen direkt literarisch verarbeiten. Die drei Autoren lassen sich in dieser Hinsicht miteinander vergleichen, weshalb im folgenden kurz einige Werke genannt werden.

Limonovs Held und Ich-Erzähler Eddie in Eto ja Édička zum Beispiel ist wie der Autor aus der Sowjetunion in die USA ausgewandert. Dort stürzt Eddie jedoch in eine Existenzkrise, aus der heraus er hemmungslos seine Verachtung für die Amerikaner und inren way of life artikuliert. Entgegen aller Emigranten-stereotypen präsentiert er sich mit seinem Heimweh als Linker. Zusammen mit der extensiven und bewußt provokativen Darstellung anrüchigen Sexualverhaltens löste der Roman deshalb einen Skandal aus und verschaffte dem Autor das Image des pro-sowjetischen enfant terrible. ${ }^{79}$ Diese literarische Gestaltung des Emigrantenda-

77 Zinik, "silence, ...", a.a.0., s. 71.

78 Die Beschäftigung mit allgemein-menschlichen Problemen war in der offiziellen Sowjetliteratur stets unzulässig und nur in der Emigranten- oder Untergrundliteratur möglich (vgl. Wolfgang Kasack, Russian Literature .... a.g.0.. S. 106).

79 zusammenfassung der Urteile in Robert Porters Aufsatz "Eduard Limonov and the Benefit of the Doubt", Under Eastern Eyes, hg. McMillin, a.a.0., S. 62-63. Zum Roman s. 
seins erhielt in Dnevnik neudačnika, ili Sekretnaja tetrad' (1982) eine Fortsetzung, da dieser Roman viele Parallelen zu Éto ja - Édička aufweist. Ein weiterer Roman, Palać (1986), veranschaulicht die Identitätsprobleme eines Einwanderers anhand der Geschichte eines Polen in den USA. Sie schildert, wie sein Versuch, sich $2 u$ integrieren und so ein neues Leben $z u$ beginnen, letztlich fehlschlägt. 80

In den Romanen von Vasilij Aksënov, die nach seiner Auswanderung entstanden, spiegeln sich seine eigenen Erlebnisse, Enttäuschungen und Ansichten wider, indem sie teilweise über einen autobiographischen Hintergrund verfügen. Bumažnyj pejzaž (1983), Skaži izium (1985) und $V$ poiskach grustnogo bebi (1987) zeigen jeweils die Konfrontation des russischen Helden mit der westlichen Realität, spielen aber auch in der Sowjetunion, so daB beide welten kontrastiert werden. Dabei vermittelt Aksënov im Gegensatz zu Limonov eine eher positive Einschätzung seiner zweiten Heimat, oder mit den worten von Arnold McMillin ausgedrückt: "a lively, revealing, and, above all, balanced picture". 81

Bei beiden Autoren gibt es somit thematische Parallelen zu ziniks Werk, in denen die Hauptfiguren grundsätzlich sowjetische Emigranten sind und Probleme haben, sich im Westen, in diesem Fall in Grobbritannien einzuleben. Inr Scheitern verbindet sie bis $z u$ einem gewissen Grad mit

darüber hinaus u.a. Olga Matich, "The Moral Immoralist: Edward Limonov's "Éto ja - Edicka'", Slavic and East European Journal, Bd. 30, H. 4, Winter 1986, S. 526-540; Patricia Carden, "Limonov's Coming Out", The Third wave, hg. Matich u. Heim, a.a.0., S. 221-233. Die Herausgeberin olga Matich weist darauf $h i n$, daß die narrative struktur in Limonovs Werken durchaus realistisch sei und erst die darin ausgedrückte Einstellung eine kluft zum Lager der konservativ gesinnten Realisten öffne (S. 184-185). Der Fall bestätigt die Dominanz ideologischer und inhaltlicher Kriterien in der Literatur der Dritten Welle.

${ }_{80} \mathrm{zu}$ den beiden letztgenannten Romanen s. Porter, a. a.0.. S. 62-75.

81 A. McMillin, "Western Life as Reflected in Aksenov's work before and after Exile", Under Eastern Eyes, hg. ders., a.a.0., s. 60. In dem Aufsatz analysiert McMillin die genannten Romane (S. 50-61). 
Limonovs Helden. Als Beispiele seien bereits vorweg die Romane Russkaja služba (1983) und Russofobka i fungofil (1984; engl. The Mushroom-Picker; 1987) genannt, die ebenso wie Aksënovs Werke auch teilweise in die Sowjetunion zurückblicken. Bei der Darstellung Englands offenbart Zinik kritisch die Schwächen dieser Gesellschaft, doch das Bild, das er in teilweise satirischer übertreibung zeichnet, ist nicht absolut widerwärtig wie das Amerikas bei Limonov.

Die angeführten Romane sind narrativ fixierte Versuche einer individuellen selbstbestimmung im kulturellen zwischenraum und belegen die Auseinandersetzung mit der Welt, in der sich die Autoren wiederfinden. Die Neuartigkeit dieser Thematik in der russischen Emigrantenliteratur betonte auch Il'ja Serman bei einer Konferenz 1989:

"Проблема самопознания в условиях жизни свободного мира ещё только начинает разрабатываться эмигрантской прозой."

("Das Problem des Selbstverständnisses unter den Bedingungen des Lebens in Freiheit steht erst am Anfang seiner Verarbeitung durch die Prosa der Emigranten." 82

Für pioniere in dieser Richtung hält Serman ebenfalls Limonov und Zinik sowie Jurij Miloslavskij, der seit 1973 in Jerusalem lebt und die situation der sowjetischen Einwanderer in Israel literarisch festgehalten hat. Diese und andere Autoren thematisieren die orientierungsschwierigkeiten, die mit dem Gewinn der Freiheit verbunden sind, und setzen dadurch diese Freiheit zugleich kreativ um. Der literarische Text bildet das Medium, in dem sich das neue Ich manifestiert. Die Hinwendung zum westen ist ebenfalls im Kontext des strebens nach Selbsterkenntnis zu sehen, und zwar in Sermans Worten als "Selbstprüfung im neuen Leben" ("samoproverka èmigrantov $v$ novoj žizni"). ${ }^{83}$

82 I. Serman, "Puti samopoznanija $v$ uslovijach svobody: Russkaja èmigrantskaja proza 1975-1985", Manuskript des deutschen Beitrags zur Konferenz der ICSEES über die Literatur der Dritten welle in Washington D.C., 1989, S. 14 .

83 serman, a.a.0., S. 10 . 
Auf der stilistischen Ebene kennzeichnet die "neue Prosa" allgemein die Verwendung von Umgangssprache und Vulgärausdrücken (mat), wofür wiederum Limonov, aber auch Aksënov und Zinik hinreichend Beispiele bieten. Ein weiteres Merkmal sind die deutlichen Einflüsse der Fremdsprache, in denen sich bei innen und vergleichbaren Autoren die Konfrontation mit der fremden Kultur äußert. 84 Eingeschobene fremdsprachige Elemente, aber auch Barbarismen, Neologismen und sprachdeformationen sind nach einem Aufsatz von Il'ja Levin typische Verfahren eines "spezifischen Emigrantenstils", um den standpunkt des Helden zwischen der eigenen und der fremden Kultur anzuzeigen.85 Dieser Faktor stellt gleichzeitig eine Innovation in der Literatur der Dritten Welle dar.

Levin bewertet $\dot{E}$ to ja - $\dot{E} d i c k k a$ aufgrund der aufgeführten Verfahren als erstes Werk der Dritten welle, in dem das Thema der Emigration seine adäquate sprachliche Gestaltung gefunden habe. ${ }^{86}$ Limonov verwendet unter anderem in der Figurenrede die übliche Umgangssprache der in den

84 S. V.a. Arnold McMillin, "Bilingualism and Word Play in the Work of Russian Writers of the Third wave of Emigration: The Heritage of Nabokov", The Modern Language Review (London), Bd. 89, H. 2, April 1994, S. 417-426. Die Studie behandelt die vielfältige Präsenz des Englischen bei Aksënov, Zinik und Brodskij. Erwähnt werden auBerdem die Erzähler Juz Aleškovskij und vladimir Matlin; die Lyriker Aleksej Cvetkov und Lev Loseff stellt McMillin als "beinahe zweisprachig" vor. - Einen Überblick darüber, wie weit Experimente mit Englisch, Französisch oder Hebräisch in der Literatur der Dritten welle verbreitet sind und welche Schriftsteller zumindest teilweise in der Fremdsprache arbeiten, gibt auch Elizabeth Klosty Beaujour in Alien Tongues: Bilingual kussian Writers of the "First" Emigration, Ithaca u. London, 1989, S. 158-159.

85 I. Levin, "Ob évolucii i iteraturnogo jazyka $v$ emigracil", The Third Wave, hg. Matich u. Heim, a.a.0., S. 263 . - Grundsätzlich sind diesbezüglich verschiedene Techniken in der Literatur der Dritten Welle $\mathrm{zu}$ beobachten, darunter die wörtliche übersetzung von Konstruktionen in die eigene Sprache mit dem Effekt syntaktischer Verzerrungen, die Einfügung unübersetzter Ausdrücke als "Fremdkörper" mit einer Kontrastfunktion, die wiedergabe von Dialogausschnitten in der Fremdsprache oder Wortspiele mit Entlehnungen. Vgl. V. Moskovic in "Zametki o jazyke literatury russkogo zarubežja", Russian Philology and History: In Honour of Professor Victor Levin, Jerusalem, 1992, S. 129.

86 Levin, a.a.0., S. 268. 
USA lebenden Russen mit eingestreuten amerikanischen slang-Ausdrücken. Diese vergegenwärtigen die situation des betreffenden Helden in der fremden Umgebung und zeugen andererseits von seiner Weigerung, den Mustern der konservativen Emigranten $z u$ entsprechen. So kommt ein doppeltes AuBenseitertum zum Ausdruck. ${ }^{87}$ Vasilij Aksënov bezog englische Elemente bereits ein, als er noch in der Sowjetunion lebte, und entwickelte dieses stilmittel nach der Emigration weiter. Amerikanische vokabeln treten bei inm wörtlich übersetzt oder russifiziert auf, sind also stärker in die russische Rede eingegliedert als bei Limonov. ${ }^{88}$ In $\mathrm{Zi}-$ niks Prosa wird das Englische in vielerlei Funktionen wirksam, die in der Textanalyse gesondert aufgeschlüsselt werden. In den ersten Romanen aus seiner zeit in Israel zeigen sich gleichermaßen Spuren des Hebräischen; dies gilt zudem für die Werke von Jurij Miloslavskij und vladimir Lazaris. ${ }^{89}$

Das Beispiel der fremdsprachigen Einflüsse veranschaulicht, daß die Emigration und die so errungene künstlerische Freiheit nicht nur inhaltlich, sondern auch sprachlich einen schöpferischen Impetus bedeuten können. Innerhalb der Dritten welle heben sich einige Autoren in dieser Hinsicht durch virtuosität hervor, freilich mit stilistischen Unterschieden. Insgesamt gesehen handelt es sich um ein charakteristisches Merkmal derjenigen russischen Literatur der Gegenwart, die sich im Ausland herausgebildet und entwickelt hat. $\mathrm{zu}$ diesem Aspekt sei auf das Slavic and East European Journal hingewiesen, das in einem Sonderforum Limonov und Aksënov in eine Reihe mit Saša Sokolov stellt. Dieser Meister der experimentellen prosa hat sein Talent erst in den vereinigten staaten entfaltet. Ferner werden die Lyriker Aleksej Cvetkov und Iosif Brodskij einbezogen. 90

$87 \mathrm{Vgl}$ E. Brown, "Russian Literature beyond ...", a.a. O. S. 382 .

88. MCMillin, "Bilingualism...", a.a.o., S. 422-423.

89 S. Moskovic, a.a.0., S. 130-134.

90 "forum: The Third' Wave", SEEJ, Bd. 30, H. 3, Fall 1986, S. 380-419; H. 4, Winter 1986, S. 509-552. - Zur Einordnung von Cvetkov: Seine Gedichte können als Avantgarde bezeichnet werden, während die Lyrik der Dritten 
Brodskij soll hier zum SchluB noch besonders erwähnt werden, obwohl er mit den zuvor genannten prosaikern auBer der zugehörigkeit zur gleichen Generation (Geburtsjahr 1940) wenig gemein hat und für das Porträt von zinik kaum relevant ist. Er ist aber im zusammenhang mit der Frage nach der Umsetzung der Emigration interessant, weil die Erfahrung seines Exils in den USA ebenfalls in seine Gedichte eingeflossen ist.91 Darüber hinaus verbindet Brodskij aber Elemente beider Kulturen und schafft aus inrer synthese eine eigene welt, das heiBt, er erhebt sich quasi über die situation des Exulanten. Damit bildet er eine Ausnahmeerscheinung innerhalb der Dritten welle, zumal er auch als einziger einen sprachwechsel vollzogen nat. 92

Welle meist eher traditionell in Form und stil ist (2.B. Naujm Koržavin, Natali ja Gorbanevskaja).

91 S. Z.B. Lev Loseff, "Home and Abroad in the works of Brodskil", Under Eastern Eyes, hg. McMillin, a.a.O., s. 25-41; Valentina Polukhina, "The Self in Exile", Renaissance and Modern Studies, Bd. 34,1991, S. 9-18.

92 S. seine Essaysammlung Less Than One: Selected Essays, New York, 1986. 


\section{RUSSISCHE AUTOREN IN ENGLAND}

\subsection{Grobbritannien als Aufnahmeland}

In der Geschichte der russischen Emigration war GroBbritannien für Künstler und Schriftsteller als Aufnahmeland nie von Bedeutung, wohl aber zeitweise für andere Gruppen. So fanden im 19. Jahrhundert eine Reihe berühmter Revolutionäre in London Asyl, darunter Aleksandr Gercen (Herzen), der zuvor auch dichterische Werke geschrieben hatte, sowie der Anarchist Michail Bakunin, Pjotr Fürst Kropotkin und nicht zuletzt vladimir Il'ic Uljanov alias Lenin.93 Von 1905 bis 1917 strömten Juden auf der Flucht vor Pogromen nach England, und zwar im Rahmen der vorrevolutionären Auswanderungswelle aus dem Zarenreich, die sowohl religiös als auch politisch motiviert war. Die jüdischen Einwanderer wurden in London, Manchester, Leeds und Liverpool seBhaft. ${ }^{94}$

Nach der Revolution und dem Bürgerkrieg gelangte gemessen am Gesamtumfang dieser Ersten Emigration aus SowjetruBland nur ein kleiner Teil auf die britischen Inseln. Laut statistik lebten 1922 dort 8000 bis 10000 der 620000 bis 740000 Russen, die inr Land bis dahin verlassen hatten; 1927 waren es von rund 920000 schätzungsweise nur 3000, gegenüber 400000 in Frankreich und 150000 in Deutschland. 95 Für die zweite welle liegen in der verwendeten Literatur keine einschlägigen Belege vor. Allgemein ist festzustellen, $d a B$ die Einwanderung aus osteuropa ins-

93 s. U.a. Tabori, a.a.o., S. 123-128.

94 S. Tabori, a.a.o., S. i77-179.

$95 \mathrm{~S}$. Raeff, "La culture russe ...", a.a.0.. S. 859-860; Glenny u. Stone, a.a.0., S. xvi-xvii. Michael Marrus veranschlagt die zahl der Russen in Grobbritannien nach dem Ersten Weltkrieg auf 15000 (The Unwanted: European Refugees in the Twentieth Century, New York and oxford, 1985, S. 149). - Einen Eindruck von der Situation der russischen Emigranten in England zwischen den Weltkriegen vermittelt Pjotr Petrovic Sidlovskij in "Here is Imperial Russia ...". The other Russia, hq. Glenny u. Stone, a.a.o., S. 289-297. 
gesamt während und kurz nach dem zweiten weltkrieg erheblich zunahm. 96

Mit der Dritten welle kamen nur einige Hunderte nach Großbritannien: Von 1975 bis 1980 gewährten die Behörden jährlich maximal 60 sowjetischen staatsbürgern die Erlaubnis, sich niederzulassen. ${ }^{97}$ Im Gegensatz zu den Emigranten in Frankreich und den vereinigten staaten fanden die Aufgenommenen keine Institutionen vor, die russische Einwanderer vor ihnen aufgebaut hatten. Selbst in London fehlten seit jeher Einrichtungen für ein russisches Kulturleben, abgesehen von den beiden russisch-orthodoxen Kirchen. ${ }^{98}$ sie zogen jedoch nur vereinzelt Angehörige der Dritten Welle an, da die meisten Juden waren.

Um eigene Zeitschriften oder Verlage $z u$ gründen, war die Gemeinschaft der russischen Intellektuellen in England stets $z u$ klein und $z u$ heterogen. Als einzige Emigrantenzeitschrift in den vergangenen Jahrzehnten erschien 1976 und 1977 Dvadcatyj vek. Sie enthielt politische und literarische Beiträge, die zuvor das gleichnamige Samizdat-organ in Moskau unter Roj A. Medvedev veröffentlicht hatte. Die Hefte in London gab dessen Bruder Žores heraus. 99 Beide

96 Die Polen bildeten dabei mit Abstand die Mehrheit. S. peter P. Burnett von der Bodleian Library, Oxford, in "East European Emigré Publications in Great Britain", Proceedings of the second International conference of Slavic Librarians and Information specialists, hg. Marianna Tax Choldin, New York, 1986, S. 192-193.

"Table 14 (b) Total acceptances for settlement on arrival and on removal of time limit by nationality Foreign nationals", Control of Immigration statistics, United Kingdom, CM 8533, 1981.

98 Im einzelnen handelt es sich um die russisch-orthodoxe Kirche in Ennismore Gardens und die russisch-orthodoxe Exilkirche in Emperor's Gate, die sich im Gegensatz zur ersten vom Moskauer Patriarchen lossagte. Den Zwist zwischen beiden schildert olga Petrovna Lawrence, die als Kind in den 20er Jahren nach England kam, in "Getting by in England", The other Russia, hg. Glenny u. Stone, a.a.0. S. 300. Zum Leben der Russen, die sich nach der Revolution in London ansiedelten, und $z u$ ihrer heutigen Situation s. auch die Reportage von Beryl Downing "Retreat from Moscow" in der Londoner Tageszeitung The standard, $4 \cdot \frac{1}{69} 1.1987$.

99 Dvadcatyj vek: Obśćestvenno-politićeskij i literaturnyj al'manach, red. Roj A. Medvedev i Raisa Lert, London: T.C.D. Publications, 1976. 
gehörten allerdings unter den Samizdat-Aktivisten und russischen Emigranten zur Minderheit der Marxisten und Sozialisten. 100 Im Bereich des Verlagswesens war lediglich "Overseas Publications Interchange" in London für die Publikation von russischsprachigen sowie in der Sowjetunion verbotenen und zensierten Texten bedeutsam. 101 Das 1966 gegründete Unternehmen existiert inzwischen nicht mehr.

Bei den etablierten Emigrantenverlagen in Paris und New York konnten unbekannte, junge, unkonventionelle und überdies jüdische Autoren wie Zinovij zinik und Igor' Pomerancev kaum damit rechnen, unterstüzung $2 u$ finden. Deshalb gründeten beide zusammen mit drei anderen Teilhabern den Selbstverlag "Russian Roulette Press", um von Pomerancev eine sammlung von sujetlosen, stilistisch virtuosen Erzählungen unter dem Titel $A I^{\prime}$ by $i$ serenady und von $z i n i k$ den Roman Russofobka i fungofil herauszugeben. 102 In den Ausgaben wird als Erscheinungsjahr 1985 b2w. 1986 genannt, tatsächlich waren die Titel erst 1987 auf dem Markt. 103 später folgte allerdings entgegen den ursprünglichen Plänen nur noch der philosophische Roman Filosofija odnogo pereulkal04 von Aleksandr Pjatigorskij (1989).

100 S. Alekseeva, a.a.0., S. 240-241.

101 Nähere Angaben bei Burnett, a.a.0., s. 198. Der Verlag setzte den Schwerpunkt auf Politik, Geschichte, Kultur und zeitgeschichte und veröffentilichte Bücher zu entsprechenden Themen von westeuropäischen, amerikanischen und russischen verfassern, ferner Belletristik zeitgenössischer Exilautoren und moderne Klassiker. Von den vertretern der Dritten Welle in England wurden Irina Ratušinskaja, vladimir Bukovskij und viktor Suvorov, die an späterer stelle noch vorgestellt werden, ins programm aufgenommen.

102 S. Ziniks Erläuterungen im persönlichen Gespräch, Anhang, S. 185 .

Pressenotizen $2 u$ "Russian Roulette": Elizabeth Writer, "Russian Roulette", The Times Literary Supplement, H. 4387, 1.5.1987, S. 462: James Campbell, "Vodka on the Lawn", The Observer, 17.1.1988, S. 25; "Opening Shots", The Daily Telegraph, 20.4.1987, S. 15. Selbstverlage sind ein typisches Merkmal der Dritten welle laut Henry, a. a 0 . $\mathrm{S}$. 118 .

Voller Titel: Filosofija odnogo pereulka, ili Istorija eśë ne okoncennoj zizni odnogo russkogo filosofa, rasskazannaja avtorom, a także nekotorymi drugimi, bolee ili menee russkimi filosofami. 
Anders als in Frankreich, Israel, Deutschland und den USA, wo viele russische Exulanten publizistisch tätig waren, gab es in Grobbritannien allein beim "Russian service" der BBC die Möglichkeit, in der eigenen sprache zu arbeiten, wenn man von übersetzungsaufgaben absieht. Die Anstellung erforderte in erster Linie ausreichende Englischkenntnisse, so daB die Mitarbeiter ursprünglich aus verschiedenen Berufsrichtungen kommen. Auch wenn der gemeinsame Arbeitsplatz kein geistiges zentrum ersetzen konnte, fungierte die $B B C$ in den 70er und 80er Jahren als eine Art Sammelpunkt jener Emigranten, die sich mit Literatur beschäftigten oder selbst literarische Texte verfaBten. 105

Neben Zinik kann hier der inm literarisch wie persönlich nahestehende prosaiker und Lyriker Igor' Pomerancev genannt werden. Er emigrierte $1978 \mathrm{mit} 30$ Jahren und lebt inzwischen in München. Seine Kurzprosa, Essays und Gedichte wurden vor allem in sintaksis und Vremja $i$ my abgedruckt. Außerdem übersetzte Pomerancev für die BBC Samuel Beckett, Harold Pinter und andere moderne Klassiker der anglo-amerikanischen Literatur ins Russische. 106 Aleksandr Donde, verantwortlich für das Ressort "Russian Features", nat unter dem Pseudonym Kustarëv seinen Roman Raznoglasie $i$ bor'ba (1990) sowie Kurzgeschichten, Essays und Rezensionen in den Zeitschriften sintaksis und Lvadcat' dva veröffentlicht. Der Dichter Jurij Kolker, in seinem Schaffen klassisch orientiert, arbeitete vier Jahre lang bei der BBC. Zudem soll an dieser Stelle die Literaturexpertin Natalija Rubinštejn erwähnt werden.

Viele Redakteure des russischsprachigen Dienstes sind erst auf ein konkretes Vertragsangebot hin ins Land gekommen. Zinik, Kolker und der übersetzer Georgij Ben beispielsweise wurden in Israel angeworben. Der langjährige

$105 \mathrm{Vgl}$. Sabine Durrants Reportage über diese Funktion des "BBC world Service" mit dem Titel "Dissident Voices, Literary Lives" in The Independent, 26.11.1993, S. 23.

106 Die literarischen Einflüsse in seiner Jugend, seine Verhaftung und sein Literaturverständnis erklärt Pomerancev in "The Right to Read", Partisan Review, Bd. 49, H. 1, 1982 , S. 54-67. 
Leiter der "Features"-Abteilung und Kontinent-Autor Leonid Finkelstein wechselte 1979 von "Radio Liberty" in München zur BBC. Er hatte sich bereits 1966 in GroBbritannien abgesetzt und zunächst als Korrespondent für "Radio Liberty" gearbeitet. $107 \mathrm{zu}$ den ersten der Dritten welle in London gehörte auBerdem der Erzähler Anatolij Kuznecov: Er bat 1969 um politisches Asyl. 108

Andere russische Intellektuelle folgten der Einladung einer Universität. Der Philosoph, Semiotiker, Indologe und Experte für Religionsgeschichte Aleksandr Pjatigorskij109 lehrte von 1975 bis 1994 an der "School of oriental and African Studies" der University of London. Vladimir visnjak, Journalist und Essayist, wanderte ursprünglich nach Israel aus und übernahm dann eine stelle an der Manchester University. Die Aufnahme in England setzte in der Regel den Nachweis einer Einkommensquelle voraus - ein wichtiger Grund, warum die Dritte Welle nur bestimmte Personen dorthin brachte.

Die Literatur der russischen Einwanderer wurde in Großbritannien nur in geringem Maß rezipiert, zumal der Markt traditionell mit Werken aus dem groBen anglo-amerikanischen sprachraum gesättigt ist und übersetzte Literatur in eine Nebenrolle drängt. Am meisten Aufmerksamkeit in der britischen öffentlichkeit erhielten vladimir Bukovskij, ein führender vertreter der Dissidentenbewegung, 110 und die Menschenrechtlerin Irina Ratusinskaja, 111

107 S. dazu sein eigener Bericht "Speaking the Truth" in The other Russia, hg. Glenny u. Stone, a.a.0., S. 422-426. Finkelstein hat zum Teil unter seinem vatersnamen vladimirov veröf fentlicht.

108 Ein Jahr später kam sein Roman Babij Jar heraus, der die Greueltaten der SS und des NKWD in Kiev schildert. Kuznecov starb 1979 in London.

109 Pjatigorskij (geboren 1929) war vor seiner Ausreise 1974 Dozent an der Moskauer Universität und anschlieBend Mitglied der "Tartuer Schule" um Jurij Lotman, die die Grundlagen für eine neue semiotik entwickelte.

110 Bukovskij (geboren 1942) wurde zweimal in einer Psychiatrie zwangshospitalisiert, mit drei Jahren Arbeitslager bestraft und 1971 abermals 2412 Jahren Freiheitsentzug verurteilt. $1976 \mathrm{kam}$ er im Austausch gegen den chilenischen KP-Führer Luis Corvalan frei. Nach Aufenthalten 
die als freie Autoren in Cambridge bzw. London leben. Mit ihren autobiographischen Büchern, in denen sie ihre Erfahrungen als Oppositionelle und Häftlinge in der Sowjetunion schildern, hatten sie großen Erfolg: Die Titel wurden in etliche sprachen übersetzt, mehrfach aufgelegt und weltweit in zeitungen und Fachzeitschriften rezensiert. 112 Es handelt sich um typische Beispiele der damals aktuellen Dissidentenliteratur.

Bukovskij verfolgte mit seiner regen publizistischen Tätigkeit (bislang acht Bücher und zahllose Artikel in der westlichen Presse, aber keine fiktive Literatur) stets den Zweck, über die Sowjetunion aufzuklären und auf die westliche Politik einzuwirken. Er veröffentlichte kaum in russischer Sprache und war grundsätzlich auf den westlichen Leser ausgerichtet, also in dem sinn kein Emigrantenautor. Für Ratušinskaja ist inre Lyrik keine politische waffe, sondern Selbstausdruck. 113 Die Gedichte sind meditativ, metaphysisch und geprägt vom russisch-orthodoxen Glauben. sie spiegeln seelische Vorgänge und tiefe Gefühle wider.114

in der Schweiz, Cambridge und den USA lieB er sich 1987 in Cambridge nieder.

Ratuśinskaja engagierte sich ebenfalls gegen das sowjetische Regime. Wegen inrer Gedichte wurde sie 1983 mit 29 Jahren $2 \mathrm{u} 12$ Jahren Arbeitslager und inneres Exil verurteilt. Dank diplomatischer vermittlung durfte sie 1986 nach Großbritannien ausreisen.

112 Von Bukovskij wurden vor allem To Build a Castle: My Life as a Dissenter (1978) und Cette lancinante douleur de la liberte (1981) Bestseller. Letzteres stellt die Gesellschaften in ost und west kritisch gegenüber und enthält auch eine Passage über die nationalen Eigenheiten der Engländer mit dem Titel "Eindruck eines sinkenden Schiffes: liebenswertes Großbritannien" (Dieser stechende Schmerz der Freiheit: Russischer Traum und westliche Realitat, Stuttgart, 1983, S. 136-147). Die darin zusammengefaßten Eindrücke haben allerdings teilweise den charakter von Pauschalurteilen und Klischees. - Von Ratušinskaja erschienen neben diversen Lyrikbänden das Buch Grey is the Colour of Hope (1988) über inre Jahre im Arbeitslager und die Autobiographie In the Beginning (1990).

$113 \mathrm{Vgl}$. Interview in der Komsomolskaja pravda, 4.3.1990, $\mathrm{S} \cdot 114^{3}$

$114^{\circ}$ S. 2.B. Raymond Cooke, "The Poetry of Irina Ratushinskaya", Journal of Russian Studies, Bd. 53, 1987, S. 4855. Zur Einordnung innerhalb der russischen Emiqrantenliteratur s. auch $\mathrm{Zajcev,} \mathrm{a.a.0.,} \mathrm{S.} 7 \mathrm{u} .12$. 
Vollkommen isoliert ist viktor Suvorov. Der ehemalige sowjetische spion lebt unter falschem Namen auf einer Militärbasis; den genauen ort hält er nach wie vor geheim. Seine acht Bücher, die Einblicke in die Rote Armee und den sowjetischen sicherheitsapparat geben bzw. sich mit dem Zweiten Weltkrieg beschäftigen, waren bislang besonders in Deutschland gefragt. 115

Die russischen Schriftsteller, die während des Kalten Krieges nach England gelangten, 116 blieben uber persönliche Freundschaften hinaus weitgehend voneinander unabhängig. Um sich in zirkeln zusammenzuschlieBen, waren sie ohnehin $\mathrm{zu}$ wenige. Im Rahmen der Dritten welle waren sie die AuBenseiter der AuBenseiter, denn wie alle Einwanderer befanden sie sich sowohl hinsichtlich der Heimat als auch der Gesellschaft des Aufnahmelandes in einer Randposition, darüber hinaus aber auch abseits der traditionellen zentren der russischen Emigration. Bezeichnend für ihre individualistische Haltung ist, daB die Engländer von ihnen im allgemeinen als besonders tolerant geschätzt werden. In persönlichen Gesprächen bestätigten einige Vertreter der Dritten Welle die folgende Aussage von Professor Alexander Kennaway, der bereits in den 20er Jahren als Kind ins Land kam:

"I think that, like a lot of Russians, England represents to me a country in which it is nowadays easy to live because the English leave you alone to be yourself - they don't force you to be someone else $[\ldots]^{1117}$

Die traditionell groBe Achtung der Privatsphäre erlaubt die persönliche Entfaltung und die Wahrung der eigenen Identität. Gleichzeitig waren die Russen in London und ganz England eher als ihre Landsleute etwa in New York oder Paris gezwungen und geneigt, sich äußerlich in die

115 Suvorovs erfolgreichster Titel Der Eisbrecher: Hitler in Stalins Kalkul erschien 1994 in stuttgart in der 8 . Auflage.

Ilf Die Angaben in diesem Abschnitt stützen sich hauptsächlich auf eigene Recherchen vor ort und die Kurzporträts in Free voices .... hg. Stevanovich u. Wertsman, a. IIj 0 . Kennaway, "Living with the English", The other Russia, hg. Glenny u. Stone, a.a.O., s. 319. 
fremde Gesellschaft einzufinden, eben weil die russische Minderheit hier kleiner ist und über keine eigenen Institutionen verfügt. Erleichtert wurde der ProzeB den meisten dadurch, daB sie schon bei der Ankunft die Sprache beherrschten. Dies gilt auch für zinovij Zinik. Er entschied sich bewußt für das Leben auf der Insel, weil es den russischen Einwanderer in Konfrontation mit der fremden Kultur auf sich stellt und Zinik diese Bedingungen als Person und als schriftsteller entgegenkamen. 118

\subsection{Die Verarbeitung der Emigration}

Von den Schriftstellern der Dritten Welle in England setzt sich niemand so intensiv mit dem Land und der Kultur sowie der eigenen Identität als Emigrant auseinander wie Zinovij Zinik.119 Die anderen, etwa Bukovskij, Suvorov, Donde oder Finkelstein, haben kein entsprechendes Interesse und konzentrieren sich thematisch hauptsächlich auf RuBland. Auch in der Lyrik von Irina Ratušinskaja hat ihr Leben in England keinen direkten Niederschlag gefunden. 120

Filosofija odnogo pereulka, der bislang einzige Roman von Aleksandr Pjatigorskij, spielt zwar zum Teil in England, wobei die Plätze konkret benannt werden.121 Inhalt-

118 In einem Gespräch mit Petr Vajl' und Aleksandr Genis für die in Los Angeles erscheinende Emigrantenzeitschrift Panorama (27.3.-3.4.1987, S. 18-20) beschreibt Zinik die Situation der sowjetischen Emigranten in GroBbritannien. Seiner Meinung nach bildeten sie auch deshalb keine 2irkel, weil sie sich der englischen Tendenz zur selbstisolation angepaßt hätten.

119 England hat als Thema auch keine Tradition in der russischen Emigrantenliteratur. Gerald Stanton Smith hat dies im Bereich der Lyrik genauer recherchiert. Erwartungsgemäß fand er nur sehr vereinzelte Werkbeispiele der wenigen russischen Dichter, die zwischen den 20er Jahren und heute in England vorübergehend oder ständig lebten. Brodskijs Gedichtzyklus "V Anglii" ("In England"), den Smith analysiert, fällt somit aus der Reihe. S. "England in Russian Emigré Poetry: Iosif Brodskii's 'V Anglii'", Under Eastern Eyes, hg. McMillin, a.a.0., S. 17-24.

120 Im Interview mit der Komsomolskaja pravda (a.a.o.) beschreibt die Lyrikerin auch ihr Verhältnis zu England.

12l Pjatigorskij, Filosofija ...., Moskau, 1992, S. 79, 107 u.a. - Der Autor arbeitet nach eigenen Angaben derzeit 
lich geht es jedoch um andere Themen. Das Buch erzählt die authentische Geschichte von ein paar russischen Freunden, die gemeinsam in Moskau aufwachsen und von denen zwei der Ich-Erzähler und die Hauptfigur - sich zum SchluB in England wiedertreffen. Eine kette von Rückblicken rekonstruiert wie ein Mosaik die allmähliche Herausbildung philosophischer Erkenntnisse und den ProzeB der subjektiven BewuBtwerdung in Begegnungen, Gesfrächen und Briefen.122 Die Emigration erscheint in diesem Verlauf als äuBere Lebensveränderung und wird auch reflektiert. ${ }^{123}$ sie markiert aber nicht, wie in ziniks Prosa, einen ausschlaggebenden Faktor oder Einschnitt in der inneren und geistigen Entwicklung der Personen, sondern lediglich eine weitere Etappe.

Nur Igor' Pomerancev hat sich in ähnlicher weise wie zinik, obgleich weniger ausgiebig, mit seinem Aufnahmeland und seinem Emigrantenstatus beschäftigt. Zum einen behandelt er konkrete Aspekte der englischen Kultur und Geschichte, so daß er eine vermittlerfunktion übernimmt. So führt die Erzăhlung "Muzej anglijskogo detstva, ili Ja nenavižu syna"l24 den Leser durch das Londoner spielzeugmuseum und verfolgt in diesem Rahmen zugleich die Erziehungsmethoden in England durch die Jahrhunderte. Der feuilletonistische Aufsatz "Bez vetki persika" wiederum stellt Beobachtungen zur Reklame im heutigen GroBbritannien zusammen. 125

Darüber hinaus abstrahiert Pomerancev die Erfahrung der Emigration. In der sujetlosen Erzählung "...Moja ro-

an einem zweiten Roman mit den Schauplätzen Moskau, Petersburg und London, der auf einer wahren Lebensgeschichte beruht.

122 S. die Rezension in Novyj mir, Nr. 10, Okt. 1993, S. 251-252. - zum realen Hintergrund $s$. das Interview mit dem Autor "Ja - čelovek nikakoj kul'tury", Nezavisimaja gazeta, 1.6.1993, S. 5 .

123 Z.B. wird das Verhältnis von Freiheit und der Bindung zur Heimat angesprochen (S. 116).

124 Pomerancev, "Muzej anglijskogo detstva ...", Oktjabr', Nr. 2, Feb. 1994, S. 85-91.

125 Pomerancev, "Bez vetki persika", Literaturnaja gazeta, 17.6.1992, S. 5 . 
dina odinočestvo"l26 beispielsweise wird das Alleinsein in einem fremden Land zur Metapher für das Wesen des Dichtens. Der Geschichte zufolge muB sich der Poet erst von der überdeterminierten sprache, in der er beheimatet ist, gleichsam losreiBen, um eigene worte finden zu können:

"Дома мне мешали чужие слова. Мой мозг жил вне законов трения и притяжения. Едва ли не каждое слово, услышанное или увиденное, вызывало во мне обвалы, лавины. [...] Измотав в конец, меня выбросило на берег, на сушу, на твёрдую почву. Теперь я отчётливо вижу, словно на карте звёздного неба, холодные раскалённые слова, связанные во времени и пространстве."

("Back home, other people's words got in my way. My brain functioned outside the laws of friction and gravity. Almost every word I heard or saw evoked landscapes, avalanches in me. [...] Eventually exhausted, I was washed up on the shore, on to dry land, terra firma. Now I see with crystal clarity, as on a map of the heavens, cold, incandescent words, connected in time and space."1) 127

Die Fremde ist in Pomerancevs Erzählung ein Land des Schweigens, in dem sich die Einheimischen durch Gesten verständigen - für den Einwanderer wie eine Fremdsprache, die er erst lernen muB, während er als Dichter auf sich zurückgeworfen bleibt (123). Sinneseindrücke spielen allgemein eine groBe Rolle: die Erinnerung ist "scharf wie Schafskäse" (122), wenn die Frauen die Betten ausschutteln, riecht es nach Sperma (125), ihre Gesichter erscheinen blau und der wein "erregend rot" (128). Die expressive Darstellung vermittelt das Befremden, mit dem der Außenstehende seine Umgebung wahrnimmt, und ist typisch für Pomerancev. Im Vergleich $z u$ zinik ist seine Prosa sehr viel lyrischer, komprimierter und reflexiver, verzichtet ganz auf eine Handlung und setzt den Akzent deutlich auf stil und Sprache. 128

126 Pomerancev, "...Moja rodina odinocestvo", Al'by $i$ serenady, London, i985, S. 121-130. (Engl.: "My Motherland is Solitude", übers. v. Frank Williams, Stand Magazine (Newcastle-upon-Tyne), Bd. 29, H. 1, winter 1987-88, S. $48-53$.

127 Pomerancev, "...Moja rodina odinočestvo", a.a.o.. s. 124-125 (mit dem entsprechenden zitat aus der angegebenen engl ischen übersetzung auf $S .50$ ).

$128 \mathrm{Vgl}$. die Rezensionen zu Al'by $i$ serenady in Russkaja mysl' (Nr. 3623, 30.5.1986, S. 10) und Dvadcat' dva (A. 
Bei allen stilistischen Unterschieden gibt es einige Parallelen zwischen den Autoren. Das bei zinik zentrale Problem der Selbstfindung nach der Emigration zum Beispiel beschäftigt auch Pomerancev, etwa in dem Einakter mit dem deutschen Titel "Mit Blumen auch schön". 129 Darin plaudern zwei Emigranten über ihre Erinnerungen und die Nationen, die sie kennengelernt haben. Woher sie kommen und wie das Land heiBt, das innen angeblich gerade neue pässe ausgestellt hat, bleibt unklar. Die beiden, relativ schwach charakterisierten Helden existieren nur in einem irrealen Raum - in der Fiktion. Pomerancev erzählt kein bestimmtes Schicksal, sondern veranschaulicht eine Lebenssituation.

Zinik und Pomerancev haben sich gleichermaßen erst in der Emigration als Schriftsteller entfaltet. Sie sind in vieler Hinsicht miteinander vergleichbar und vertreten beide - als einzige der russischen Gegenwartsautoren in England - innerhalb der Dritten Welle die "neue Prosa" der Emigration.

Ptaškin, "Zametki čitatelja", Nr. 53, April/Mai 1987, S. $215-218)$.

129 Pomerancev, "Mit Blumen auch schön", sintaksis, Nr. 15, 1986, S. 169-177. 
III. $\mathbf{T} \in \boldsymbol{i} \boldsymbol{I}=$

Das werk von zinovij zinik

\section{LITERARISCHE ENTFALTUNG IN DER EMIGRATION}

\subsection{Biographie}

Zinovij Zinik (eig. Zinovij Efimovic Gluzberg) wurde am 16. Juni 1945 in Moskau geboren und wuchs in einem relativ schäbigen Stadtviertel auf.1 Er studierte Mathematik (Topologie) an der Moskauer Staatlichen Universität und Malerei an der dortigen Kunsthochschule. Ab 1965 schrieb Zinik Theaterkritiken hauptsächlich für die Monatszeitschrift Teatr. Zugleich verfaBte er Prosa, versuchte aber erst gar nicht, sie zu veröffentlichen, da stil und Inhalt nicht den Richtlinien der Zensur entsprachen.

Zinik stand in diesen Jahren unter dem EinfluB einer inoffiziellen literarischen Gruppe um den Schriftsteller Aleksandr Asarkan, den Prosaiker und übersetzer Pavel Ulitin sowie den Dichter, übersetzer und Kritiker Jurij Ajchenval'd.2 sie beeindruckten ihren jungen Anhänger ins-

1 Seine Kindheit in den letzten Jahren der Stalin-Ära schildert Zinik in "Édipov Stalin" (Vremja i my, Nr. 87, 1985, S. 28-42) und in "Lico epochi" (Sintaksis, Nr. 33, 1992, S. 122-147). - Die folgenden biographischen Angaben stammen aus den vorliegenden Interviews und Autorenporträts sowie den Einträgen $z u$ zinik in: Wolfgang Kasack, Lexikon der russischen Literatur des 20. Jahrhunderts: Vom Beginn des Jahrhunderts bis zum Ende der Sojwetara, 2 ., neu bearb $u$. wesentl. erw. Aufl., München, 1992; Martin Tucker (Hg.), Literary Exile in the 20th Century: An Analysis and Biographical Dictionary, New York, 1991; Bosiljka Stevanovich u. wladimir wertsman, Free voices in Russian Literature 1950-80s: A Bio-Bibliographical Guide, New York, 1987; Index on Censorship, Bd. 15, H. 3, März 1986 , S. 13 .

2 Zinik hat Ulitin in sintaksis eine Hommage gewidmet: "Privetstvuju vaś neuspech: Pamjati Pavla Ulitina" (Nr. 32, 1922, S. 149-162); s. auch die entsprechenden Reminiszenzen in "Soviet Paradise Lost" (Ausstellungskatalog Carnegie International 1991, Bd. 1, Pittsburgh, Penns., 1991, S. 44) und "Art and Travel: Pictures of My Moscow Friends" (Modern Painters, Bd. 6, H. 4, Winter 1993, S. $51 \mathrm{ff.).} \mathrm{Zu} \mathrm{Ajchenval'd} \mathrm{s.} \mathrm{Ziniks} \mathrm{Nachruf} \mathrm{"Ličnoe}$ 
besondere durch ihre Fremdsprachenkenntnisse und ihr wissen über die westeuropäischen Literaturen. Ulitin beispielsweise war in der englischen Literatur bewandert. Die Gruppe traf sich bevorzugt im café "Artisticeskoe" (während andere Samizdat-zirkel eher in Privatwohnungen und vorzugsweise in deren Küchen zusammenkamen). Zinik erhielt durch diese Kontakte wesentliche Anregungen. Andererseits fühlte er sich angesichts der Erfahrungen der älteren Freunde aus der stalin-zeit in die Rolle des zuhörers und Schüler gedrängt. Der Bann seiner Vorbilder hinderte inn insofern auch, seine eigene Persönlichkeit zu entwickeln. ${ }^{3}$

1972 kam Zinik in Schwierigkeiten mit dem Staat, weil er angeblich den wehrdienst verweigern wollte. Der ProzeB gegen inn wurde jedoch wegen mangelnder Beweise eingestellt. Als Jude erhielt er drei Jahre später aufgrund eines fiktiven Verwandten eine Ausreisegenehmigung und emigrierte über wien nach Israel; seine Frau Nina und seine Tochter Margarita muBte er zunächst zurücklassen. Dafür gelang es ihm, mit Hilfe der niederländischen Botschaft einen Koffer voller Tagebuchaufzeichnungen und Manuskripten aus dem Land $z u$ schmuggeln: komplizierte, selbstreflexive und avantgardistische Prosa, in denen sich der EinfluB der zirkel um Ulitin niedergeschlagen hatte. Im Ausland erkannte zinik jedoch, daß diese Entwürfe ohne den Kontext, in dem sie entstanden waren, ihren wert verloren hatten.'

In Jerusalem übernahm er die Leitung des russischen Theaterstudios an der Universität und arbeitete außerdem

delo vracej: Pamjati Ju. A. Ajchenval'da" (Sintaksis, Nr. 34 f 1994 , S. 87-98).

S. Ziniks Rückblick in "Na puti k 'Artistićeskomu'", Teatr, Nr. 6, Juni 1993, S. 123-142; auch "Emigraci ja kak literaturnyj priëm", Sintaksis, Nr. 11, 1983, S. 173-177.

S. 2.B. das Interview "Zinovij Zinik: Ja ne proćël 'Annu Kareninu' do konca...", Literator (St. Petersburg), Nr. 14 (68), April 1991, S. 8. Zitat: "No, otkryv ćemodan po priezde, ja ponjal, cto eto soversenno ne prinadlezit moemu nyneśnemu nastojaścemu." ("Aber beim öf fnen des Koffers wurde mir klar, daß dies überhaupt nichts mit meiner jetzigen Gegenwart $z u$ tun hatte.") $S$. dazu auch das persönliche Gespräch mit zinik, Anhang, S. 181-182. 
als übersetzer und freier Journalist. Hier entstanden seine ersten Romane: Izveščenie (1976), die Ich-Erzählung eines Emigranten in Israel, und Peremešcennoe lico (1977) über den Versuch des Helden, in der Fremde die eigene Vergangenheit $z u$ rekonstruieren. Beide werke markierten inhaltlich und stilistisch einen Bruch gegenüber den sujetlosen Texten, die zinik aus der sowjetunion mitgebracht natte.

Die äuBeren Bedingungen in Israel waren von Beginn an günstig. Dennoch lieB sich der Autor nach einem vorübergehenden Aufenthalt in Paris 1977 in London nieder, um ein Angebot der BBC anzunehmen und im "Russian Service" Redakteur und kritiker im Bereich kunst, Theater und Film zu werden. Im Rahmen dieser Tätigkeit hat $\mathrm{Zinik}$ auch Theaterstücke etwa von Michail Bulgakov und Vladimir Vojnovic für das Radio bearbeitet. Schon mehrere Jahre gestaltet er die Magazinsendung "West-End", die über aktuelle Kulturereignisse in London berichtet. 5 Darüber hinaus erscheinen von inm seit Ende der 70 er Jahre regelmäBig Beiträge über vornehmlich russische Theaterauffürungen und Neuerscheinungen auf dem Buchmarkt in The Times Literary Supplement, der Literaturbeilage der Tageszeitung The Times. ${ }^{6}$ Durch seine journalistische Tätigkeit vermittelt $\mathrm{zinik}$ also einerseits den russischen Hörern die englische Kultur, andererseits den englischen Zeitungslesern Aspekte der russischen.

$5 \mathrm{zu}$ seiner Arbeit äuBert sich zinik in dem Interview "Kogda lord stanovitsja egerem" der Moskauer Tageszeitung Moskovskij komsomolec (23.5.1992, S. 10).

Bsp.: "A Russian Monster" (H. 4447, 24.-30.6.1988, S. 698 ) stellt vladimir Sorokins Erzählung Ocered' (The Queue) vor: "A Ceremonial Autopsy" (H. 4540, 6.-12.4.1990, S. 374) kommentiert eine Fernsehproduktion über Stalin: "Failing Triumphantly" (H. 4696, 2.4.1993, S. 18) rezensiert eine Inszenierung von Aleksandr Griboedovs Komödie Gore ot uma (engl. Chatsky) im Londoner Almeida Theatre. Zinik hat auch Artikel, Rezensionen und Essays für die Zeitschriften The spectator, The Encounter und The Listener sowie die Tageszeitungen The Guardian, The Independent und The Daily Telegraph geschrieben. (Alle erscheinen in London. ) 
Sein bislang veröffentlichtes werk umfaßt neben zahlreichen Essays insgesamt 15 Erzählungen und sieben Romane, 7 in denen fast ausschließlich russische Emigranten die Hauptfiguren darstellen. Die originaltexte sind $z$ einem großen Teil in den Emigrantenzeitschriften sintaksis (Paris) und Vremja $i$ my (Tel Aviv, später New York) erschienen. Die ersten vier Romane gibt es auch in Französisch (Albin-Michel, Paris), davon Niša $v$ Panteone (1979) zudem in Hebräisch. 8

Es ist bemerkenswert, daß zinik eher einen französischen Verleger fand als einen russischen und einen englischen. Seine Ablehnung bei den etablierten Emigrantenverlagen hing damit zusammen, daß junge apolitische Autoren sich dort allgemein nur schwer durchsetzen konnten, wie im Abschnitt $2 u$ den "AuBenseitern" der Dritten welle erläutert wurde. Im zweiten Fall spielt die traditionelle Sättigung des Marktes durch die anglo-amerikanische Literatur eine Rolle.

Bis heute wurden fünf Erzählungen von zinik in englischer übersetzung gedruckt, davon aber nur zwei in Großbritannien. Immerhin sendete die BBC auf "Radio 3" 1984 den Roman Russkaja sluźba (1981) sowie 1985 und 1986 insgesamt drei Kurzgeschichten. Aber erst 1987 lag ein Roman in Englisch vor: Russofobka $i$ fungofil (1984) mit dem Titel The Mushroom-Picker. Das Buch wurde in allen großen britischen Tageszeitungen rezensiert und relativ gut verkauft, so daß bis heute zwei weitere englische Ausgaben sowie eine holländische und eine polnische herauskamen. Außerdem verwandelte die $B B C$ den stoff in eine TV-Serie. Zinik schaffte es mit The Mushroom-Picker erstmals, aus der Isolation als russischer Exilschriftsteller herauszukommen und in England rezipiert $z u$ werden. Der zweite Roman, der von ihm auf den britischen Markt gelangte, konnte

7 S. das Werkverzeichnis in der Bibliographie.

8 Niša $v$ Panteone schildert den Transformationsprozeß eines sowjetischen Emigranten in Israel. Wegen des Schauplatzes wird das Werk in dieser Arbeit ebenso wenig berücksichtigt wie die bereits erwähnten Romane Izveśčenie und Peremesciennoe lico sowie Uklonenie ot povinnosti (1982) über einen russischen Soldaten in Israel. 
den Erfolg des ersten indes nicht fortsetzen: The Lord and the Gamekeeper (Lord $i$ eger': 1989) fand weder bei der Kritik noch beim Leser Resonanz.

Nach der politischen wende in RuBland wurden dort mittlerweile drei Romane von zinik aufgelegt, nämlich 1991 Russofobka $i$ fungofil und Lord $i$ eger' sowie zwei Jahre später Russkaja sluzba. Darüber hinaus publizierten diverse Zeitschriften bislang fünf Erzählungen. Zinik selbst hat Moskau erstmals 1988 und seither mehrfach besucht. Eine endgültige Rückkehr ist für ihn ausgeschlossen, da er sich innerlich $z u$ sehr von der Heimat entfernt und in England eingelebt hat. 1988 erhielt er die britische staatsbürgerschaft.

In einem Interview porträtiert der schriftsteller sich selbst mit den Worten: "Duśa u menja evrejskaja, um russkij, a serdce - anglijskoe, poskol'ku serdce moźno peresazivat'..." ("Meine seele ist jüdisch, mein Verstand russisch und mein Herz englisch, soweit man das Herz umpflanzen kann ..." $)^{9}$ Zinik praktiziert seinen Glauben nicht, so daB dieser in seinem Leben und seinem Werk kaum eine Rolle spielt. Er entschloB sich, in London wurzeln zu schlagen, weil ihm nach eigenen Aussagen aufgrund der englischen Toleranz hier - im Gegensatz zu Israel - keine Identität aufgezwungen worden sei. ${ }^{10} \mathrm{zinik}$ nimmt ausdrücklich die Zwischenposition des Emigranten ein, der sich bis $\mathrm{zu}$ einem gewissen Grad integriert und dennoch seines Fremdseins bewuBt bleibt. Diese Haltung spiegelt sich in seiner Prosa wider, die genau diese situation verarbeitet.

9 Interview mit Jaroslav Mogutin, "špion s evrejskoj dušj, russkim umom i anglijskim serdcem", stolica (Moskau), Nr io 17 (75), 1992 , S. 56.

io $\mathrm{S}$. persönliches Gespräch mit Zinik, Anhang, S. 181 . Hier erklärt er zugleich, daB er sich den Briten geistesverwandt fühle, weil sie von inrer Insel aus andere Länder erobert hätten, um "sich selbst in exotischen Umständen $2 u$ entdecken". Ähnlich sagt er im Interview der Nezavisimaja gazeta ("Esli ne ljubit, ne znacit - gad", 14.4.1992): "Dlja angličan voobśče charakterno iskat' blizkoe v cuzdom." ("Die Engländer neigen allgemein dazu, im Fremden das $z u$ suchen, was ihnen nahe ist.") 
Ziniks Lebenslauf ist typisch für seine Generation der Dritten Welle: Er wurde von dem liberaleren gesellschaftlichen Klima in der "Tauwetter"-Periode geprägt und wanderte nach der verschärfung der sowjetischen Politik in den Westen aus, wo er sich persönlich wie künstlerisch entfalten konnte. Wie bei vielen führte sein Weg über Israel in ein anderes Land. Zinik war gegen das kommunistische system eingestellt, aber kein aktiver Dissident. Er verließ die heimat freiwillig, um die persönliche Freiheit $z u$ gewinnen. Aus seiner sicht überwand $\mathrm{zinik}$ seine "jugendliche sprachlosigkeit", die inn in seinem Moskauer Samizdat-Kreis beherrscht hatte, indem er die innere, geistige Emigration physisch nachvollzog, sich unmittelbar in eine andere welt begab und dort $z u$ einer eigenen (literarischen) sprache fand.ll Diese Umstände erklären zum Teil, warum seine Prosa apolitisch ist und vielmehr das persönliche Erlebnis der Emigration, ihre pschologischen Aspekte und die englische Kultur thematisiert.

\subsection{Die Poetik von Zinovij Zinik}

Zinovij Zinik befaBt sich auf zwei Ebenen mit dem Thema der Emigration. Zum einen gestaltet er die spezifische Situation des Auswanderers, seine psychischen Probleme und seine innere Transformation literarisch, nämlich in Erzählungen und Romanen. Zum anderen erläutert er theoretisch in Essays die genannten Aspekte und sein Verständnis einer Literatur der Emigration, wobei die Beziehung zwischen Autor und Held von zentraler Bedeutung ist. Sein Konzept wird im folgenden vorgestellt, um daraufhin zu untersuchen, ob und wie er es in der Fiktion umgesetzt hat. Die wichtigsten Essays hierzu sind "Émigracija kak literaturnyj priëm",12 "Gotičeskij roman užasov èmigracii"l3 und "Glavnyj geroj $v$ poiskach avtora".14

11 vgl. Zinik, "Na puti ...", a.a.O., s. 124 .

12 Zinik, "Émigracija kak ...", a.a.O., S. 167-187. Die deutsche übersetzung ("Emigration als literarische Form", Individualitat, Bd. 5, Nr. 12, Dez. 1986, S. 3-13) enthält 
Die Aufsätze beschreiben den Emigranten als Personentyp und Romanhelden zugleich, ohne immer klar zu unterscheiden, ob von der realen situation oder ihrer fiktiven Darstellung die Rede ist. Grundsätzlich geht zinik von dem sowjetischen Auswanderer der Dritten Welle aus. Ihn charakterisiert er durch zwei Merkmale, die beide im historischen Kontext $z u$ sehen sind, nämlich die Endgültigkeit seines Abschieds und seine innere Prägung durch das hermetische sowjetische system, die inm erst im Ausland bewuBt werde und von der er sich nicht befreien könne. ${ }^{15}$

Diese Faktoren bedeuten zinik zufolge, daB der Abtrünnige beim schritt über die Landesgrenzen sich für immer aus der Gesellschaft ausschliebt, aus der eigenen Vergangenheit heraustritt und sich von seinem selbst entfremdet. ${ }^{16}$ Zugleich kehrt das Heimatgefühl wieder, das sich in der vorausgegangenen inneren Emigration verloren hatte. Weil es kein zurück gibt, erlebt der Emigrant gewisserma-

massive Kürzungen, Ergänzungen und veränderte Formulierungen, die offenbar dem mit der Thematik weniger vertrauten Leser das Verständnis erleichtern sollen; sie ist aber von Zinik nicht autorisiert, wie sich bei einer Nachfrage herausstellte.

I3 Zinik, "Gotičeskij roman ...", Sintaksis, Nr. 16, 1986 , S. 34-70.

14 Zinik, "Glavnyj geroj ...", Sintaksis, $\mathrm{Nr}$. 31, 1991, S. 132-137. Engl. Ubers.: "The Hero in Search of an Author", Under Eastern Eyes: The west as Reflected in Recent Russian Emigre Writing, hg. Arnold McMillin, New York, 1992 , S. 12-16.

$15^{\prime}$ In dem Artikel "Tout cela fait partie de notre conscience" beschreibt zinik die Besonderheiten der Sowjetkultur und inre verankerung in der Psyche. Zitat: "D'ici, de l'émigration, il devient compréhensible que toutes ces légendes [du mythe soviétique] font partie de notre conscience, partie de notre passé auquel nul ne peut échapper et le retour de ce passé - méme sous la forme d'un reportage à la télévision occidentale lors des funérailles de Brejnev - promet un sorte de béatitude comme un retour à la maison natale, au mythe natal, aux sources de sa propre conscience." (La Quinzaine Littéraire, H. 468, Aug. 1986, S. 28). - Auf die Dominanz der sowjetischen Identitat gegenüber der russischen verweist auch Igor' Pomerancev in einem Interview der zeitschrift Index on censorship, in dem er die Dritte welle der Ersten gegenüberstellt: "[...] we had only soviet roots - we completely lacked this deep support from our national culture." ("Out of step", Bd. 15, H. 3, März 1986, S. 16).

\{6 "Émigracija kak ...", a.a.O., s. 169. 
Ben seinen Tod, und zwar beim freiwilligen Exil von eigener Hand.17 In diesem Fall beherrscht ihn das BewuBtsein, für das eigene Schicksal allein die Verantwortung zu tragen, sowie ein ständiges Bedürfnis der Selbstrechtfertigung dafür, die Heimat im stich gelassen $z u$ haben und so schuldig geworden $2 u$ sein. 18

Verharrt der ehemalige Sowjetbürger innerlich in der welt, der er äußerlich den Rücken zugekehrt hat, statt sich auf sein neues Leben diesseits des Eisernen Vorhangs einzulassen, so läßt sich seine schattenexistenz mit der eines Phantoms vergleichen, das es ständig $z u$ Freunden und Verwandten zurückzieht. Diese Metapher liegt dem Aufsatz "Gotičeskij roman užasov èmigracii" zugrunde. In jedem Fall werden die Vergangenheit und die Heimat im Gedächtnis konserviert, dadurch fiktiv und zum persönlichen Mythos des Emigranten. Aus der räumlichen und zeitlichen Distanz entwirft er ein Bild von diesem abgebrochenen Leben, indem er ständig aufs neue versucht, es "umzuschreiben", nostalgisch $z u$ verklären, $z u$ einem Ganzen $z u$ konstruieren oder auch in Form einer Utopie $z u$ einem idealen Ende $z u$ führen. 19 Die Fixierung wird ermöglicht und provoziert durch den totalen Umsturz der Lebensverhältnisse, den zinik als "persönliche Revolution" bezeichnet, während er sich selbst "Schriftsteller der dritten russischen Revolution" nennt. 20 Die radikale Wende des Lebens erlaubt seine Be-

17 "Émigracija kak ...", a.a.0., s. 180-181.

18 "Emigracija kak ..." a. a.o.. S. 182-183. Die Wurzeln für das Gefühl, als Verräter verdammt zu sein, sieht zinik in der psychischen Beeinflussung durch die sowjetische Propaganda ("Goticeskij roman ...", a.a.0., s. 41). In dieser Hinsicht zieht er in "Goticeskij roman ..." eine Parallele zwischen der geistigen Atmosphäre in der Sowjetunion unter Breznev und im England des 18. Jahrhunderts, als sich der englische Schauerroman (Gothic novel) herausbildete, mit dem zinik folglich den Emigrantenroman vergleicht.

19 "Émigracija kak ...", a.a.o., s. 183-185; "Gotičeskij roman ...", a.a.O., S. 56-57, 63-64 u. auch 35-36, wo $\mathrm{Zi}-$ nik über den Helden seines Romans Nisa $v$ Panteone schreibt: "[...] mir 'tam', mir ostavlennyj geroem, suscestvuet tol'ko potomu, čto geroj o nëm dumaet." ("[...] die 'dortige' Welt', die der Held zurückgelassen hat, existiert nur, weil er an sie denkt.")

$20^{\prime}$ "Ėmigracija kak ...", a.a.0., s. 179-180. 
trachtung aus einer vollkommen neuen Perspektive und damit seine Literarisierung: "[...] emigration, as a major step in life, creates the illusion of a ready-made novel." 21

An anderer stelle definiert zinik die Emigration wörtlich wie übertragen als "Ausweichen vor einer endgültigen Formulierung des eigenen Lebens" oder die suche nach einem neuen Ich. Genau darin sieht er auch die Motivation eines Romans und kommt $z u$ folgendem SchluB: "Socinenie romana - svoego roda èmigracija, èmigracija - literaturnyj priëm." ("Das Verfassen eines Romans ist an sich eine Emigration und die Emigration ein literarisches Verfahren." ${ }^{22}$ Somit stellt seine Poetik eine Analogiebeziehung her, wonach einerseits das Leben des Emigranten romanhaft ist und andererseits der Roman als Genre im metaphorischen sinn eine (geistige) Emigration manifestiert. In ziniks Fall setzten seine Romane die reale Ausreise aus der Sowjetunion voraus, weil die Literatur dort seinen Ausführungen zufolge stets politischen Aufgaben gewidmet sowie ideologisch und moralisch war, wobei sie für eine wertfreie Behandlung persönlicher Themen keinen Raum gelassen habe. Erst der Übergang von der inneren zur äuBeren Emigration machte den weg zum Roman frei:

"Свобода это право на выпадение из исторического процесса. Я считал, что выбираю роман, а не жанр моралистической эпики, к которой проговорён каждый советский писатель. Эмиграция была для меня литературным приёмом."

("Freiheit ist das Recht, aus dem historischen ProzeB auszusteigen. Ich dachte, ich wähle als Genre den Roman und nicht die moralistische Epik, zu der jeder sowjetische

21 "The Hero ...", a.a.o., s. 14. (Russ. Originalzitat: "Glavnyj geroj ..."."a.a.o. s. 134 .)

22 Interview "Émigracija kak literaturnyj priëm", Literaturnaja gazeta, 20.3.1991, S. 11. - Ein Autorenporträt in Vremja (Tel Aviv) hebt hervor, daB ziniks "Antihelden" in inrer Zerrissenheit zwischen dem Wunsch nach einer Identität und der Flucht vor jeder Festlegung den typischen Helden unserer zeit vertreten ([Michail Ajzenberg], "Boj s ten'ju", 3.4.1992, S. 20). Diese Aussage macht zinik auch seíbst in "Emigracija kak ...", a.a.0., S. 168 . 
Schriftsteller verdammt ist. pie Emigration war für mich ein literarisches Verfahren.") 23

Der letzte Satz ist direkt auf die Textgenese zu beziehen: Die Emigration machte das eigene Leben zum stoff für die Narration und veranlabte die schöpferische Phantasie $z$ dessen Verarbeitung in einer bestimmten Form, nämlich der des Romans. Den Unterschied zur Epik definiert Zinik damit, daB im Roman die standpunkte von Autor, Erzähler und Held getrennt sind. Weil der Autor dabei über seinen Helden steht, kann er durch sie über das private offentlich erzählen, wobei sie im Rahmen der Handlung einen inneren wandel durchmachen. 24

Den literarischen werken von zinik gingen lange Briefe voraus, die er an die Daheimgebliebenen schrieb in dem Versuch, sein neues Leben $2 u$ vermitteln und einen sprachlichen Ausdruck dafür $z u$ finden. Zugleich waren sie das Medium, um mit der zurückgelassenen welt in Verbindung zu treten. Briefe aus der Fremde in die Heimat, so ziniks Feststellung, bauen eine subjektive, autonome wirklichkeit auf; das darin auftretende Ich ist ein selbstentwurf des Schreibers in Bezug auf Vergangenheit und Gegenwart. Damit scheint das sujet für einen Roman bereits gegeben. ${ }^{25} \mathrm{Zu}$ seiner literarischen Umsetzung bleibt nach ziniks Auffassung ein kleiner schritt, den er eben auch selbst vollzogen hat.

Aus dem Gesagten wird deutlich, daB der Emigrantenroman mit zwei orten und zwei Zeiten operieren muB. Denn der Auswanderer verhält sich $z u$ der Heimat in seiner Erinnerung so, als habe er sie erst gestern verlassen, das heiBt, als sei die zeit dort stehengeblieben. Seine gegen-

23 "Ėmigracija kak ...", a.a.O., S. 178; nähere Erläuterungen auf $\mathrm{S} .176-177,179 \mathrm{u} .181$.

25 "Emigracija kak ...", a.a.0., S. 176-177.

25 "Goticeskij roman ...", a.a.o., s. 61; "Ėmigracija kak ...", a.a.0., S. 180. Im persönlichen Gespräch sagte Zinik dazu: "I realised that a kind of new reality grows out of it [these letters]. Suddenly I started to write as $I$ had never been able to write before." (Anhang, S. 184). Vgl. Interview in stolica (a.a.0., S. 56): "[...] ja ponjal, cto eto i est" sjužet." ("Ich beqriff, daB dies auch ein sujet war.") 
wärtige Welt bildet demgegenüber eine andere geographische und auch zeitliche sphäre.26 sie wird mit den alten Wahrnehmungsmustern erfaBt, umgekehrt entwickeln sich neue Sichtweisen für das Vergangene und vertraute. 27 Das literarische Werk ist Teil und Ausdruck dieses Prozesses zugleich. Die Herausforderung der Emigration besteht laut zinik darin, in dem Fremden, Neuen, Gegenwärtigen die Wahrheit uber das Eigene, Alte, Vergangene und zukunftige zu suchen, um die Kontinuität des eigenen Lebens und die Einheit des gespaltenen Bewubtseins wiederherzustellen. Die situation verlangt analog zur Aktualisierung des Gedächtnisses eine Anpassung der Sprache. ${ }^{28} \mathrm{zinik}$ betont:

"[...] нужно вспомннать старые слова, играющие в новых обстоятельствах, и старыми обстоятельствами проверять новые слова."

("[...] es kommt darauf an, sich an alte worte zu erinnern, die unter den neuen Umständen sich spielend einfügen, und für die alten Gegebenheiten neue worte auszuprobieren." ) 29

Mit den "Worten" ist der sprachliche Ausdruck an sich gemeint, aber auch übertragen die kulturell geprägten Denk- und Wahrnehmungskategorien. Das zitat macht deutlich, daB es einer Erweiterung und Erneuerung des Kodes bedarf, um die selbstentfremdung wie das Fremdsein im Ausland $z u$ verarbeiten, und zwar im psychischen und kognitiven Bereich ebenso wie im literarisch-kreativen. Für zinik sind sie miteinander verbunden, denn die Funktion von Literatur besteht nach seiner Auffassung grundsätzlich in der überwindung von Entfremdung ("defeat of

26 "Gotičeskij roman ...", a.a.O., s. 57-58.

27 In dem Aufsatz "Podstrónik" nennt Zinik als Beispiel, daß sowjetische Emigranten in anderen städten stets "ihr" Moskau, Leningrad usw. erkennen (Sintaksis, $\mathrm{Nr}$. 8, 1980, S. 102). Vgl. "Émigracija kak ...", a.a.0., s. 180: "Uvidennoe takim obrazom načinalo dvoit'sja: na novoe, zame¿ennoe preżnim vagljadom, i prošloe, oformljavšeesja $v$ novom slovare." ("Mein Blickfeld begann auf diese Weise, sich $z u$ verdoppeln: in das Neue, wahrgenommen mit meinen fruheren Augen, und das neu formulierte vergangene.") zur Verdoppelung der Denkkategorien und der sprache $\mathbf{s}$. auch "Goticeskij roman ....", a.a.o., s. 43.

28 "Podstroćnik", a.a.0., s. 101-104.

29 "Podstročnik", a.a.O., S. 103. 
alienation") durch die Entwicklung des eigenen Ausdrucks. 30 Das literarische Werk begreift er darüber hinaus als die Konstruktion eines "idealen Gesprächs", in dem man "über sich redet, als sei man ein anderer, und über den anderen, als handele es sich um einen selbst", um herauszufinden, was man sich selbst verschweigt. ${ }^{31}$ Dieser verschriftlichte innere Dialog, bei dem der Autor fiktiven Gesprächspartnern bestimmte Rollen in Bezug auf sein Ich zuweist, stellt eine Entpersönlichung der eigenen Erfahrung dar, dient aber letztlich der Selbsterkenntnis. Seine Beziehung zum Helden formuliert zinik konkret wie folgt:

"An author is not identical to the hero of his novel, but the hero is a part of the author, if not in his opinions or his physiology, as it is described, then at least for the reason that the author created his hero, that is, he selected a particular prototype that suited his intentions. The ideological aspects of this selection are, in my view, the central feature in the metamorphoses of the émigré novel." 32

Das Zitat wertet die besondere Mittlerfunktion des Helden im Emigrantenroman als gattungsspezifisches Kennzeichen. Der tatsächlich emigrierte Autor, der sich weiter der Heimat verbunden fühlt und gleichzeitig zunehmend eine neue Identität annimmt, spielt durch die von inm charakterisierte Figur seine inneren Konflikte und Ideen aus, oder anders formuliert: "This authorial duality plays a direct role in the formation of the world-view of the hero that the author creates."33 wenn die Emigration, wie in diesem Abschnitt ausgefüht, reales Erlebnis und literarisches verfahren zugleich ist, beeinflussen die Bewußtseinsspaltung des Autors und seine Position zwischen den Kulturen nach ziniks Theorie unmittelbar den kreativen Akt. Auch der Held, der beispielsweise mit seiner Nostalgie für die

\footnotetext{
30 "The Hero ...", a.a.o., s. 13-14 bzw. "Glavnyj geroj - il" "a.a.O. S. 134 .

32 "Podstrocnik", a.a.0., s. 92-93.

32 "The Hero ...", a.a.o., s. 12. (Russ. Originalzitat: "Glavnyj geroj ...".", a.a.o., s. 132.)

33 "The Hero ...", a.a.o., s. 13. (Russ. originalzitat: "Glavnyj geroj ...".", a.a.0., s. 133.) Vgl. die Aussage im persönlichen Gespräch: "Idea is a contradiction of two things that couldn't be resolved without playing it out with characters." (Anhang, S. 180).
} 
Sowjetunion im Gegensatz zum Autor steht, reflektiert dennoch zum Teil dessen eigene Emigrationserfahrung und Selbsterkenntnis. 34

Ziniks Konzept steht weitgehend im Einklang mit dem theoretischen Modell, das im ersten Teil dieser Arbeit dargelegt wurde: Die Genese des literarischen Textes erfolgt direkt aus der situation des psychischen und kulturellen Zwischenraums heraus, der durch die Emigration bedingt ist (wobei den betreffenden theoretischen Texten allerdings der Begriff "Exil" zugrunde liegt). Die Narration fixiert die spezifische Erfahrung und fungiert als Medium einer neuen selbstbestimmung.

\subsection{Die Darstellung der englischen Kultur}

Zinovij zinik hat die Frage, warum er sich gerade in Großbritannien niedergelassen habe, immer damit beantwortet, $d a \beta$ die englische Lebenskultur inm besonders fremd, neu und seltsam erschienen sei. 35 sie stand für ihn im absoluten Gegensatz $z u$ seiner Heimat. Insbesondere entsprach London uberhaupt nicht seinen Erwartungen. Hier stellte sich ziniks Angaben zufolge das Gefühl ein, das er bei seiner Emigration gesucht und in Israel nicht gefunden hatte, nämlich ein Ausländer und allein zu sein, zumal es auf der Insel keine russische Emigrantengemeinschaft

34 "Émigracija kak ...", a.a.0., s. 185. Vgl. das folgende zitat aus Vremja (a.a.o.) über ziniks Narration, das diesen zusammenhang nochmal verdeutlicht: "Avtor $v$ etoj proze javno prisutstvuet, no on ne odno iz dejstvujuscich lic, a moźet byt' - ljuboe. Vmeste $s$ nimi on iscet svoé otraźenie $i$ pugaetsja ego, otvoracivaetsja, peredergivaetsja ot otvrascenija." " "Der Autor ist in dieser Prosa offensichtlich anwesend, aber nicht als eine der Figuren, sondern eher als jede beliebige. Zusammen mit ihnen sucht er sein spiegelbild und fürchtet es [zugleich], wendet sich $a b$ und schüttelt sich vor Abscheu.")

35 S. 2.B. die Interviews in der Nezavisimaja gazeta und in Literator, beide a.a.0.: ferner das von Tom Birchenough verfaßte Autorenporträt "Outsider's view of an Incomer", The Times, 28.1.1993, S. 38 . 
gibt. ${ }^{36}$ Aus dieser Situation hat er nach eigener überzeugung schöpferische Impulse gewonnen. Außerdem sei er sich erst in England seiner jüdischen und russischen Herkunft bewuBt geworden, während er sich zuvor nur mit der sowjetkultur identifiziert nabe. 37

Der Nationalcharakter der Engländer ist nach Ziniks Beobachtung vor allem von ihrem Bestreben geprägt, sich zumindest dem Anschein nach voneinander abzugrenzen. In einem Gespräch mit Petr Vajl' und Aleksandr Genis für die Emigrantenzeitschrift Panorama (Los Angeles) zum Beispiel illustriert er diese Neigung mit der Unterteilung der Eisenbahnwaggons, der Straßenarchitektur in Londons Vorstädten und der Atmosphäre in den pubs. Daraus ergebe sich eine gewisse Unverbindlichkeit im Umgang miteinander. In Panorama begründet zinik auch das Einzelgängertum der sowjetischen Schriftsteller in Großbritannien mit der Tendenz zur "Dezentralisierung" in der englischen Kultur, die sie übernommen hätten. 38

Um die englische Alltagswelt den russischen Lesern $z u$ vermitteln, muß Zinik sie seinen Angaben zufolge in deren kulturellen Kode übersetzen, was für inn eine satirische Verzerrung bedeutet:

"If you think about your readership as not understanding what is happening here, you distort the reality here, and you always write a satire. Because you have to shape it into something familiar to the Russian." 39

Zinik versucht demnach, bewußt aus der Perspektive des Russen zu schreiben, dem diese wirklichkeit unbekannt ist. Entsprechend verwendet er Verfremdungsverfahren, ${ }^{10}$

36 S. U.a. Ziniks Beschreibung von Israel und seinem "shock of the new" in London im persönlichen Gespräch (Anhang, S. 183).

37 Persönliches Gespräch, Anhang, S. 182.

38 P. Vajl' u. A. Genis, "Vagljád s nulevogo meridiana", Paporama, 27.3.-3.4.1987, S. 18-20.

39 Persönliches Gespräch, Anhang, S. 179.

10 Nach Viktor Sklovskij, der den Begriff der "Verfremdung" geprägt hat, besteht das verfahren u.a. darin, einen Gegenstand so $z u$ beschreiben, als werde er zum ersten Mal gesehen. (V. Śklovskij, "Die Kunst als Verfahren", Texte der russischen Formalisten, Bd. 1, hg. Jurij striedter, München, 1969, S. 17.) 
übertreibt die Merkmale der englischen Lebensart und Verhaltenweisen und stellt MiBstände oder Schwächen blOB, indem er sie lächerlich macht. Dabei wird der Emigrantenheld, der mit dieser bizarren welt konfrontiert ist, zur Identifikationsfigur. Er führt die typischen orientierungsprobleme vor, die der sowjetische Einwanderer angesichts der ungewohnten Pluralität, Atomisierung und Konkretheit des westlichen Lebens bewältigen muB. 11 Sein Befremden versucht er durch eine ironische Einstellung gegenüber seiner Umgebung $z u$ vertuschen und $z u$ überwinden. In "Gelächter, Ironie, Spott" sieht zinik nämlich natürliche Reaktionen des verunsicherten Emigranten. Der Romanautor überlasse die Verunglimpfung der fremden Kultur und uberhaupt die Auseinandersetzung mit inr freilich seinem Helden, der von vornherein ein "negativer charakter" sei, weil er sich durch eine Verweigerungshaltung definiere. 12

Andererseits schreibt Zinik auch für den englischen Leser über RuBland, das er gemäB seiner eigenen Einschätzung wie ein Engländer sieht:

"[...] when I write in England about England, I still see it with Russian eyes, whereas when I write about Russia, I already see it with English eyes."13

Das bedeutet, daB zinik seine frühere Heimat ebenfalls wie in einem zerrspiegel abbildet. Insofern ist seine Prosa von einer verfremdenden Doppelperspektive geprägt, die daraus resultiert, $d a \beta$ er sich ausdrücklich zwischen die kulturen stellt und $2 u$ beiden die position des AuBenseiters einnimmt. $11 \mathrm{Da}$ der Autor jedoch seine Erzählungen und Romane (bislang noch) in der russischen sprache schreibt, kann er die russische oder sowjetische

11 s. "GotiCeskij roman ...", a.a.0., s. 52 ff.

12 "The Hero ...", a.a.o., s. 14-is bzw. "Glavnyj geroj -." a.a.0., s. 134-135.

i3 Persönliches Gespräch, Anhang, S. 184.

11 Vgl. die These von Edward J. Brown, für den diese doppelte Verfremdung ein typisches Verfahren des Exil- bzw. Emigrantenautors ist, "whose mixed images of home and abroad have the effect of defamiliarizing - of making strange in shklovsky's sense - both the experience of exile life and memories of home." ("The Exile Experience", The Third Wave, hg. Matich u. Heim, Ann Arbor, Mich., 1984, S. 53.) 
Realität direkt benennen, obwohl er sie mit den Augen eines Fremden und im Rückblick betrachtet. Die englische hingegen muB er stets in die Muttersprache übertragen. Für spezifische Phänomene des Alltagslebens gibt es jedoch im Russischen keine Entsprechung, so daB die Umschreibung oder der betreffende Ausdruck in der Fremdsprache an ihre stelle treten. Abgesehen von den stilistischen Aspekten dieses Vorgehens stößt zinik hier auf grundsätzliche Schwierigkeiten der Kulturvermittlung. 15 In der englischen Fassung erscheint die Darstellung Englands dann gewissermaßen rückübersetzt. Darin sieht zinik selbst ein Rezeptionsproblem hinsichtlich des englischen Lesers, da dieser sich mit seiner sichtweise nicht identifizieren könnte. 16

Allerdings glaubt der prosaiker auf der anderen Seite, $d a B$ er sich mit zunehmender Assimilierung immer mehr von der übersetzerhaltung entfernt. Im persönlichen Gespräch veranschaulichte zinik diesen ProzeB damit, daß er den "Lärm", aus dem er - gleich einem Rohstoff - seine Werke quasi modelliere, inzwischen auch in Englisch höre. Die logische Konsequenz dieser Entwicklung wäre ein totaler Sprachwechsel, den er bereits erwogen habe. ${ }^{17}$ Bislanq

$45 \mathrm{Vgl}$. "The Hero ...", a.a.O., S. 13 bzw. "Glavnyj geroj - i6" a.a.O.. S. 133-134.

i6 Persönliches Gespräch, Anhang, S. 184. Zinik erklärt sich damit zum Teil den MiBerfolg seines Romans The Lord and the Gamekeeper. - Bei der Konferenz Literature in Exile (hg. John Glad, Durham u. London, 1990) hat der israelische Schriftsteller Anton Shammas an einem Beispiel anschaulich erklärt, wie stark die Rezeptionshaltung kulturell geprägt ist: Das Schreiben von links nach rechts in den europäischen sprachen bestimme z.B. auch die Blickrichtung in einem barocken Gemälde, das somit seitenverkehrt projiziert unverständlich sei (S. 117-118). Ähnlich ist Ziniks England-Bild dem englischen Leser nicht unmittelbar zugänglich.

47 Persönliches Gespräch, Anhang, S. 179 u. 185. Zinik bekennt hier, daB er sich vor einem sprachwechsel fürchte. Dies entspricht der Beobachtung von Elizabeth Klosty Beaujour in inrer studie uber zweisprachige Schriftsteller: "1... competent bilinguals or polyglots who attempt to become bilingual as writers have to struggle with a variety of emotional obstacles that are much more serious than the purely linguistic ones." (Alien Tongues: Bilingual Russian Writers of the "First" Emigration, Ithaca $u$. London, 1989, S. 160.) 
hat der Schriftsteller nur Essays und in diesem Jahr erstmals eine (noch nicht veröffentlichte) Erzählung mit dem Titel "No Cause for Alarm" auf englisch verfaBt, doch gebraucht er die Zweitsprache ständig im beruflichen und privaten Alltag. Während dies von seiner persönlichen Integration in England zeugt, ist er mit seinem literarischen Schaffen ein russischer schriftsteller geblieben. Bei den überlegungen, auch hier zur Fremdsprache überzugehen, geht es letztlich um seine zugehörigkeit zur russischen Literatur:

"I am beginning to rid myself of my parodic (that is, seen through a Russian's eyes) perception of English realia. That is, I am ceasing to translate (that is, to parody). That is, I see and hear like some Englishman of a rather strange and monstrous kind - thinking in English but expressing himself in Russian. But is not this, then, the end of Russian literature? or is Russian literature in, so to speak, 'Russian' English a possibility - that is the question." 48

18 "The Hero ...", a.a.o., s. 16. (Russ. Originalzitat: "Glavnyj qeroj ...", a.a.0., s. 136.) 


\section{RUSSKAJA SLUŻBA}

\subsection{Als Sowjetbürger in England}

Der Roman Russkaja služba (1981) ist der vierte von zinovij zinik und der erste uber einen Emigranten in England, während die Handlung der vorhergehenden in Israel spielt. Ansonsten folgt Russkaja služba thematisch wie stilistisch der in Israel eingeschlagenen Richtung. 19

Die Anfangsszene zeigt den Helden Kirill Narator als Statisten bei den Dreharbeiten $z u$ einem Film über die russische Revolution. Dabei wird inm sein Regenschirm gestohlen, der wiederum eine Art Pfand für einen anderen verschwundenen Schirm war; diesen hatten ihm seine Kollegen in Moskau zum Geburtstag geschenkt. Ein Rückblick schildert die Feier und erklärt, warum Narator sich bei einer Reise in Großbritannien absetzte: Er wollte erfahren, wer sich hinter den stimmen des "BBC Russian Service" verbirgt, wo er jetzt selbst arbeitet. In Moskau war der unscheinbare Mann in einem Ministerium angestellt, um in Schriftstücken orthographische Fehler $z u$ berichtigen. Da diese Arbeit beim Radio überflüssig ist, läßt man inn im "Russian Service" die richtigen Akzente setzen.

Die Schreibkraft Cilja, ebenfalls russischer Herkunft, sieht Narator in Gefahr, als er inr seine Lebensgeschichte und den Vorfall mit dem Regenschirm erzählt. Sie spekuliert, daß die sowjetischen Geheimdienste inn - wie bereits einen anderen $B B C$-Redakteur - bei einem Anschlag mit einer vergifteten Schirmspitze töten wollen.50 Dank

19 In den ersten drei Romanen (Izvesćenie, Peremescéennoe lico, Niśa $v$ Panteone) geht es um die Suche des Emigranten nach den eigenen Wurzeln und seine Verbundenheit mit der Vergangenheit, die den Beginn eines neuen Lebens belastet. Dabei vermischen sich Erinnerung, Legende, Traum und Fiktion mit der Realität. Den Werken ist auBerdem eine Tendenzz zum Komischen und Phantastischen gemeinsam.

50 Ein solcher "Regenschirmmord" hat sich tatsächlich 1978 in London ereignet. Das opfer war Georgi Markow, ein bulgarischer Schriftsteller und Mitarbeiter des bulgarischen Dienstes bei der BBC. Indizien deuten auf den bulgarischen Geheimdienst als Urheber. (S. Markows Kurzbiographie in Peter Boris, Die sich lossagten: Stichworte zu Le- 
inres Geschwätzes steht Narator plötzlich im Mittelpunkt der Aufmerksamkeit. Besonders interessiert sich die englische Reporterin Valery für inn. Sie geht einige Male mit dem vermeintlichen Dissidenten aus und läBt inn bei sich wohnen, wird ihn aber bald wieder leid. Narator verläBt sie und stirbt wenige stunden später, nachdem inm ein Mann mit einem Regenschirm erschienen ist. 51

In dem Roman steht die psychologische Dimension des Geschehens im Vordergrund. Kirill Narator, auf dessen Name später noch eingegangen wird, scheitert an der Unmöglichkeit, sich als "einfacher sowjetischer Mensch"52 in dem fremden Land einzuleben. Er findet keinen Platz für sich, zumal er auch bei der BBC nicht wirklich gebraucht wird, und fühlt sich nichtig und allein (33 u. 64). Der Grund ist die für ihn unüberbrückbare kluft zwischen seinem früheren und seinem jetzigen sozialen und kulturellen Umfeld. Das England in Russkaja slużba unterscheidet sich fundamental von dem zentral und kollektiv organisierten Sowjetstaat dadurch, daß hier Distanz zwischen den Menschen herrscht und jeder sich selbst überlassen bleibt. ${ }^{53}$ Bezeichnend für die andere Mentalität sind die höflichen Umgangsformen, die auf Narator falsch wirken. ${ }^{54}$ Als er zum Beispiel in der BBC-Kantine die schwingtüren offenhält,

ben und Werk von 461 Exkommunisten und Dissidenten, Köln, 1983 ).

5l Ein Vergleich mit der Erzählung Sinel' (Der Mantel) von Nikolaj Gogol' bietet sich an: Ihre zentrale Figur, Akakij Akakievic, ist ebenfalls ein unbedeutender, einsamer Angestellter, der in einer Amtsstube Abschriften anfertigt. Sein Leben dreht sich - wie Narators - um einen Gegenstand, hier einen Mantel, der dadurch schicksalhafte Bedeutung erhält. Akakij Akakievic stirbt schlieblich an seiner Schwäche und Lebensangst. Somit hat die Erzählung auch ein ähnliches Ende wie Russkaja služba. - Priscilla Meyer führt in einer Rezension aus, daB zinik sich nicht nur inhaltlich, sondern auch stilistisch an Gogol' angelehnt habe, um eine irreale stimmung zu erzeugen ("zinovy Zinik: The Russian Service", Ulbandus Review (New York), $\mathrm{Nr}_{52}$ 5, Fall 1987, S. 179-182).

52 Zinik, Russkaja slużba, Paris: Sintaksis, 1983, S. 40.

53 Bsp.: die Straßenarchitektur mit Reihenhäusérn, die Narator wegen ihrer Leblosigkeit wie "Särge" vorkommen (32); die Geschlossenheit der sozialen Klassen (164u. $167)$.

4 . auch den vergleich mit dem groben, aber ehrlichen verhalten, das in der Sowjetunion üblich sei (102). 
bedankt sich jeder vorbeigehende mit einem maskenhaften Lächeln, doch niemand löst inn $a b$, bis die Türen ihm aus Versehen entgleiten und einer Kollegin das Tablett voller Kaffeetassen aus der Hand schlagen (125 ff.). In ironischer Ubertreibung geben solche szenen von der Außenseiterposition des Emigrantenhelden aus humorvoll, aber kritisch Einsicht in die heuchlerische englische Gesellschaft.

Zugleich wird durch Narators charakterisierung das Sowjetsystem angeprangert, das seine Bürger offenbar so unselbständig und dumm macht, daB sie in einer anderen Umgebung nicht lebensfähig sind. Besonders anschaulich wird dies in den satirischen Alltagsepisoden, in denen ziniks naiver Antiheld Mühe hat, banale probleme zu lösen. Wenn er zum Beispiel nicht die richtigen stecker finden kann, um ein Heizgerät anzuschließen und die ungewohnte kälte im zimmer $z u$ vertreiben (7l ff.), symbolisiert die komische Begebenheit den Mangel an menschlicher Wärme in Narators Emigrantendasein und seine Hilflosigkeit in der neuen Realität, der er ausgesetzt ist.55 Ähnlich werden ironisch noch andere, für den Ausländer unverständliche Gepflogenheiten der Engländer vorgestellt, etwa die Kontrolle der Zugfahrkarten erst nach dem Aussteigen (56-57) oder die getrennten Wasserhähne (100-101 u. 143).

Narators Fremdsein in London illustriert auch die Beschreibung der stadt aus seiner Perspektive. Die starken Sinneseindrücke am Leicester square beispielsweise spie-

55 Die Darstellung weist Parallelen zu dem Roman Pnin von vladimir Nabokov auf. Der Titelheld, ein russischer professor in den USA, ist zwar im Gegensatz zu Narator gebildet, doch ebenso uberfordert mit dem amerikanischen Alltagsleben, was inn in den Augen der Einheimischen schrullig macht. Nabokov vermittelt ähnlich wie zinik beide Perspektiven. In einem Aufsatz uber den EinfluB Nabokovs auf russische Exilautoren sieht Priscilla Meyer zinik in seiner Nachfolge, da beide in inrem werk thematisierten, wie schwer es sei, die Welt "mit neuen Augen" $z u$ sehen ("Nabokov: Sintez kul'tur", Obozrenie (Paris), Nr. 15, Juli 1985, S. 11). - Von einer gewissen Auseinandersetzung mit dem berünmten Autor zeugt auch ziniks fiktives Interview "Voobrażaemoe interv'ju s vladimirom Nabokovym", Sintaksis, $\mathrm{Nr} .15,1986, \mathrm{~S} .178-187$. 
geln sich in einer lyrischen Bildsprache wider (149; vgl. auch 159).56 zugleich assoziiert Narator mit dem wahrgenommenen "automatisch" Erinnerungen an die Sowjetunion (151; auch 149). Ein Ausflug in das chinesische viertel soho setzt dann gleichsam seine Emigration fort. Hier ist er absolut verloren, so $\mathrm{daB}$ es $\mathrm{zu}$ einer Kette von MiBverständnissen beim Bestellen in einem chinesischen Restaurant kommt (152 ff.). Wie in der Anekdote mit der steckdose nutzt zinik auch in diesen szenen die potentielle Komik, die die Konfrontation einer Person mit einer fremden kultur birgt.

Durch die Gegensätzlichkeit von Narators sowjetischer Prägung und seiner äuBeren Welt entsteht eine Doppelperspektive auf die Sowjetunion und England. 57 AuBerdem hat der Held auch zeitlich die orientierung verloren: zum einen konkret durch die zeitdifferenz zwischen Greenwich und Moskau sowie die Sommerzeit (62), zum anderen sprachlich durch das englische Tempus der "Vergangenheit im Futur" (75). Übertragen bedeutet diese Verwirrung den Verlust sowohl seiner Vergangenheit als auch seiner zukunft, da er sie mit der Gegenwart nicht in einen zusammenhang bringen kann. Das folgende zitat belegt, daß inm die Leere seines Lebens bewuBt wird, wenn auch nur vage, wobei die unklare Ausdrucksweise die Einfachheit seines Geistes widerspiegelt:

"Сначало ему казалось, что если сейчас ничего у него за душой не осталось, то было, по крайней мере, что-то прежде; но потом он понял, что и прежде ничего не было, и в будущем ничего не будет."

("Anfangs dachte er, wenn inm jetzt nichts für die Seele bleibt, so gab es zumindest früher etwas: doch dann

56 In seiner Rezension stellt Alex de Jonge ebenfalls eine Analogie zu Nabokov fest, indem er in den Passagen über London züge von Nabokovs Berlin-Porträt in dem Roman Dar ("Das Geschenk") erkennt: "They are highly lyrical, while retaining the strangeness of an alien point of view." ("Un- and Other Realities", The Times Literary Supplement, H. 4182, 27.5.1983, S. 538).

Vgl. P. Meyer in Ulbandus Review: "[...] the author manages to hold an England and a Russia in suspension, merging and separating them so that both are heightened, [...]" (a.a.0., S. 181). 
begriff er, daß auch früher nichts war und in der zukunft nichts sein wird.") (61)

In einer entsprechenden Schlüsselszene (79-85) hört Narator in einer U-Bahn das Lied einer straBenmusikerin, das inn an seine Kindheit erinnert. Doch die Sängerin verschwindet, und Narator vernimmt nur noch ein Echo. Bei dem Versuch, dieser spur der Vergangenheit zu folgen, verläuft er sich in den Gängen der U-Bahn-Station, die zum sinnbild für das Labyrinth seines Lebens werden (vgl. 192).

\subsection{Die Metaphorik}

Zinik führt in seinen Essays aus, daB der Emigrant eine eigene adäguate Sprache, das heiBt, Wahrnehmungs- und Ordnungskategorien sowie Ausdrucksmittel entwickeln müsse, um seine situation und sein Leben $z u$ erfassen. Metaphorisch spricht der Autor von der Notwendigkeit, "neue Worte" zu finden. Russkaja sluzba entfaltet diesen Gedanken anhand der Hauptfigur.

Narator definiert sich im wesentlichen durch sein Verhältnis zur sprache. Dies macht bereits sein Beruf deutlich. Die Aufgabe, Manuskripte auf inre sprachliche Korrektheit $z u$ prüfen, hat er so verinnerlicht, daB er auch im privaten Gespräch automatisch Aussprachefehler verbessert (z.B. 88). Der Inhalt der Texte und Aussagen spielt für inn hingegen keine Rolle. Der beflissene Einsatz für die Einhaltung der grammatischen und phonetischen Regeln offenbart den typischen Sowjetbürger, der sich an vorgegebenen Normen orientiert, ohne sich eigene Gedanken zu machen. In England hält er daran fest, was für sein Verharren in den gewohnten Denkschablonen steht. Darauf deutet auch ironisch seine Erklärung, er sei kein defektor (von engl. defector für "überläufer"), sondern ein nevozvraśčenec, weil dieses russische Wort dem Anglizismus vorzuziehen sei (88). 
Was sein status unabhängig von der Bezeichnung konkret und praktisch bedeutet, reflektiert Narator jedoch nicht. zu einer selbstdefinition ist er ohnehin unfähig, denn es fällt inm schwer, sich auszudrücken (63). Statt seine stimme $z u$ erheben, um beachtet $z u$ werden, ist der Antiheld daran "gewöhnt, sein eigenes Leben nicht einmal wie ein Wort, sondern wie einen namenlosen Laut vor sich hinzumurmeln" ("privykšij probarmatyvat" sobstvennuju zizn' pro sebja kak nekoe daže ne slovo, a anonimnyj zvuk"; 106). Der Erzähler beschreibt diese Hemmung, sich zu artikulieren, als ein Merkmal der sowjetischen Mentalität (160-161). In der westlichen Gesellschaft aber werden von Narator "eigene Worte" verlangt (161), das heiBt, Selbstbewußtsein, Individualität und Urteilsvermögen. Da er darüber nicht verfügt, kann er weder sein früheres noch sein jetziges Leben verarbeiten: Für beide Welten "gibt es keine Worte" (180). Die gegenwärtige Realität kann er so wenig wie ein kind begreifen und in das richtige Verhältnis zu sich selbst setzen. 58

In der Sowjetunion war der Westen für Narator das Jenseits, von dem er keine konkrete Vorstellung hatte, aber aus dem stimmen $z u$ inm hinüberklangen: die ausländischen Radiosender. In London muß er feststellen, daß die Stimmen mit den jeweiligen Personen "nicht zusammenpassen" (61). Außerdem wiederholen sich die gesendeten Nachrichten im Prinzip, das heiBt, es handelt sich gar nicht um Mitteilungen, sondern lediglich um einen Wortschwall (133). Die stimmen verfügen mithin über eine eigene ewige Existenz, so daß sogar ein toter Redakteur im Äther weiterleben kann (60). Hier wird die Idee, daß Narator wegen seiner Sprachlosigkeit nicht wirklich präsent und lebendig

\footnotetext{
58 Zitat (182): "Esli vsë éto $i$ zapominalos" glazom, to kak necto razroznennoe, bez smysla i obšcj idei, kak v golove u rebënka, ne sposobnogo svjazat' razmer predmeta $s$ rasstojaniem ot glaz, risujuščego sebja v tom ze masštabe, cto $i$ dom, gde on íivët." ("Wenn er das alles auch im Gedächtnis vor Augen hatte, so nur als etwas Uneinheitliches, ohne sinn und eine umfassende Idee, wie im Kopf eines Kindes, das die GröBe eines Gegenstands nicht mit dessen Entfernung verbinden kann und sich selbst genauso groß zeichnet wie das Haus, in dem es wohnt.")
} 
ist, umgekehrt und ins Absurde gesteigert. Die Metapher der stimme durchzieht in dieser Weise den ganzen Roman, um die Atmosphäre des Irrealen, Unheimlichen und Schattenhaften $z u$ vermitteln, die den Emigranten umgibt. 59

Die Verbindung zur zentralen Regenschirm-Metapher schafft ein Zitat von Anna Achmatova, das auf dem Griff des Damenschirms eingraviert ist, den Narator als Ersatz für seinen sowjetischen erhält. Die betreffenden worte "Mne golos byl" ("Mir war eine stimme") sind der Anfang eines Gedichts, in dem das lyrische Ich von einem lockenden Ruf in eine andere, reine welt erzählt, den es in sich vernommen habe. ${ }^{60}$ Russkaja sluzba realisiert Achmatovas Metapher auf zwei Ebenen, indem der Held den Stimmen der BBC nach London folgt und auBerdem dort vor seiner Verantwortung und der Realität in eine sphäre der Erinnerung und Phantasie flieht. ${ }^{61}$ Der Schirm dient dabei als Leitmotiv. Er spukt guasi durch Narators Geschichte, während er tatsächlich verschwunden und angeblich über Umwege zurück nach Moskau gelangt ist (99-100). Das Erinnerungsstück, das Narators Herkunft bezeugt (26-27), wird zum Identifikationsobjekt. ${ }^{62}$ Es repräsentiert seine unverarbeitete vergangenheit, die inn verfolgt, und verdeckt sinnbildich die sicht auf seine gegenwärtige Umgebung und das wirkliche Leben:

$59 \mathrm{Vgl.} \mathrm{Ziniks} \mathrm{Essay} \mathrm{"Goticeskij} \mathrm{roman} \mathrm{..."} \mathrm{(a.a.o.).}$

60 Das Gedicht findet sich in A. Achmatova, Soćinenija $v$ dvych tomach, Bd. 1, Moskau, 1986, S. 135 .

6) Elena Gessen führt in einer Analyse von ziniks frühen Romanen aus, daB sie im wörtlichen sinn aus Literatur hervorgingen, da sie auf Metaphern anderer Autoren basierten. Bei Izvešcenie stammen sie den Angaben zufolge aus dem Märchen "Der kleine Muck" von Wilhelm Hauff, bei Nisa $v$ Panteone von dem französischen Schriftsteller Anatole France. Gessen hebt auch hervor, daB die Helden in allen drei Romanen sich beruflich mit Sprache beschäftigen und inre Probleme mit der Fremasprache die mangelnde Anpassungsfähigkeit belegen. ("Kto my $i$ otkuda?...", Vremja $i$ my, Nr. 107, 1989 , S. 170-171.)

62 Vgl. "GotiČeskij roman ..." (a.a.o.. s. 52) über die Beziehung sowjetischer Emigranten zu inrer mitgebrachten Kleidung. 
"[...] эта крышка была у него на мозгах, где бы он ни был и что бы ни делал, [...] и под этой крышкой, что ни кричи, услышишь только эхо собственного голоса [...]. Или это не крышка, а зонтик, зловещая тень которого ходит за солнцем, за которым ходишь ты."

("[...] sein Verstand war unter einem Deckel, wo immer er auch war und was immer er auch tat, [...] und unter diesem Deckel kannst du schreien, wie du wilist, und hörst doch nur das Echo der eigenen stimme [...]. Oder es handelt sich nicht um einen Deckel, sondern einen Schirm, dessen drohender Schatten hinter der Sonne geht, hinter der auch du gehst.") (198)

Das unheimliche, einsame Emigrantenleben drückt sich somit in Narators Besessenheit von dem Schirm aus. Auf inn projiziert er seine schuldgefühle gegenüber der verlassenen Heimat, was sich in einem Alptraum äuBert (98), und seine Lebensangst, die in seinem Todeswahn bildhaft wird.63 In einer phantastischen szene, also offenbar in seiner Einbildung, erhält er nämlich den prophezeiten stich mit einer vergifteten Schirmspitze.64 $\mathrm{DaB}$ sie dabei genau in eine Tätowierung trifft, ist für die Interpretation des Endes von besonderer Bedeutung. Die Tätowierung symbolisiert Narators Brandmarkung in seinen Jugendjahren durch eine Erniedrigung: Er wurde von Kameraden sexuell belästigt (184-188). Dieses verdrängte Erlebnis wird in eine Beziehung $z u$ seiner Emigration gesetzt, indem Narator erkennt, daß es inn unbewußt immer wieder veranlaßte, vor sich und dem realen Leben $2 u$ fliehen. ${ }^{65}$ In diesem Moment nimmt er endlich erstmals das wirkliche London wahr (188),

$63 \mathrm{Vgl}$. Il'ja serman, der bemerkt, daß zinik mit der Angst ein Motiv aufgreife, das etwa auch für die deutsche Exilliteratur typisch sei ("Puti samopoznanija v uslovijach svobody: Russkaja emigrantskaja proza 1975-1985", Manuskript des dt. Beitrags zur Konferenz der ICSEES uber die Literatur der Dritten welle in Washington D.C., 1989 , S. 4 ) .

64 Nach der Interpretation von Elena Gessen realisiert der SchluB eine weitere Metapher aus einem literarischen Zitat, nämlich von Majakovskij, der forderte, die Feder mit dem Bajonett gleichzusetzen. Narator assoziiere mit der Schirmspitze das Bajonett des vaters, der einst als Revolutionär für die sprachreform gekämpft hatte, während er selbst wegen seiner sprachlosigkeit versagt habe und dafür büßen müsse (a.a.0., S. 173-174).

65 Mit der Episode gibt' Zinik eine psychoanalytische Erklärung für die Komplexe, Opferhaltung, Scham, Impotenz und Unreife seines Helden. 
das bedeutet, die Realität. Doch seine Ängste, Phantasien und Komplexe holen inn wieder ein, symbolisiert durch den Schirm, den er plötzlich wiederfindet (194), und den Vater, der inm in einer Erscheinung sein Versagen klarmacht (199). Der stich mit der Schirmspitze in die Tätowierung besiegelt quasi den zusammenhang zwischen seiner Lebensangst und dem Trauma seiner Jugend. Er setzt den "grammatisch richtigen Schlußpunkt" (199) unter diese Geschichte, in der Zinik das Scheitern des Emigranten im realen Leben aufgrund der Dominanz seiner inneren welt und seiner Vergangenheit metaphorisch gestaltet.

Zum AbschluB sollen noch einmal bestimmte Metaphern herausgegriffen werden, um ziniks Verknüpfungstechnik $z u$ erläutern. In Russkaja služba finden sich wiederholt Bilder, die mit wasser $z u$ tun haben. Sie stehen insofern alle indirekt in Verbindung mit Narators Schiffsreise nach England. Narators Tätowierung zum Beispiel stellt eine Möwe auf einer welle dar (169). Wellen tauchen auch in dem Lied über den Kampf gegen das stürmische Meer des Lebens auf, das er in einer U-Bahn-Station hört $(80)$. Es sind die Möwen an der Themse, die inm plötzlich für einen Moment das wirkliche Leben um inn bewußt machen, und als zeichen dafür spürt Narator den Regen - ein Teil der englischen Realität, gegen die er sich immer abgeschirmt hat (192193). Die "Wasser-Bilder" ziehen sich so durch den ganzen Roman und zeigen exemplarisch die Leitmotivik bei der Verarbeitung der Emigrationsthematik in ziniks prosa.

\subsection{RuBland-Mythen und Heldenrollen}

An einer stelle wird Narators Leben mit einem Manuskript verglichen, das er mit jedem Einschnitt erneuert (184).66 DaB die Gestalt nur ein schriftlich fixierter,

66 Die Auffassung des Lebens als Text liegt insbesondere auch Ziniks Roman Peremescennoe lico zugrunde. Der Emigrantenheld versucht hier, sein mitgebrachtes Archiv mit Zeitungsartikeln, Zitaten, Briefen und anderen Dokumenten zu ordnen, nachdem eine Katze ein heilloses Durcheinander angerichtet hat. Damit steht er vor der Aufgabe, seine 
narrativer Entwurf ist und als erzählerische Fiktion existiert, betonen von vornherein sein Vorname kirill, der auf die kyrillische schrift verweist, und sein Nachname, der sich auf das lateinische narrator für "Erzähler" bezieht. Freilich widerspricht der Name ironisch Narators Defizit an rhetorischen Fähigkeiten, und an seiner stelle redet eigentlich der Romanerzähler über inn. AuBer inm romantisieren und mythologisieren aber. auch die anderen Figuren Narators Emigrantenschicksal und seine Heimat, so daB innerhalb der Handlung weitere Fiktionen aus verschiedenen Perspektiven entstehen und dem eigentlichen Antihelden diverse Heldenrollen übergestreift werden.

Bereits in der Eingangsszene tritt Narator verkleidet auf, und zwar in einem Film als Fahnenträger bei der russischen Revolution. Die Beschreibung vermischt Eindrücke der Dreharbeiten mit den Filmsequenzen, wobei absurde Effekte entstehen. ${ }^{67}$ sie werden dadurch verstärkt, daß Narator das Schauspiel ernst nimmt, weil er die glorreiche zeit seines vaters nachempfindet, und stolz das Banner schwingt (8), bis er in eine andere statistengruppe geschickt wird. 68 Der Diebstahl des Regenschirms reiBt inn aus diesem Theater heraus, und er sieht sich plötzlich von Fratzen umgeben (28-29). Der Eindruck des Maskenhaften, der sich später angesichts des aufgesetzten Lächelns der Engländer wiederholt (125 ff.), kennzeichnet Narators Fremdsein. Niemand kann die Tragweite seines Verlustes nachvollziehen, so daß er mit seiner Erfahrung isoliert

Vergangenheit aus verschiedenen Ausschnitten $2 u$ einem ganzen Text bzw. seiner Identität zusammenzusetzen. Diese Tätigkeit entspricht wiederum der des Schriftsteliers in der Emigration.

67 Bsp.: eine Megafonstimme mahnt, mit dem Schnee sparsam umzugehen (8); die statisten rennen im Kreis, um den Eindruck einer Massenbewegung $z u$ erzeugen (12).

68 Bei dem Film zählt nur sein slawisches Gesicht, das auch "Sema", "Sena", "Sanja" und "Seva" (5, 17, 19) haben, wobei die Aufzählung Austauschbarkeit impliziert. Übertragen wird so auf die Nichtigkeit des einzelnen Emigranten angespielt. - Auch hier gibt es eine Parallele zu Nabokov: In dessen erstem Roman Maschenka ubernimmt die Hauptfigur Ganin in Filmen Statistenrollen, die das schattenhafte Dasein der russischen Emigranten im Berlin der 20er Jahre versinnbildlichen (V. Nabokov, Maschenka, Reinbek b. Hamburg, 1994, S. 21-22 u. 39-40). 
ist. Der Roman macht so gleich zu Beginn die situation und die psychische Verfassung des Emigrantenhelden plastisch, für den sich Erinnerung, Fiktion und wirklichkeit ineinanderschieben. Der triviale amerikanische Film kontrastiert dabei mit Narators innerer Welt. Priscilla Meyer erläutert anschaulich die Funktion der szene:

"The brilliant opening, then, provides a rich comicpathetic image of the problem of projection from all angles: from the Russian emigre Narator's to the American film-maker's literal projection. Each one of them has his portable Russia, and all of these Russias are fictions." 69

In dem Roman erscheinen noch andere RuBland-Bilder, die ebenso fiktiv sind. So hält cilja, deren Mutter vor den Bolschewiken fliehen muBte, den Mythos des vorrevolutionären RuBlands lebendig, indem sie etwa ihre wohnung der Epoche gemäß einrichtet (70-71; 87-88). Hier fühlt sich Narator abermals an einen anderen ort und in eine andere Zeit verschlagen, was seine allgemeine Verwirrung diesbezüglich noch steigert. Die wohnung gleicht einem "Mini-RuBland" mitten in London. Ähnlich verwandelt Kostja in Russofobka $i$ fungofil die Küche seines neuen Domizils in ein Abbild seines RuBlands. Der Gegensatz zwischen der eigenen und der fremden kultur wird so räumiich manifestiert.

Cilja vertritt den rückwärtsgewandten, in Nostalgie versunkenen Emigrantentyp (2.B. 79). Inre nationalistische Gesinnung äußert sich vor allem im streitgespräch mit inrem kosmopolitisch eingestellten Landsmann Lidin (69 ff.). Die beiden parodieren den Diskurs sowjetischer Exulanten uber die Heimat, das kommunistische Regime, den Westen und die "Mission" der Russen im Ausland, denn es handelt sich um bloße Rhetorik, während die Diskussion an sich nicht ernstgenommen werden kann. Ein weiteres Beispiel für das Stilmittel der Parodie ist eine BBC-Nachricht, die den sowjetischen Propagandastil imitiert (136-137). Das Verfahren wird so an verschiedenen stellen im Roman wirksam,

69 P. Meyer in Ulbandus Review, a.a.0., S. 182. - Meyer zufolge berunt der Romananfang auf Ziniks eigenen Erfahrungen bei der BBC-Produktion "10 Days That Shook the World" (S. 181). 
indem sich prinzipiell hinter einem Text stets andere Texte verbergen und die Fiktionalisierung verschiedene Ebenen umfaBt. ${ }^{70}$

Cilja beschwört ihre eigene vision von Narator, indem sie auf ihn ihre wahrnehmungsschablonen projiziert: seine berufliche Tätigkeit deutet sie als kampf für die russische Kultur und gegen die böse Sowjetmacht, so daB der Schwächling zu einem oppositionellen und potentiellen Märtyrer erhoben wird (91 ff.). Die Geschichte wird zur Farce, als ihn seine Umwelt am nächsten Tag ebenso behandelt. Daraufhin identifiziert sich Narator mit der Rolle und fühlt sich auf einer stufe mit seinem für ihn legendären Vater (117-118). Bemerkenswert ist, daB er sein Filmkostüm anbehält. Ziniks Held wird quasi innerhalb des Romans tatsächlich ein Romanheld im heroischen sinn und distanziert sich dabei - analog zum Emigrantenautor - von sich selbst. Auf diese Weise wird der BewuBtseinszustand des Emigranten, den zinik in seinen Essays beschreibt, auf die Figur übertragen. Plötzlich kann Narator "sich selbst von der seite" sehen, wie es heiBt, und sein Leben scheint sinn zu machen (118).

Durch die Zuwendung der englischen Reporterin Valery, kurz Val genannt, sieht sich Narator erst recht mitten in einen Roman und an die Schwelle einer "glänzenden zukunft" transferiert, wodurch inm London in einem ganz anderen Licht erscheint und der straßenname "World's End", Vals noble Adresse, eine symbolische Bedeutung erhält (162163). Mit Val nimmt Zinik die englische Gesellschaft und ihr Verhältnis zu Russen aufs Korn. Das berufliche und sexuelle Interesse der Journalistin an Narator resultiert daraus, daB RuBland gerade ein Modethema ist (191) und sie "mit Dissidenten verkehrt wie in den 60er Jahren mit

$70 \mathrm{Vgl}$. die Rezension in The Times Literary Supplement (a.a.o.): "The constant use of [...] gentle exaggeration is an invitation to seek for 'the truth' by reading between these comical and slightly distorted lines. In other words the book constitutes what some would refer to as a text, inviting deconstruction and the perception of subtexts." 
Hippies" (171).71 Mit dem Land verbindet sie unter anderem Gefängnisse und Arbeitslager (150), Devisenrestaurants (152), Dissidenten (164), Tolstoj (165) und Achmatova (171-172), lüsterne Machos (172), Kommunismus (174), Gleichheit und Brüderlichkeit (191). Mit Bezug auf den Diskurs bestimmter politischer Gruppen und die Medien karikiert zinik hier typisch westliche Klischees (der damaligen zeit) und verdreht sie bis ins Groteske:

"Продолжая говорить про Россию и за что она её любит: может быть, большевики и устроили тюрьму народов, но в результате все друг $\mathrm{k}$ другу ходят, навещают друг друга в камере предварительного заключения и едут друг за другом в ссьлку."

("Dabei sprach sie weiter über Rußland und warum sie das Land liebe: mag ja sein, daß die Bolschewiken ein Gefängnis der Völker errichtet hätten, aber deshalb gingen alle aufeinander $z u$, besuchten sich gegenseitig in Untersuchungshaft und folgten einander ins Exil.") (171)

Ihre abstrusen, oberflächlichen und pauschalen Vorstellungen überträgt die Engländerin auf Narator, den sie vor einem Torgitter als "Gefängnis-Kulisse" ablichtet (176) und auch sonst in ein vorgefertigtes Muster steckt. Doch inr RuBland-Bild deckt sich nicht mit seinem, was sich darin ausdrückt, $d a \beta$ er nicht weiß, wie "das alles geschrieben und betont" wird, was Val über seine Heimat sagt (174). Schon bald stellt sich heraus, daB Narator weder im Leben noch im Bett der Held ist, für den sie inn gehalten hat. "Ty ne pochoz na russkogo" ("du bist gar nicht wie ein Russe") stellt sie enttäuscht fest, weil er ihren Erwartungen nicht entspricht, während er versichert, sich zu "bemühen" ("ja postarajus""; 173). Hier kommt die lächerliche Diskrepanz zwischen dem westlichen Dissidenten- und Russenimage und Narators Gewöhnlichkeit zum Tragen. Zugleich erhellt die Komik den Identitätsverlust des Helden.

71 Eine ähnliche Bekanntschaft schildert zinik in der Erzählung "Kriket" ("Cricket", Vremja i my, Nr. 109, 1990, S. 5-45): Die Engländerin Joan, die der Held kennenlernt, stammt wie Val aus der feineren englischen Gesellschaft, die von zinik bloBgestellt wird, und schmückt sich gleichsam mit einem russischen freund wegen seiner "Exotik". 


\subsection{Funktionen der Fremdsprachigkeit}

In Russkaja služba lassen sich durchgehend Einflüsse des Englischen feststellen. Entsprechende Verfahren werden wirksam, um Narators Fremdsein zu veranschaulichen, seine Emigrantenperspektive anzuzeigen und die englische Gesellschaft genauer $z u$ porträtieren. Dieses stilmerkmal ist auch in anderen Werken von zinik zu beobachten, von denen die früheren statt englischer Elemente hebräische enthalten. Volf Moskovic hat sie untersucht und ebenfalls festgestellt:

"Ивритские заимствования выполняют в его прозе определённую художественную задачу - они не только передают местный колорит, но и служат средством передачи мироощущения героя - иммигранта."

("Die hebräischen Entlehnungen erfüllen in seiner Prosa eine bestimmte künstlerische Funktion: Sie vermitteln nicht nur Lokalkolorit, sondern dienen auch als Medium, um die Weltsicht des Helden, nämlich des Immigranten $\mathrm{zu}$ vermitteln.") 72

Moskovic charakterisiert ziniks stil zusammenfassend dadurch, daß der Autor die betreffenden Entlehnungen und Wortdeformationen "organisch in das sprachgewebe einflechtet". 73 Die These läßt sich auf Russkaja slużba übertragen, doch sie erfaßt nur bestimmte Techniken und nicht die gesamte und vielfältige Präsenz der Fremdsprache in diesem Werk. Sie ist hier besonders wichtig, da der Roman die Bedeutung von sprache für die Identität und die Existenz des Helden sowie die Verarbeitung der Emigration deutlich thematisiert. Die folgende Kategorisierung schlüsselt exemplarisch für ziniks Werk auf, in welchen Formen und mit welchen Funktionen das Englische in diesem Text auftritt. 74

72 v. Moskovic, "Zametki o jazyke literatury russkogo zarubez'ja", Russian Philology and History: In Honour of Professor Victor Levin, Jerusalem, 1992, S. 132.

73 Moskovic, a.a.O., S. 129.

$74 \mathrm{~S}$. auch die Beobachtungen von Arnold MCMillin in "Bilingualism and Word Play in the Work of Russian Writers of the Third Wave of Emigration: The Heritage of Nabokov", The Modern Language Review, Bd. 89, H. 2, April 1994, S. 421-422. 
Zunächst ist die Gruppe der Anglizismen anzufüren, die transliteriert oder gemäB inrer Aussprache in die kyrillische Schrift übertragen werden, wobei die wiedergabe teilweise in Anführungsstrichen erfolgt und bei wiederholung mitunter (vermutlich versehentlich) differiert. Sie fügen sich oft so in die Erzähler- oder Figurenrede ein, daB die typische sprechweise von Immigranten erzeugt wird. Einige Vokabeln entstammen Narators Arbeitsalltag und verleihen dessen Darstellung mehr Authentizität, etwa rota (139), das englische Äguivalent für "Schichtplan", oder cholidej (holiday: 145). Andere gehören zum kulinarischen Bereich und sind insofern unübersetzbar: koka-kola (19), sendvic (sandwich; 19) bzw. sandvic (25), fis's cipsami (fish and chips; 130), kebab (149), karri (curry; 158), kornfleksy (cornflakes; 178). ${ }^{75} \mathrm{Zinik}$ bennent so die EBgewohnheiten der Engländer und bildet damit einen Teil ihrer Kultur ab. Das gleiche gilt für Begriffe, die Spezifika des englischen Lebens benennen: fajf-o-klok (five-o-clock [tea]; 125), lejborist (labourite, das heiBt, Mitglied der Labour-Partei; 140), prajuisi (privacy; 168), chippi (hippie; 171). Der seks-zop (sex-shop; 149) ist ein Detail des Londoner straßenlebens, wobei die falsche Transliteration mit "§" statt "ś" auf zopa für "Hintern" anspielt. Avantaz (advantage; 10) wird bei der vergabe der statistenengagements für den Revolutionsfilm gebraucht; hier weist das fremde wort darauf $h i n$, daB die betreffende Konkurrenzsituation typisch für das westliche Gesellschaftssystem ist.

Zuweilen nimmt der Erzähler auch explizit die Haltung des Kulturvermittlers ein und liefert dem russischen Leser eine kurze Umschreibung, etwa für żoping (shopping; 65) oder den "sogenannten gig" im Theater ("tak nazyvaemyj gig": 159). SchlieBlich werden Anglizismen bevorzugt, wenn

75 "Arbeit" und "Küche" gehören tatsächlich zu den wichtigsten Wortfeldern, aus denen sowjetische Emigranten Vokabeln der Fremdsprache übernehmen; $s$. die entsprechende Untersuchung in den USA von David $R$. Andrews, "A Semantic Categorization of Some Borrowings from English in ThirdWave Emigré Russian", Topics in Colloquial Russian, hg. Margaret H. Mills, New York, 1990, S. 157-174. 
Narator eine Person besonders fremd vorkommt. Die Freundin des amerikanischen Schauspielers Dżon Rid (John Reed) tritt entsprechend als dessen gerl-frend (girl-friend; 11) auf, und der Unbekannte, der Narator vor seinem Tod erscheint, ist schlicht ein dżentl'men (gentleman; 196). An einer anderen stelle wird ungekehrt die englische Perspektive vermittelt, aus der nämlich die Nostalgie der Russin cilja dem entspricht, was "auf englisch spleen heiBt" ("ich žizn' zdes' po-anglijskij nazyvaetsja splin"; 88).

Nur dreimal sind englische wörter in lateinischer schrift eingefügt. Es sind Vulgärausdrücke, die auf diese weise umso ausfallender wirken und jeweils mit dem kyrillisch geschriebenen wort kontrastieren, das Narator an inrer stelle versteht. So hört er, nachdem inm bei den Dreharbeiten sein Schirm gestohlen wurde, in dem wiederholten fuck der fluchenden statisten bei den Dreharbeiten stets nur fakt ("Tatsache"; 28) als Ausdruck mangelnden Mitgefühls. Den Graffito CUNT ("Fotze"; 80) liest er als "Kant", also den Namen des Philosophen. Valery übersetzt ihren Ausruf "Shit!" (150) zunächst selbst, um ihre Russischkenntnisse $z u$ demonstrieren, betont das entsprechende govno jedoch falsch und wird von Narator prompt korrigiert. In allen drei fällen wirkt der Held extrem naiv, weil er den fremden Kode nicht entschlüsseln kann. Als Emigrant befindet er sich gewissermaßen auf dem Erfahrungsniveau eines Kindes.

Der Text enthält aber auch ordinäre russische Ausdrücke, die teilweise der Verfremdung englischer Bezeichnungen dienen. Die stilistische wie semantische Ambivalenz solcher bilingualen Neologismen entspricht der überlagerung verschiedener welten in dem Roman. Bibisiski (50) zum Beispiel setzt sich aus BBC und siski für "Busen" zusammen. Im Berufsjargon der zweisprachigen BBC-Mitarbeiter im "Russian Service" heißen dispatches ("Korrespondentenberichte") nur disrači (62), in dem sraka ("Scheiße") steckt. Weniger anstößig ist die spielerische Kombination von panočka nach dem polnischen Ausdruck für "Mädchen" und pank für das englische punk zu dem Doppelbegriff panočka- 
pank, um die schillernde Erscheinung einer Kollegin $2 u$ erfassen (136).

Die zweisprachigen Wortschöpfungen grenzen an die Kategorie der phonetischen, semantischen und syntaktischen Verzerrungen, die unter anderem ortsangaben einschliebt. ${ }^{76}$ Den Londoner Bahnhof "Waterloo" zum Beispiel tauft Zinik um in Vokzal Vaterklozet ("Bahnhof Wasserklosett"; 56), was die Assoziation an Dreck und Gosse weckt. Aus "Leicester Square" wird entsprechend ein "klebriger Fleck", nämlich Klejster skverna aus klej ("Leim") und dem altrussischen Wort für "Fleck". Der Name der Küstenstadt plimut, also Plymouth, in der Narator ankommt, klingt in seinen Ohren wie primut (55), 3. Person plural von primjat" ("niederdrücken, -treten"), worin sich bereits eine Ahnung von seinem Emigrantenleben ausdrückt.

Narator miBversteht freilich auch Floskeln der Alltagssprache, was inn in der gewöhnlichen Konversation als Fremden und AuBenseiter isoliert. Das gemurmelte thanks des Fahrkartenkontrolleurs im Bus reduziert sich für ihn auf die "rätselhafte Interjektion " $t a$ '" ("zagadočnoe meždometie 'ta'"; 61). Ciljas erschrockene Schreie angesichts des verkleideten Narators sind nur noch ein Schwall fremder Laute ("anglijskie zvuki") aus maj (my), aj (I) und elp (help) (66). In einer anderen Episode antwortet er zwar auf die Begrüßung chau ar ju? (How are you?; 140), wie es sich in England gehört mit sen'ku, also thank you, gefolgt von der gleichen Frage. Er spricht diese aber nur nach, ohne ihren sinn wirklich zu begreifen, so daß er charju in grotesker Ableitung von charja ("Fratze, Fresse") formuliert." Bei anorak (167) hingegen hat Narator sozusagen keine eigene Version parat; stattdessen zählt er im Geist die inm bekannten wörter auf, die möglichst fremd und passend klingen, obgleich sie seman-

76 Interessant ist in diesem Zusammenhang Ziniks Hinweis, daß der sowjetische Emigrant Straßennamen u.ä. nicht gewöhnt sei und ihn die Konkretheit der westlichen stadttopographie verwirre ("Gotičeskij roman ...", a.a.o., s. 54 .

Ähnlich ist Narators Phantasie von der chinesischen Sprache in Soho angeregt (150 ff.). 
tisch weit entfernt sind: kunak (ein besonderer Freund bei kaukasischen Völkern), cuvjak (weiches Schuhwerk im Kaukasus), arak (ein ostindischer Branntwein), lapserdak (der Gehrock der polnischen und galizischen Juden).

Zinik parodiert aber auch das fehlerhafte Russisch der Engländer, vor allem von Valery, in deren Geplauder zum Beispiel ein svingujuščij London (171) erscheint - die unverständliche Russifizierung des Begriffs swinging London aus den 60er Jahren. AuBerdem wird darauf hingewiesen, daß sie gemäß der englischen question tags an viele sätze budem my? (152-153) anhängt. Ähnlich verunstaltet ein Vertreter von "Scotland Yard" nach einer Befragung die russische Sprache, indem er Narator versichert: "Éto interv'ju buduci byt' tretiruemo konfidencial'nym." (145) offenbar versucht er eine wörtliche übersetzung des englischen Satzes: "This interview will be treated confidentially." Dabei mißlingt inm jedoch die Partizipkonstruktion, und semantisch ergibt sich eine komische verschiebung durch das Verb tretirovat" ("geringschätzig behandeln"). zinik macht also mit seinen Wortspielen nicht nur seinen Helden lächerlich, weil er sich in der fremden kultur und sprache nicht auskennt, sondern umgekehrt auch die Engländer, denen es ebenso geht.

Die Aufstellung in diesem Abschnitt zeigt, daB die englische sprache den Text stilistisch durchdringt und semantisch vielschichtig macht. Die kreativen Wortspiele bewirken einen verfremdungseffekt und gestalten auf komische weise die situation von Narator, der den Kode der fremden Kultur nicht versteht. Dabei dient die Fremdsprache vorrangig dazu, seinen standpunkt in Beziehung $2 u$ anderen näher $z u$ bestimmen. Die dargestellten stilverfahren entsprechen der Emigrationsthematik und zeugen von der eigenen Erfahrung des russischen Autors in England. 


\section{THB MUSHROOM-PICKBR}

\subsection{Handlung, Rezeption und Verfilmung}

Ziniks sechster Roman Russofobka $i$ fungofil (1984) war der erste, der in englischer übersetzung erschien. ${ }^{78}$ Zuvor hatte der Autor das Werk in der von inm angeregten Verlagskooperative "Russian Roulette" herausgegeben: außerdem hatte Vremja $i$ my den Text in drei Teilen abgedruckt. 79 Erst in der englischen Fassung the MushroomPicker wurde der Roman über die russischen Emigrantenzirkel hinaus einer breiteren Leserschaft zugänglich und in Grobbritannien rezipiert. Daher scheint es legitim und auch zweckmäBig, der folgenden Analyse die übersetzung von Michael Glenny zugrunde $z u$ legen, zumal sie relativ wortgetreu ist, gleichzeitig ziniks stil trifft und allgemein positiv beurteilt wurde. 80

Thematisch und stilistisch weist der Roman einige Parallelen zu Russkaja slużba auf. Der wesentliche Unterschied besteht darin, daB The Mushroom-Picker nicht nur einen Emigranten aus der Sowjetunion in Großbritannien porträtiert, sondern inm seine englische Frau gegenüberstellt und beide Länder auch aus inrer Perspektive zeigt. ${ }^{81}$ Anders als in den vorhergehenden Romanen berücksichtigt zinik in diesem Werk stärker den realen politischen Hintergrund, indem er das Eheleben der Hauptfiguren als ironische Parabel über den Ost-West-Konflikt gestaltet. Dabei

78 Zwischen Russkaja služba und Russofobka i fungofil verfaBte Zinik Uklonenie ot povinnosti (1982). Dieser Roman wird hier übergangen, weil er in Israel spielt. phice)

Genaue Quellenangaben im Werkverzeichnis (Bibliogra-

${ }_{80}$ S. z.B. World Literature Today (fortan World Lit. Today), Bd. 64, H. 1, Winter 1990, S. 148; Anabel Donald, "There's a Fungus among Us", The New York Times Book Review (fortan NY Times Book Rev.), 19.2.1989, S. 10; John Bayley, The Times Literary Supplement (fortan TLS), $\mathrm{H}$. 4423 , 8.-14.1.1988, S. 29. - Verwendete Ausgabe: Zinik, The Mushroom-Picker, London: Minerva, 1993.

81 Sie ist die einzige weibliche Hauptfigur mit einer gleichwertigen Rolle wie die männlichen Helden in ziniks Werk. Die Dominanz des einen Geschlechts hängt mit dem autobiographischen Hintergrund der Romane und Erzählungen zusammen, in denen sich der Autor direkt oder indirekt selbst abbildet. 
gewinnen realistische Darstellungsverfahren und die Gesellschaftssatire an Bedeutung, während auch eine Tendenz zur Farce wie in Russkaja služba vorhanden ist.

In der ersten Hälte von The Mushroom-Picker erfolgen innerhalb einer Rahmenhandlung mehrere Rückblicke, so daß die Schauplätze London und Moskau sich abwechseln und bereits durch den äuBeren Aufbau ein Kontrasteffekt entsteht. In der zweiten Hälfte wird die Handlung allmählich zum dramatischen Höhepunkt geführt.

Die Geschichte spielt in den 70er Jahren. Clea, eine einfache Sekretärin in London, lernt den Russen Nikolai oder kurz Kostya bei einer Neujahrsfeier in Moskau kennen und verliebt sich in ihn. Sie folgte einer Einladung ihrer Freundin Margot, die mit sowjetischen Dissidenten verkehrt. Nach weiteren Reisen bleibt clea zunächst bei Kostya, einem als Fabrikpförtner beschäfigten wirtschaftsprofessor. Seine Eigenart besteht darin, sich praktisch und geistig nur mit Essen, genauer mit seiner Beschaffung, Herkunft und zubereitung $z u$ beschäftigen. Die Situation in der Kommunalwohnung und das sowjetische Alltagsleben werden für die Engländerin zum Alptraum, so daB sie mit Kostya, den sie inzwischen geheiratet hat, nach Großbritannien zurückkehrt und in einen Londoner vorort zieht. Hier beginnt er, fanatisch die kulinarischen sitten seines Landes $z u$ pflegen, wobei er sich nur mit dem polnischen Inhaber eines Delikatessenladens Pan Tadeusz austauschen kann. Kostyas größtes Glück besteht darin, nachts Pilze zu sammeln, was er vor seiner Frau geheimhält.

Clea wird er immer unheimlicher und widerwärtiger, während sie vergeblich versucht, den Anschein von Normalităt zu wahren. Das wird bei einem Besuch von Margot mit Anthony, ihrem Gatten und zugleich cleas Chef, in der Rahmenhandlung deutlich, bei dem Kostya durch sein vulgäres Verhalten für einen Eklat sorgt. Als er in den darauffolgenden Morgenstunden wie gewohnt in den wald fährt, folgen inm Clea und Pan Tadeusz unbemerkt. Bevor es aber zur Konfrontation kommt, werden alle drei verhaftet: Es stellt 
sich heraus, daB Kostyas Pilzgebiet mitten auf dem Gelände eines Atomwaffenstüzpunktes liegt. Nach einem absurden Verhör rücken Soldaten $z u$ einem Spezialeinsatz aus, um die Angaben der mutmaBlichen Agenten über die Pilzvorkommen in der Umgebung $2 u$ prüfen, während im Hintergrund Anhänger der Friedensbewegung demonstrieren. Am Rand des komischen Trubels kommt es $z u$ einem tragischen Unfall, als der junge Colin, den clea aus inrem Büro kennt und der sie einmal vergewaltigen wollte, plötzlich auftaucht, Kostya angreift und sich an dessen Messer tödlich verletzt. Clea unternimmt daraufhin einen Selbstmordversuch, während ihr Mann des Mordes angeklagt wird, aber schlieblich auf mysteriöse Weise verschwindet.

The Mushroom-Picker erhielt in der britischen Presse relativ große und hauptsächlich positive Resonanz. 82 Bei der Vorstellung von $\mathrm{Zinovij} \mathrm{Zinik} \mathrm{betonen} \mathrm{einige} \mathrm{Kritiker,}$ daB er für die Literatur der sowjetischen Emigration untypisch sei.83 sein Roman wird in erster Linie als Satire oder Farce auf beide Welten dies- und jenseits des Eisernen Vorhangs sowie deren gegenseitige Wahrnehmung gesehen. Die Urteile stimmen weitgehend darin überein, daß die Satire gelungen, ausgefallen, scharfsinnig und äuBerst komisch sei, wobei ihr spott nichts und niemanden verschone. Die Sunday Times schreibt entsprechend, Ziniks Hohn treffe "jegliche soziale und politische Heuchelei",84 und das London Magazine stellt fest:

"[...] zinik trains a satirical wit with equal force and accuracy on the 'incurable egotism' of the English character on the one hand and on the tasteless boorishness of the Russian on the other."185

82 AuBerhalb GroBbritanniens ließen sich in Englisch lediglich die folgenden Besprechungen finden: Joseph Coates, "Literature That's Written on the Run", Chicago Tribune, 14.3.1989, Sektion 5, S. 3; NY Times Book Rev., a.a.O.: World Lit. Today, a.a.o.

${ }_{83}$ S. z.B. Carol Rumens, "Far from Typically Dissident", The Sunday Times (fortan Sun. Times), 24.1.1988, Sektion G, S. 6: "Moscow's Mushroom clouds: Hugh Hebert on a Russian Novelist who Is Not Trying to Be Another Solzhenitsyn", The Guardian, 13.1.1988, S. 9 .

84 sun. Times, a.a.o.

85 John Meliors, "Innocents Abroad", London Magazine (fortan Lon. Mag.), Feb. 1988, S. 106. 
Die Klassifikation von zinik als Gesellschaftssatiriker, die the Mushroom-Picker mit seinen derb-komischen Episoden provoziert, rückt freilich die für den englischen Rezipienten offenbar weniger interessante psychologische Dimension der Emigrantenthematik in den Hintergrund. ${ }^{86}$ Die Reaktionen lassen aber in jedem Fall darauf schließen, daß der Autor seine ironische sichtweise vermitteln konnte und den englischen sinn für Humor getroffen hat. John Bayley (TLS) bescheinigt ihm in dieser Hinsicht ein feines Gespür für kulturelle Differenzen bei wahrung seiner russischen Prägung:

"The joke goes on as far as it can. Readers of Krokodil [russisches Satiremagazin], who are said to find English humour rather flimsy, would perhaps be more appreciative than readers of Punch [britisches Satiremagazin]. But zinik is well aware that national modes of humour contrast as much as anything else, and he exploits this as effectively as every other ingredient in his sexual and gastronomic farce." 87

Manche Rezensenten äußern indes stärker Zweifel daran, daß der Roman dem Geschmack des englischen Lesers entspricht: sie halten ihn für stilistisch und symbolisch überfrachtet. Ziniks Kompositionstechnik, aus einer zentralen Metapher fast den gesamten Roman zu entfalten und dabei der Phantasie und sprachlichen Ausschweifungen breiten Raum zu lassen, läuft dem observer zufolge der englischen Rezeptionshaltung mitunter zuwider:

"In other places, Kostia's relentless pursuit of gastronomical bliss leads his creator into thickets of description and narrative intervention which the reader weaned on the trim English novel might find overwhelming." 188

86 Ausnahmen: The Guardian (a.a.o.) mit zitaten von zinik selbst zur Charakterisierung von clea und Kostya; Sally Lairds Erläuterungen in The Literary Review (London) zur Gespaltenheit des Emigranten als eigentlichem Thema des Romans ("Russophobe and Fungophile", Jan. 1988, S. 17; fortan Lit. Rev.).

TLS, a.a.o.

88 James Campbell, "Vodka on the Lawn", The observer, 17.1.1988, S. 25. Vgl. Janice Elliott, "Quarrels with Fungus", The Independent, 4.2.1988, S. 19: "[...] it can be irritating - as when he bangs his symbols with Günter Grass-like insistence [...]." S. auch Richard Deveson, "In a Stew", New Statesman (London), 5.2.1988, S. 32: "It's 
Die meisten Kritiken loben jedoch eher ziniks Stil als lebendig und kraftvoll. ${ }^{89}$ Die Hinweise auf die Schwächen von Ziniks Narration geben allerdings mögliche Anhaltspunkte dafür, warum sein zweiter Roman auf dem britischen Markt, The Lord and the Gamekeeper, so wenig Erfolg hatte.

Die vorliegende russische Rezension von Zufar Gareev in der Nezavisimaja gazeta erörtert Russofobka $i$ fungofil in Form eines Essays.90 Ein Vergleich mit den englischen Besprechungen zeigt, daß Gareev wesentlich stärker die Charakterisierung der Figuren und die politisch-philosophischen Aussagen im Roman kommentiert, während er dessen satirische Qualitäten nicht besonders hervorhebt.91 Ziniks stil vergleicht der russische kritiker unter anderem mit Musik, die bei aller Düsterkeit wegen der durchscheinenden "Zartheit" auch ergreifen könne. Insgesamt wird deutlich, daß Gareev vollkommen andere Beschreibungs- und Argumentationskategorien verwendet und den Roman sozusagen ernster nimmt als seine englischen Kollegen. Das Beispiel veranschaulicht die Zwischenstellung des emigrierten Autors zwischen der Rezeption in der Heimat, die im Fall RuBlands traditionsgemäB moralische und politische Aspekte in den Vordergrund stellt, und im Aufnahmeland, hier also in Grobbritannien, wo marktbedingt der Unterhaltungswert und die Originalität des Werkes größeres Gewicht haben.

Die BBC schätzte The Mushroom-Picker in dieser Hinsicht so hoch ein, daß sie den stoff in eine dreiteilige

never really possible to work out what all the symbolic goings-on are symbolising."

89 S. 2.B. Alan Brien, "Glasnost without Tears", Punch (London), 29.1.1988, S. 43 ("vigorous, physical, sweating, alive stretches of prose"): ferner sun. Times, a.a.o. ("effervescent piece of writing"): NY Times Book Rev., a.a.o. ("meltingly rich on the tongue").

90 Zufar Gareev, "Citaja Russo, sobiraja griby", Nezavisimaja gazeta (Moskau), 14.4.1992, S. 7.

91 Bsp.: Für Gareev ernält clea durch inre neurotische Leidensbereitschaft, auf die hier noch eingegangen wird, die moralische Reinheit des opfers, was sie gleichsam zu einer russischen Heldin mache. Hinter der Geschichte von Kostya sieht er die Erkenntnis, das niemand vor sich selbst fliehen könne. 
Fernsehserie verwandelte. 92 Die Produktion wird der Vorlage nach meiner Ansicht aber nicht gerecht, da sie sich ganz auf die karikaturistischen Momente beschränkt. Die Satire wird extrem überspannt und verkommt dadurch $z u$ einer posse voller vulgaritaten, Plattheiten und Klischees mit grell gezeichneten Figuren, die nur noch verrückt und grotesk wirken. 93 Die psychologischen Aspekte und die Tendenz zur politparodie in ziniks Werk, die in der folgenden Analyse herausgearbeitet werden, gehen auf diese weise verloren. Insofern bietet die eher kitschige verfilmung AnlaB zum Zweifel, ob sie zinik tatsächlich zugute kam, auch wenn sie ein Massenpublikum erreichte. ${ }^{94}$

\subsection{Eine Engländerin in Moskau}

Die Doppelperspektive des Emigranten, der die verlassene und die gegenwärtige welt zugleich verfremdet sieht, wird in the Mushroom-Picker auf die beiden Hauptfiguren übertragen. Clea und Kostya erleben jeweils das Heimatland des anderen als abweisend und seltsam, so daB ihre ursprüngliche Faszination der Ernüchterung weicht und ihnen inr fundamentales Anderssein bewuBt wird. Dabei stoBen die "Eindringlinge" jeweils mit bestimmten Typen der anderen

92 Drehbuch: Liane Aukin; Regie: Andy wilson; Produktionsleitung: Estelle Daniel; in den Hauptrollen: Nigel Terry, Lynsey Baxter: Sendetermine: 3.2.1993, 10.2.1993, 17.2.1993 im Abendprogramm von BBC 2. Nach Angaben von Tom Birchenough in The Times ("Outsider's View of an Incomer", 28.1.1993, S. 38) handelt es sich um die erste verfilmung eines zeitgenössischen russischen Romans durch BBC 2 .

${ }_{93}$ Die vorliegenden Pressestimmen gestehen der serie durchaus Komik und originalität $2 u$. Hier ist $2 u$ berücksichtigen, daB eine derart überzogene Darstellung bei britischen Unterhaltungssendungen üblicher ist als etwa bei deutschen. S. Mick Imlah, "Choice Cuts, Fine Fungi", TLS, H. 4689, 12.2.1993, S. 18; Benedict Nightingale, "Russian Recipe Uses Strange Ingredients", The Times, 4.2.1993, S. 33 9.

Der Autor äuBerte sich im persönlichen Gespräch zurückhaltend: "In English it [the novel] is so exotic in a way that the more they would have tried to make it real, the better it would have been, I think. [...] on the other hand it has been done with such a spark and force that it has its own merit. Apart from the third part it says very little of the real motives in the novel." (Anhang, S. 186) 
Gesellschaft zusammen: Kostya in London mit Anthony, cleas Chef und Bekannten, und clea in Moskau mit Kostyas Nachbarn in der Kommunalwohnung. Die Konfrontation der Figuren ermöglicht die Entlarvung beider Gesellschaften durch die Ubertreibung charakteristischer Merkmale. Der Roman analysiert so insbesondere nationale vorurteile und Klischees sowie die verschiedenen Haltungen zur eigenen kultur, die sich jeweils im verhältnis zur fremden indirekt ausdrücken.95

In den ersten Kapiteln überwiegt cleas Perspektive. sie ist ihrer Heimat überdrüssig, wo ihr Leben so eintönig grau ist wie das wetter (58) und inre soziale stellung relativ gering. Deshalb empfindet sie es als umso scheinheiliger, wenn beispielsweise Anthony mit gespielter Bescheidenheit erklärt, er bevorzuge einfachen Parkettboden, der aber tatsächlich viel teurer als Teppich ist (136), oder clea von Margot Komplimente über ihren Garten und inr Haus bekommt ("lovely!"; 13-14) und dennoch deren Geringschátzung spürt (10). Besonders zur weihnachtszeit offenbart sich für clea die Falschheit der Engländer etwa in dem Sammeln von spenden für soziale Minderheiten:

"Deprived by history of the opportunity to experience fraternity on the revolutionary barricades, people exhibited their unexpended enthusiasm for solidarity in such a way that incurable egotism and an innate standoffishness might look like sincere gestures of each individual's concern for the collective." (44)

Diese Gesellschaft wird nach cleas Auffassung von Egozentrik und dem primat des privaten (privacy) beherrscht (51), auf das sie inre Einsamkeit zurückführt, und überläßt jedem die Verantwortung für sich selbst (59), die clea als Last empfindet. Ziniks Heldin ist überzeugt, daB die resultierende Gefahr der Verlorenheit für den einzelnen in anderen Ländern kaum existiert ( 51 u. 58). Besonders in der Sowjetunion vermutet sie eine "Gemeinschaft

95 Der Chicago Tribune (a.a.o.) aủbert sich anerkennend über Ziniks Perspektivierung: "The Mushroom-Picker is also a technical triumph in use of point of view to put the reader exactly where he should be at any given point in the action for the book's meaning to unfold in his mind." 
der Gedemütigten und Unterdrückten" (116), mit der sie sich emotional verbunden fühlt. Rußland scheint überhaupt der ideale zufluchtsort für die frustrierte sekretärin zu sein, weil es in absolutem Gegensatz zum kapitalistischen Großbritannien steht. Deshalb beginnt Clea auch ihre Beziehung mit Kostya, obwohl oder gerade weil sie gleich bei der ersten Ankunft in Moskau merkt, daß ihre vagen, romantischen Vorstellungen von der harten Realität weit entfernt sind (21) und sie sich "niemals an diesen ort gewöhnen wird" (15).

Schon die Neujahrsparty, auf der sie Kostya trifft, befremdet clea total, weil sich die Menschen ganz anders benehmen, als sie es gewöhnt ist. Dabei wird ihr standpunkt deutlich sprachlich markiert. Die schwüle Atmosphäre in der überheizten Wohnung voller "Ausländer" (16), deren überschäumende Herzlichkeit (17) und wilde Ausgelassenheit drohen die Engländerin förmlich zu erdrücken. In eine Ecke und somit im wörtlichen wie übertragenen sinn an den Rand dieses Kulturraums gedrängt (24), nimmt sie die lärmenden Gäste wie "Eingeborene" (natives; 21) und "Barbaren" (22) wahr, die sich hemmungslos auf das Fleisch stürzen, das Kostya mitbringt (29).96 seine Erscheinung weckt in clea alle stereotypen, die sie mit russischen Männern assoziiert und nun auf ihn allein projiziert: vom echten proletarier (28) über den Chauvinisten (34) und die tapferen Helden der Volkslegenden (38) bis $2 u$ den Folterknechten in der Lubjanka (41). Als derart mystische Figur übt er eine fast magische Anziehungskraft auf clea aus.

Bei der folgenden, weitgehend realistischen Schilderung ihres Lebens in Moskau führt zinik die ganze Idiotie des sowjetischen Alltags vor, die erst durch cleas Augen sichtbar wird, während die sowjetbürger selbst sie für

96 Der Trubel kontrastiert stark mit der weinnachtsfeier von Cleas englischen Kollegen, bei der eine kindische Fröhlichkeit herrscht, aber sich niemand wirklich gehenläßt (57). - Viele Kritiken loben diese szene besonders, 2.B. Observer ("The Moscow party [...] displays Zinik's comic-satirical talent at its best."), TLS ("a superb setpiece"), Sun. Times ("a Moscow party, whose manic, claustrophobic atmosphere is vividly evoked"), alle a.a.o. 
Normalität halten. Der Autor betrachtet somit das system, das er von innen kennt, mittels der Figur cleas ironisch von dem AuBenstandpunkt, den er als Auswanderer einnimmt und mit dem sich auch der englische Leser identifiziert. Dieser wird durch clea in die hermetische sowjetische Lebenswelt geführt, die vor allem von dem verteilungskampf um Nahrungsmittel geprägt ist. Zinik beschreibt unter anderem, wie seine Heldin den "Kode" dieser Kultur lernt, nämlich das Vokabular für diverse Tricks beim Beschaffen von Produkten (78), und bei der Suche nach saurer Sahne an den ungeahnten Schwierigkeiten verzweifelt (116 ff.). Auf dem Weg kommen ihr die Menschenschlangen vor den Geschäften wie "Eingeweide einer Leiche" (119) vor - ein Bild für den morbiden Zustand des Sowjetstaates $z u$ jener Zeit.

Die Verdorbenheit des Volkes offenbart sich insbesondere in der dreckigen Kommunalwohnung (109), in der clea mit Kostya haust. Hier wohnt auch Tonya, die von ihrem verkrüppelten und ständig betrunkenen Mann geprügelt wird. Die Russin lockt ihre neue Nachbarin in einen perversen Handel: Sie besorgt ihr über inre Arbeit Frischfleisch und darf dafür ihr eigenes fleischliches Begehren von Kostya befriedigen lassen. Sarkastisch bemerkt der Erzähler: "[...] Clea soothed her conscience with the thought that perhaps this was what communism was, namely a return to barter on a basis of mutual assistance." (103) Die Heldin versinkt in die typisch sowjetische Lethargie (116), bis Tonya von ihrem Mann und Kostya bei einer Kundgebung zusammengeschlagen werden. Diese Ereignisse offenbaren clea vollends die verrohung der Sowjetbürger und veranlassen sie zur Rückkehr in ihr gesittetes spiebbürgerleben in London, das zinik als das andere Extrem präsentiert.

Seine Satire über die Sowjetunion wurde von vielen britischen Kritikern positiv hervorgehoben. ${ }^{97}$ Ein Grund mag darin liegen, daB der englische Leser cleas Erlebnisse in der Sowjetunion eher nachvollziehen kann als kostyas in England, das heiBt, diese Rezeption hängt mit der Perspek-

97 Bsp.: New Statesman, Independent, beide a.a.0., ferner die zur Party-Szene genannten Stimmen (s.o.). 
tivierung im Roman zusammen. Allerdings verlagert sich der Schwerpunkt im zweiten Teil von Anekdoten und Schilderungen, in denen ziniks stärke liegt, auf Dialoge. Während der Autor RuBland weitgehend in szenen gestaltet, läBt er England durch bestimmte Figuren, im einzelnen clea, Margot und Anthony repräsentieren und konzentriert sich auf ihre Charakterisierung bzw. Karikaturisierung in der opposition zu Kostya (s.u.). Dadurch wirkt die Satire in der zweiten Romanhälfte stärker konstruiert und (zumindest für den westlichen Leser) teilweise $z u$ wortreich.

\subsection{Kostyas kulinarisches Weltbild}

In der Analyse von Russkaja služba wurde bereits erläutert, wie zinik den ganzen Roman auf einigen wenigen Metaphern und Motiven aufbaut, indem er sie auf vielfältige Weise entfaltet und kombiniert. In The MushroomPicker wird dieses Kompositionsprinzip radikalisiert: Fast alles, was geschieht oder gesagt wird, ist direkt oder indirekt mit Essen verbunden.98 Insbesondere die Charakterisierung von Kostya zeichnet sich dadurch aus. Zinik karikiert so den Sowjetbürger, dessen Alltag sich ums Essen dreht und der gleichsam aus dem Bauch heraus lebt. Darüber hinaus ironisiert der Autor die hohe Wertschätzung eines ausgefüllten inneren Lebens in der russischen Kultur. ${ }^{99}$ Andererseits bietet sich die kulinarische Metaphorik an, um die Engländer $z u$ verspotten, da sie für ihre schlechte Küche bekannt sind. Die Unterschiede im Geschmack stehen also in The Mushroom-Picker für die kulturellen allgemein. Überdies werden sie aber auch auf die politischen Verhältnisse bezogen, so daß sich permanent eine Doppelsemantik ergibt.

98 Im Interview mit der Literaturnaja gazeta (a.a.o.: fortan Lit. gaz.) beschreibt zinik die Textgenese so: "Ja daju idee vozmoznost' obrasti detaljami, sozdaju vokrug neẻ illjuziju logičnosti." ("Ich gebe einer Idee die Möglichkeit, sich mit Details anzureichern, und umgebe sie mit der Illusion des Logischen.")

99 Vgl. Interview in Panorama, a.a.o. 
Kostya ist ein Feinschmecker und Meisterkoch; zudem erforscht er die Wurzeln und Entwicklung gastronomischer Bräuche. ${ }^{100}$ Aus diesen Erkenntnissen bezieht er sein Weltbild, nach dem der Westen, den er im Gegensatz zu clea als Einheit wahrnimmt (37), traditionell führend ist (2.B. 37 u. 88) und sein Land nur durch die "Verwestlichung des russischen Magens" ("westernisation of the Russian stomach"; 94) gerettet werden kann. Er ist sogar überzeugt, daB es in der russischen Geschichte immer wieder Fälle von Kannibalismus gegeben nat. Darüber arbeitet er an einer geheimen studie mit dem Titel "Russian Cooking - A story of Terror and Cannibalism" (93), womit zinik die publizistische Tätigkeit sowjetischer Dissidenten parodiert.

In Grobbritannien stellt Kostya wider Erwarten fest, daB inm das westliche Leben nicht bekommt. Seine Emigrationsgeschichte bringt bereits der erste Satz des Romans auf den punkt:

"Marriage to a foreigner and consequent emigration in partes infidelium do not go unpunished: he felt sick and his guts were churning with heartburn." (1)

Sein physisches Leiden resultiert aus dem seelischen an seinem Fremdsein, das wiederum AufschluB über England gibt. Kostya widerstreben die Förmlichkeit und sterilität seiner neuen Umgebung, unter anderem symbolisiert durch den kurzen Rasen im Hausgärtchen (10). Die Engländer sind für Kostya leblos (1) und unverständlich wie ihre sprache (2.B. 128, 137, 205). Er fühlt sich von ihnen wie ein exotisches Tier behandelt ("a specimen of homo sovieticus in an English 200"; 138),101 und seine Unkenntnis der sitten

100 In seinen Exkursen erläutert Kostya unter anderem die Entdeckung der Kartoffel durch Kolumbus (37), die Herkunft des Samowars (37), die gastronomischen Errungenschaften der russischen und sowjetischen Machthaber von Peter dem Großen bis Chrušeèv (89), die Beschreibung eines ukrainischen Nationalgerichts bei Gogol' und seltener Gemüsesortep bei Proust ( 89 ).

101 Den vergleich verwendet zinik mit ähnlicher Funktion auch in der Erzählung "Slučajnaja vstreča" (Vremja $i$ my, Nr. 108, 1990, S. 86-116). In diesem Fall markiert er die Kluft zwischen einem Emigranten, der nach Jahren seine Heimatstadt Moskau wieder besucht, und seinen früheren Bekannten (S. 104, 107, 110). 
macht ihn zum Gespött, etwa als er versehentlich Katzenfutter iBt (139).

Seine negativen Erfahrungen dämpfen rasch seine Begeisterung über das breite Konsumangebot (140) und lösen eine Metamorphose aus, die den Gesinnungswandel sowjetischer Emigranten satirisch widerspiegelt. Kostya wendet sich nämlich gegen die englische EBkultur (s. v.a. seine Schimpftirade 149-152) und besinnt sich auf die entsprechenden Traditionen seiner Heimat: "[...] only here, in voluntary exile, have I come to realise that the secret of great cookery lies in familiarity, habit - in what you're used to." (153). Dabei entdeckt er, daß besonders die Fleischgerichte erst durch die "vertraute Abgestandenheit und Fäulnis" der zutaten ("that familiar staleness, decay"; 154) die richtige würze erhalten, das heiBt, er lernt sein Land gerade wegen seiner verrottung schätzen. Kostya vereinnahmt die küche im Haus und baut sie zu einem Hort russischer Gaumenfreuden um. Hier schmort er Fleischbrocken und massenweise Zwiebeln (142-143), hängt Fische auf einer Leine zum Trocknen auf (144-145) und pflegt mit dem Polen Pan Tadeusz bei Wodka und marinierten Köstlichkeiten slawische Bruderschaft (152 ff.).

Kostyas Neurose, die mit vielen Digressionen geschildert wird, steht metaphorisch für seine Ablehnung der westlichen Lebensart und seine Emigrantennostalgie. Sein Heimweh drückt sich insbesondere in seiner Leidenschaft für das Sammeln und Einlegen von Pilzen aus, die typisch russisch ist und bei dem Romanhelden zur Manie wird.102 Der

102 Die Idee $\mathrm{zu}$ The Mushroom-Picker basiert zinik zufolge auf der Beobachtung, daB Emigranten oft aus Heimweh ins Schwärmen für nationale spezialitäten geraten ( $L i t$. gaz., a.a.o.). In einem Essay äuBert er sich speziell zur PilzSymbolik: "[...] kogda ja stal soćinat' parodiju na èmigrantskuju nostal'giju, ja ponjal, ¿to bez gribov ne obojtis'. $v$ nich - kvintéssencija patriotizma." ("[...] als ich anfing, eine Parodie über die Emigrantennostalgie $z u$ schreiben, wurde mir klar, das ich ohne pilze nicht auskomme. Sie enthalten die Quintessenz des Patriotismus.") Den Engländern hingegen sei jede Metaphysik und symbolik bezüglich des Erdbodens fremd, und von Pilzen hätten sie keine Ahnung. In: "Po griby - s Gil'bertom i Dżordžem", Inostranec (Moskau), Nr. 2 (30), $19.1 .1994, \mathrm{~S} .12$. 
Verzehr der Delikatesse ist für inn ein ästhetischer GenuB ("Boletus - see? Cap to cap, stalk to stalk - like a ballet at the Bolshoi Theatre!'"; 155), und er umgibt ihn mit der Aura eines Rituals (155 ff.). Die Pilzsuche führt ihn aus der verhaßten "wohlgeordneten Zivilisation" (212) in London zurück $2 u$ seinen russischen Wurzeln und zur Natur, wo er ganz er selbst sein kann (216). Zinik ironisiert und vulgarisiert freilich auch diese Kontemplation von Kostya im wald, indem er beschreibt, wie dieser mit Wonne seine Notdurft verrichtet (217-219). Wie wenig Verständnis die Engländer für Kostyas Kultur haben, wird zum SchluB plastisch, als Soldaten buchstäblich darauf herumtrampeln und sein Pilzreich zerstören.

\subsection{Psychodrama und Politfarce}

Clea erkennt erst in London, wie fremd inr Kostya ist und wie wenig er in die englische Gesellschaft paBt, wo bereits seine Physiognomie plump wirkt (10), er die Normen nicht kennt und alles falsch oder gar nicht versteht (137). Sie schämt sich zunächst für ihren Mann (135-136), aber er flöBt inr auch zunehmend Angst ein. So erscheinen inr seine Fleischmahlzeiten und seine verwesenden Fische in der Küche wie alptraumhafte visionen (142-145) und Kostya selbst wie ein Ungeheuer (auch 179). Besonders irritiert Clea das Messer, das er stets bei sich trägt (2.B. 126), bis sie sich von dem vermeintlichen Kannibalen direkt bedroht sient:

"And now the Soviet shylock was sharpening his knife in order to claim his due, a pound of the live flesh of Europe. Her Europe. She, clea, was Europe in his eyes. In the eyes of the Soviet Union. And he wanted his due." (202)

Das zitat ist zum einen auf der psychologischen Ebene zu verstehen. Clea nimmt eine opferhaltung ein, und zwar nicht nur gegenüber ihrem verrückten Mann, sondern auch schon zuvor bei dem Vergewaltigungsversuch von colin (59 ff.) und in RuBland, wo sie sich der Fremde und Tonya ausliefert. Hinter ihrem Masochismus verbergen sich 
"unbegründete Schuldgefühle" und "falsche Scham" auch für ihr Land sowie "mangelndes Selbstvertrauen" (190-191) und Selbsttäuschung (189). Mit ihren Gefühlen erkennt sich Clea in Jean-Jacques Rousseau wieder: In seinem Buch Confessions findet sie ihre eigenen seelischen Nöte und ihre Selbstverachtung formuliert (2.B. 70). Zum SchluB verwirft sie jedoch angesichts des Desasters, in das sie sich selbst getrieben hat, die darin ausgedrückte Lebenshaltung, worauf der russische Romantitel mit der Russifizierung des Namens Rousseau in russofobka aus rusofobka ("Russenhasserin") anspielt. 103

Als Colin durch Kostyas Messer stirbt, sieht sie inn an inrer stelle (236-238). Inr folgender Selbstmordversuch mit Fliegenpilzen versinnbildlicht inre innere vergiftung durch alles, was sie in ihrem Leben von anderen und besonders von Kostya "geschluckt" hat (245). In cleas Porträt mit vielen komischen zügen gestaltet zinik im Grunde eine ernste Thematik. Die fatale Anziehung durch das Fremde wird auf einen tiefen seelischen konflikt mit sich selbst und der eigenen Kultur zurückgeführt. Auch wenn die Figur eine Engländerin ist, beruht sie wie alle Helden von zinik letztlich auf seinen eigenen Erfahrungen des Fremdseins und der selbstentfremdung. 104

Auf der zweiten, politisch-satirischen Ebene in the Mushroom-Picker fungiert die binationale Ehe als Metapher für den Kalten Krieg, in dem irrationale Feindbilder (wie

103 Zinik interpretiert confessions als Verarbeitung von SelbsthaB, der bei Rousseau zu einer selbstbestrafung durch die bedingungslose Freisprechung anderer führe: mit dem gleichen Motiv unterwerfe sich Clea dem Monster Kostya (Lit. gaz., a.a.0.). Zum Schluß erkennt sie allerdings inre sinnlose selbstzerstörung, verbannt kostya aus ihrem Leben (242) und haBt Rousseau (244).

104 vgl. Zinik in der Lit. gaz. (a.a.o.): "Vo mne sidit i mazochistka klio s ložnym cuvstvom viny, i fungofil Kostja $s$ ego svidrigajlovskoj koncepciej raja kak banki s paukami, gde chot' i duśnovato, no teplo i nikakoj lićnoj otvetstvennosti." ("In mir steckt die Masochistin Clea mit inrem falschen schuldgefüh ebenso wie der Fungophil Kostja mit seinem Svidrigajlov [Figur aus Dostoevskijs Roman Schuld und Suhne] nachempfundenen Konzept eines Paradieses wie eine Dose mit spinnen, wo es zwar stickig, aber warm ist und keine persönliche verantwortung gibt.") 
der Russen als Barbaren) und das Waffenpotential der anderen Seite (Kostyas Messer) jeden Kooperationsversuch vereiteln. Anfangs sieht sich Clea mit Kostya noch naiv als Modell für détente:

"[...] it seemed to clea as if all around there was no one but herself and Konstantin, two plenipotentiary representatives of West and East engaged in a top-level discussion in which the General secretary of the East was insisting on the primacy of the West, while the lady premier of the West was obstinately inclined to favour the East." (38)

Clea wird schnell desillusioniert. Die kulturellen Unterschiede und das gegenseitige MiBtrauen sorgen fur Spannungen, die eskalieren und zu gewaltsamen Konfrontationen fuhren. In einer Episode versucht clea mit ihrer "Waffe", dem Rasenmäher, Kostyas "stützpunkt" im Garten anzugreifen - eine verwilderte Ecke mit einer Birke, die ein ähnliches Reservat russischer Kultur wie die Küche darstellt (180-183). Der Autor gebraucht penetrant militärische Begriffe (machine-gun fire für das Mähergeräusch, strategist für Kostya, battlefield u.a.) und erhebt den streit auch explizit zum stellvertreterkrieg:

"[...] Pan Tadeusz, dashing up and down beside the fence, resembled an observer from a UN peace-keeping mission caught unawares by a local conflict that before his eyes had escalated into a confrontation between two great powers." (182)

Das zitat ist exemplarisch für Ziniks parodistisches Verfahren, auf das banale Geschehen politische Paradigmen aufzulegen und so eine absurde Analogie zwischen den persönlichen Animositäten der Romanhelden und dem realen ost-West-Konflikt herzustellen. In dieser Politfarce ubernimmt der Pole Pan Tadeusz (mit Ausnahme der zitierten Textstelle) die Rolle der osteuropäischen Blockstaaten (2.B. 163). Anthony und Margot vertreten die britische Linke, deren Ansichten bloBgestellt werden. Margot spielt dabei die RuBlandkennerin (z.B. 129, 132-133), doch ist offensichtlich, daß sie sich in erster Linie interessant machen will. Ihr Mann propagiert die Grundsätze der Frie- 
densbewegung, 105 aber Kostya konterkariert bereits durch seine provokative Erscheinung Anthonys Rhetorik der Versöhnung $(7,67)$. Die eigentliche Ignoranz des Engländers wird unter anderem darin symbolisiert, daB er versehentlich einen besonderen $\mathrm{Pilz}$ zerdrückt und den Russen prompt gegen sich aufbringt (135). In der küche, also auf seinem Territorium gibt sich Kostya dann offen als Chauvinist und stalinist $2 u$ erkennen $(164,173-174)$ und demonstriert sogar mit seinem Penis seine Potenz (175-177). Anthonys Idealismus ("let's all unite in a single brotherhood"; 171) erweist sich als lächerlich und haltlos.

Die Opposition der Weltbilder äuBert sich sprachlich in ständigen Interferenzen von politischem und kulinarischem Diskurs. So spaltet sich der Globus für Kostya weniger in kommunistische und kapitalistische staaten als in "Kaffee- und Teezonen" (131) mit ganz Westeuropa in der ersten; die Persiflage gründet darauf, daB die Frage der richtigen Teezubereitung bei Russen und Briten gleichermaBen den Nationalstolz berührt und Kostya deshalb mit seiner Einordnung einen Affront liefert. ${ }^{106}$ Die englische Art des AufgieBens produziert nach seiner Theorie Wasserstoffbomben (135) - ein Beispiel für Ziniks bizarre Brücken von einem semantischen Feld zum anderen, die die gastronomische Metaphorik teilweise überdehnen. Die Einbindung von Pilzen in den politischen Kontext ist durch die Atombombe gegeben. Der folgende Dialogausschnitt dazu macht besonders deutlich, wie sehr jede Figur in ihrer Denkwelt gefangen ist:

"'Kostya loves discussing mushrooms,' clea explained in English to Anthony [...] 'Ah, yes - the atomic mushroom-cloud!' Delighted, Anthony returned to his favourite theme." (128)

105 Bsp.: "It is time to reject the concept of an 'enemy' altogether [...]" (65); "I must tell you frankly [...] I am against the Soviet invasion of Afghanistan." (167).

$106 \mathrm{Vgl}$. Russkaja sluźba: Hier wird ebenfails zur illustration der kulturellen Unterschiede angefüht, wie und wann die Engländer Tee trinken (a.a.0., S. 122-123 u. 125126 ). 
Beide Bedeutungen des symbols werden auf dem Militärgelände, wo Kostyas Sammelgebiet liegt, gleichzeitig wirksam. Im Finale kommt es hier zum katastrophalen Zusammenprall der Hauptfiguren sowie der britischen Armee und der Friedensdemonstranten, also aller im Roman enthaltenen Perzeptionen, Gesinnungen und Feindbilder.

\subsection{Der Autor und sein Held}

Im letzten Kapitel "The Trial" bringt sich der Erzähler mit deutlichen autobiographischen zügen (253, 276) selbst ins spiel. Zunächst berichtet er realistisch und kritisch von dem MordprozeB gegen Kostya und dem damit verbundenen Medienrummel. In dieser Art Epilog benennt der Erzähler konkret die in der britischen öffentlichkeit vorherrschenden stereotypen hinsichtlich der Sowjetunion ${ }^{107}$ und vermittelt einen Eindruck von der gespannten politischen Atmosphäre $z u$ jener zeit. Dann wird jedoch die Handlung auf einer übergeordneten Ebene weitergeführt.

Der Auftrag von Kostyas Anwälten, als Literaturexperte für den ProzeB einen Roman ihres Mandanten zu begutachten, bringt den Ich-Erzähler mit Kostya zusammen. In einer ( $\mathrm{zu}$ ) abrupten Wendung entpuppt dieser sich im folgenden Dialog als scharfsinniger pro-sowjetischer Historiker, der von clea aufgrund inrer vorurteile vollkommen verkannt und für verrückt erklärt wurde (272), während seine kulinarischen Exzesse nur dazu dienen sollten, sie abzuschüteln (270). Sein Roman, eine Selbstdarstellung (258), handelt von einem aus der Sowjetunion nach England emigrierten Geschichtsprofessor, der wiederum den weg

107 Zitat: "[...] both judge and jury - and, indeed, counsel himself - had only the haziest conception of Soviet life, which in their minds was limited, I should think, to an opera scenario in which the Soviet Army marches across Red square to bar the way to foreign journalists trying to interview Sakharov, who sits reading solzhenitsyn in samizdat, while the KGB, from a space satellite, watches Baryshnikov dancing a ballet in New York." (247) Vgl. auch 252-253, auBerdem die Vorstellungen der Reporterin Valery in Russkaja služba (unter III. 2.3.). 
eines Sklaven im 18. Jahrhundert von einem Bojarenhof nach London und zurück nachzeichnet. So ergibt sich eine verwirrende Hierarchie von Zinik bis $2 u$ dem Bojarendiener, in der jeweils ein russischer Emigrant über einen anderen erzählt.

Gemäß einem Lehrbeispiel für seine Poetik führt Zinik hiermit vor, wie ein Autor seine Fimigration durch einen fiktiven Doppelgänger verarbeitet, genauer seine Nostalgie und seinen Identitätsverlust (258-259), wobei sich das Leitmotiv des Heimwehs bis zur Biographie des Sklaven durchzieht (257). Kostyas Geschichte wird potenziert, um im nachhinein die psychische Verfassung eines sowjetischen Auswanderers besonders herauszustellen. Da der Ich-Erzähler, ziniks unmittelbares sprachrohr, eine andere, nämlich dem Aufnahmeland zugewandte Emigrantenhaltung vertritt, kommt es quasi zur konfrontation des Autors mit seinem Helden, in dem er sein negatives spiegelbild gestaltet. In der Form eines Dialogs werden die standpunkte kontrastiert: "[...] he was defending his allegiance to a world from which I had been scandalously divorced and whose death I longed for with all my soul." (267) Kostya stellt das selbstverständnis seines Gegenubers radikal in Frage und deckt dessen selbsttäuschung bezüglich der Heimat und der Vergangenheit auf (277 ff.). Das poetologische Konzept einer Auseinandersetzung mit sich selbst mittels der eigenen literarischen Schöpfung setzt zinik hier wörtlich um. Dabei verläßt er den Bereich des Grotesken und Satirischen zugunsten einer relativ realistischen Diskussion. Im Chicago Tribune heiBt es entsprechend:

"The fallout from this imbroglio [on the missile base] lifts the book to an entirely different level, from the (Groucho) Marxist sexual comedy we thought we were reading to a bleak orwellian plateau where Kostya turns out to have been a philosophical novelist all along, $[$... ]" (a.a.o.)

Im allgemeinen bemängelte die Kritik den Schluß als überflüssig und langatmig. ${ }^{108}$ Keine Rezension geht inhalt-

108 S. Lon. Mag. ("unsatisfactory end"), Independent ("over-extending the book after its natural end to the point of longeur"), sun. Times ("further revelations and 
lich auf das Kapitel ein, weil diese Thematik den englischen Leser offenbar nicht berührt. Im Vergleich etwa zur Buchbesprechung in der Nezavisimaja gazeta, die $z$ u dem Exkurs umfassend stellung nimmt, treten abermals nationale Unterschiede in der Rezeption hervor. Dessen ungeachtet bleibt festzuhalten, daß die vielschichtige Erörterung der Emigrationsproblematik einen $z u$ starken Bruch $z u m$ vorhergehenden Roman darstellt, und zwar inhaltlich wie stilistisch. Dadurch schafft zinik eher Verwirrung darüber, wie The Mushroom-Picker letztlich zu verstehen und einzuordnen ist.

plot-twistings do more to confuse than illuminate"), alle a.a.o. 


\section{THE LORD AND THE GAMEKBEPER}

\subsection{Aufbau und Handlung}

Lord $i$ eger', Ziniks siebter und bislang letzter Roman, entstand als Auftragsarbeit (so die Angabe des Autors) und wurde 1991 von dem britischen Verlag "Heinemann" in einer Ubbersetzung von Alex de Jonge mit dem Titel The Lord and the Gamekeeper herausgegeben. Aus dem gleichen Jahr datiert auch eine russische Ausgabe von "slovo" in Moskau. Da das Buch jedoch vorrangig für den britischen Markt geschrieben und zuerst in Englisch veröffentlicht wurde, erfolgt die Romananalyse abermals anhand des englischen Textes, der sich auch hier relativ nah an das original hält. Im Vergleich $z u$ The Mushroom-Picker und erst recht zu Russkaja služba ist die narrative struktur des Werkes wesentlich komplexer. Trotz einiger grotesker Elemente liegt diesmal keine Farce vor. Eine eindeutige Kategorisierung scheint wegen der Mischung verschiedener Genres - darunter Komödie, Satire, phantastischer und realistischer Roman - kaum möglich.

Wie The Mushroom-Picker umfaBt auch the Lord and the Gamekeeper eine psychologische und eine politische Ebene, wobei der Schwerpunkt auf ersterer liegt. Dies belegt bereits die Rahmenhandlung, die durchgehend kapitelweise mit der eigentlichen Handlung alterniert und in einer psychiatrischen Klinik spielt. Das Sanatorium befindet sich in einem SchloB in der südostenglischen Grafschaft Kent. Die sowjetischen Exulanten silva, Felix und victor sind auf Einladung des mysteriösen Hausherrn Lord Edward hierhergekommen, um mit Hilfe dessen Leibarztes Dr. Genoni ihre gegenseitigen Beziehungen, ihre Vergangenheit und ihre Identitätsprobleme zu klären. Der Roman zeichnet die Gespräche eines Tages im Herbst 1984 auf und analysiert dadurch explizit bestimmte "Emigrantensyndrome". Die Kapitel, die direkt zur Rahmenhandlung gehören, sind mit asylum über- 
schrieben, wobei die beiden Wortbedeutungen "Asyl" und "Irrenanstalt" simultan zum Tragen kommen. 109

Die Kunsthistorikerin Silva, der übersetzer Felix mit "Theaterambitionen" und der "professionelle Dissident" Victor (3) kennen sich seit ihrer Jugend. Die ersten Kapitel zeigen sie im Ruckblick in Moskau, wo sie den gleichen Untergrundkreisen angehörten. Victor hatte ein Verhältnis mit Silva, während der eifersüchtige Felix immer an zweiter stelle rangierte. Einige Jahre später kommen die drei in London wieder zusammen. Bereits bei der willkommensfeier für den als letzten ankommenden Victor gibt es Reibereien, deren Ursachen aber dann mit Hilfe von Dr. Genoni allmählich aufgedeckt werden.

Die Hauptfiguren und inre Dreiecksgeschichte werden realistisch gestaltet und beruhen auf einem autobiographischen Hintergrund. Victor, aus dem Gefängnis von vladimir direkt in den Westen entlassen, ist ein fiktiver Doppelgänger von Vladimir Bukovskij, der tatsächlich einige Monate mit zinik und einer gemeinsamen Freundin im Londoner Stadtteil Hampstead eine wohnung teilte. Die Kapitel in Moskau verarbeiten ziniks Jugenderfahrungen, wobei die Samizdat-Autoren und Lehrer der drei Helden, Migulin und Avestin, an seinen realen Vorbildern, dem Schriftsteller Pavel Ulitin und dem Theaterkritiker Avestin, orientiert sind. 110 Auf Victors party in London erscheinen Vertreter des "BBC Russian Service" und andere sowjetische Emigranten sowie Engländer, die berufsmäßig mit ihnen zu tun haben, so daß auch ein Eindruck des dortigen Exillebens vermittelt wird.lll an einer stelle stellt zinik sogar explizit fiktive und reale personen in eine Reihe (238).

109 Die Überschrift ist auch im russischen original auf englisch zu finden, beim ersten Mal mit einer Anmerkung, die den Doppelbegriff als "prijut, psichiatriceskaja lecepnica" übersetzt (a.a.0., s.9).

$110 \mathrm{~S}$. Ziniks Erinnerungen in "Na puti $k$ 'Artisticeskomu'", a.a.0., S. 123-142.

III Dér ironische Ton der entsprechenden Abschnitte wird bereits bei der Beschreibung der Gäste gesetzt: "There were the usual academics from slavonic departments - those vegetable-looking chaps whose cannibalistic cravings for the big Russian heart, soul and liver transformed them 
Schließlich spiegelt sich der Autor selbst in Felix wider, der freiwillig uber Jerusalem nach London ausgewandert ist. Er erhält von Lord Edward den Auftrag, eine der "Kleinen Tragödien" von Puskin, nämlich "Pir vo vremja cumy" ("Gelage zur Zeit der Pest") ins Englische zu übersetzen. Seine Recherchen führen ihn wiederum $z u$ anderen Schriftstellern. Die literaturhistorischen Exkurse von Felix bilden eine Einheit für sich, freilich mit Relevanz für seine Charakterisierung. AuBerdem wird die Geschichte erweitert durch ein teilweise phantastisches und groteskes Verwirrspiel um den Mann, der sich innen gegenüber als Lord Edward ausgibt, aber vermutlich dessen verrückter wildhüter Edmund ist. Die Identität von beiden bleibt bis zum Schluß ambivalent.

Bei allen Erzählsträngen geht es darum, hinter einer Fiktion oder Täuschung das wahre, Authentische und Verheimlichte $z u$ enthüllen, ob es sich um ein literarisches original und sein Plagiat, die Maskerade von EdwardEdmund oder in der Haupthandlung um den Heldenmythos des Dissidenten victor und die Illusionen von Felix und silva handelt. 112 Dabei entsteht ein Netz von Verknüpfungen mit einem thematischen Kern, denn die einzelnen Elemente der Narration verweisen metaphorisch stets auf die emigrationsbedingte suche nach der Realität, der wahrheit und einer orientierung. Der Rezensent in The Times Literary supplement vermutet gerade in der "Disziplinlosigkeit" durch die Fülle an Details, Symbolen, Abschweifungen und

into freaks in the eyes of their own tribe. There was also an assortment of BBC Russian service and Radio Liberty contributors who, used to going on the air every day, regarded themselves as being somewhere in the sky above the ordinary, definitely not in an émigré guarantine. There were also those, like the émigré essayist Gluzberg, with no patriotic heart whatsoever, who simply covered with their British passports a big emotional hole in their breasts." (154) - Zur Einordnung in den historischen Kontext enthält der Text Erläuterungen zur Dritten Welle (27) und $z u$ den Bedingungen der Emigration nach GroBbritannien (39) - ein Zeichen dafür, daß Zinik beim Schreiben insbesondere den englischen Leser vor Augen hatte.

112 Vgl. die zentrale Bedeutung von Mythen und Rollenspiel in der struktur von Russkaja služba. 
Anspielungen, über die der Gesamtzusammenhang zeitweise verlorengeht, eine entsprechende Erzăhlstrategie:

"[...] Zinovy Zinik's exuberant novel bubbles with narrative intricacies and overlapping metaphors. [...] the principal metaphors are sprayed so liberally that - presumably on purpose - they become as blurred as Felix's identities. [...] Perhaps zinik wants to seem distracted, as if toying with the conventional anglophone irritation and envy at Russian indiscipline. He can be economical when he chooses. The interspersed scenes in Moscow, the Asylum and Blackheath are acute commentaries on one another."Il\}

Ein Kommentar von zinik selbst legt allerdings nahe, daB er sich weniger bewuBt war, als hier impliziert wird, wie "russisch" und "irritierend" sein stil für die Engländer ist:

"With Lord and the Gamekeeper I thought I am writing the most English novel in my life. In fact I have written the most Russian novel ever possible. It is extremely difficult to read in English [...] The style, the construction is so .... elaborate. And they [the English readers] are not used to this type of novel, they don't like it [...]. I thought it was English because a lot of it is happening in England [...]."If

Das Zitat veranschaulicht, daB zinik das "Russische" seiner Schreibweise, das sich insbesondere auch im satzbau niederschlägt, 115 erst durch die englische Rezeption erkannte. Es wird deutlich, wie schwer es für einen Autor in der Emigration ist, bewuBt für den Leser im Aufnahmeland

113 Simon Franklin, "In a Garden-of-England Madhouse", TLS, H. 4599, 24.5.1991, S. 20. - Auch die Oxford Times konstatiert eine gewisse verwirrung insbesondere durch die breit angelegte Geschichte um den rätselhaften Lord und bezeichnet das werk wegen seiner Vielschichtigkeit als "novel novel" (Philippa Logan, "Monty at the Barber's, Ike at Home", The Oxford Times, 28.6.1991, S. 17).

114 Persönliches Gespräch, Anhang, S. 183-184.

115 Im Russischen ermöglichen Partizipialkonstruktionen u.ä. komplexe Sätze, die im Englischen umständlich und überladen wirken. Bsp. für einen beinahe unlesbaren satz in The Lord and the Gamekeeper: "In this Aladdin's cave of sexual curios, sons of Albion and citizens of other Western parts, imbued with the characteristic British sense of parliamentary tolerance and calm curiosity, were inspecting various creations of local and foreign manufacture, cunningly devised to satisfy sundry erotic fantasies, and to drive various libidinous desires out of the subconscious in order that they should play their part in the sexual revolution." (164) 
zu schreiben, vor allem in der Muttersprache, da er mit der übersetzung stilistische Veränderungen in Kauf nehmen muB.

\subsection{Demaskierung in Irrenhaus}

Die psychiatrische Klinik, Schauplatz der Rahmenhandlung, ist eine Metapher für die Exilsituation der drei Hauptfiguren: Fern von der gegenwärtigen Realität ${ }^{116}$ befinden sie sich in einem schwebezustand des verharrens im Rückblick. Nach dem Bruch mit ihrem früheren Leben scheint die zeit hier stehenzubleiben $(24,54)$. Die äußere Idylle dieses Asyls im Westen, repräsentiert durch die Schloßumgebung, bildet einen Gegensatz zu dem Chaos im Innern der Emigranten und ihren schwelenden Konflikten untereinander (2.B. 37).

Eine ironische Parallele verbindet den Klinikaufenthalt im Exil mit der im sowjetischen strafsystem üblichen Zwangseinweisung von Andersdenkenden in psychiatrische Anstalten, worüber im Roman Migulin (11-12) und insbesondere victor (2.B. 130) aus eigener Erfahrung berichten. Den Betroffenen wurde freilich gerade dadurrh, daß dieses ideologisch verrannte Regime sie für geistesgestört erklärte, indirekt ihr gesunder Menschenverstand bescheinigt, während der Rest des Landes "ein großes Irrenhaus" war, wie Victor sich ausdrückt (130). Die Position des verrückten AuBenseiters ändert sich jedoch im Ausland nicht, weil die Exulanten hier infolge der kluft zwischen dem früheren und dem jetzigen Leben tatsächlich unter Schizophrenie leiden - so die zynische Logik des Romans. Diese BewuBtseinsspaltung sollen Felix, silva und victor

116 An mehreren stellen wird erwähnt, daß die westliche Welt den Helden irreal vorkommt; $s .2 . B$. Felix in Italien ("a sense of hallucinatory unreality"; 33) und victor am Londoner stadtrand ("unreal", "dream-like"; 96). Das Gefühl, vom Leben des Aufnahmelandes ausgeschlossen $2 u$ sein, illustriert der Vergleich mit einer "unbewohnten Insel": "[...] because, for an emigre, natives don't count, the life of the natives is obscure and incomprehensible $[\ldots] . "(141)$ 
durch die Therapie von Dr. Genoni überwinden, der sein Vorgehen wie folgt umschreibt:

"'Aren't we all, in one way or another, émigrés and dissidents in this world? All cut off from our pasts by an 'iron curtain' of things done that cannot be undone. In order to restore an emigré to reason you have to break that taboo, enter the forbidden zone, cross the iron curtain and get back into the past." " (227)

Dr. Genoni will seine Patienten in ihre Vergangenheit zurückführen und damit $z u$ allem, was ihre Erinnerung korrigiert oder ausgeblendet hat. Der Eiserne Vorhang, von dem er als reale wie mentale Trennlinie spricht, steht auch für den imaginären Bühnenvorhang, den der Psychiater hebt. Denn er inszeniert die Konfrontation der drei Exulanten als drama therapy (34) oder psychodrama (37, 229), bei dem er gleichsam die Fäden zieht und in dessen Verlauf die Akteure, für die allein das spiel Ernst ist, sich durch ihre Täuschungen selbst entlarven. Um die dramatische Qualität der Geschichte hervorzuheben, umgibt der Autor sie mit zahlreichen literarischen Bezúgen etwa auf william Shakespeare oder den italienischen Dramatiker Luigi Pirandello, bei dem die psychologische Analyse und die Problematik der menschlichen Persönlichkeit im Vordergrund stehen.117

Der Emigrantenheld im Widerstreit mit seiner eigenen Vergangenheit fächert sich hier in drei Figuren auf.118 silva ist allerdings viel schwächer charakterisiert als die beiden anderen, weshalb sie in dieser Analyse vernachlässigt wird. Alle Gespräche in der Klinik durchzieht die

117 Das wiedersehen von Felix und victor nach längerer Trennung und ihre Rivalität um Silva vergleicht die Kapitelüberschrift "The Two Gentlemen of Verona" (70) mit den entsprechenden Motiven in Shakespeares Komödie. Die Doppelfigur Edward-Edmund zeigt wesentliche Gemeinsamkeiten mit dem Titelhelden von Pirandellos Tragikomödie "Enrico IV", die Avestin, Lehrer der drei Helden in Moskau und Pirandello-Experte, mit den Insassen einer sowjetischen Psychiatrie einstudiert (13-15), was wiederum Genonis Therapie ironisiert. Vgl. 2.B. auch den Ausruf des Arztes "Inçredible. Anna Karenina all over again!" (203).

vgl. die Konstellation im SchluBkapitel von the Mushroom-Picker, wo eine Opposition von zwei Figuren dazu dient, Emigrantenhaltungen zu kontrastieren. 
für sowjetische Emigranten zentrale Frage nach der persönlichen Schuld, wobei politische und emotionale verstrickungen ineinandergreifen ("in the best traditions of melodrama"; 69). Victor provoziert Felix zu einer selbstrechtfertigung für seine freiwillige Auswanderung (37-38) und verdächtigt Silva, aus Eifersucht dem KGB ein Samizdat-Versteck verraten $2 u$ haben (68-69). $\mathrm{zu}$ ihrer Verteidigung führt sie an, $d a \beta$ er sie mit einer anderen Frau betrogen habe (202-203). Sein seitensprung wurde bis dahin von beiden genauso übergangen wie der von silva mit Felix, von dem wiederum victor die ganze zeit gewuBt hat (18-23, 246). Zwischen den Männern steht ferner Felix' einstige Weigerung, eine von victor verfabte Petition $2 u$ unterzeichnen (235-236).

Diese unverarbeiteten Konflikte und das Bedürfnis nach Klarstellung sind im Kontext der sowjetischen Mentalität zu sehen. Denn das system machte grundsätzlich jeden zum verräter und opfer zugleich. Auf die Exulanten trifft dies in besonderem Maß zu: "This atmosphere of quilt by association, of shame and helplessness, pushed everyone into exile of one kind or another - to siberia or to the West." (7) Doch auch hier bleibt das Gefühl einer "unbeweisbaren Schuld" erhalten, wie es in einem Autorenporträt der Zeitschrift Vremja heiBt:

"Это какая-то особая проза: проза-выяснение. В переплетении ложных свидетельств и искренних самооговоров выстраивается сложнейшая эквилибристика доказательств недоказуемой вины. [...] В основе почти всех внутренних конфликтов романа - спор между предателем, узником и тираном, а если только между предателем и узником, то оба действуют как настоящие тираны. [...] Сюжет так или иначе строится на столкновении героя со своим двойником, то есть с самим собой. Это бой с тенью."

("Diese Prosa ist von besonderer Art, nämlich eine Prosa der Klarstellung. In dem Geflecht falscher Zeugnisse und aufrichtiger selbstverleumdungen entsteht eine komplizierte Beweiskonstruktion einer unbeweisbaren schuld. [...] Fast alle inneren Konflikte des Romans beruhen auf einem streit $z w i s c h e n$ Verräter, Gefangenem und Tyrannen oder nur zwischen Verräter und Gefangenem, die wie Tyrannen handeln. [...] In jedem Fall besteht das sujet in dem Zusammensto $B$ zwischen dem Helden und seinen Ebenbildern, 
das heiBt, mit sjch selbst. Es ist ein Kampf mit dem eigenen Schatten.") 119

wie das zitat ausführt, projiziert jeder der drei Helden seinen Kampf mit sich selbst auf die anderen. Genoni läBt seine Klienten dabei all das zur sprache bringen, was sie bislang in stillem Einvernehmen sich gegenseitig und auch sich selbst verschwiegen haben (2.B. 203). Das Ziel dieser "Theatertherapie" ist die allmähliche Demaskierung.

\subsection{Der Dissident und der falsche Lord}

Victor personifiziert den typischen Dissidenten der Dritten welle, der sich ganz dem Kampf gegen das Sowjetregime verschrieben hat und hier mit leichter Ironie charakterisiert wird ( $z u$ seinen Ansichten 93 ff.). Seine Aktivitäten bringen ihn mehrfach ins Gefängnis, Arbeitslager und psychiatrische Anstalten und machen inn zum berühmten Helden. Nach der Ausweisung steht er in GroBbritannien zunächst im Blickpunkt der öffentlichkeit und spielt mit Hingabe seinen neuen Part im "circus of émigré politics": "[...] he was entirely absorbed in a headlong plunge towards a turbulent and radiant future - which is how he saw his own heroic past." (77) Bei einem ersten Besuch auf dem Herrensitz von Lord Edward, der sich für sowjetische oppositionelle einsetzt und auch victor aus der Haft befreit hat, wird er allerdings massiv verunsichert. In diesem Kapitel (91 ff.) tritt victor mit seinem Nachnamen Karvalanov auf, wie auch später, wenn seine Dissidentenrolle betont werden soll.

Der Mann, der sich inm als Lord Edward vorstellt, entspricht überhaupt nicht seinem Bild von dem noblen Aristokraten. Vielmehr erweist sich sein vermeintlicher

119 [Ajzenberg], "Boj s ten'ju", Vremja, a.a.o., s. 20. vgl. Felix: "Don't you see that we are doing exactly the same now, trying out again and again this soviet recipe for collective paradise by proving to each other that we are all shit, that we are all guilty and accomplices and no better than the KGB itself." (204) 
Retter als fanatischer Tierschützer, bei dem herrenlose Hunde aus Moskau Asyl finden (111-112) und die Wachhunde in den sowjetischen straflagern mehr Mitgefühl wecken als die inhaftierten Dissidenten (121-122). Diese Karikatur eines Menschenrechtlers - und damit auch victors - verkehrt den entsprechenden Diskurs ins Absurde. Beispiel:

"I hold that any dog, regardless of sex and nationality, has the right to an owner of its own. People get thrown into jail and as a result innumerable domestic animals are turned into strays. With their owners behind bars, they're deprived of their civil rights and their means of support." (136)

Mit besonderer Leidenschaft verdammt der angebliche Lord die Fasanenjagd auf seinem eigenen Grundstück ("bloody habits of the English aristocracy"; 106). Zum Befremden von Karvalanov erzăhlt er, daß die wildhüter hier das Sagen haben, aus der Jagd Profit schlagen und ihren Herrn als Geisteskranken einsperren (119-120); es gebe sogar ein Komplott mit dem KGB (131). Die von victor hochgehaltene hierarchische Klassengesellschaft (95-96) und seine Vorstellungen vom Exilleben in einer Welt, die sozusagen in ordnung ist (137), drohen sich in Illusionen aufzulösen. 120 Dabei werden phantastische und vor allem satirische verfahren in der bizarren Figur des fragwürdigen Lords wirksam. Unter den dargestellten Umständen scheint er Victor in grotesker Weise ebenbürtig (140, 193) und hält inm so einen zerrspiegel vor. ${ }^{121}$ Das folgende zitat

120 Als Symbol für Victors Ernüchterung im realen SchloB von Lord Edward zerbricht sein Geschenk für inn - ein ModellschloB aus Plastilin, das er während seiner Inhaftierung als Ausdruck seines Ideals von Freiheit und Wahrheit gebaut hat (122-123). Er erkennt: "What had seemed, in the siberian frosts, to be a castle in the air, became a chunk of plasticine that melted away in the heat of the night, to become a grey formless blob. And the time has come to get rid of it as quickly as possible [...]." (198) Das Motiv beruht auf einem biographischen Detail von vladimir Bukovskij; vgl. dessen Werk To Build a Castle: My Life as a Dissenter (1978).

121 In einem stegreifspiel mit silva mimt er sogar direkt victor (194-197). Die amüsante parodie auf dessen Dissidentenleben endet abrupt, als silva sein zweifelhaftes Verhalten inr gegenüber ins spiel bringt. Die szene zeigt exemplarisch die fließenden Grenzen von Fiktion und Realität, Komik und Ernst, Maskerade und Entlarvung in der Struktur des Romans. 
hierzu zeugt auch von einer gelegentlichen Penetranz der Exil- und Emigrationsparadigmen bei Zinik:

"'They keep me here as if $I$ were in exile. I'm an internal emigrant. I'm a foreigner in my own country, an enemy of the people almost." "(116)

Erst Dr. Genoni klärt die Situation auf: Karvalanov habe seinen patienten Edmund getroffen, den irrsinnigen Sohn eines früheren wildhüters mit einer "gemischten Identität", und das SchloB von Lord Edward sei eine psychiatrische Klinik (143-144). Victor muB erkennen: "Nothing was what it seemed, [...] they were all fakes." (144) Er hat plötzlich das Gefühl, als Exulant genarrt und einer scheinrealität ausgeliefert $z u$ sein, nachdem inm bereits bei seiner Ankunft das Gelände wie ein "Dschungel der westlichen Welt" vorkam, wo er sich wider Erwarten nicht zurechtfindet (99). Die Erfahrung der verfremdeten Wirklichkeit und die Begegnung mit dem Wahnsinnigen wecken in inm die Angst, selbst den Verstand $z u$ verlieren. Sein Schicksal, hier wie dort ein heimatloser, vom Leben der "Normalen" ausgeschlossener AuBenseiter $2 u$ sein $(110,116-$ 117), empfindet er wie das eines streunenden, tollwutgefährdeten Hundes (92-93). Das Sinnbild impliziert zum einen kritisch eine gewisse Xenophobie der Briten, wie das folgende zitat von Edward-Edmund zeigt, das ihre Schutzmaßnahmen gegen das Einschleppen von Infektionskrankheiten metaphorisch auf ihre Einwanderungspolitik bezieht:

"My fellow-countrymen categorically refused to let a stray soviet dog into this country. A typically chauvinistic British attitude to refugees. The pretext for their refusal was the same old excuse - suspected rabies." (135)

Zum anderen wird die Tollwut-Metapher in einen Zusammenhang mit dem Sowjetstaat gebracht, der nämlich die Dissidenten wie tollwütige Hunde bekämpfte (82, 193). Der Vergleich von victor mit einem Hund kommt demgemäB unter anderem auch im Dialog mit Felix vor:

"Oh, come on,' said Felix dismissively. 'You went out and chose to behave in a way that got you chucked out of the country willy-nilly.'

'The dog is not responsible for its master.' 
'But the master isn't responsible for his dog if it starts to stray." (90)

Mit der Frage der verantwortlichkeit wird die der Schuld aufqeworfen. GemäB der Metapher von Hund und Herr ist der Sowjetstaat die Autorität uber victor, von der er sich losgesagt hat. Dr. Genoni findet jedoch heraus, daß sein klient dabei unter einem Komplex leidet, den er als "Oedipal dissimulation" (244) bezeichnet. "Dissimulation" meint die bewuBte Verheimlichung einer Krankheit. Denn die wahre Motivation für Victors widerstand liegt in seinem Haß für den übermächtigen Rivalen, das heiBt, den sowjetstaat, von dem er freilich selbst abstammt, was inn gegen seinen willen schuldig macht. "Guilt leads to shame, and hence to rebellion", folgert Genoni (248).

Der ödipus-Mythos und seine psychoanalytische Auslequng sind aber auch in dem Kindheitstrauma von Edmund $z u$ entdecken: Angeblich erschoB der vater des Lords aus Versehen seinen wildhüter, nämlich den Vater von Edmund, als dieser beim spielen den Jäger anstieB, so daß der Junge unwissentlich zum Vatermörder wurde (115). Genonis Erklärung zufolge hat sich Edmund zur verdrängung und vertuschung seiner Schuld in den Glauben verstiegen, Edward zu sein, der von Edmund bedroht wird, das heiBt, er sieht sich selbst als Feind (225).122 Um inn zu heilen, läBt der Arzt die drei Emiqranten und ihre Freunde zum SchluB des Romans die damalige Jagd nachstellen, wobei der Patient vor Schreck einen herzanfall erleidet (237-240). Das Theater, von inm als real erlebt, geht so in die wirklichkeit über, was die Gratwanderung von Genonis "Psychodrama" zwischen Fiktion und Realität belegt.

In der Doppelfiqur, meist Edward-Edmund genannt, konzentrieren sich die Motive der unbeweisbaren Schuld,

122 Später wird diese Version zur gänzlichen Verwirrung der anderen Romanfiguren und des Lesers noch einmal ins Gegenteil verkehrt: Es könnte sich auch um Edward handeln, der andere glauben läßt, er sei Edmund (242-243). Damit bleibt der Lord, der kein einziges Mal leibhaftig auftritt, ein geheimnisvoller Mythos. Die Wahrheit hinter dieser Fiktion des edlen englischen Aristokraten wird nicht erkennbar (vgl. die Bezeichnung als demi-qod; 33 ). 
der Schizophrenie und der Identitätskrise, die bei zinik grundsätzlich zentrale Elemente der Emigrationsthematik darstellen. Der verrückte Lord erfült somit über die Wechselbeziehung $2 u$ victor hinaus eine allegorische Funktion. DaB Edward-Edmund zum Medium der Selbsterkenntnis für alle drei Emigrantenhelden wird, verdeutlicht eine Szene gegen Ende: Er veranstaltet mit ihnen eine imaginäre Jagd und benennt exakt, worauf sie "zielen" sollen, um ihr Leben neu zu beginnen. Zitat:

"All these notions of treachery, jealousy and disappointment, all these stupid imaginary pheasants with their wings clipped - isn't it wonderful to let loose with both barrels and see their feathers fly? victor, you shoot first. The truth does not come from fighting your father, [...] Felix, you no longer have to pretend to be someone you were not - take careful aim at your original self. And finally silva. Your lovers disappoint you because they're obsessed with false ideals. [...] Aim for sincerity, aim for the heart." (228)

\subsection{Der Obersetzer, das Plagiat und die Pest-Metapher}

Der übersetzer Felix ${ }^{123}$ leidet seit jeher unter Minderwertigkeitskomplexen gegenüber Victor, weil dieser stets mehr Erfolg hatte, insbesondere auch bei Silva. Mit seiner Emigration wollte Felix aus dem Schatten des Rivalen heraustreten und sich von ihren "Gurus" (38) im Untergrund, Avestin und Migulin, emanzipieren, deren Bann er im Rückblick eher kritisch sieht $(13,43) .124$ Sein ziel war es, einen eigenen weg einzuschlagen und gleichsam in eine neue Haut $2 u$ schlüpfen (37). Freiheit bedeutete für ihn die bewußte selbstentfremdung durch die Versetzung in eine welt, in der es keinerlei "anspielungsreiche zitate der Vergangenheit" gibt (47). Hier spürt der vor sich selbst Geflüchtete das Verlangen, Teil des Lebens um inn herum zu werden (60) und dadurch eine neue Identität anzunehmen.

123 wie schon in den Romanen aus Ziniks Jahren in Israel und Russkaja slużba tritt hier abermals ein Held auf, der sich berufiich mit Sprache beschäftigt (s. III. 2.2.).

$124 \mathrm{Vgl}$. Ziniks Reflexionen aufgrund seiner eigenen Erfahrungen in dem Essay "Emigracija kak literaturnyj priëm", a.a.0., S. 173-177. 
"My patriotism is passport-based", erklärt er in der Überzeugung, daß inm der britische $\mathrm{PaB}$ diese Identität bestätigt $(48)$.

Doch stattdessen bemerkt Felix bald eine innere Leere (54). AuBerdem erkennt er, daB er sich von seinen Erinnerungen nicht lösen kann, zumal sie inn in Gestalt victors wieder einholen $(66,71)$. Felix hält seine Emigration mit mehreren stationen, nämlich über Jerusalem und Verona nach London, letztlich für gescheitert: "[...] he'd ended up in the wrong place at the wrong time." (70)

Seine stellung zwischen den Kulturen manifestiert sich in seiner Übersetzungsarbeit an Puskins "Pir vo vremja cumy" über eine mittelalterliche pestseuche in London. Dabei entdeckt er, daß der russische Romantiker einige Passagen aus der Tragödie "The city of the Plague" des kaum bekannten englischen Schriftstellers John wilson direkt übernommen hat. ${ }^{125}$ Felix kann einfach auf die stellen zurückgreifen und sie als seine übersetzung verkaufen (199). Da er seine Erkenntnisse geheimhält, handelt er wie ein Plagiator. Ausgerechnet der sowjetische Übersetzer $\mathrm{Ku}-$ pernik deckt die Fälschung auf (216). Der ungebetene Gast auf Victors Willkommensfeier erscheint als Karikatur seines Berufsstandes, wenn er beispielsweise die Bibel für korrekturbedürftig erklärt (207), und wird selbst der Unredlichkeit überführt. 126 Er erfüllt somit eine ähnliche Spiegelfunktion gegenüber Felix wie zuvor Edward-Edmund gegenüber Victor, wobei auch Kuperniks Identität zweifelnaft ist (166).127

125 Die Zitate aus wilsons werk stehen im russischen originaltext auf englisch (mit anschließender übersetzung), um die Authentizität zu wahren (Lord $i$ eger', Moskaug 1991 . S. 179-182).

126 Der Parteigünstling verhielt sich unrechtmäBig gegenüber Avestin, der auf der Liste der sowjetischen Zensoren stand (212-213). Die Frage der legitimen übersetzung - als Bild für die Aneignung fremder Gedanken bzw. einer fremden Kultur - wird also durch insqesamt drei Figuren aufgegriffen 127

Kupernik spielt überdies eine wichtige Rolle gegenüber den anderen Emigranten auf der Party, indem er ihnen ihren unnatürlichen status vor Augen führt: "[...] all of them looked in the presence of a full-blooded Soviet citi- 
Mit seiner Enthüllung trifft er auBer der Berufsehre seines Kollegen vor allem dessen Identitätsprobleme im Kern: Felix sucht nicht nach dem Eigenen, sondern kopiert fremde originale. Seine literaturhistorischen studien, die - analog zur psychologischen Analyse - aus diversen Quellen Wirkungszusammenhänge rekonstruieren, 128 sind insofern eine Flucht vor dem eigenen Ich in die fiktiven Welten anderer, in denen er indirekt wiederum sich selbst sucht (2.B. 201). AuBerdem veranschaulichen die Recherchen, daB jede Fiktion mit weiteren zusammenhängt, was als strukturprinzip den gesamten Roman beherrscht und die Realität für die Emigrantenhelden so schwer greifbar macht. Insbesondere bei felix bestimmt seine geistige Welt bzw. die fiktive Puskins seine Wahrnehmung und Verarbeitung der Emigrationserfahrung. So vergleicht er die Dritte Welle mit einer Flucht vor dem "schwarzen Tod" und fragt nach der Schuld derjenigen, die damit ihre Landsleute im stich ließen (51). AuBerdem führt er ein zitat von wilson an:

"[...] The Plague broke out

Like a raging fire within the darksome heart

of a huge mad-house; and one stormy night

As I was passing by its iron gates

With loud crash they burst open, [...]" (148)

Das lyrische Ich berichtet weiter, daB die entflohenen Menschen alle umkamen bis auf zwei, die verrückt wurden. Die Parallele von Wilsons Vision zur Massenemigration aus der Sowjetunion ist deutlich: Menschen durchbrechen in großer Zahl den Eisernen Vorhang ("iron gates"), um dem wirklichkeitsfremden Kommunismus ("huge mad-house")

zen like a bunch of displaced apparitions." (155) AuBerdem parodiert er durch sein Geschwätz als scheinbarer Insider der russischen Diaspora deren Leben (153-160).

128 Die ausführlichen Exkurse (50-52, 147-150, 170-172) führen weiter $z u$ Thomas de Quincey und vor allem Dostoevskij, der auch deshalb einbezogen wird, weil in seinem Werk Fragen von Schuld und Moral im Vordergrund stehen. Felix' Monologe sind im Stil einer wissenschaftlichen Abhandlung verfaBt, unter anderem mit exakten bibliographischen Angaben (2.B. 199). Dadurch stören sie den FluB der Narration. Man hat den Eindruck, daß Zinik den Roman als Plattform benutzt hat, um seine eigenen komparatistischen Forschungsergebnisse $2 u$ präsentieren, die er zudem in den Interviews mit dem Literator und der Nezavisimaja gazeta (beide a.a.o.) erläutert. 
zu entfliehen, aber sie können die Freiheit wegen ihrer inneren "Verseuchung" nicht nutzen. Das Pest-Motiv erscheint ferner in den Passagen über London, in denen Felix' Perspektive dominiert. So erfährt er von einer Legende, derzufolge der südöstliche Stadtbezirk Lewisham auf einem uber 300 Jahre alten Massengrab mit Pestleichen stehen soll (64).129 Mit den Hinweisen auf eine Rattenplage (63, 215), die Müllberge in den straßen (79), die Ansteckungsgefahr durch einen Grippevirus (78), die ungewöhnliche Hitzewelle (78), die Menschenmassen und den Schmutz (79-81) entsteht das Bild einer morbiden stadt, in der nach Felix' Beobachtung alle voneinander Abstand halten, als müBten sie sich vor einer seuche schützen (64, 80-81).

Wie bereits das Detail einer grassierenden Grippe zeigt, wird die Pest-Metaphorik im Roman durch weitere Epidemien ergänzt. In den Kapiteln über Moskau versinnbildicht die cholera, die im Land ausgebrochen ist und sich allmählich der stadt nähert, die bedrohliche verschärfung des politischen Klimas (2.B. 52) und die künstliche Abgeschlossenheit der Moskauer (17). Die Massenverhaftungen werden im Verhältnis mit der Ausbreitung der Tollwut gesehen (82). Epidemien symbolisieren so gleichermaßen den Niedergang der sowjetischen und der britischen Gesellschaft. Wie in The Mushroom-Picker werden beide kritisch, aber weniger satirisch einander geqenübergestellt. Zur Darstellung Englands gehören außer den neqativen und verfremdenden Eindrücken von Felix auch die lebendige Schilderung der Atmosphäre in einem pub (55-57) und die Anekdote mit einem Fahrkartenkontrolleur, der von einer äuBerst naiven sicht der Sowjetunion in seinem land zeugt (96-99). Solche szenen haben überwiegend illustrativen charakter. Insgesamt tritt die Gesellschaftsanalyse in The Lord and the Gamekeeper hinter der psychologischen zurück.

129 S. Ziniks Ausführungen im Interview mit der Nezavisimaja gazeta, a.a.o. 


\section{DIE ERZX̄HLUNGEN}

\subsection{Vorbenerkung}

Anders als in den Romanen verwendet zinik in seinen Erzählungen überwiegend realistische Verfahren, kaum Metaphern und bis auf einzelne Ausnahmen die Ich-Form. Sie beschränkt die Perspektive auf den Erzähler, in allen Fällen ein aus der Sowjetunion nach England ausgewanderter Russe mit teilweise deutlichem autobiographischen Bezug. Die Betonung liegt darauf, welche Vorgänge sich in ihm abspielen, also auf den psychologischen Aspekten des emigrationsbedingten Zwischenraums und noch stärker als in den Romanen auf der inhaltlichen Ebene. Die Handlung besteht im Kern meistens aus einer Begegnung zwischen inm und einer fremden oder einst vertrauten Person, durch die seine Identität und sein Selbstverständnis, seine Haltung $z u$ Vergangenheit und Gegenwart sowie zum Eigenen und zum Fremden hinterfragt werden. Von der Analyse werden vier Erzählungen ausgeschlossen, weil sie vom dargestellten Schema und dem Emigrationsthema abweichen. 130

\subsection{Besuch aus der Vergangenheit}

Die beiden Erzählungen "Za krjučkami" (1987) und "Doroga domoj" (1990), die im folgenden besprochen werden, basieren auf der gleichen Situation: Der Ich-Erzähler bzw. die Hauptfigur wird durch einen unwillkommenen Besuch aus der Heimat mit der Vergangenheit konfrontiert und veranlaBt, eine Art Bilanz der eigenen Emigration zu ziehen.

130 "Lišnij biletik" (1981) handelt von einer Begebenheit im Bahnhof von Kiev. "Deva i monstr" (1985) ist eine märchenhafte Parabel über die Sowjetunion, die Menschen zu Märtyrern oder Monstern macht. In "Édipov Stalin" (1985) schildert Zinik die Eindrücke, die der Kult um stalin bei ihm als kind hinterließ. Seine Erfahrungen in den Samizdat-Kreisen um Pavel Ulitin und andere hat er in "Na puti k "Artističeskomu'" (1992) festgehalten. Solche autobiographischen Erinnerungen sind als Rückblick aus der zeitlichen und örtlichen Distanz mit der Exilsituation zwar verbunden, setzen sich aber nicht direkt mit ihr auseinander und bleiben daher hier nur erwähnt. (Quellenangaben s. Werkverzeichnis.) 
In "Za krjuckami" trifft der Ich-Erzähler in London einen sowjetischen Reisenden, der inn um Hilfe bei der Suche nach bestimmten Angelhaken bittet. Er willigt nur ungern ein, da er meint, einen typischen sowjetbürger vor sich zu sehen, mit dem inn nichts mehr verbindet:

"[...] взрослым он лишь казался, потому что советская цивилизация превращает всех в малолетних, когда речь заходит о вещах [...]: и жалко его, и раздражает, и знаешь, что не отвяжешься."

("[...] er war nur scheinbar erwachsen, denn die Sowjetkultur verwandelt alle in kinder, wenn es um Dinge geht [...], er tut einem leid und regt einen zugleich auf, und man weis auch, daß man inn nicht mehr loswird.")!3

Der herablassende Ton zeugt von einer überheblichkeit gegenüber den eigenen Landsleuten, die vermutlich ein schlechtes Gewissen kaschieren soll. Der Versuch, auf Distanz zu gehen, miBlingt schon deshalb, weil der strömende Regen beide Männer unter einen Schirm zwingt (143-144). AuBerdem wird die sicht getrübt, und da sich das richtige Geschäft nicht so schnell finden läßt, irrt der Ich-Erzähler mit seinem Gast lange in der stadt umher - ein Bild für seine verunsicherung. Er gibt jedoch nicht auf, denn er will beweisen, daß es im westen tatsächlich alles zu kaufen gibt, um sein Emigrantenleben ins rechte Licht $z u$ setzen (146). Die letztlich unvermeidbare Erinnerung an Moskau macht dem Ich-Erzähler aber klar, was er für sein sorgenfreies Leben verloren hat: das Gefühl der Hoffnung, das er damals in sich trug, nämlich auf ein neues, besseres Leben (148-149). Mit der Gewöhnung an die Verhältnisse im westen hat er auch verlernt, sich so $z u$ freuen wie der Unbekannte beim Anblick der ersehnten Angelhaken. zitat:

"Ради этой сцены - засвидетельствовать чужую жадность к твоей новой жизни, к которой у тебя самого давно потерян интерес, - я, видимо, и таскался с этим маститым советским чиновником под проливным английским дождём."

131 Zinik, "Za krjučkami", sintaksis, Nr. 18, 1987, S. 143 . 
("Das war offenbar der Grund, weshalb ich mit diesem ehrbaren sowjetischen Beamten im strömenden englischen Regen herumgelaufen war: Ich wollte die Gier eines Fremden nach meinem neuen Leben beobachten, das mich selbst schon lange nicht mehr reizt.") (149)

Nur der sowjetische Besucher kann dem desillusionierten Ich-Erzähler wieder bewußtmachen, warum er freiwillig seine Heimat verlieb.

Stärker noch als in "Za krjučkami" wird die Hauptfigur in "Doroga domoj" gezwungen, ihr Leben zu überdenken. 132 Alek sieht nämlich nach 15 Jahren erstmals seinen vater wieder. Ähnlich wie dem Emigranten in der vorhergehenden Erzählung widerstrebt ihm das Gefühl der Zusammengehörigkeit. Sein erster Eindruck vom vater ist der eines "Zerrbilds" seiner selbst (105), und inn quält der Gedanke, daß er seine Abstammung schon äuBerlich nicht verleugnen kann $(109,112,119)$. Die subjektivität dieser Wahrnehmung wird bei einem Perspektivenwechsel deutlich, als Aleks Freundin umgekehrt auffällt, wie verschieden beide Männer sind (120). Alek konnte sich offenbar innerlich nie von seinem Vater befreien, der ihn als kind ständig Prüfungen unterzog, um festzustellen, ob er allein den richtigen weg findet $(112,117)$. Diese Kontrolle scheint sich bei diesem Besuch bezüglich seines Lebensweges fortzusetzen, und Alek fürchtet sie, weil er sich für einen Versager hält:

"[..] что он может продемонстрировать как результат своего пребывания на так называемой свободе? Отец приехал для подведения итогов его несостоятельности и неспособности самостоятельно найти путь в жизни. Дорога домой."

("[...] was konnte er als Ergebnis seines Lebens in der sogenannten Freiheit vorweisen? Der Vater war gekommen, um eine Bilanz $z$ u ziehen, eine Bilanz seiner Unselbständigkeit und seiner Unfähigkeit, einen weg im Leben $2 u$ finden. Den weg nach Hause.") (116)

Entsprechend verläuft sich Alek bereits beim Abholen im Bahnhofsgebäude (107 ff.) und verrät damit, daß er mit

132 Zinik, "Doroga domoj", Drużba narodov (Moskau), Nr. 2 , 1993, S. 103-123. 
dem Leben in England weniger vertraut ist, als er vorgibt, wobei die situation als symbol für seine Verwirrung mit der in "Za krjučkami" vergleichbar ist.133 Er verteidigt die englische Gesellschaft, als ihnen zum Beispiel eine arme Alkoholikerin mit ihrem kind begegnet (108), um seine Auswanderung $z u$ rechtfertigen und seine eigene Enttäuschung $z u$ überspielen. Besonders in den zahlreichen ÄuBerungen $2 u$ den Verhältnissen "bei uns" wider "bei euch" (2.B. 108) wird jedoch deutlich, daß der vater $2 u$ seiner Welt steht und inr gegenwärtiges Leben sie trennt. Als alte Konflikte aus seiner Kindheit aufbrechen, erkennt Alek in der gegenseitigen Anklage, daB ihre gemeinsamen Erfahrungen sich auf die Vergangenheit zur zeit des stalinismus beschränken. Inm wird aber zugleich klar, daB sich die Freiheit, in die er aus der Bindung an den vater fliehen wollte, als Illusion erwies (123). Somit ist auch diese Lebensbilanz von Frustration bestimmt.

In "Lico èpochi" $(1992)^{134}$ geht es statt der Ernüchterung im neuen Leben um die Entmystifizierung der Vergangenheit in der Sowjetunion. Der Ich-Erzähler versucht zunächst ebenfalls, seine Emigration im Kontext seiner Kindheit und Jugend nachzuvollziehen. In einem Rückblick begründet er sie mit dem Einfluß seiner regimekritischen, weltoffenen Tante Irena (137-139). Der Bogen zur Gegenwart wird erneut durch einen Besuch gespannt; in diesem Fall begibt sich aber der Ich-Erzähler selbst nach Moskau.135 Als er dort von den Ehebrüchen der Tante und der Eltern erfährt (144) und die Haare der einst vergötterten Irena als Perücke $2 u$ Boden fallen (146), bricht die welt seiner Erinnerung zusammen. In diesem Moment entblößt sich das "wahre Gesicht" der Tante und damit auch das seiner Heimat (147).

$133 \mathrm{Vgl}$. auch die symbolische Funktion einer solchen Szene in Russkaja slużba, als sich Narator in den Gängen def U-Bahn verläuft (a.a.O., S. 79-85).

Z34 Zinik, "Lico épochi", Sintaksis, Nr. 33, 1992, S. $122-147$.

135 Die Erfahrungen der Heimkehr nach vielen Jahren hat Zinik mehrfach verarbeitet (s.u.). 


\subsection{Konfrontation mit seinesgleichen}

Die drei Erzählungen in diesem Komplex zeigen jeweils, wie der Ich-Erzähler unerwartet einem anderen Emigranten gegenübersteht. Die Schauplätze sind weder in der alten noch in der neuen Heimat gelegen, sondern in einem dritten Land, so daB beide Figuren den gleichen status haben und die ausgelöste selbstreflexion in einem neutralen Raum stattfindet. Im ersten Fall - "Nezvannaja gost'ja" $(1989)^{136}$ - liegt abermals eine Besuchssituation zugrunde: Im portugiesischen Feriendomizil des Ich-Erzählers erscheint eine ältere russische Emigrantin. zu "Doroga domoj" besteht ein weiterer vergleichspunkt darin, daß anhand der Begegnung die problematische Beziehung des Helden zur Mutter thematisiert wird.

Wie in den vorhergehenden Erzählungen fällt es dem Ich-Erzähler schwer, sich gastfreundlich zu geben, weil er sich mit seiner Heimat nicht mehr identifiziert. Mit der Besucherin, die ihn anscheinend nur wegen der gleichen Herkunft beehrt, will er gerade deshalb nichts $2 u$ tun haben (166). Ihr Geschwätz ist inhaltlich $(169,172)$ und stilistisch ${ }^{137}$ aus seiner sicht ebenso typisch für russische Auswanderer wie inr Verhalten (2.B. 173), wobei der Ich-Erzähler sie beobachtet, als stünde er über ihr. offensichtlich wehrt er sich gegen das Bekenntnis seiner Gemeinsamkeiten mit dieser Frau, von der er sich zur Betonung seiner Individualität bewuBt absetzen will. Dennoch kann er nicht vermeiden, daß sie ihn im Geist in die kind-

136 Die folgenden Textverweise stammen aus: Zinik, "Nezvannaja gost"ja", Sintaksis, Nr. 29, 1990, S. 161-182. (Im Titel liegt offenbar ein Druckfehler vor, da es "nezvanaja" heiBen müBte.)

137 Ihre Rede ist u.a. mit fremdsprachigen Ausdrücken versetzt, die sie mit Akzent ausspricht, z.B. marmajt für das englische marmelade und lenć für lunch (174). Der Erzăhler bemerkt auBerdem: "V eë reči neożidanno proryvalis" zargonnye slovečki, podchvačennye na peresadoćnych perronach, $v$ vagonach $i$ stancionnych bufetach eë trëch èmigracij, v putanice stran, èpoch i pokolenij." ("In ihrer Rede tauchten unerwartet umgangssprachliche wörtchen auf, die sie in den Umsteigebahnhöfen und Zügen ihrer drei Emigrationen und in dem Durcheinander von Ländern, Epochen und Generationen aufgeschnappt hatte.") (169) 
heit versetzt. In einer szene zwischen Realität und Phantasie erlebt er einen Herzanfall des Gastes wie den Tod seiner Mutter (176 ff.), wobei Zinik wieder die Motive der Selbstverachtung (163-164) und der Schuldgefühle (181-182) einbezieht.

"Mea culpa" (1987)138 spielt ebenfalls in einem Urlaubsort, und zwar an der nahöstlichen Mittelmeerküste. Die Vergleiche der orientalischen Kultur mit der westlichen belegen, daß dem Ich-Erzähler, der durch den Namen zinovij Efimovic als stellvertreter des Autors auftritt, die einst fremde englische Mentalität nunmehr so vertraut ist wie die gewohnte englische zeitung (149-151). Das verinnerlichte Fremde wird in der noch fremderen Umgebung das Eigene. Der Zufall verschlägt jedoch einen weiteren sowjetischen Emigranten, Michail Sergeevic Gerc, an den gleichen ort, und da der Ich-Erzähler für ihn ein Landsmann und sowjetischer oppositioneller ist, gerät sein standpunkt als Engländer ins Wanken.

Im Gegensatz zu den bisher vorgestellten Texten kommt es hier zu keiner direkten Konfrontation der Figuren. $\mathrm{zi}$ novij Efimovic umgeht vielmehr Gerc beharrlich, um keine Verbundenheit heucheln zu müssen (154 ff.), zumal dieser ideologisch ein anderes Exulantenlager (152-153) und den Typ des russischen Intellektuellen vertritt, der dem IchErzähler unerträglich ist (154). Vor dem fremden Hintergrund, der beide als Russen auf eine stufe stellt, kommen inm ihre Differenzen besonders kraß vor. Allerdings schildert er seinen "Gegner", seine Abneigung gegen ihn, seine Ausweichmanöver (etwa durch militärische Ausdrücke auf $\mathrm{S}$. 156) und sein anschließendes schlechtes Gewissen (160) mit Ironie. 139 sie zielt allgemein auf den verkrampften umgang

138 Zinik, "Mea culpa", Sintaksis, Nr. 21, 1988, S. 149163

139 Stilbsp.: "Tol'ko nado sidet' ne šelochnuvsis', i togda ostryj vzgljad étogo udava, pripolzśego iz ćaśćoby rossijskoj duchovnosti, skol'znet mimo, ne zametiv menja, myšku zapadničeskogo racionalizma." ("Ich muß nur absolut regungslos sitzenbleiben, und der scharfe Blick dieser Riesenschlange, die aus dem Dickicht der russischen Geistigkeit herausgekrochen ist, wird vorbeigleiten, ohne 
der sowjetischen Emigranten miteinander (s. auch 159-160) und wird dadurch verstärkt, daß sich die Geschichte in Banalität auflöst: Gerc gesteht seinerseits, den Bekannten absichtlich übersehen $z u$ haben, weil er in Gesellschaft einer Amerikanerin unerkannt bleiben wollte.

Die dritte Erzählung, die nach dem gleichen Handlungsmuster die Identitätsprobleme des Emigranten darstellt, ist "Beženec" (1987).140 Diesmal soll der Ich-Erzähler in wien einen Ankömmling aus der Sowjetunion aufsuchen. Das Geschehen wird auf Mai 1979 fixiert. Die russischen Flüchtlinge, für die wien eine Durchgangsstation ist (144-147), wecken eine "aristokratische" Arroganz (147) in ihm, der im Westen bereits Wurzeln geschlagen hat und ihnen damit voraus ist. In Abgrenzung von der sowjetischen prägung, die er für unverkennbar hält (148), stellt er sich einem vermeintlichen Russen als Engländer vor (150). Dabei dienen ihm die Zigarettenmarke "Benson and Hedges" und die Times als Beweise. Sie belegen aber andererseits zusammen mit der Bezeichnung des Mannes als moj sootečestvennik (148), daß es sich um eine angenommene Identität handelt, die der Ich-Erzähler wie ein neues kleid zur Schau trägt:

"Признаться этому монстру в родстве значило проигнорировать собственный многолетний опыт освобождения от рабства советского прошлого [...]. Признайся я в своём российском происхождении, разговор тут же скатился бы к выяснению того, где и как можно устроиться. Я же не был заинтересован в увеличении российского этнического меньшинства на британских островах."

("Das Bekenntnis meiner Verwandtschaft mit diesem Monster bedeutete, den langjährigen Proze $\beta$ der Befreiung aus der Sklaverei der sowjetischen vergangenheit auBer acht $z u$ lassen [...]. Hätte ich meine russische Herkunft offenbart, wäre das Gespräch darauf gekommen, wie man sich wo niederlassen kann. Ich hatte aber kein Interesse an einer stärkung der russischen Minderheit auf den britischen Inseln.") (150-151)

mich, das Mäuschen des westlichen Rationalismus, $z u$ bemerkep. ") (154)

152. 
Das zitat verdeutlicht, daß jeder weitere Emigrant von den bereits integrierten als potentielle Bedrohung ihres mühsam errungenen status gesehen wird. In einer ähnlich überraschenden Wende wie in "Mea culpa" stellt sich zum Schluß heraus, daß der vermeintlich russische Asylant aus dem Libanon stammt. Der Ich-Erzähler hatte sich von einer Fehleinschätzung leiten lassen, die seine von den eigenen Erfahrungen bestimmte und begrenzte Weltsicht verrät.

\subsection{Fremdsein in London und in Moskau}

Für die Auseinandersetzung mit der englischen Kultur bevorzugt zinik als Gattung den Roman, da inm Erzählungen offenbar $2 u$ wenig Raum dafür lassen. Eine Ausnahme bildet "Kriket" (1990).141 Bereits der Titel benennt mit dem transkribierten englischen Begriff eine nationale Eigenheit, wobei im Text ausgefüht wird, daß solche spezifika einer fremden Kultur "nicht übersetzbar" seien $(7,10)$. Die Begeisterung der Engländer für das spiel ist Ausländern im allgemeinen vollkommen unverständlich.112 Das Interesse an diesem Sport, das der Ich-Erzähler, ein weiteres Ebenbild des Autors, in der Anfangsszene demonstriert, wird daher zum Symbol für seine Anpassungsversuche.

Bei zinik steht die Distanzierung zum Eigenen, die in den bereits vorgestellten Erzählungen demonstriert wird, der suche nach einer neuen Identität im Fremden gegenüber. Das heißt, er führt durch seine Helden beide Verhaltenweisen vor, die sich gegenseitig bedingen. In "Kriket" geht es vornehmlich um die Hinwendung zum Fremden. Der Ich-Erzähler bemüht sich dabei vergebens, in die besseren Kreise der englischen Gesellschaft einzudringen, deren Prototyp

141 Zinik, "Kriket", Vremja $i$ my, Nr. 109, 1990, S. 5-45.

142 Die Schilderung aus der Perspektive des unwissenden zuschauers enthält entsprechend folgende Ausdrücke: prekrasnaja $v$ svoej absurdnosti logika, vpećatlenie zaputannosti, složnaja cuźdost', jew. s. 5: raznogolosica (30): miraz $v$ pustyne (31): mehrfach aus dem Wortfeld "verrückt", 2.B. belye, do sumasšestvija, odeżdy igrokov (6), s psichiatričeskim fanatizmom (31), man'jaki (31). 
der exklusive cricket club ist $(9,12,31)$ und in deren traditionell-nationaler Prägung gerade der Reiz für inn liegt (9). Seine Hoffnung dazuzugehören legt er in die Bekanntschaft mit Joan, in seinen Augen eine echte englische Lady. Ein code-switching markiert diesbezüglich das Klischee: "[...] ona byla obrazcom anglijskogo soversenstva i bezuprecnosti. The way she wears her hat, the way she sips her tea, the memory of all that..." ("[...] sie war ein Musterbeispiel für englische Vollkommenheit und Tadellosigkeit. The way usw.") (11). Joan macht den Freund $z u$ ihrem Vertrauten:

"Мне же льстило сознание того, что через интимничанье с ней я приобщаюсь, пускай заочно, $\mathrm{x}$ тому избранному меньшинству из тех, кого и следовало считать истинными англичанами."

("Ich fühlte mich geschmeichelt bei dem Gedanken, daB die intimen Gespräche mit ihr mich, wenn auch in Abwesenheit, $z u$ jenen Auserwählten reihten, die man als wahrhafte Engländer betrachten kann.") (22)

Entsprechend irritiert inn freilich, daB Joan inn ständig als Moskauer vorstellt (z.B. 22) und wie einen "dressierten Bären aus Sibirien", also ein Exotikum vorfuhrt (12), aber aus inrem Freundeskreis an sich heraushält $(20,23 \mathrm{ff.})$ und ihm auf dem Kricketplatz das Gefühl gibt, deplaziert $z u$ sein (9). Dort wird inm allerdings später selbst klar, daß er nicht mit Akzeptanz rechnen kann. Zinik analysiert in diesem Werk zum einen kritisch die britische Haltung gegenüber Fremden, zum anderen die Minderwertigkeitskomplexe des angeblich als "Barbar" (9) behandelten Ich-Erzählers, der die Position des Einwanderers schon von selbst einnimmt:

"Я порой дурно говорю по-английски не потому, что я плохо знаю этот язык, а потому, что не могу до конца представить себя англичанином, говорящим по-английски."

("Ich spreche manchmal schlecht Englisch, nicht weil meine sprachkenntnisse mangelhaft sind, sondern weil ich mir nicht richtig vorstellen kann, ein Engländer $z u$ sein, der Englisch spricht.") (22) 
Allmählich erkennt der Ich-Erzähler, daß die Anbiederung an die Gesellschaft einem selbstverrat gleichkommt (23) und er als "heimatloser kosmopolit" (18) keine zweite Heimat finden kann (31). Die Attraktivität der von Joan vertretenen $\mathrm{zirkel}$ relativiert sich ohnehin, als die Doppelmoral dieser snobs ${ }^{143}$ zutage tritt. Ausgerechnet mit seiner Einweihung in ihre heimlichen bi- und homosexuellen Dreiecksbeziehungen hört der Russe das ersehnte "Welcome to the club" (41), wendet sich aber daraufhin von selbst ab. Von seinem Standpunkt des Außenseiters präsentiert die Erzählung mithin das satirische porträt einer schickeria,114 die mit elitärem Dünkel auf makellosen Schein (1819). AuBerlichkeiten (z.B. bezüglich der kleidung auf $S$. 24 ) und standesbewußtsein bedacht ist; hinter der Fassade aber weicht jeder von der Norm ab und ist im Grunde isoliert (42).

während "Kriket" die Schwierigkeiten der sozialen und kulturelien Integration im Aufnahmeland vorführt, hat "Slučajnaja vstreča" (1989) 145 die gleichzeitige Entfremdung von der Heimat zum Gegenstand. Die Erzählung beruht auf Ziniks erstem Besuch nach dreizehn Jahren 1988 in Moskau. Seine Eindrücke und Gedanken hat er bereits in "Na obratnom puti" $(1988)^{146}$ im stil einer Reportage mit Erläuterungen über das Land und Rückblicken festgehalten, und zwar aus der Perspektive des Ausländers (v.a. 32). Die Gefühle des Fremdseins und der zeitverschiebung bei der scheinbaren Rückkehr in die abgeschlossene vergangenheit (38) gestaltet zinik in "Slučajnaja vstreča" literarisch, wobei er einige Passagen von "Na obratnom puti" unmittelbar weiterverarbeitet hat, so daß sich die Textgenese als

113 Das wort erscheint im russischen Text als Anglizismus, überdies adjul'ter (adultery) und afera (affair), um diese zweifelhafte Lebenswelt zu kennzeichnen (22). AuBerdem wird Joans Rede durchgehend mit englischen Elementen wiedergegeben, wobei ihr exaltiertes darling inre Falschheit unterstreicht $(11,22,23)$.

lit $\mathrm{S}$. auch die Einblicke in das Londoner szeneleben bei einem Rundgang durch die entsprechenden Bars ( $32 \mathrm{ff}$. ).

115 Zinik, "Slućajnaja vstreča", Vremja i my, Nr. 108, 1990, S. 86-116.

Zinik, "Na obratnom puti", sintaksis, Nr. 24, 1988, S. 29-38. 
stufenweiser Proze $B$ der Umsetzung eigener Erfahrungen zum Teil rekonstruieren läßt. 147

Der Ich-Erzähler in "Slučajnaja vstreča" sieht sich in ein Moskau zurückversetzt, in dem für ihn die zeit stehengeblieben ist (87-88 u. 97). Bei aller Vertrautheit von früher trennt ihn eine unüberwindliche Distanz von der jetzigen Realität (90). Er verliert sich in seinen Erinnerungen, die insgesamt rätselhaft bleiben (91-92): Veränderungen wie ein improvisierter ImbiBstand mit dem pseudoenglischen Namen bif-gril' wirken aus seiner sicht unpassend (92). Im zentrum der Handlung steht eine spontane willkommensfeier bei einer einstigen Bekannten namens Evgenija. Mit den Gästen verbindet den Ich-Erzähler indes nur die Vergangenheit, so daß jeder die Person seiner Erinnerung vor sich sieht und gleich $2 u$ Beginn eine Kluft spürbar wird (98-100).148 zur Illustration der gegenseiti-

147 Die folgende Reflexion wurde inkl. der Sätze, die hier in der Mitte ausgelassen sind, beinahe wörtlich übernommen: "[...] na kakuju-to dolju mgnovenija mne pomereśčilos', čto otsjuda uže ne vyrvat'sja, [...] i ja stanu neotlicim ot ostal'nych sovetskich graz̉dan." ("[...] für einen kurzen Moment kam es mir vor, als könnte ich mich von hier nicht mehr losreiBen, [...] und ich werde wieder genauso wie die anderen sowjetbürger.") In: "Na obratnom puti", a.a.0.. s. 30: vgl. "Slučajnaja vstreča", a.a.0.. S. 113. Die Überlegungen $z u$ der Frage, ob die freiwiligen Emigranten wie Ratten das sinkende Schiff verließen und sich gegenüber den Zurückgebliebenen schuldig machten, hat $\mathrm{zinik}$ in ein Gespräch umgesetzt (36/107108). Die im Aufsatz angefühte englische Redensart "The past is a foreign country: they do things differently there." wird dem Ich-Erzähler in den Mund gelegt (37/102). $S$. auch die in beiden Texten vorhandenen Hinweise auf einen neuen ImbiBstand $(32 / 92)$ und ein unangebracht wirkendes Festplakat $(34 / 90)$ sowie die Episode mit einer Kreditkarte $(32 / 102)$.

$148 \mathrm{Vgl}$. das Verhältnis von Vater und Sohn in "Doroga domoj". Vgl. auch Ziniks Ausführungen in seinem Essay "Gotičeskij roman užasov èmigracii" (a.a.0., s. 60): "[ [..] $v$ nekij moment $v$ proślom sud'ba buduśćego émigranta i 'buduścich' ostavśichsja - razdelilas'. Vernuvśijsja, poètomu, popadaet $v$ drugoe, 'ne svoë' prošloe. Kak prizrak umeršego, on nanosit vizit ne svoim sovremennikam - drugomu pokoleniju, esli ne po vozrastu, to po opytu i myšleniju." ("[...] in einem gewissen Moment in der Vergangenheit haben sich die Schicksale des künftigen Emigranten und der 'künftigen' Zurückbleibenden geteilt. Der Heimkehrer gelangt daher in eine andere, 'nicht seine eigene' Vergangenheit. Wie der Geist eines Toten besucht er nicht 
gen Befremdung verwendet der Autor Ausdrücke wie muzejnyj éksponat (98), prizrak (98), èkzoticeskij zver' (104) und obez'jany (107).

Der Ich-Erzähler spielt sich als Engländer auf: Amüsiert schildert er seine touristischen Eindrücke von Moskau (101), prahlt mit seiner kreditkarte und seinem Englisch (102) und erzählt ausführlich, wie er seinen britischen $P a B$ bekam (105). Erst nach einer weile wird inm seine Taktlosigkeit bewuBt: "Ja daval, koroče govorja, ponjat', čto ja uže ne ichnij, čto ja - vol'nyj, a oni vse ze te že sovetskie raby." ("Ich gab ihnen also $z u$ verstehen, daß ich nicht mehr einer von ihnen bin, sondern frei, während sie sowjetische sklaven geblieben sind."; 106). Von den teils berechtigten, teils neidisch klingenden Vorwürfen seiner Landsleute, ihre situation nicht $2 u$ begreifen ( $101 \mathrm{ff.}$ ), fühlt er sich angefeindet und zur Rechtfertigung gedrängt. Aus der immer offeneren Diskussion hört er aber vor allem selbstverachtung (106), das russische Leidenspathos und das Eingeständnis der eigenen Leblosigkeit (109) heraus, womit er wiederum sich selbst mit seiner Emigration bestätigt sieht. Die kluft zwischen inm und den anderen wird nicht überwunden.

Bei einem anschließenden Gespräch mit Evgenija entsteht allerdings doch noch eine Brücke zwischen Vergangenheit und Gegenwart, als er in ihrer Hand einen alten Schlüsselanhänger wiedererkennt: der englische Gardesoldat erinnert inn zugleich an das heutige London (112-113) und eine frühere Beqebenheit in Moskau (113-114). Die Bilder an die damalige Nacht schieben sich dabei mit denen der unmittelbaren Realität ineinander. Zum SchluB stellt sich heraus, daß der Ich-Erzähler die Frau vor sich für seine frühere Bekannte persönlich hielt, sie aber tatsächlich deren mittlerweile erwachsene rochter ist. Die Verwechslung macht plastisch, wie stark seine zeitverwirrung (116)

seine Zeitgenossen, sondern die Angehörigen einer anderen Generation, wenn nicht dem Alter nach, dann gemessen an ihrer Erfahrung und Denkweise.") 
seine Wahrnehmung verzerrt und ihn in den wahn versetzt, daB die Vergänglichkeit hier aufgehoben sei.

\subsection{Der neue Roman}

AbschlieBend werden drei Texte vorgestellt, die nach Angaben des Autors $z u$ dem Roman "Meeting the Original" gehören, an dem er gerade arbeitet, und bereits vorab in vremja $i$ my als Erzählungen erschienen sind: "Mol'" (1992), "Desant $v$ Koljure" (1993) und "Dvojnoj akt $v$ Socho" (1994). Wie in den vorherigen Romanen gibt es hier wieder einen auktorialen Erzähler. Im Mittelpunkt des neuen Werkes, das in der Gegenwart spielt, soll Alek stehen. 149 Alek ist Schriftsteller und BBC-Redakteur wie $\mathrm{Zinik}$ selbst, und wie dieser emigrierte er in den 70er Jahren aus der Sowjetunion über Israel nach London. Dort ist Alek längst heimisch geworden, aber nicht zufrieden. Der autobiographisch geprägte Held in ziniks Prosa ist also gleichsam mit dem Autor älter geworden und durchlebt nach fast 20 Jahren im Ausland eine mid-life crisis, da er sich moralisch, seelisch und finanziell "bankrott" sieht - so seine Bilanz in "Dvojnoj akt $v$ Socho". 150 Annlich wie in The Lord and the Gamekeeper werden Aleks Probleme unter anderem durch seine Beziehung $z u$ einer anderen Emigrantin und seine Kontrastierung mit ihr sichtbar gemacht. Es handelt sich um die junge Lena, die schon als kind mit ihren Eltern die Heimat verlieB.

"Dvojnoj akt v Socho" erzählt, wie sich die beiden kennenlernen. Alek verfolgt Lena zunächst heimlich, nachdem sie inm wegen ihrer russischen züge aufgefallen ist. Eingangs wird ironisch erläutert, daB er sich als Emigrant diese "unbewohnte Insel" erschlossen und sein eigenes "Reich" geschaffen habe, in dem jedes russische Gesicht einen "Eindringling" signalisiere (5-8). Doch natürlich

149 Der Name verbindet inn mit der Hauptfigur in "Doroga domgj" 1994 , S. 30-31. 
stellt Alek der fremden frau nicht deshalb nach, weil sie seinen status bedroht, sondern weil sie ihm gefällt, seine Frustration und Depression (16) vergessen läBt und gerade als Russin anzieht. Bei seiner charakterisierung wird ersichtlich, wie widersprüchlich das Selbstwertgefühl des Helden ist, der sich in der englischen Gesellschaft wegen seiner Andersartigkeit gewohnheitsmäßig versteckt (7-8, 15, 40, 50) und sich trotzdem für einen "echten Londoner" hält $(18 ; \mathrm{vgl} .44)$.

Auf Lenas Spur entdeckt Alek eine Seite der vertraut scheinenden stadt, die er nie bemerkt hat $(22,35)$ : die sex-shops in dem zentralen viertel Soho. Die Erzählung ist größtenteils dieser Halbwelt und der Londoner szene mit ihren schillernden orten und Typen gewidmet, wo Alek mit seinem neu erwachten Interesse am Leben aus der Realität in eine bühnenhafte sphäre gehoben wird. Als er und Lena miteinander bekannt werden, rücken seine Gefühle eines zweiten Frühlings stärker ins Blickfeld. Der Erzähler begründet abermals halb ironisch die selbsttäuschung, in die sich der verliebte Alek versteigt, mit dessen Biographie: Durch die Emigration habe er ein zweites Leben begonnen und die verbindung zur eigenen Generation verloren, so daB inn die Jugend anziehe (13-14); mit Lena scheint er den damaligen Neubeginn $z u$ wiederholen und endlich Teil des Londoner Lebens $z u$ werden (65-67). Insgesamt tritt die Emigrationsthematik aber in "Dvojnoj akt $v$ Socho" zugunsten der Milieuschilderung in den Hintergrund, was für $\mathrm{Zi}-$ nik ungewöhnlich ist. 151

Im ganzen Roman wiederum wird das Thema der Emigration offensichtlich in den Kontext des politischen und gesellschaftichen Umsturzes in RuBland gesetzt. Dazu

151 Der Titel der Erzählung bezieht sich auf den Namen "Double act" eines der Etablissements in Soho, ubbertragen aber auch auf das Schauspielern von Alek und Lena, als sie dort bestimmte Informationen erhalten wollen. AuBerdem gliedert sich die Geschichte gleich einem Zweiakter in zwei Teile, nämlich Aleks "Verfolgung" von Lena und ihren gemeinsamen Rundgang durch Soho. Der Begriff ist typisch für die Mehrdeutigkeit in Ziniks Sprache. 
wechselt der Schauplatz in "Mol" "152 in das postkommunistische Moskau. Zinik verarbeitet hier also abermals seine Reisen dorthin. Geschildert wird der erste Besuch von Lena in ihrer Heimat (bei dem Alek nicht in Erscheinung tritt). Das Bild der sowjetischen Gesellschaft, das The MushroomPicker aus der sicht einer Fremden zeichnet, wird mithin aktualisiert. Lena tritt sogar buchstäblich in die FuBstapfen von clea, als sie in einer Moskauer Inszenierung des Romans deren Rolle übernimmt. Von inrer Vorgängerin unterscheidet sie freilich ihre binationale Identität, um die es im wesentlichen geht. Die überlagerung von Theater und Leben in ihrem Schauspiel als Engländerin und Russin (s. v.a. 23, 26) erinnert an The Lord and the Gamekeeper. Den Anzeichen nach entspricht der neue Roman überhaupt kompositionstechnisch und stilistisch weitgehend den beiden vorhergehenden.

Für die Konfrontation mit dem heutigen RuBland hat zinik vermutlich deshalb Lena gewählt, weil er durch sie das Befremden angesichts der dortigen Realität bei gleichzeitiger innerer Verbundenheit, das er selbst ähnlich empfunden hat (s. U.a. "Na obratnom puti"), anschaulich vermitteln kann. Ihre Nostalgie für das Land baut sich auf den Erzählungen der Eltern auf (6), während die wirklichkeit sich ihr ganz anders darstellt (15-16) und Moden wie Denkweisen sie von ihren russischen Altersgenossen trennen (11, 16-20). Moskau wirkt "exotisch" und verwirrend (1415) und ruft inr englisches Nationalbewubtsein wach: "[...] imenno $v$ Moskve ona okončatel'no počuvstvovala sebja dočer'ju Al'biona." ("[...] gerade in Moskau fühlte sie sich endgültig als Tochter von Albion.") (14) Genauso wird der Gast offenbar auch von den Russen wahrgenommen (18-19). Ein Zeichen für Lenas "defekte" russische Identität sind inre sprachfehler. Dabei entfalten die verwechslungen und Verdrehungen von Ausdrücken und Redewen-

152 Zinik, "Mol'", Vremja $i$ my, Nr. 119, 1993, S. 5-45. 
dungen eine besondere Komik, und ihre Anglizismen belegen regelmäBig inre zwitterhaftigkeit. 153

Wie bei Clea endet Lenas Aufenthalt traumatisch: Ihre Bekannte Ljudmila, die Frau inres Liebhabers Sergej, wird nach einem streit über diese Affäre von einem Bus überfahren, was mit Vokabeln aus der Theatersprache zynisch wie der Höhepunkt ihres "Gastspiels" in Moskau geschildert wird (30). Die Betrachtung des gegenwärtigen Rußlands vom standpunkt des Besuchers endet mit einer totalen Ernüchterung. Zudem wird Lenas Mythos von der Vergangenheit zerstört, als sie die Tagebuchnotizen eines Denunzianten aus der stalin-zeit findet (34 ff.).

In "Desant $v$ Koljure"154 werden Alek, Lena und Sergej zusammengebracht. Im Prinzip liegt die gleiche dramatische Dreieckskonstellation vor wie in the Lord and the Gamekeeper mit den Unterschieden, daß das Trio zwei Generationen angehört und Sergej kein Emigrant ist. Mit inm führt zinik erstmals eine Hauptfigur ein, die gegenüber den Auswanderern im Westen das veränderte RuBland repräsentiert, mit dem sich zinik im neuen werk auseinandersetzt. Die Darstellung der Konflikte von Alek mit sich selbst und den beiden anderen geschieht abseits des Alltagslebens vor neutraler Kulisse in Coliour, einem Urlaubsort in den Pyrenäen.155 Im Gegensatz $2 u$ der heiteren Ferienatmosphäre (2.B. 18-19) steht die desolate stimmung von Alek, dessen

153 Mehr Beispiele als in "Mol"" finden sich in "Desant $v$ Kol jure"; s. Vremja $i$ my, Nr. 122, 1993, S. 6, 8, 14, 16, $20,21,26,37$.

154 Zinik, "Desant v Koljure", a.a.0., S. 5-65.

$155 \mathrm{Vgl}$. die Urlaubssituation bei der Begegnung des Helden mit anderen Emigranten in "Nezvannaja gost'ja" und "Mea culpa" (s.o.) sowie die Landidylle um die Klinik in The Lord and the Gamekeeper. - Die zahlreichen deutschen Touristen in Coliour nimmt Alek wie "Besetzer" wahr (24), wobei seine Feindseligkeit mit seiner tiefen Krise zusammenhängt, aber auch auf sein Judentum zurückgeführt wird. Dieser Aspekt der Identität von Ziniks Emigrantenhelden wird in anderen werken kaum berücksichtigt und hier dadurch aktuell, daB Alek mit dem Aufschwung der russischorthodoxen Kirche sein Judentum bewuBt wird (s. z.B. 2829). Somit resultiert dieses neue Motiv bei $z$ inik aus der nunmehr zentralen Frage, welche Konsequenzen die radikalen Veränderungen in der Heimat für das selbstverständnis der russischen Emigranten haben. 
Perspektive vorherrscht. Er ist auf sergej eifersüchtig und bemerkt seinen Abstand von dem jungen Paar, wenn er beispielsweise ihrem Gespräch nicht folgen kann (14). Mit Monologen (2.B. 27-28) uberspielt er seine Gereiztheit, von der folgende stelle zeugt:

"Тот факт, что Сергей решил воспользоваться его транзистором, Алек воспринимал, хроме всего прочего, как ещё посягательство на свою личную свободу, свой интимный мир."

("Die Tatsache, daß Sergej einfach sein Radio benutzte, wirkte auf Alek neben allem anderen wie ein weiterer Eingriff in seine persönliche freiheit, seine privatsphäre.") (27)

Seine Irritation wurzelt darin, daB Alek sich vom Leben allgemein betrogen und ausgeschlossen fühlt. Ihm zufolge ist in der Heimat heute genauso wenig Platz für inn wie fruher, und mit dem Zusammenbruch des systems und der öffnung der Grenzen wurde inm auch noch seine Lebenskonzeption als Exulant genommen (15, 59). Gegenüber Sergej, dem lebendigen Beweis der veränderungen, ruft er verbittert aus: "I ja - snova vnutrennij emigrant." ("Ich bin also wieder ein innerer Emigrant."; 29). Nach außen tut er freilich so, als beruhre ihn der wandel RuBlands nicht (13). Andererseits zeigt sich Alek stolz, ein "echter Moskauer" $2 u$ sein (8), obgleich er sich in "Dvojnoj akt $v$ Socho" ebenso als "echten Londoner" definiert (s.0.). Insgesamt ergibt sich das Porträt eines Mannes, der mit sich und der welt uneins und vom Leben enttäuscht ist - im Kontrast zum lebenshungrigen sergej (34) und der nach Idealen dürstenden Lena (44-45), die sich weitgehend mit RuBland bzw. England identifizieren. Sie halten den Freund von ihrer warte für bemitleidenswert (46): Er sei mit seiner Emigration nicht fertig geworden, gräme sich über das Leben, das er damit verloren habe, und suche in anderen die Schuldigen (43-44).

Aleks Denken in Kategorien von Kampf und Niederlage sowie sein belastetes Verhältnis $2 u$ sich und seiner Umgebung spiegeln sich in der irreal anmutenden Militärübung wider, die unvorhergesehen am Nachmittag in Coliour abge- 
halten wird (40 ff.). Alek begrüBt die soldaten insgeheim (39, 42), da sie die für inn falsche Idylle um inn (19) zeitweise zerstören. In einer Prügelei mit einem deutschen Touristen und französischen polizisten, also gegen einen gemeinsamen äußeren Feind (48-50), sowie in einem wirbelsturm ( $57 \mathrm{ff.}$ ) entladen sich am Abend alle Spannungen. Die streitereien des Tages wirken im nachhinein nichtig (52, 58 ) und das Manöver in dem paradiesischen ort wie ein spuk (61). Alek zieht sich auf seine Resignation und seine Einsamkeit zurück:

"[...] ни ада, ни рая, когда всё - как сквозь мутное стекло. Но, может быть, это и есть ад: наблюдать за жизнью как сквозь мутное стекло и чувствовать полную исключённость из разговора."

("[...] es gibt keine Hölle und kein Paradies, wenn alles wie durch ein trübes Glas erscheint. Aber vielleicht ist gerade das die Hölle: das Leben wie durch ein trübes Glas $z u$ beobachten und sich von dem Gespräch vollkommen ausgeschlossen zu fühlen.") (65) 


\section{FAZIT}

Die Emigration spielt bei Zinovij $\mathrm{Zinik}$ vorrangig und durchgängig inhaltlich eine Rolle: Das zentrale Thema in den Romanen und Erzählungen ist die Selbstbestimmung des Emigranten in der Fremde. Wie die vorhergehenden Kapitel zeigen, wird es vielfach variiert gestaltet, wobei die stilmittel entsprechend funktionalisiert werden, also die Form dem Inhalt untergeordnet ist. In der diachronen Betrachtung sind keine wesentlichen inhaltlichen oder stilistischen Veränderungen $2 u$ erkennen. Stattdessen lassen sich im überblick eine Reihe von Konstanten in der literarischen verarbeitung feststellen.

\section{Komposition:}

Die Handlung spielt überwiegend im London der Gegenwart und zeitweise im Moskau der Stalin-Ära, der BrežnevZeit oder in den jungsten werken auch der perestrojka. Um beide orte und die verschiedenen zeiten, die den kulturellen und psychischen zwischenraum des russischen Emigranten in England kennzeichnen, präsent $z u$ machen, operiert $\mathrm{zinik}$ unter anderem mit Rückblicken. In den Romanen reduziert er die Haupthandlung und erweitert sie um Nebenhandlungen und Exkurse, in denen die situation und die seelischen Konflikte der Figuren indirekt ausgedrückt bzw. explizit erörtert werden. Die Emigrationsthematik wird somit simultan von mehreren Seiten und in diversen Formen angegangen, wobei das innere Geschehen und psychologische Aspekte im vordergrund stehen. Das deutlichste Beispiel für diese vielschichtige struktur ist The Lord and the Gamekeeper, in dem sich verschiedene Genres und Geschichten permanent überschneiden. Ziniks Erzählungen konzentrieren sich demgegenüber bis auf wenige Ausnahmen auf ein bestimmtes Erlebnis des Ich-Erzählers, das er meist ohne viel Umschweife schildert. Der Akzent liegt auf seinen Gefühlen, Gedanken und Eindrücken als Emigrant.

Ein wesentlicher Faktor in Ziniks Prosa ist die Perspektivierung. Oft nimmt der Erzähler den standpunkt des Helden ein, vermittelt also dessen Wahrnehmung der 
Realität und damit dessen spezifische position zwischen dem Eigenen und dem Fremden. In den Romanen werden aber auch andere Perspektiven wirksam, um die Hauptperson oder die beiden Kulturen aus der sicht der anderen Figuren $z u$ zeigen. Die Kontrastierung von Denk- und Verhaltensweisen in inrer kulturellen Prägung und die Profilierung des Emigrantenhelden erfolgen häufig im Rahmen ausgedehnter Dialoge und Gespräche. In einigen Erzählungen sowie in der Rahmenhandlung und einzelnen Episoden der Romane liegt dazu eine Besuchskonstellation vor.

\section{Die Helden:}

Bei den Hauptfiguren handelt es sich fast immer um sowjetische Einwanderer in England. Einige erscheinen offensichtlich als fiktive Doppelgänger von zinik, wie Felix in The Lord and the Gamekeeper, dessen Emigrationsgeschichte sich in vielen Details mit der des Autors deckt, oder die Ich-Erzähler in "Kriket" oder "Mea culpa", die sogar namentlich als seine Ebenbilder auftreten. Andere Figuren wie der naive Narator oder der chauvinistische kostya stellen eher fiktive Gegenbilder dar. ob die Helden unmittelbar Ziniks eigenen Erfahrungen ausdrücken und verkörpern oder möqliche Erfahrungen in der Emigration fiktiv durchspielen, stets gestaltet zinik durch sie die Situation des Auswanderers und somit eine Art narrativen Selbstentwurf.

Alle Helden vereint ihre sowjetische Mentalität, die sie daran hindert, sich in der westlichen welt einzuleben. sie äußert sich in den Romanen unter anderem in Nostalgie (Kostya), einem ödipus-Komplex und Schuldgefühlen (victor, Felix) oder einem orientierungsverlust im westen (Narator). Diese Motive treten auch in den Erzählungen auf. ziniks Fiquren haben also alle mit einer Last der Vergangenheit zu kämpfen, da sie sich durch die Emigration nicht von ihrem alten Ich befreien konnten. In der spaltung zwischen zwei Welten sowie zwischen Gegenwart und Vergangenheit sieht der Autor eine besondere Schizophrenie, die er in der Fiqurencharakterisierung umsetzt. Nara- 
tor wird zum Schluß verrückt, weil er seine innere und die äuBere Welt nicht zusammenbringen kann. Kostya macht sein Heimweh zu einem besessenen Verfechter der russischen Küche. Die drei Freunde in The Lord and the Gamekeeper zeigt der Autor sogar von Beginn an in einer psychiatrischen Klinik, wo sie nach den wurzeln ihrer diversen Neurosen suchen. Die mentale Verwirrung der Helden in ziniks prosa versinnbildicht in der Übertreibung das innere Ungleichgewicht und die Identitätskrise, die durch eine Emigration ausgelöst werden können.

\section{Die Verfahren:}

Zinik verwendet in seinen Romanen eine verzweigte Metaphorik, um die Emigrationsthematik zu transportieren, den Emigrantenhelden $z u$ charakterisieren und die inneren Vorgänge in inm $2 u$ verbildlichen. Die einzelnen Metaphern werden im gesamten Text entfaltet und miteinander verknüpft, sind aber stets im kontext der Exilsituation $z u$ interpretieren. Dabei werden verschiedene Bedeutungen, die teilweise auf unterschiedliche Kodes verweisen, gleichzeitig aktiviert. Der Pilz in The Mushroom-Picker beispielsweise symbolisiert zum einen die Heimatverbundenheit von Kostya, also im weiteren Sinn Rußland, während seine englischen Bekannten damit auf einer ganz anderen Ebene den Atompilz und insofern den ost-West-Konflikt assoziieren. Auf diese Weise überschneiden sich verschiedene semantische Felder, was wiederum die Unterschiede zwischen den Personen, die jeweils verschiedene Welten vertreten, krasser hervortreten läßt.

In den Romanen überlagern sich realistische Darstellungen mit eingebauten Fiktionen, Erinnerungen, Mythen, Träumen, Theaterspielen und szenen, die ins phantastische reichen. Die Grenze zur Realität bleibt häufig unklar. Darin spiegelt sich das erschütterte BewuBtsein des Auswanderers wider, dem Ziniks Essays zufolge das eigene Leben wie ein Roman und die neue Umgebung irreal vorkommen. Seiner verzerrten Wahrnehmung und seinem Gefühl des Befremdens entsprechen die Verfahren der Parodie, der Iro- 
nie und der verfremdung, die alle Romane und teilweise auch die Erzählungen durchdringen. zinik nutzt zudem ausgiebig komische Mittel, um kulturelle Differenzen und das Fremdsein der Emigrantenhelden sichtbar $2 u$ machen. Insbesondere gilt dies für szenen, in denen sie sich lächerlich machen, weil sie den anderen Kode nicht kennen.

Auf der stilistischen Ebene zeugen besonders augenfällig Einflüsse der englischen sprache in der Erzählerund Figurenrede von der Konfrontation mit der anderen Kultur, etwa durch die übernahme fremdsprachiger Ausdrücke oder inre spielerische Verzerrung. Diese Elemente dienen bei zinik in vielfacher weise der standpunktbestimmung und der Darstellung der fremden Kultur.

\section{RuBland und England:}

Die genannten Verfahren kennzeichnen insbesondere auch die Vermittlung der englischen versus der russischen bzw. sowjetischen kultur. In beiden fällen erfolgt sie vorzugweise vom Standpunkt des AuBenseiters: GroBbritannien erscheint meist aus der sicht des russischen Einwanderers und RuBland aus der des englischen Besuchers oder fremdgewordenen Heimkehrers. Auch diese Perspektivierung ist durch das Emigrationsthema motiviert, da die situation des Auswanderers davon geprägt ist, daß er sich einerseits von der Heimat entfremdet hat und andererseits nur begrenzt im Aufnahmeland integrieren kann. Diese Schwellenerfahrung überträgt zinik mittels seiner figuren in seine Prosa.

Bei der Schilderung der hiesigen wie der dortigen Gesellschaft dominiert grundsätzlich die satire, wobei nationale Merkmale übertrieben sowie Klischees aufgegriffen und kritisch beleuchtet werden, so daß die Gegensätze umso klarer erkennbar sind. Auf beiden seiten treten auBerdem mehr oder weniger karikaturistische Typen als Repräsentanten ihrer Gesellschaft auf und werden an ihrer Stelle bloßgestellt (z.B. Valery in Russkaja slużba, Tonya und Anthony in The Mushroom-Picker oder zum Teil Lord Edward in The Lord and the Gamekeeper). Die Gestaltung ten- 
diert dabei öfters zur Farce, an anderen stellen zur politischen Satire, so daB die Emigrationsthematik auch in einen aktuellen Zusammenhang gestellt wird.

Da zinik sich sowohl der früheren als auch der jetzigen Heimat zuwendet, erfüllt sein Werk eine doppelte Vermittlungsfunktion. Zum einen gibt der Autor einen Einblick in den Sowjetstaat, wonach dieser die Bürger dumm, unselbständig, vulgär und amoralisch macht sowie ihnen Schuld- und Haßgefühle einflöBt. Er zeigt ebenso das triste Alltagsleben (The Mushroom-Picker) wie die Intellektuellenszene im Untergrund (The Lord and the Gamekeeper). In seinen jüngsten Werken führt $\mathrm{zinik}$ auch in das postkommunistische RuBland mit besonderem Augenmerk auf der jungen Generation ("Mol"", "Slučajnaja vstreca").

Zum anderen wirft er als Fremder einen kritischen Blick auf die englische Gesellschaft. Die besseren, auf Formlichkeit bedachten Kreise entlarvt er in Russkaja sluźba und der Erzählung "Kriket" als heuchlerisch, ignorant, falsch und arrogant, insbesondere gegenüber Russen, für die man sich nur auf dem Niveau einer Mode wegen inrer "Exotik" interessiert. The Mushroom-Picker gibt mit der Figur cleas ein Beispiel für die spieBbürgerliche Mittelschicht, und the Lord and the Gamekeeper vermittelt einen Eindruck von den Schattenseiten der Hauptstadt im verkommenen südosten und dem zustand der Aristokratie. Somit zeigt $\mathrm{Ziniks}$ Gesamtwerk die englische Gesellschaft in mehreren Facetten und führt dabei auch in anschaulichen Bildern durch verschiedene viertel von London (u.a. Soho, Chelsea und Lewisham).

Die Ich-Erzähler in den Erzăhlungen vertreten in der Regel den Emigrantentyp, der sich um Integration und eine neue Identität bemüht sowie vom Eigenen möglichst distanziert. Inre Einstellung deckt sich weitgehend mit ziniks eigener Haltung. Die Romanhelden hingegen stehen größtenteils stärker in Opposition zum Autor, da sie eher in Nostalgie verfallen und in den vertrauten Denkmustern verharren (Narator, Kostya, in gewisser Hinsicht auch vic- 
tor). In jedem Fall läßt sich die Kluft zwischen der eigenen und der fremden Kultur letztlich nicht überwinden, was zinik auch damit illustriert, daB binationale Liebesbeziehungen in seinen Geschichten grundsätzlich scheitern (Russkaja slużba, The Mushroom-Picker, "Kriket"). Allgemein konstatieren die Romane und Erzählungen meistens eine Desillusionierung des Emigranten in der neuen welt, wo er nur am Rand Platz findet. Zinik selbst erklärt:

"The whole émigré experience is about loneliness, departure, lack of belonging, etc. - all negative aspects of human existence, which writers turn into something creative and positive. 156

In dem zitat formuliert der Autor die Quintessenz seiner Prosa, die aus der situation der Emigration heraus entstanden ist und diese schöpferisch umsetzt. Sie ist das Produkt einer kreativen Entfaltung im kulturellen und psychischen Zwischenraum des freiwilligen Exils und zugleich von inm unmittelbar geprägt.

156 Persönliches Gespräch, Anhang, S. 181. 


\section{Anhang :}

\section{GESPRACH MIT ZINOVIJ ZINIK}

am 20.4.1994 in London (Auszüge der Tonbandaufzeichnung)

Question: Do you write fiction in English?

Answer: The thing is that $I$ always use something which is happening here. Sometimes I am shorthanding the conversation $I$ had of some events in English. But then I have to translate it into Russian. I always remember something in English first. But indeed, apart from numerous essays - and I write more and more essays in English - I never wrote a piece of fiction from the beginning to the end in English. [...] Prose is dealing with a kind of noise. You have a noise of events or words which don't have shape, and they are getting accumulated in your memory and in your mind. You're basically trying to reduce, to shape them into certain ideas which are in current to your life and to the essence of your being, or something that happened in your childhood [...] This noise comes with I don't know what experience, with the sensitivity of your ear or probably your attitude towards the country you live in. I started to hear this noise, a correlation of words or sentences or events, unpronouncable, still not having a kind of linguistic form, not long ago in English. I am now thinking of writing a novel in English, but then it is frightening. Because once you write in English, you wouldn't go back to Russian.

Q: Wouldn't you then take a further step towards a change of identity? Because as long as you write in Russian, you still describe things with Russian eyes, and writing in English would mean losing your Russian identity.

A: I don't know what Russian identity is, I really don't know. It is very much a question of attitude rather than identity. The moment you accept this life as the place of your aspirations, it doesn't matter in what language you write in. If you think about your readership as not understanding what is happening here, you distort the reality here, and you always write a satire. Because you have to shape it into something familiar to the Russian.

Q: You mean when you write as a stranger about the life here, it can only be a satire?

A: There is a good metaphor to explain this: When you look from the outside into a house, you have to press your 
face against the window, so your face becomes distorted. So as a result you always get a caricature.

Q: But of yourself?!

A: of course of myself. The moment I start writing, it is already a part of me, but a caricatured part of me. But if you are in the inside, you look at it as a part of your normal vision. I was going on and on about the impossibility to translate the "English sausage" into Russian. You use the word "whisky", because it is untranslatable, it is a matter which uniquely exists as Scottish. But people in Russia nowadays know what it is, because it has been imported, people read and hear about it, so they do associate a lot of things with the word "whisky".

Q: Do you then rather feel like being in the inside and describing it to the people outside?

A: No, I don't describe it to someone outside, I am just describing it, constructing a certain interaction of ideas I carry in me, which has been provoked inside of me by the different events. And I hear this noise in English and in Russian, but I write in Russian. [...] [Living as a writer in another country] can only become a problem when you can't be published in your native country in your native language in that your novel is written. Then you feel that you are a strange creature. Otherwise I regard myself basically as a citizen of Britain. My heart is here, not there. At a certain moment of my life I started to be much more obsessed with what is happening here than with what is happening in Russia. But I write in Russian, and the subject is Russia, too, but it is seen by an Englishman. [...] You see, I have many identities.

Q: And do you think that is fruitful for your work?

A: Every contradiction is fruitful. [...] Novelists live of a certain development of ideas in their heads, which are being shaped throughout the process of writing. In my case they stem from certain people I met in my youth, and the spiritual and human conflict, the conflict of relationship with people older than me and with more experience than me - these conflicts are still very much alive and provide an impetus for a development of a certain set of ideas. But these ideas are getting transformed throughout my own writing [...] Idea is a contradiction of two things that couldn't be resolved without playing it out with characters. [...] I am not talking about the idea in a proper philosophical sense, I mean a conception of how things work.

$[\cdots]$

Q: Do you think you have assimilated into the English culture? 
A: No, I think it is impossible. It is like being Jewish: You have to be born in England to be English. But what makes me close to the psyche of the people on this island is that on the one hand, they were always cautious to get too close to the continent, and on the other hand is the idea of the empire, the willingness to merge with the rest of the world to become bigger, to have more space to breathe [...] The British feel that this island is their home, but they conquer other countries for experience, to discover themselves in exotic circumstances. That is the spirit of the nation. [...] I think this emigre attitude in general - if you enlarge the notion of emigre - is a constant urge to become part of something, belong to something, and at the same time the inner knowledge of your own unigueness and separateness. This makes me sort of akin to their experience.

$[\ldots]$

Q: Why didn't you stay in Israel?

A: Because you have to be really Jewish. I am Jewish, however not practising. In Israel you have to be really involved. When you come to Israel, you immediately acquire an Israeli identity, that is, you are regarded as an Israeli. But I knew I was a stranger, as well in Israel as in Britain, where it was openly declared from the beginning. In Israel it is impossible to be a Russian writer, you are declared an Israeli or Jewish writer and presented as such, while in Britain you are a writer, and the question is in what language wou write in. So there is no identity imposed on you, and I preferred this situation. [...] In my childhood I read two authors constantly: chekhov and Dickens. [...] I remember all the characters. So you see, one can invent a lot of reasons [for staying in England].

Q: Can you name other English authors you have you been influenced by?

A: I feel enormous affinity with Somerset Maugham. [...] he revolutionised the narrative technique. I can learn from him much more than from any of his contemporaries. He was neglected by the critics, but managed to overcome the bitterness caused by this and turn it into something positive. He grew up in France and felt a stranger in this country. The whole emigré experience is about loneliness, departure, lack of belonging, etc. - all negative aspects of human existence, which writers turn into something creative and positive.

$[\ldots]$

A: In my youth I was writing hundreds and hundreds of pages of very elaborate modernist prose, just rendering of my friends' conversation, rather avantgarde prose. 
I never published it, I am stealing from it from time to time. But my whole effort was to achieve some clarity in the narrative. Russian literature is suffering from this half-cooked modernism. This experimental prose is absolutely unreadable and very provincial. [...] stalinist prose was somewhat saved from this. At least it developed a technique of constructing a plot - ideologically biased, but at least they learnt how to write a proper commercial novel. Apart from that Russian writers wrote confessions without commas and fullstops - absolutely unreadable and useless.

$[\ldots]$

Q: And the English authors you mentioned helped you to develop your technique of constructing a plot?

A: Basically my emigration, because emigration gives your life a plot. You realize that you are not inside the one and only circle, but there is a life outside.

$[\ldots]$

A: I am an exotic animal, because there was no Russian community here. So I have become more and more involved in local affairs and always had English friends, and I have always been involved in one way or the other in the cultural scene here. I have been writing in English since the late $70 \mathrm{~s}$ for the TLS [Times Literary supplement], I have been taking part in different discussions at the ICA [Institute of Contemporary Arts in London] or other gatherings. $[\ldots]$ But don't forget that I was born as a Soviet, and only in Britain did I realise that $I$ am JewishRussian something, Muscovite. Because the English like to make a catalogue of persons, origins and religious backgrounds. In Moscow I never felt I am Jewish. I felt that I am Soviet, and I was a Soviet. $[\ldots]$

Q: Was your experience of emigrating more profound because you came to a country where you don't have a Russian community?

A: of course. If you make this mad step of leaving your country, you don't do it for an Ersatz. That's death in my opinion. What do you call it when you sleep with a corpse? Nekrophilia, that's right, that's what it is. If you leave your country, you should leave for something drastically different. Israel was yet another substitute. There were a lot of Russians, everyone writing novels and poetry subsidised by the government. Or you come to New York, and you are back to Moscow.

Q: So being more on your own is an advantage of being in Britain? 
A: I don't know whether it is an advantage, but it is definitely what I prefer. My mind was rather muddled when I came out of Moscow, literally and psychologically, and to understand something you should be in an alien surrounding $[\ldots]$ I didn't come out to be a novelist. I came out for the spiritual experience, I wanted to make this jump. [...] Because it was prison.

\section{Q: And the jump to Israel wasn't big enough?!}

A: That's right, it was too familiar. [...] I didn't imagine that London should look like that: small houses, and these suburban streets ... It was a shock of the new in a way.

$Q$ : So the shock of the new you rather got here than in Israel, although Israel was the first country of the west you came to?

A: [...] Israel is basically a socialist country, there is this spirit of collectivism, so recognisable. [...] It is very much russified, and I felt like coming back to a soviet republic. It has been built by Russians who emigrated from Russia and seems to be another version of Soviet Russia, which is fascinating, but I wanted something different and found it here ... In Moscow I was told I would die abroad, and when I arrived here in the 70s, people were rather pessimistic about what was happening in Britain. So Soviet bureaucrats and administrators of culture as well as left-wing British intellectuals were telling me the same. Here they told me immediately that I would die because there was no culture in Britain. But every inch of the soil is soaked in literary allusions! Your thought is provoked by one connection or another. [..] I remember London of the 70 s the same way I remember Moscow of the 60 s - as a passage of time, which makes something very dear to you. So I started to become nostalgic about London in the 70 s.

Q: You said earlier on that you always write a satire when you write about England.

A: Yes, bearing in mind the Russian reader, who doesn't know what's happening here. So you have to distort it to make it understandable to him, and by distorting it you are making a satire. [...] with Lord and the Gamekeeper I thought I am writing the most English novel in my life. In fact I have written the most Russian novel ever possible. It is extremely difficult to read in English, and I don't think it is the translator's fault. Plain, clear, balanced phrases, not much of modern usage, but good, clear, classical language. It is meant to be so fuli of allusions and reminiscences and between-the-lines-quotations, subconsciously creeped into this seemingly clean language. The style, the construction is so ... elaborate. And they [the English readers] are not used to 
this type of novel, they don't like it, because why should they get involved in intellectual games. In fact it is very Russian [...] I thought it was English, because a lot of it is happening in England, but in fact when I write in England about England, I still see it with Russian eyes. Whereas when I write about Russia, I already see it with English eyes.

$[\cdots]$

Q: But Russia has changed a lot over the last few years, so don't you write about a different country?

A: I have 30 years of experience [living in Russia], so that even a story that is set in modern Russia is still recognisable as something close to the Russian heart. Whereas when I write in Russian about England, it is all translated, so to speak. [...] [For the English] this is rather bizarre, while they feel a familiar point of view in the Russian parts. Anyway, in Russian both aspects of the writing - English and Russian - work, but not in the English translation of the recent novel. It worked in the Mushroom-Picker.

$[\ldots]$

Q: Did you have that feeling of being dead as an emigrant which you describe in your essays?

A: Yes, but never in my everyday life, because I was happy in a way [in Israel]. [...] But suddenly you know you are part of a big culture, you belong to beautiful people, and you know that it disappeared, you will never be able to come back to it. It's death!

Q: And how did you overcome it?

A: I came here 19 years ago, so I am nearly 20 years old, you see. That's how I overcame it: You start anew. My first novel or novella, Izveshchenie, was written in 1976, one year after my arrival, and it is about death basically. [...] I started to write letters, long letters almost every day, describing my new experiences. And I realised that a kind of new reality grows out of it. Suddenly I started to write as I had never been able to write before. I didn't come to be a writer. I thought I was going to be a new man, but I never thought I would be able to write.

$[\ldots]$

Q: A return to your homecountry has recently become possible. What effect did that change have on you?

A: I always had a very extensive correspondence with my friends back in Moscow. I was constantly in touch and knew every movement. As a shadow I was still existing there and part of the conversation to a certain extent. Peremeshchennoe litso is very much written in 
the spirit of that. So when I went back for the first time in 1988, it was as if I had always been there, and I still had a glimpse of the old country. Then I started to come every year, and it started to change in front of my eyes into something unrecognisable. The people there emigrated to a new country. The old country slipped off from under their feet, and they are now in the new one. And it is as alien to them as it is to me. But they have already emigrated to that country and are going to live there and adapt to the new country, and me not. So it is a parting point, I think.

Q: But on the other hand you now have the possibility to publish there.

A : [...] [In Russia] I never cared for a larger audience than the people I cared for. My readers were my friends. Even until recently I was relying in my mind on the perception of my friends. But that is changing now. They are getting separated due to the new experience. [...] I think I will try to write my next novel in English. It would be logical. I would like to do it, but I am also frightened. Maybe I can write it in Russian and translate myself into English.

$[\ldots]$

A: The story of my Russian publication [abroad] is a painful one [...] because everything was controlled by the people of the former soviet literary establishment, who had left because they had come into conflict with the authorities. Here they founded publishing houses, but they would behave to new names in the same way as the soviet establishment. Then you had the old white émigre publishing houses, like YMCA. They wouldn't publish me either, because first of all I am Jewish, second I didn't belong to the kosher émigré circles. I would not mix with all these ideological gatherings, I wasn't involved in any political campaign organised by them. I was on my own. And a terrible aspect of Russian literature in general is that unless you $\mathrm{mix}$ with somebody personally, you are not going to be mentioned or published.

Q: But then Sintaksis started to publish you.

A: Yes, they had reasons to attract authors who were not favoured by continental, white émigré publishers. [...] of course I rather sympathised with sinyavsky than with Maximov because of Maximov's editorials in Kontinent. They were defamatory and slanderous, and secondly written in such a bad Soviet language I cannot stand. I admired Sinyavsky as a writer. But I never joined this quarrel except for expressing some sympathy on some occasion. I have never written about it, because I don't think it is worth writing about.

$[\ldots]$ 
Q: Was your own publishing house a success?

A: Yes, we destroyed the conspiracy, the overimportance of the Russian publishers. But at that time I didn't need it, because I was published. "Russica" published Peremeshchennoe litso, and they were the forepost of good taste in New York. Sinyavsky had published Russkaia sluzhba. So I gave "Russian Roulette" The Mushroom-Picker simply to support it. It was my idea to found it [...] The first book was Pomerantsev, because his work was completely outside of any frame. Nobody would have published it, at least at that time.

$[\ldots]$

Q: What do you think about the TV production of The Mushroom-Picker?

A: The third part is wonderful, the first is alright. In English it is so exotic in a way that the more they would have tried to make it real, the better it would have been, I think. They went into a completely different direction: They decided to have it completely unreal and try to find the realistic elements engraved in it. So it is stylistically very bizarre. On the other hand it has been done with such a spark and force that it has its own merit. Apart from the third part it says very little of the real motives in the novel. [...] It was a popular success, but not with high-brow critics, who knew the novel and saw that it was entirely different. [...] They told me I was the first modern Russian writer who had a work adapted by British TV in three parts.

$[\ldots]$

Q: The interest in Russian dissident literature has faded away, so do other Russian writers now stand a better chance to $f$ ind response?

A: [...] The thing is that now the road is clear for a real, good novel to come forward as a real, exciting novelist experience, without any political cloud, shading the matter. [...] But I don't really see any powerful writer as a real novelist at the moment [in contemporary Russian literature]. Vladimir Sorokin is absolutely brilliant, there are also some interesting poets. So there are some talents, but no novel which you read right through to the end, which just takes you. [...] [The writers in Russia] today go through the same experience I described: Everyone in Moscow now experiences this situation of being an émigré in a new country. They have got their past and a new reality, they have to play on these two realities and still don't do it! They should read much more my novels! Did you take the hint? They have published the Mushroom-Picker, but not Nisha $v$ Panteone and Peremeshchennoe litso, which could teach them a bit 
how to write a novel in emigration and about emigration. I am only half joking! - Essays haven't been published either. [...] An Italian translator who has lived in Moscow on and off for 14 years wanted to translate some short stories, and she said to me: "Don't expect to be loved here."

Q: But Pomerantsev said to me: "You are not loved here [in the West]."

A: No, I think I am loved here. Even before I was successful. I mean, I was always treated with kindness. But each time I come to Russia - and I have got a kind of name there - I notice this strange authoritarian atmosphere in literature, even now. Either you are a genius, or you are shit. There are no niches. Here you publish something in an obscure magazine, and somebody would notice it and come to you to encourage you or participate in something. Even those who haven't heard about you before. In Russia [...] it is still a very tribal, self-centred, vertically structured pyramid, and either you are on the top or nowhere. And they don't want it to change, because they think it would diminuish the status of literature. But the status of literature diminuished the moment it stopped playing politics. [..] They talk about the end of culture - nonsense! It is the end of a culture affiliated with political power. Every novelist says thank God for that. On the other hand every novelist is a power-seeker - me too, I want my words to be heard. [...] Literature can't be apolitical, it is a part of iife. Even in Britain they think literature doesn't play any particular role. Nonsense! It is very important here, every politician quotes it. [...] 


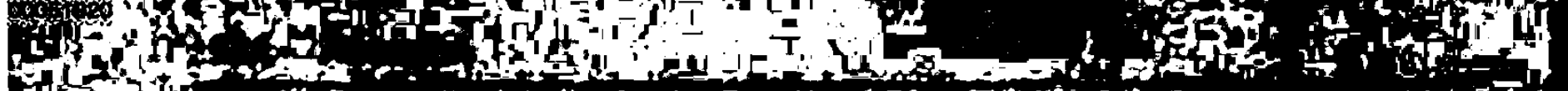

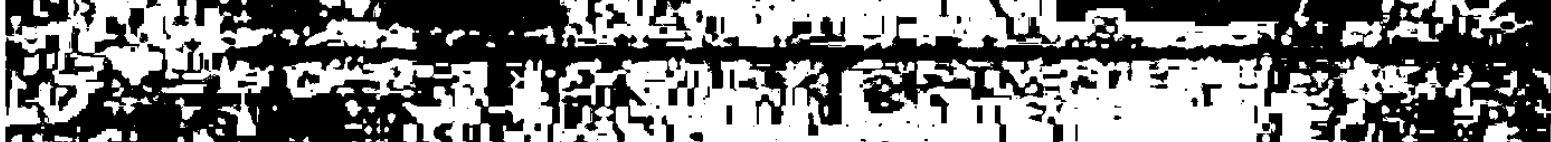

0 of

Af of

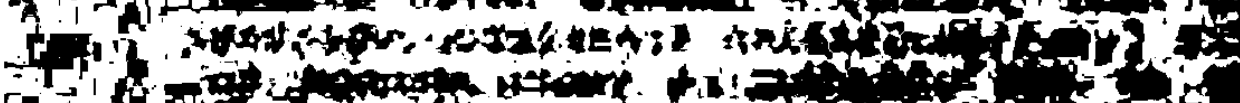

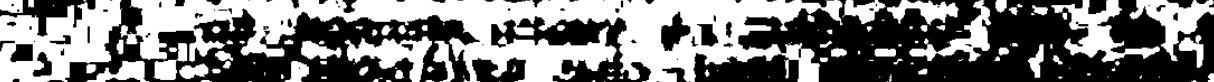

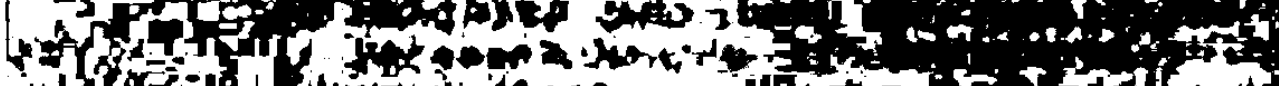

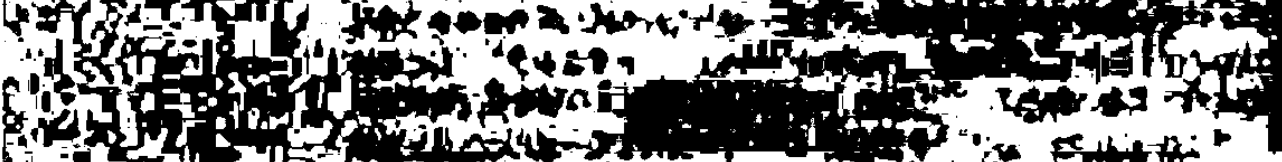

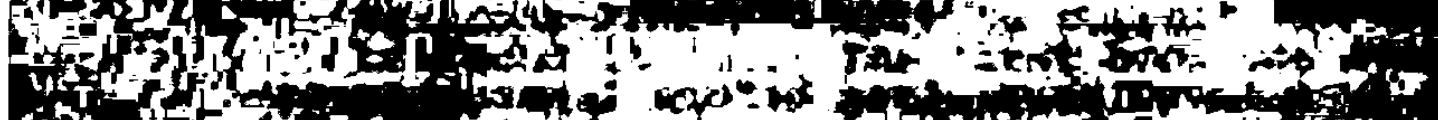
o.

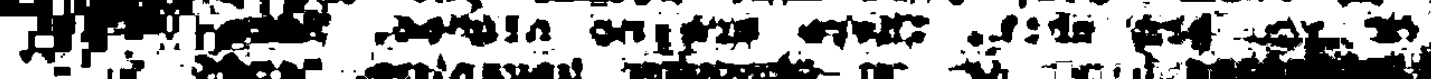

1)

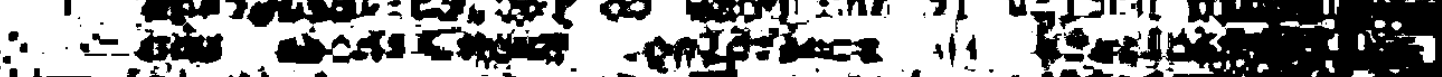

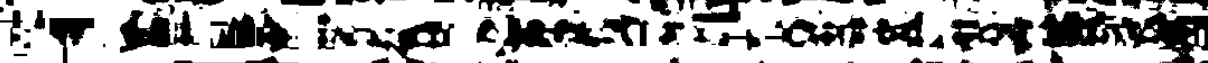

i

14

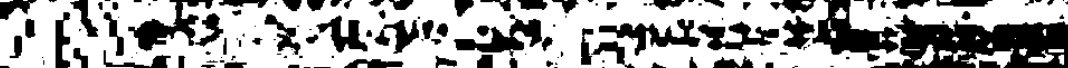

直

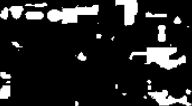

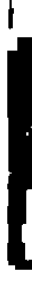

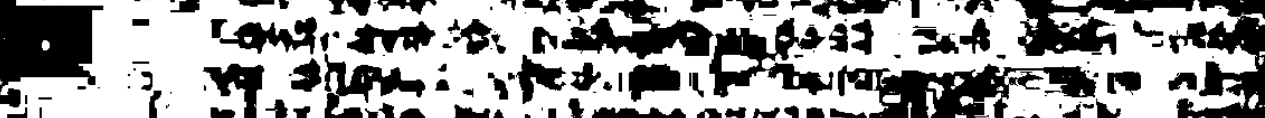

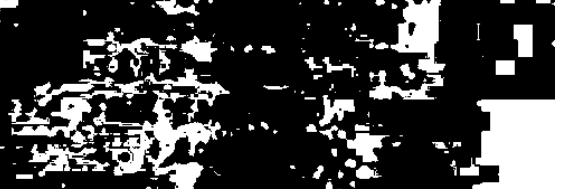

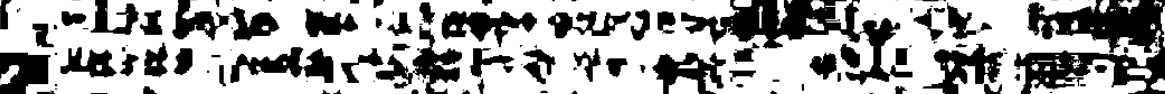

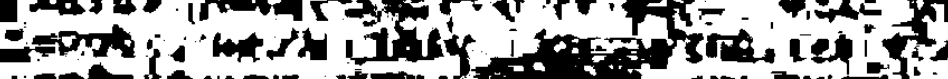

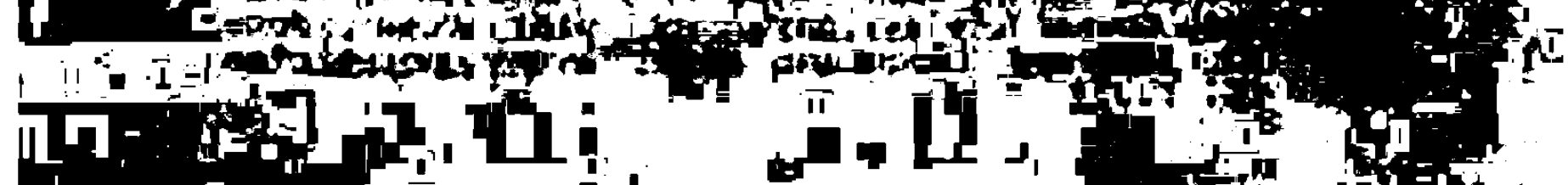

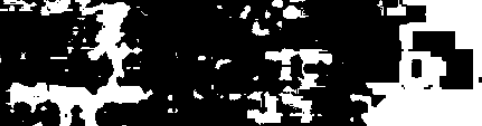

is 1

72

t.

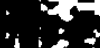

4f.

1 (1)

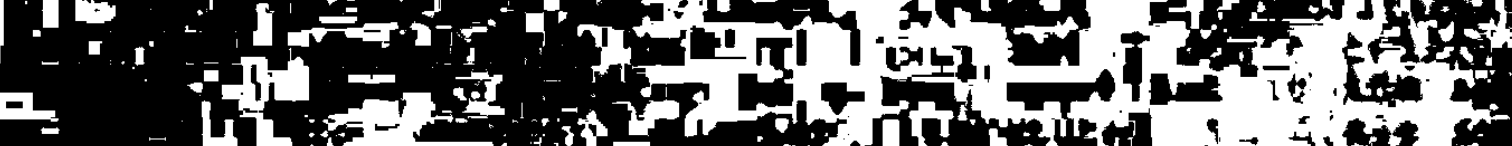

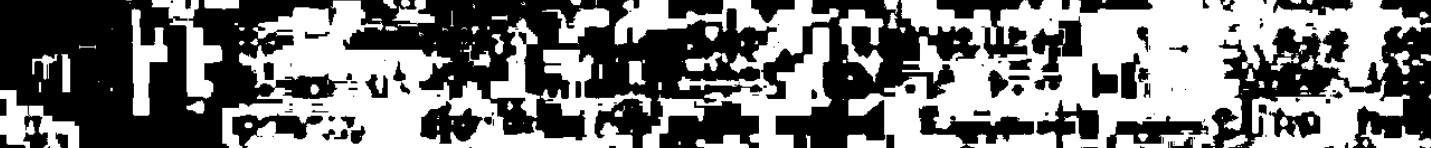

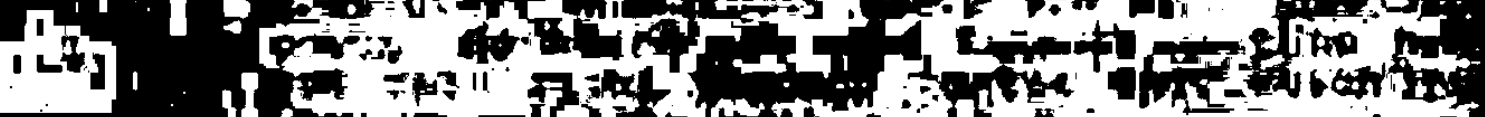

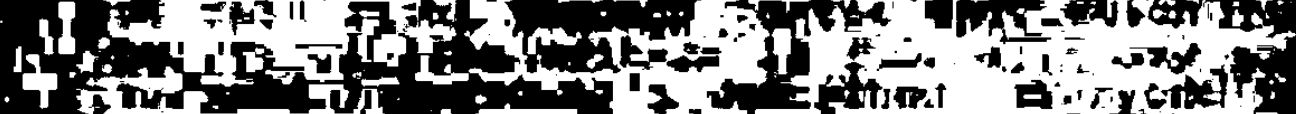

H

I 5 fol-

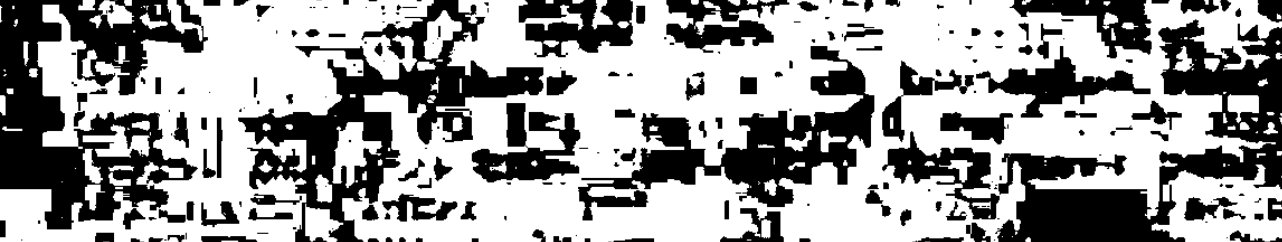
(1) 
Bibliographie

\section{PRIMÃRLITERATUR VON ZINIK}

(chronologisch nach dem Erscheinungsjahr)

\section{Romane}

"Izvescenie" (1976). Vremja i my, Nr. 8, 1976, S. 3-83. (zugleich in Auszügen in Skopus: Antologija poèzii $i$ prozy, hg. Vladimir Glozman u. Natalija Rubinstejn, Jerusalem, 1979, (Biblioteka Alija, Nr. 69), S. 123139. [Anqaben nach der Bibliographie von Stevanovich, s.u.j)

Une personne déplacee [Peremeścennoe lico, französisch]. Ubers. Annie Sabatier $u$. Antoine Pinqaud. Paris: Albin-Michel, 1981.

"Uklonenie ot povinnosti" (1982). Vremja i my, Nr. 69, 1982 , S. 5-79.

Russkaja slużba (1981). Paris: Sintaksis, 1983. (Zugleich in Rodnik (Riga), Nr. 5-9, 1990. Zugleich in dem Sammelband "Russkaja slużba" i drugie istorii, Moskau: Slovo, 1993.)

Service russe [Russkaja služba, französisch]. Übers. Annie Sabatier. Paris: Albin-Michel, 1984.

Peremeśċennoe lico (1977). New York: Russica, 1985. (Zugleich in Vremja $i$ my, Nr. 22, 1977, S. 3-105; Nr. 23,1977 , S. 5-90.)

Niśa V Panteone (1979). Paris: Sintaksis, 1985. (Zuqleich in Auszügen in Vremja $i$ my, Nr. 63, 1981, S. 5-52.)

Une niche au Pantheon [Niśa $v$ Panteone, französisch]. Übers. Annie Sabatier in Zusammenarb. m. Oksana Bigard. Paris: Albin-Michel, 1986.

Russofobka $i$ fungofil (1984). London: Russian Roulette, 1986. (Zugleich in Vremja i my, Nr. 82, 1985, S. 569; Nr. 83, 1985, S. 5-90; Nr. 84, 1985, S. 5-78. Zugleich Moskau: Russlit, 1991.)

The Mushroom-Picker [Russofobka i fungofil, englisch]. Übers. Michael Glenny. London: William Heinemann, 1987. (Zugleich New York: St. Martin's Press, 1989. Zugleich London: Minerva, 1993.)

Gumkha be Panteon [Niša $v$ Panteone, hebräisch]. Übers. Jakob Sharet. Tel Aviv: Am Oved, 1989. 
De Paddestoel Plukker [Russofobka i fungofil, niederländisch]. Baarn: De Prom, 1989.

Lord $i$ eger' (1989). Moskau: Slovo, 1991.

The Lord and the Gamekeeper [Lord $i$ eger', englisch]. Übers. Alex de Jonge. London: William Heinemann, 1991.

Grzybowstapienie [Russofobka $i$ fungofil, polnisch]. Übers. Wieslawa Karaczewska. Warschau: MUZA, 1994.

Rousseaufoob ja punapuravikud [Russofobka i fungofil, estnisch]. Ubers. Vilma Matsov. Tallinn: UMARA, 1994.

\section{Brzăhlungen}

"Lišnij biletik" (1981). Russica-81: Literaturnyj sbornik, hg. A. Sumerkin. New York: Russica, 1982. S. 167-177.

"Deva i monstr" (1985). Sintaksis, Nr. 13, 1985, S. 96-99.

"Edipov stalin" (1985). Vremja $i$ my, Nr. 87, 1985, s. 2842 .

"The Maiden and the Beast" ["Deva i monstr", englisch]. Übers. Frank Williams. Index on Censorship (London), Bd. 15, H. 3, März 1986, S. 13-14.

"A Ticket to spare" ["Lišnij biletik", englisch]. Übers. Frank williams. B flat, Bebop, Scat: Jazz short stories and Poems, hg. Chris Parker. London: Quartet Books, 1986. S. 58-70.

"Oedipus" Stalin" ["Edipov Stalin", englisch]. Übers. Frank williams. 2 Plus 2: A Collection of International Writing. Lausanne: Mylabris Press, 1987. S. 1-10.

"Za krjučkami" (1987). Sintaksis, Nr. 18, 1987, S. 138150. (Zugleich in Pjatyj ugol: sbornik sovremennoj prozy, hg. Sergej Kaledin, Moskau: Knižnaja Palata, 1991, S. 368-377.)

"Mea culpa" (1987). Sintaksis, Nr. 21, 1988, S. 149-163. (Zugleich in $Z a$ tridevjat' zemel: Antologija émigrantskoj prozy $1980 \mathrm{ch}$, hg. Elena Gessen, Tenafly: Ermitaż, 1992, S. 89-101.)

"Beženec" (1987). Sintaksis, Nr. 23, 1988, S. 144-152. (Zugleich in stolica (Moskau), Nr. 10, März 1991, S. $51-56$.

"Hooks" ["Za krjuċkami", englisch]. Übers. Alan Myers. The New Yorker, 6.11.1989, S. 56-61. (Zugleich in The Moscow Guardian, 20.8.1993.) 
"Mea culpa" ["Mea culpa", ungarisch]. Übers. Maráz Lászlo. Utazas Hollywoodba. Budapest: Teka Könyvkiado, 1990. S. $162-176$.

"Nezvannaja gost'ja" (1989). Sintaksis, Nr. 29, 1990, S. 161-182. (Zugleich in Neva (st. Petersburg), Nr. 8, 1993, S. 199-215.)

"Slucajnaja vstreca" (1989) . Vremja $i$ my, Nr. 108, 1990, S. 86-116.

"Kriket" (1990). Vremja i my, Nr. 109, 1990, S. 5-45.

"Doroga domoj" (1990). Vremja i my, Nr. 113, 1991, S. 553. (Zugleich in Druźba narodov (Moskau), Nr. 2, 1993, S. 103-123.)

"Lico épochi" (1992). Sintaksis, Nr. 33, 1992, S. 122-147.

"Mea culpa" ["Mea culpa", englisch]. Übers. Frank Williams. Glas: New Russian Writing (Moskau/Birmingham), Nr. 4, 1993, S. 137-151.

"Na puti k 'Artistićeskomu'" (1992). Teatr (Moskau), Nr. 6, Juni 1993, S. 123-142.

"Mol'" (1992). Vremja i my, Nr. 119, 1993, S. 5-45.

"Desant v Koljure" (1993). Vremja $i$ my, Nr. 122, 1993, S. $5-65$.

"Dvojnoj akt $v$ Socho" (1994). Vremja $i$ my, Nr. 123, 1994, S. 5-73.

"Bal-maskarad". Neva (St. Petersburg), Nr. 3, 1995, S. 729.

One-way Ticket [Sammelband]. London: Harbord, 1995.

\section{Essays}

"Strach pered pauzoj". Russkaja mysl" (Paris), Nr. 3160, 14.7 .1977 , S. 8 .

"Soc-art". Sintaksis, Nr. 3, 1979, S. 74-102.

"Podstroćnik". Sintaksis, Nr. 8, 1980, S. 73-104.

"Émigracija kak literaturnyj priëm". Sintaksis, Nr. 11, 1983 , S. 167-187.

"Voobražaemoe interv'ju s vladimirom Nabokovym". Sintaksis, Nr. 15, 1986, S. 178-187.

"Goticeskij roman uźasov èmigracii". Sintaksis, Nr. 16, 1986 , S. 34-70. 
"Tout cela fait partie de notre conscience". La Quinzaine Litteraire, Nr. 468, 1.-31.8.1986, S. 27-28.

"Emigration als literarische Form" ["Emigracija kak literaturnyj priëm", deutsch]. Übers. Silvia Kübler. Individualität (stuttgart), Bd. 5, H. 12, Dezember 1986, S. 3-13.

"Dvujazycnoe men'sinstvo". Sintaksis, Nr. 22, 1988, S. 185-198.

"Na obratnom puti". Sintaksis, Nr. 24, 1988, S. 29-38.

"Emigration as a Literary Device" ["Émigracija kak literaturnyj priëm", englisch]. Ubers. Frank williams. Lovely Jobbly (London), Bd. 1, H. 1, 1990, S. 42-45.

"Silence, Exile \& Glasnost: A Bilingual Minority" ["Dvujazyćnoe men'sinstvo", englisch]. Übers. Frank williams. The Encounter (London), Bd. 74, H. 5, Juni 1990 , S. 66-71.

"Pis'ma iz Dublina: 1. Blumov den'; 2. Glavnyj geroj v poiskach avtora". Sintaksis, Nr. 31, 1991, S. 127137 .

"Soviet Paradise Lost". Carnegie International 1991 [Ausstellungskatalog]. Bd. 1. Pittsburgh, Pennsylvania: The Carnegie Museum of Art, 1991. S. 41-47. (Zugleich New York: Rizzoli, 1992.)

"The Hero in Search of an Author" ["Glavnyj geroj $v$ poiskach avtora", englisch]. Übers. Galya u. Hugh Aplin. Under Eastern Eyes: The west as Reflected in Recent Russian Emigre Writing, hg. Arnold McMillin. New York: St. Martin's Press, 1992. S. 12-16.

"Privetstvuju vaś neuspech: Pamjati Pavla Ulitina". Sintaksis, Nr. 32, 1992, S. 149-162. (Zugleich in Vestnik novoj literatury (st. Petersburg), Nr. 5, 1993, S. 203-213.)

"Zarja kommunizma". Sintaksis, Nr. 33, 1992, S. 5-12.

"Samoderźavie literatury". Literaturnaja gazeta, Nr. 24 $(5452), 16.6 .1993$, S. 5 .

"Art and Travel: Pictures of My Moscow Friends". Modern Painters (London), Bd. 6, H. 4, Winter 1993, S. 4753.

"Lićnoe delo vraćej: Pamjati Ju. A. Ajchenval'da". Sintaksis, Nr. 34, 1994, S. 87-98.

"Po griby - s Gil'bertom i Díordżem". Inostranec (Moskau), Nr. $2(30), 19.1 .1994$, S. 12. 


\section{Interviews}

"Vzgljad s nulevogo meridiana". Mit P. Vajl" and A. Genis. Panorama (Los Angeles), Nr. 311, 27.3.-3.4.1987, S. 18-20.

"Émigracija kak literaturnyj priëm". Mit S. Tarościna. Literaturnaja gazeta, 20.3.1991, S. 11 .

"Zinovij Zinik: Ja ne procël 'Annu Kareninu' do konca". Mit Sergej Kalinin. Literator (st. Petersburg), Nr. 14 (68), April 1991, S. 8.

"Kogda lord stanovitsja egerem". Mit S. Tolkacëv. Moskovskij komsomolec, 23.5.1992, s. 10 .

"Spion s evrejskoj duśoj, russkim umom i anglijskim serdcem". Mit Jaroslav Mogutin. Stolica (Moskau), Nr. $17(75), 1992$, S. 55-56.

"Crossborders: Zinovy Zinik". Mit Isabel Montgomery. The Guardian, 19.1.1993, Beilage "G2", S. 17.

"Literatura i emigracija. Beseda s Z. Zinikom". Vestnik novoj literatury (St. Petersburg), Nr. 8, 1994, S. 201-217.

\section{ANGEFÜHRTE PRIMÄRLITERATUR ANDERER AUTOREN}

Aksënov, Vasilij. "Lućsee sostojanie literatury - èmigracija". Sem' dnej, Nr. 50, 1984, S. 20-24.

Limonov, Eduard. Eto ja-Edicka. New York: Index, 1979.

ders. Dnevnik neudacnika, ili sekretnaja tetrad'. New York: Index, 1982.

ders. Palac. Jerusalem: Chameleon, 1986.

Pjatigorskij, Aleksandr. Filosofija odnogo pereulka, ili Istorija eścë ne okoncennoj żizni odnogo russkogo filosofa, rasskazannaja avtorom, a takze nekotorymi drugimi, bolee ili menee russkimi filosofami. London: Russian Roulette, 1989. (Zugleich Moskau: Progress, 1992.)

Pomerancev, Igor'. Al'by $i$ serenady. London: Russian Roulette, 1985.

ders. "Mit Blumen auch schön". Sintaksis, Nr. 15, 1986, S. 169-177. 
ders. "Lost in a strange City". The Times Literary Supplement, Nr. 4395, 26.6.1987, S. 695.

ders. "Bez vetki persika". Literaturnaja gazeta, 17.6 .1992$, S. 5 .

ders. "Muzej anglijskogo detstva, ili Ja nenavižu syna". oktjabr' (Moskau), Nr. 2, Februar 1994, S. 85-91.

III. SEKUNDÃRLITERATUR

1. Zur Exil- und Emigrantenliteratur (Schwerpunkt RuBland)

Alekseeva, Ljudmila. The Thaw Generation: Coming of Age in the Post-stalin Era. Boston u.a.: Little, Brown + Co., 1990.

Andrews, David R. "A Semantic Categorization of Some Borrowings from English in Third-Wave Emigré Russian". Topics in Colloquial Russian, hg. Margaret H. Mills. New York: Peter Lang, 1990. S. 157-174.

Beaujour, Elizabeth Klosty. Alien Tongues: Bilingual Russian Writers of the "First" Emigration. Ithaca $u$. London: Cornell Univ. Press, 1989.

Bethea, David M. "Emigration and Heritage". Slavic and East European Journal, H. 31, 1987, S. 141-164.

Bevan, David (Hg.). Literature and Exile. Amsterdam u.a.: Rodopi, 1990.

Boer, S. P. de, E. J. Driessen U. H. L. Verhaar. Biographical Dictionary of Dissidents in the Soviet Union, 1956-1975. The Hague u.a.: Nijhoff, 1982.

Bol'dt, F., D. Segal u. L. Flejšman. "Problemy izučenija literatury russkoj emigracii pervoj treti $X X$ veka". Slavica Hierosolymitana (Jerusalem), Bd. III, 1978, S. 75-88.

Bonnières, Françoise de. "Russian and East European Emigré Publications in France". Proceedings of the Second International Conference of Slavic Librarians and Information specialists: Books, Libraries and Information in Slavic and East European Studies. New York: Russica, 1986. S. 178-192. ("Russica" Bibliography Series, 8.)

Brodsky, Joseph. "The Condition We Call Exile". Renaissance and Modern Studies, Bd. 34, 1991, S. 1-8. 
Bronfen, Elisabeth. "Exil in der Literatur: Zwischen Metapher und Realität". Arcadia, Bd. 28, H. 2, 1993, S. 167-183.

Brown, Deming. "On the Relationship between the Literature of the Third Emigration and Soviet Literature on the Eve of "Glasnost". Russianness: studies on a Nation's Identity, hg. Robert L. Belknap. Ann Arbor: Ardis, 1990. S. 29-37.

Brown, Edward $J$. "Russian Literature beyond the Pale". Slavic and East European Journal, Bd. 30, H. 3, Herbst 1986, S. 380-388.

Burnett, Peter P. "East European Emigré Publications in Great Britain". Proceedings of the Second International Conference of Slavic Librarians and Information Specialists: Books, Libraries and Information in Slavic and East European Studies. New York: Russica, 1986. S. 193-204. ("Russica" Bibliography Series, 8.)

Bystrina, Ivan. "Kodes und Kodewandel". Zeitschrift fur Semiotik, Nr. 5, 1983, S. 1-22.

ders. "Die Kultur und inre Codes". Zeichen und Realitat. Akten des 3. Semiotischen Kolloguiums der Deutschen Gesellschaft für Semiotik e.v., Hamburg 1981, hg. Klaus Oehler. Tübingen: Stauffenberg, 1984. (Probleme der Semiotik, hg. Roland Posner, i/III.) S. 10231039.

"Dossier: La littérature et 1'exil". Le Magazine littéraire, Nr. 221, Juli-August 1985, S. 14-65.

Drawicz, Andrzej. "La littérature des années soixante-dix et du début des années quatre-vingt". Histoire de la litterature russe (Le XXe siecle), hg. Efim Etkind, Georges Nivat, Ilya Serman u. Vittorio Strada, Bd. 3: Gels et Degels. Paris: Fayard, 1990. S. 680-706.

ders. "La littérature russe à la $f$ in des années quatrevingt". Histoire de la litterature russe (Le XXe siecle), hg. Efim Etkind, Georges Nivat, Ilya Serman u. Vittorio strada, Bd. 3: Gels et Degels. Paris: Fayard, 1990. S. 891-906.

Durzak, Manfred. "Laokoons Söhne: Zur Sprachproblematik im Exil". Akzente, 21. Jg., H. 1, Februar 1974, S. 5363 .

Eagleton, Terry. Exiles and Emigrès: Studies in Modern Literature. London: Chatto \& Windus, 1970.

Edwards, Robert. "Exile, Self, and Society". Exile in Literature, hg. Maria-Inés Lagos-Pope. Lewisburg. London u. Toronto: Associated Univ. Presses, 1988. S. $15-31$. 
Filip, Ota, u. Egon Larsen (Hg.). Die zerbrochene Feder: Schriftsteller im Exil. Stuttgart: Thienemanns, 1984.

Forster, Leonard. The Poet's Tongues: Multilingualism in Literature. London: Cambridge Univ. Press, 1970.

"Forum: The Third Wave". Slavic and East European Journal, Bd. 30, H. 3, Herbst 1986, S. 380-419; Bd. 30, H. 4, Winter 1986 , S. 509-552.

Glad, John. Literature in Exile. Durham u. London: Duke Univ. Press, 1990.

ders. Conversations in Exile: Russian writers Abroad. Durham u.a.: Duke University Press, 1993.

Gladkova, T. L. L'emigration russe: Revues et recueils, 1920-1980. Paris: Institut d'études Slaves, 1988.

Glenny, Michael, $u$. Norman Stone. The other Russia: The Experience of Exile. New York: Viking, 1991. (zugleich London $u$. Boston: father and father, 1990.)

Gorbanevskaja, Natal'ja. "Jazykovye problemy poeta v izgnanif". Tret'ja volna: Almanach literatury $i$ iskusstva (Paris u. New York), Bd. 15, August 1983, S. 35-38.

Gove, Antonina Filonov. "Multilingualism and Ranges of Tone in Nabokov's 'Bend Sinister'". Slavic Review, Nr. 32, 1973, S. 79-90.

Grinberg, Leon $u$. Rebeca. Psychoanalyse der Migration und des Exils. München u. Wien: Verlag Internationale Psychoanalyse, 1990.

Guerra, René. "L'émigration russe des années trente aux années soixante". Histoire de la littèrature russe (Le XXe siecle), hq. Efim Etkind, Georges Nivat, Ilya Serman u. Vittorio Strada, Bd. 3: Gels et Degels. Paris: Fayard, 1990. S. 116-139.

Henry, Kathryn. Between Cultures: Third-Wave Russian Fiction in Russian and English. Stanford, Phil. Diss., 1990 .

Hosking, Geoffrey. "The Twentieth century: In Search of New Ways, 1953-1980". The Cambridge History of Russian Literature, hg. Charles A. Moser. Cambridge: Cambridge Univ. Press, 1989. S. 520-594.

Jonge, Alex de. "Russian Emigré Writers: They Are More Opposed to Vulgarity than to Ideology". The Listener (London), Nr. 108, 23.9.1982, S. 9-10.

Kasack, Wolfgang. Die russische Literatur 1945-1982: Mit einem Verz. d. Ubers. ins Dt. Wesentl. erw. Neuaufl. d. Darst. Die russische Literatur 1945-1976. München: Otto Sagner, 1983. 
ders. Russian Literature 1945-1988. München: Otto Sagner in Kommission, 1989. (Arbeiten und Texte zur Slavistik, 46, hg. ders.)

ders. "Zarubeźnye publikacii russkoj literatury". Voprosy literatury (Moskau), Nr. 3, 1989, S. 110-133.

ders. "Auf dem Wege zur wiederherstellung der Einheit der russischen Literatur". Neueste Tendenzen in der Entwicklung der russischen Literatur und sprache: Probleme in Forschung und Lehre, hg. Erwin Wedel. Hamburg: Helmut Buske, 1992. (Hamburger Beiträge für Russischlehrer, 39.) S. 101-109.

ders. "Heimatlos in der Fremde". Manuskript für die "Deutsche Welle" vom 18.5.1994.

Knapp, Bettina L. Exile and the Writer: Exoteric and Esoteric Experiences; a Jungian Approach. Univ. Park, Pennsylvania: Pennsylvania State Univ. Press, 1991.

Knotin, Leonid (Hg.). Abstracts of Soviet and East European Emigre Periodical Literature. Pacific Grove, California, 1981-1990. Ab 1991 u.d.T. Zarubeznaja periodiceskij pecat' na russkom jazyke.

Köpke, Wulf. "Die Wirkung des Exils auf Sprache und stil: Ein Vorschlag zur Forschung". Exilforschung: Ein internationales Jahrbuch, Bd. 3, 1985, S. 225-237.

Kristeva, Julia. Fremde sind wir uns selbst. Frankfurt/M.: Suhrkamp, 1990. (Im Original u.d.T. Etrangers à nousmèmes, Paris, 1988.)

Latynina, Alla. "Kogda podnjalsja zeleznyj zanaves...". Literaturnaja gazeta, Nr. 29,24.7.1991, S. 9 u. 11.

Lotman, Jurij. "Der EinfluB im kulturellen Feld". Wiener slawistischer Almanach, Nr. 12, 1983, S. 5-19.

ders. u. B. A. Uspenskij, v. V. Ivanov, v. N. Toporov u. A. M. Pjatigorskij. "Thesen zur semiotischen Erforschung der Kultur (in Anwendung auf slawische Texte)". Semiotica Sovietica: Sowjetische Arbeiten der Moskauer und Tartuer Schule zu sekundaren modellbildenden Zeichensystemen (1962-1973), hg. u. eingel. v. Karl Eimermacher, Bd. 1. Aachen: Rader, 1986. (Aachener studien zur semiotik u. Kommunikationsforschung, 5.1.) S. 85-118.

ders. u. B. A. Uspenskij. "Zum semiotischen Mechanismus der Kultur (1971)". Semiotica Sovietica: Sowjetische Arbeiten der Moskauer und Tartuer Schule zu sekundaren modellbildenden Zeichensystemen (1962-1973). hg. u. eingel. v. Karl Eimermacher, Bd. 2. Aachen: Rader, 1986. (Aachener Studien zur semiotik u. Kommunikationsforschung, 5.2.) S. 853-880. 
ders. "K postroeniju teorii vzaimodestvija kul'tur (semiotićeskij aspekt)". Izbrannye stat' $i v$ trëch tomach, Bd. 1: stat'i po semiotike $i$ tipologii kul'tury. Tallinn: Aleksandra, 1992. S. 110-120.

McMillin, Arnold. Changing Places: The Dislocation of Russian Literature. London: School of Slavonic and East European Studies, 1989.

ders. "Exiled Russian Writers of the Third Wave and the Emigré Press". The Modern Language Review, Bd. 84, H. 2. April 1989, S. 406-413.

ders. "The Effect of Exile on Modern Russian Writers: A Survey". Renaissance and Modern Studies, Nr. 34, 1991, S. 19-27.

ders. (Hg.). Under Eastern Eyes: The west as Reflected in Recent Russian Emigre Writing. New York: St. Martin's Press, 1992.

Mal'cev, Jurij. Freie russische Literatur 1955-1980 [Vol'naja russkaja literatura]. Aus dem Russ. úbers. v. Gösta Maier. Frankfurt/M.: Ullstein, 1981.

Matich, Olga ( $\mathrm{Hg}$.$) . Soviet and East European Literature in$ Exile. Sonderheft der Zeitschrift Humanities in society (Los Angeles), Bd. 7, Nr. 3-4, Sommer-Herbst 1984 .

dies. mit Michael Heim (Hg.). Tret'ja volna/The Third wave: Russian Literature in Emigration. Ann Arbor: Ardis, 1984 .

Nivat, Georges. Une ou deux litteratures russes?/Odna ili dve russkich literatury? Mezdunarodnyj simpozium, sozvannyj Fakul'tetom slovesnosti żenevskogo Universiteta i Svejcarskoj Akademiej slavistiki, Zeneva 1314-15 aprelja 1978. Lausanne: L'Age d'Homme, 1981.

ders. "Nostalgies russes". Le Magazine litteraire, Nr. 221, Juli-August 1985, S. 53-58.

Pfanner, Helmut F. (Hg.). Kulturelle Wechselbeziehungen im Exil/Exile across Cultures. Akten des vom 7. bis 10. März 1985 an der staatsuniversität von New Hampshire (Durham, N.H., USA) stattgefundenen Symposiums über deutsche und österreichische Exilliteratur. Bonn: Bouvier, 1986. (Studien zur Literatur der Moderne, 14.)

Poltorackij, Nikolaj Petrovic (Hg.). Russkaja literatura $v$ emigracii: Sbornik statej. Pittsburgh: Dep. of Slavic Lanquages and Literature, Univ. of Pittsburgh, 1972. (Slavic Series, 1.)

Raeff, Marc. "La culture russe et l'émigration". Histoire de la littérature russe (Le XXe siècle), hg. Efim Etkind, Georges Nivat, Ilya Serman u. Vittorio strada, 
Bd. 2: La Révolution et les annees vingt. Paris: Fayard, 1988. S. 61-96.

Regnaut-Labord, $c$. "Vers la fin de la troisième émigration soviétigue?". Revue d'etudes comparatives Est-ouest (Paris), Bd. 14, H. 4, 1983, S. 119-124.

Schlögel, Karl. "Das andere RuBland: zur wiederentdeckung der Emigrationsgeschichte in der Sowjetunion". Die Umwertung der sowjetischen Geschichte, hg. Dietrich Geyer. Göttingen: Vandenhoeck + Ruprecht, 1991 . (Geschichte $u$. Gesellschaft/Sonderheft, 14.) S. 238256 .

Seidel, Michael. Exile and the Narrative Imagination. New Haven U.a.: Yale Univ. Press, 1986.

Spalek, John M., u. Robert F. Bell (Hg.). Exile: The Writer's Experience. Chapel Hill: Univ. of North Carolina press, 1982 .

Stevanovich, Bosiljka, u. Wladimir Wertsman. Free Voices in Russian Literature 1950-80s: A Bio-Bibliographical Guide. New York: Russica, 1987.

Strada, vittorio. "Du "dégel" a la "dissidence": La nouvelle émigration". Histoire de la littérature russe (Le XXe siecle), hg. Efim Etkind, Georges Nivat, Ilya Serman u. Vittorio Strada, Bd. 3: Gels et Dégels. Paris: Fayard, 1990. S. 741-749.

Strelka, Joseph. Exilliteratur: Grundprobleme der Theorie, Aspekte der Geschichte und Kritik. Bern U.a.: Lang, 1983.

Struve, Gleb. Russkaja literatura $v$ izgnanii. 2 . izd. ispravlennoe $i$ dopolnennoe. Paris: YMCA, 1984 . (Erstaufl. New York: Izd. imeni Cechova, 1956.)

Tabori, Paul. The Anatomy of Exile: A Semantic and Historical study. London: Harrap, 1972.

Tucker, Martin (Hg.). Literary Exile in the 20th Century: An Analysis and Biographical Dictionary. New York: Greenwood Press, 1991 .

Uspenskij, Boris Andreevic. Poetik der Komposition: struktur des kunstlerischen Textes und Typologie der Kompositionsform. Hg. $u$. nach einer revidierten Fassung des originals bearb. v. Karl Eimermacher. Frankfurt/M.: Suhrkamp, 1975.

Vajl', Petr, u. Aleksandr Genis. Sovremennaja russkaja proza. Ann Arbor: Hermitage, 1982.

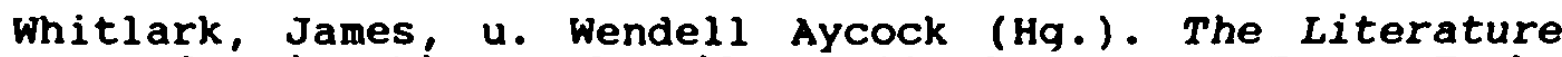
of Emigration and Exile. Lubbock, Texas: Texas Tech. Univ. Press, 1992. (studies in Comparative Literature, 23.) 
Woll, Josephine. "Guests from the Future". Russian Review, Nr. 43, 1984, S. 377-391.

"Writers in Exile: A Conference of Soviet and East European Dissidents". Partisan Review (Boston), Bd. 50 , H. 3, 1983, S. 327-372; Bd. 50, H. 4, 1983, S. 487-525; U. Bd. 51, H. 1, 1984, S. 11-44.

Zajcev, V. A. "Sovremennaja poèzija russkogo zarubez'ja". Vestnik Moskovskogo Universiteta, Serija 9: Filologija, Bd. 9, H. 1, Januar/Februar 1992, S. 3-12.

2. Rezensionen u.a. zu zinik

[Ajzenberg, Michail.] "Boj s ten'ju". Vremja (Tel Aviv), 3.4.1992, Wochenbeilage "Kalejdoskop", S. 20.

Bayley, John. "Digestive Tract". The Times Literary Supplement, $\mathrm{Nr} .4423,8 .-14.1 .1988$, S. 29.

Birchenough, Tom. "Outsider's View of an Incomer". The Times, 28.1.1993, S. 38 .

Brien, Alan. "Glasnost without Tears". Punch (London), 29.1 .1988$, S. 43 .

Campbell, James. "Vodka on the Lawn." The Observer, 17.1.1988, S. 25 .

Cheyette, Bryan. "The Eternal Emigrant". The Times Literary supplement, 7.4.1995, S. 26.

Coates, Joseph. "Literature that's Written on the Run". Chicago Tribune, 14.3.1989, Sektion 5, S. 3.

Deveson, Richard. "In a Stew". New statesman, 5.2.1988, S. 32 .

Donald, Anabel. "There's a Fungus among Us". The New York Times Book Review, 19.2.1989, S. 10 .

Durrant, Sabine. "Dissident Voices, Literary Lives". The Independent, 26.11.1993, S. 23.

Elliott, Janice. "Quarrels with Fungus". The Independent, 4.2.1988, S. 19.

Franklin, Simon. "In a Garden-of-England Madhouse". The Times Literary Supplement, H. 4599, 24.5.1991, S. 20.

Gareev, Zufar. "Ćitaja Russo, sobiraja griby". Nezavisimaja gazeta, 14.4.1992, S. 7 .

Gessen, Elena. "Kto my $i$ otkuda?...". Vremja $i$ my, Nr. 107,1989, S. 160-174. 
Hebert, Hugh. "Moscow's Mushroom Clouds". The Guardian, 13.1 .1988 , S. 9 .

Imlah, Mick. "Choice Cuts, Fine Fungi". The Times Literary Supplement, $\mathrm{Nr} .4689,12.2 .1993$, S. 18.

Jonge, Alex de. "Un- and other Realities". The Times Literary Supplement, Nr. 4182, 27.5.1983, S. 538 .

Laird, Sally. "Russophobe and Fungophile". The Literary Review (London), Januar 1988, S. 17.

Logan, Philippa. "Monty at the Barber's, Ike at Home". The oxford Times, 28.6.1991, S. 17 .

McMillin, Arnold. "Bilingualism and Word play in the Work of Russian Writers of the Third Wave of Emigration: The Heritage of Nabokov". The Modern Language Review (London), Bd. 89, H. 2, April 1994, S. 417-426.

Mellors, John. "Innocents Abroad". London Magazine, Februar 1988, S. 105-108.

Meyer, Priscilla. "Nabokov: Sintez kul'tur". Obozrenie (Paris), Nr. 15, Juli 1985, S. 10-14.

dies. "Zinovy zinik: The Russian Service". Ulbandus Review (New York: Columbus University), Nr. 5, Herbst 1987, S. 179-182.

Millet, Richard. "Un Russe en Israël". La Quinzaine Littéraire (Paris), Nr. 345, 1.-15.4.1981, S. 8 .

Moskovic, V[olf]. "Zametki o jazyke literatury russkogo zarubez"ja". Russian Philology and History: In Honour of Professor victor Levin, hg. The Hebrew Univ. of Jerusalem. Jerusalem: Praedicta, 1992. S. 126-136.

Nightingale, Benedict. "Russian Recipe Uses Strange Ingredients". The Times, 4.2.1993, S. 33 .

N.N. World Literature Today. Literary Quarterly of the University of Oklahoma. Bd. 64, Nr. 1, winter 1990, S. 147-148.

N.N. "I Drink, therefore I Am Well-Read". The Herald (Glasgow), 6.3.1993, S. 7 .

Rees, Jasper. "Funny Ha-ha and Funny Tragic". The European Magazine, 7.-13.4.1995, S. 6.

Reichmann, Edgar. "Saint-Germain-des-Prés sur la Moskova". Le Monde, 13.2.1981, S. 13 u. 15.

ders. "Des écrivains soviétiques découvrent l'Occident". Le Monde, 17.7.1987, S. 14.

Rumens, Carol. "Far from Typically Dissident". The Sunday Times (London), 24.1.1988, Sektion G, S. 6. 
Serman, Il'ja. "Puti samopoznanija $v$ uslovijach svobody: Russkaja emigrantskaja proza 1975-1985". Manuskript des deutschen Beitrags zur ICseEs Conference (Panel on Third-Wave Literature), Washington D.C., 1989.

Timofeeva, ol'ga. "Esli ne ljubit, ne znaćit - gad". Nezavisimaja gazeta, 14.4.1992, S. 7 .

Veselaja, Elena. "Russkaja služba' sobiraetsja zapet'". Moskovskie novosti, Nr. 36, 21.-28.5.1995, S. 19 . 


\section{Slavistische Beiträge Herausgegeben von Peter Rehder}

Bd. 312: Poliwoda, Bernadette: FÉKS - Fabrik des exzentrischen Schauspielers. Vom Exzentrismus zur Poetik des Films in der frühen Sowjetkultur. 1994. 224 S., 1 Abb. 44.- DM. ISBN 3-87690-578-8.

Bd. 313: Eskin, Michael: Nabokovs Version von Puskins „Evgenij Onegin“. Zwischen Version und Fiktion - eine übersetzungs- und fiktionstheoretische Untersuchung. 1994. 151 S. 38.- DM. ISBN 3-87690-579-6.

Bd. 314: Koecke. Bernadette: Diminutive im polnisch-deutschen Übersetzungsvergleich. Eine Studie zu Divergenzen und Konvergenzen im Gebrauch einer variierenden Bildung. 1994. 331 S. 48.- DM. ISBN 3-8\%690-580-X.

Bd. 315: Junghanns, Uwe: Syntaktische und semantische Eigenschaften russischer finaler Infinitiveinbettungen. 1994. 227 S. 44.- DM. ISBN 3-87690581-8.

Bd. 316: Fleischer, Michael: Overground. Die Literatur der polnischen alternativen Subkulturen der 80er und 90er Jahre. (Eine Einsicht). 1994. 175 S., zahlr. Abb. 40.- DM. ISBN 3-87690-582-6.

Bd. 317: Дуличенко, Александр Д.: Русский язык конца XX столетия. Предисловие и подготовка к изданию Werner Lehfeldt. 1994. XII, 347 S. 58.DM. ISBN 3-87690-583-4.

Bd. 318: Scheffler, Birgit: Elemente des Cechovschen Dialogs im zeitgenössischen russischen Drama. 1994. X. 223 S. 44.- DM. ISBN 3-87690-584-2.

Bd. 319: Slavistische Linguistik 1993. Referate des XIX. Konstanzer Slavistischen Arbeitstreffens Kiel 21.-23.9.1993. Herausgegeben von Hans Robert Mehlig. 1994. 331 S. 48.- DM. ISBN 3-87690-5.

Bd. 320: Соболев, Андрей, Н.: Говор села Вратарница в восточной Сербии в исторической и ареальной освещении. (К постановке проблемы южнославянской ч-, џ-зоны.) 1994. 230 S. 44.- DM. ISBN 3-87690-591-5.

Bd. 321: Becker-Nekvedavicius, Mechtild: Untersuchungen zur Bildlichkeit im Prosawerk A. A. Bestužev-Marlinskijs. 1994. X. 368 S. 56.- DM. ISBN 3-87690592-3.

Bd. 322: Sergl, Anton: Literarisches Ethos. Implikationen von Literarizität am Beispiel des konservativen Publizisten V.V. Rozanov. (Mit einem abschlie Benden Exkurs zu A. P. Cechov.) 1994. 472. S. 58.- DM. ISBN 3-87690-593-1.

Bd. 323: Tchouboukov-Pianca, Florence: Die Konzeptualisierung der Graphomanie in der russischsprachigen postmodernen Literatur. 1995. 140 S. 34.-DM. ISBN 3-87690-594-X.

Bd. 324: Lehfeldt, Werner: Einführung in die Sprachwissenschaft für Slavisten. 1995. 167 S. 30.- DM. ISBN 3-87690-606-7. (Studienhilfen. 3.)

Bd. 325: Bonola. Anna: Osip Mandel'צ̌tams „Egipetskaja marka“. Eine Rekonstruktion der Motivsemantik. 1995. 286 S. 46.- DM. ISBN 3-87690-607-5.

Bd. 326: Бирих, Алексанр: Метонимия в современном русском языке. (Семантический и грамматический аспекты.) 1995. II, 191 S. 40.- DM. ISBN 3 87690-608-3

Bd. 327: Schuster, Rudolf: Synonymität im Text. Eine Untersuchung an russischen Textbeispielen. 1995. 232 S. 44.- DM. ISBN 3-87690-609-1

Bd. 328: Miszewski, Brigitta: New-Age-Diskurs in der polnischen Literaturwissenschaft, Literaturkritik und Lyrik der 70er und 80er Jahre. Rekonstruktion eines Weltbildes. 1995. 236 S. 44.- DM. ISBN 3-87690-611-3. 